Douglas de Aquino Castro

Projeto de Estruturas sujeitas à Radiação Térmica no Interior de Confinamentos utilizando o Método da Otimização Topológica 
Douglas de Aquino Castro

\section{Projeto de Estruturas sujeitas à Radiação Térmica no Interior de Confinamentos utilizando o Método da Otimização Topológica}

Dissertação apresentada à Escola Politécnica da Universidade de São Paulo para obtenção do Título de Mestre em Engenharia Mecânica. 


\section{Projeto de Estruturas sujeitas à Radiação Térmica no Interior de Confinamentos utilizando o Método da Otimização Topológica}

Dissertação apresentada à Escola Politécnica da Universidade de São Paulo para obtenção do Título de Mestre em Engenharia Mecânica.

Área de concentração:

Engenharia de Controle e Automação Mecânica

Orientador:

Prof. Dr. Emílio Carlos Nelli Silva 
Este exemplar foi revisado e alterado em relação à versão original, sob responsabilidade única do autor e com a anuência de seu orientador.

São Paulo, 7 de janiero de 2014.

Assinatura do autor

Assinatura do orientador

Castro, Douglas de Aquino

Projeto de estruturas sujeitas à radiação térmica no interior de confinamentos utilizando o método da otimização topológica / D.A. Castro. -- ed.rev. -- São Paulo, 2013.

129 p.

Dissertação (Mestrado) - Escola Politécnica da Universidade de São Paulo. Departamento de Engenharia Mecatrônica e de Sistemas Mecânicos.

1. Radiação (Calor) 2. Topologia (Otimização) 3. Método dos elementos finitos I. Universidade de São Paulo. Escola Politécnica. Departamento de Engenharia Mecatrônica e de Sistemas Mecânicos II. t. 
Aos meus pais. 
"Eu estive fora uns dias

Eu te odiei uns dias

Eu quis te matar."

- Uns dias, Os Paralamas do Sucesso. 


\section{Agradecimentos}

Agradeço a Deus, pela força espiritual necessária para me manter perseverante durante o período de construção deste trabalho.

Aos meus pais, Raimundo de Souza Castro e Maria Euda de Aquino Castro, por me amarem incondicionalmente e por, mesmo em condições de limitação econômica, nunca deixarem de me apoiar e de investir nos meus estudos.

Ao meu orientador, Prof. Dr. Emílio Carlos Nelli Silva, por acreditar neste trabalho, pela paciência e suporte durante os últimos anos.

Ao Conselho Nacional de Desenvolvimento Científico e Tecnológico (CNPq), pelo apoio financeiro no desenvolvimento deste trabalho, através de uma bolsa de mestrado (processo No. 132369/2011-7).

À família Pellegrini, nas pessoas de Américo, Ilza, Diana e Sérgio, por me apoiarem e me darem suporte genuinamente familiar durante toda minha trajetória acadêmica.

Aos amigos Cesar Kiyono, Sandro Vatanabe, Luís Mello, Ronny Carbonari, Ricardo Doll, Ruben Salas, Ricardo Amigo, Flávio Vasconcelos, Felipe Langellotti, Erick Marinho, Diogo Dutra e Márcio Wagner, pelas frutíferas discussões científicas e por amenizarem com bom humor a solidão da atividade acadêmica.

Por fim, agradeço a todos os mestres, amigos e familiares que me apoiaram nesses 10 anos de São Paulo. 


\section{Resumo}

Estruturas que estão sujeitas a altas temperaturas absolutas, à convecção natural, ou ainda, estruturas que trocam calor na ausência de um meio físico, apresentam relevante transferência de calor por radiação térmica. Este fenômeno é importante para diversas aplicações e processos, como, por exemplo, no funcionamento de coletores solares, satélites, fornos industriais, motores a combustão e usinas nucleares. O presente trabalho de mestrado apresenta a aplicação do método da otimização topológica (MOT) ao projeto de estruturas que trocam calor substancialmente por radiação térmica no interior de confinamentos, através da distribuição de material refletor ou de aquecedores. Por meio do MOT, cuja principal característica é a liberdade de distribuição do material dentro de um domínio inicial, é possível adicionar ou remover material de uma determinada região deste domínio, criando ou desfazendo fronteiras, de forma livre, visando à obtenção de um projeto otimizado. O algoritmo de otimização é baseado no método das assíntotas móveis (MMA) e é complementado pelo método dos elementos finitos (MEF) para a análise do fenômeno de radiação em confinamentos. Ambos são implementados através do software Matlab ${ }^{\circledR}$. Os casos considerados são o da distribuição de material refletor de radiação térmica ou de aquecedores, sujeitos a uma eventual restrição nas quantidades destes materiais, sobre uma superfície plana, de forma a extremizar a irradiação ou a minimizar a temperatura em determinada área específica do domínio de projeto. Este problema depende, dentre outros fatores, da geometria das superfícies envolvidas na transferência de calor por radiação térmica. 


\section{Abstract}

Structures subjected to high absolute temperatures or to natural convection, as well structures that exchange heat in the absence of a physical medium present significant heat transfer through thermal radiation. This phenomenon is important for several applications and processes, such as in the operation of solar collectors, satellites, industrial furnaces, combustion engines and nuclear plants. The present work shows the application of topology optimization to the design of structures that exchange heat substantially by thermal radiation within an enclosure, through the distribution of reflective material or heaters. However, the design of such radiant enclosures is not trivial and it is necessary to use robust and systematic design tools, such as optimization techniques. Topology optimization is a numerical method which allows finding the layout, or topology, of a structure such that a prescribed objective is maximized or minimized subjected to design constraints. The optimization algorithm, based on the method of moving asymptotes (MMA), and the finite element method for analysis of the phenomenon of radiation in enclosures, are implemented using Matlab $^{\circledR}$. The cases considered are the distribution of thermal radiation reflective material or heaters, subjected to a volume fraction constraint of these materials on a flat surface, in order to extremize the irradiation or to minimize the temperature in a specified region of the design domain. This problem depends, among other factors, on the geometry of the surfaces that exchange heat through thermal radiation. 


\section{Conteúdo}

\section{Lista de Figuras}

\section{Lista de Tabelas}

\section{Lista de Siglas}

\section{Lista de Símbolos}

1 Introdução 1

1.1 Radiação Térmica . . . . . . . . . . . . . . . . . . . . . 2

1.2 Método da Otimização Topológica . . . . . . . . . . . . . . . . . . . . 3

1.3 Breve Revisão Bibliográfica . . . . . . . . . . . . . . . . 4

1.4 Motivação . . . . . . . . . . . . . . . . . . . . . 5

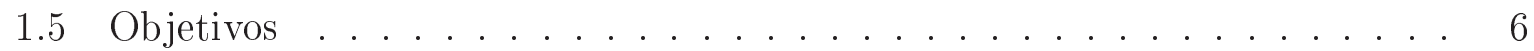

1.6 Otimizar para que, a solução não é óbvia? . . . . . . . . . . . . . . . 7

2 Radiação Térmica: Abordagem Analítica 8

2.1 Conceitos Fundamentais . . . . . . . . . . . . . . . . . . . 8

2.1.1 Emissão, Irradiação e Radiosidade . . . . . . . . . . . . . . . . . . 9

2.1.2 Radiação de Corpo Negro . . . . . . . . . . . . . . . . . . . . 16

2.1.3 Radiação em Superfícies Reais . . . . . . . . . . . . . . . . . . . . . 19

2.1.4 Transferência de Calor por Radiação entre Superfícies . . . . . . . . 25

3 Radiação Térmica: Abordagem Numérica 41

3.1 Cálculo Numérico dos Fatores de Forma . . . . . . . . . . . . . . . . . 41

3.1.1 Breve Revisão Bibliográfica . . . . . . . . . . . . . . . . . 41 
3.1.2 Aproximação Numérica da Integral no Contorno . . . . . . . . . . . . 43

3.1.3 Quadratura de Gauss Aplicada à Integral no Contorno . . . . . . . 45

3.2 Método dos Elementos Finitos aplicado à Troca de Calor Radiante em Confinamentos . . . . . . . . . . . . . . . . . 46

3.2.1 Construção da Matriz de Fatores de Forma . . . . . . . . . . . . . . 46

3.2.2 Formulação Matricial para Cálculo das Radiosidades . . . . . . . . 47

3.2.3 Formulação Matricial para Cálculo das Temperaturas e Fluxos de Calor . . . . . . . . . . . . . . . . . . . . 48

4 Otimização Topológica Aplicada à Transferência de Calor Radiante 51

4.1 Introdução . . . . . . . . . . . . . . . . . . . 51

4.2 Revisão Bibliográfica da Otimização de Confinamentos sujeitos à Radiação 54

4.2 .1 Otimização Topológica . . . . . . . . . . . . . . . . . 54

4.2.2 Problemas Inversos e Métodos Heurísticos . . . . . . . . . . . 57

4.2 .3 Método dos Gradientes . . . . . . . . . . . . . . . . 58

4.3 Conceitos Teóricos . . . . . . . . . . . . . . . . . . 60

4.3 .1 Domínio Fixo Estendido . . . . . . . . . . . . . . . . . . . 60

4.3.2 Modelo de material . . . . . . . . . . . . . . . . . . . 61

4.4 Formulação do Problema de Otimização Topológica aplicada à Troca Radiante em Confinamentos . . . . . . . . . . . . . . . . . . . 64

4.4.1 Função Objetivo de Extremização da Irradiação . . . . . . . . . . . . . 64

4.4.2 Função Objetivo de Minimização da Temperatura . . . . . . . . . . 66

4.4.3 Função Objetivo de Distribuição de Aquecedores para Maximização da Irradiação . . . . . . . . . . . . . . . . . . . . . . . 67

4.4.4 Gradientes das Funções Objetivo de Extremização da Irradiação . 67

4.4.5 Gradientes da Função Objetivo de Minimização da Temperatura . . 69

4.4.6 Gradientes das Função Objetivo de Distribuição de Aquecedores para Maximização da Irradiação . . . . . . . . . . . . . . . . . 70

4.5 Implementação do Algoritmo de Otimização Topológica . . . . . . . . . . . . 71 
5.1 Maximização da Irradiação . . . . . . . . . . . . . . . . . . . . . 75

5.1 .1 Caso $1 \ldots \ldots \ldots \ldots \ldots 7$. . . . . . . . . . . . . . . . . . . .

5.1 .2 Caso $2 \ldots \ldots \ldots \ldots$. . . . . . . . . . . . . . . . 80

5.1 .3 Caso $3 \ldots \ldots \ldots \ldots \ldots$. . . . . . . . . . . . . . 84

5.2 Minimização da Irradiação . . . . . . . . . . . . . . . . . . . . . . . 87

5.3 Minimização da Temperatura . . . . . . . . . . . . . . . . . . . 90

5.4 Distribuição de Aquecedores . . . . . . . . . . . . . . . . . . 96

6 Conclusões 101

6.1 Sugestão de Trabalhos Futuros . . . . . . . . . . . . . . . . . . 102

$\begin{array}{ll}\text { Referências } & 105\end{array}$

Anexo A - Formulação de um Variacional para Transferência de Calor por

$\begin{array}{ll}\text { Radiação } & 116\end{array}$

A.1 Dedução do Método dos Elementos Finitos . . . . . . . . . . . . . . 118

Anexo B - Aferição dos Métodos Numéricos $\quad 121$

B.1 Aferição dos Fatores de Forma calculados Numericamente . . . . . . . . . . 121

B.2 Aferição do MEF aplicado à Troca Radiante em Confinamentos . . . . . . . 124

B.2.1 Primeiro Benchmark . . . . . . . . . . . . . . . . 124

B.2.2 Segundo Benchmark . . . . . . . . . . . . . . 125 


\section{Lista de Figuras}

1.1 Conjunto de etapas para aplicação da otimização topológica em um problema de radiação térmica ocorrendo em confinamento. . . . . . . . . . 3

2.1 Espectro eletromagnético da radiação. . . . . . . . . . . . . . . . . . . 9

2.2 Fenômenos que ocorrem em uma superfície sujeita à radiação. . . . . . . . . 10

2.3 (a) Ângulo plano (b) ângulo sólido (c) emissão de radiação a partir de uma área diferencial $d A_{1}(\mathrm{~d})$ sistema de coordenadas esféricas. . . . . . . . . . . 10

2.4 Ângulo sólido subtendido por $d A_{n}$ em um ponto em $d A_{1}$, no sistema de coordenadas esférico. . . . . . . . . . . . . . . . . 11

2.5 Emissão a partir de um elemento de área diferencial $d A_{1}$ para um hemisfério hipotético centrado em um ponto de $d A_{1} \ldots \ldots$. . . . . . . . . . . . . 14

2.6 Direção natural da radiação incidente. . . . . . . . . . . . . . . . . 15

2.7 Reflexão difusa e especular. . . . . . . . . . . . . . . . . . . . . 23

2.8 Fatores de forma associados com a troca radiante entre as superfícies diferenciais $d A_{i}$ e $d A_{j} \ldots \ldots \ldots \ldots \ldots \ldots$

2.9 (a) Retângulos alinhados paralelamente (b) retângulos perpendicularmente intersectantes. . . . . . . . . . . . . . . . . . . . 28

2.10 Troca de calor por radiação em uma cavidade. . . . . . . . . . . . . . . . 30

2.11 Áreas utilizadas para ilustrar a relações dos fatores de forma (2.61) e (2.63). 30

2.12 Confinamento composto por $N$ superfícies, mostrado em seção transversal (SIEGEL; HOWELL, 2002). . . . . . . . . . . . . . . . . . . . 32

2.13 Energia incidente e que deixa uma superfície $i$ de uma cavidade (SIEGEL; HOWELL, 2002) . . . . . . . . . . . . . . . . . . . 33

2.14 Ilustração do confinamento tridimensional. . . . . . . . . . . . . . . . . . 39

3.1 Esquema que mostra 3 pontos em cada linha para a aplicação da integral no contorno. 
3.2 Exemplo do cálculo do fator de forma entre duas áreas finitas através da

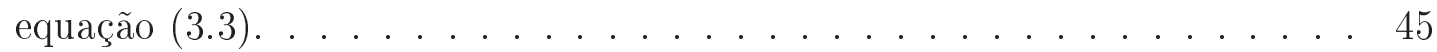

3.3 Distribuição de pontos de Gauss sobre a malha de elementos finitos para o cálculo dos fatores de forma em um confinamento. . . . . . . . . . . . . . . 47

4.1 Exemplo clássico de 3 categorias de otimização estrutural: (a) otimização paramétrica (b) otimização de forma (c) otimização topológica (AMIGO,

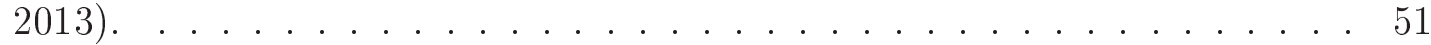

4.2 Otimização paramétrica da área da seção transversal de dissipadores de calor. 52

4.3 Otimização de forma da superfície interna de uma caldeira com o objetivo de aumentar a troca de calor convectiva (BERGLES, 2002). . . . . . . . . . 53

4.4 Otimização topológica aplicada ao projeto de um dissipador de calor no interior de uma estrutura uniformemente aquecida (GAO et al., 2008). .. . 54

4.5 Exemplo de aplicação do MOT em um problema de dissipação térmica (BENDSøE; SIGMUND, 2003). . . . . . . . . . . . . . . . . 56

4.6 Exemplo da aplicação do MOT para o projeto de micro-aletas de refrigeração sujeitas à convecção (BRUNS, 2007) . . . . . . . . . . . . . . 56

4.7 Domínio de projeto do MOT. . . . . . . . . . . . . . 61

4.8 Gráficos da função dada em (4.6), que define o modelo de material, para diferentes valores de penalização. O valor de $\rho_{0}=0,5$ e de $\rho_{m}=0,8 . \quad$. . 63

4.9 Passos seguidos durante a otimização topológica utilizando o Matlab ${ }^{\circledR}$. . 72

5.1 Exemplo de domínio de projeto e suas possíveis condições de contorno. . . 74

5.2 Abertura de um confinamento para fins de visualização dos resultados. . . 75

5.3 Áreas alvo da maximização da irradiação: (a) para um confinamento de dimensão $0,1 \times 0,1 \times 0,1 m$ (b) para um confinamento de dimensão $0,4 \times 0,5 \times 0,3$

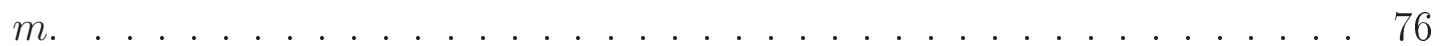

5.4 Condições de contorno de temperatura $(K)$ das paredes de 1 a 4 e de fluxo de calor $\left(W / m^{2}\right)$ das paredes 5 e 6 , para o primeiro caso de maximização da irradiação. . . . . . . . . . . . . . . . . . . . . . . 78

5.5 Convergência da função objetivo para o primeiro caso de maximização da irradiação. . . . . . . . . . . . . . . . . . . . . . . 78 
5.6 Distribuição das variáveis de projeto para o primeiro caso de maximização da irradiação: (a) última iteração do processo de otimização (b) pós-processamento. . . . . . . . . . . . . . . . . .

5.7 Distribuição de material de refletividade igual a 0,8 para o primeiro caso de maximização da irradiação: (a) domínio de projeto inicial (b) domínio de projeto otimizado. . . . . . . . . . . . . . . . . . .

5.8 Irradiações $\left(W / m^{2}\right)$ para o primeiro caso de maximização da irradiação: (a) antes da otimização (b) depois da otimização. . . . . . . . . . . . . . . 80

5.9 Convergência da função objetivo para o segundo caso de maximização da irradiação: (a) sem restrição de volume (b) com restrição de volume de 30\%. 81

5.10 Distribuição das variáveis de projeto para o segundo caso de maximização da irradiação na última iteração do processo de otimização topológica: (a) sem restrição de volume (b) com restrição de volume de 30\% . . . . . . . . 82

5.11 Distribuição de material de refletividade igual a 0,8 para o segundo caso de maximização da irradiação: (a) sem restrição de volume (b) com restrição de volume de $30 \%$. . . . . . . . . . . . . . . . 83

5.12 Irradiações $\left(W / m^{2}\right)$ para o segundo caso de maximização da irradiação, sem restrição de volume: (a) antes da otimização (b) depois da otimização.

5.13 Irradiações $\left(W / m^{2}\right)$ para o segundo caso de maximização da irradiação, com restrição de volume de 30\%: (a) antes da otimização (b) depois da otimização. . . . . . . . . . . . . . . . . . .

5.14 Condições de contorno de temperatura $(K)$ e de fluxo de calor $\left(W / m^{2}\right)$ para o terceiro caso de maximização da irradiação. . . . . . . . . . . .

5.15 Convergência da função objetivo para o terceiro caso de maximização da irradiação: (a) sem restrição de volume (b) com restrição de volume de 40\%. 86

5.16 Distribuição das variáveis de projeto para o terceiro caso de maximização da irradiação na última iteração do processo de otimização topológica: (a) sem restrição de volume (b) com restrição de volume de 40\% . . . . . . . . 86

5.17 Distribuição de material de refletividade igual a 0,8 para o terceiro caso de maximização da irradiação: (a) sem restrição de volume (b) com restrição de volume de $40 \%$. . . . . . . . . . . . . . . . . .

5.18 Irradiações $\left(W / m^{2}\right)$ para o terceiro caso de maximização da irradiação, sem restrição de volume: (a) antes da otimização (b) depois da otimização. .. 
5.19 Irradiações $\left(W / m^{2}\right)$ para o terceiro caso de maximização da irradiação, com restrição de volume de 40\%: (a) antes da otimização (b) depois da otimização. . . . . . . . . . . . . . . . . . . . 88

5.20 Condições de contorno de temperatura $(K)$ e de fluxo de calor $\left(W / m^{2}\right)$ para o caso de minimização da irradiação. . . . . . . . . . . . . . 8

5.21 Convergência da função objetivo para o segundo caso de minimização da irradiação: (a) sem restrição de volume (b) com restrição de volume de 10\%. 90

5.22 Distribuição das variáveis de projeto para o caso de minimização da irradiação na última iteração do processo de otimização topológica: (a) sem restrição de volume (b) com restrição de volume de 10\% . . . . . . . . . 91

5.23 Distribuição de material de refletividade igual a 0,7 para o caso de minimização da irradiação: (a) sem restrição de volume (b) com restrição de volume de $10 \% \ldots \ldots$. . . . . . . . . . . . . . . . . 91

5.24 Irradiações $\left(W / m^{2}\right)$ para o caso de minimização da irradiação, sem restrição de volume: (a) antes da otimização (b) depois da otimização. . . . . . . . . . 92

5.25 Irradiações $\left(W / m^{2}\right)$ para o caso de minimização da irradiação, com restrição de volume de 10\%: (a) antes da otimização (b) depois da otimização. 92

5.26 Condições de contorno de temperatura $(K)$ e de fluxo de calor $\left(\mathrm{W} / \mathrm{m}^{2}\right)$ para o caso de minimização da temperatura. . . . . . . . . . . . . . . . . 93

5.27 Convergência da função objetivo para o caso de minimização da temperatura: (a) sem restrição de volume (b) com restrição de volume

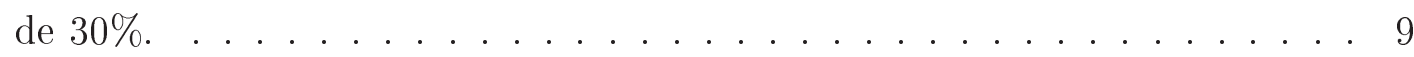

5.28 Distribuição das variáveis de projeto para o caso de minimização da temperatura na última iteração do processo de otimização topológica: (a) sem restrição de volume (b) com restrição de volume de 30\% . . . . . . . . 95

5.29 Distribuição de material de refletividade igual a 0,8 para o caso de minimização da irradiação: (a) sem restrição de volume (b) com restrição de volume de $30 \%$. . . . . . . . . . . . . . . . . . . . . 95

5.30 Temperaturas $(K)$ para o caso de minimização da temperatura, sem restrição de volume: (a) antes da otimização (b) depois da otimização. . . 96

5.31 Temperaturas $(K)$ para o caso de minimização da temperatura, com restrição de volume de 30\%: (a) antes da otimização (b) depois da otimização. 96 
5.32 Convergência da função objetivo para a maximização da irradiação através da distribuição de aquecedores: (a) sem restrição de volume (b) com restrição de volume de $30 \%$. . . . . . . . . . . . . . . . . . . . . . 98

5.33 Distribuição de aquecedores para a maximização da irradiação na última iteração do processo de otimização topológica: (a) sem restrição de volume (b) com restrição de volume de $30 \%$. . . . . . . . . . . . . . . . . . . 99

5.34 Irradiações $\left(W / m^{2}\right)$ para a maximização da irradiação através da distribuição de aquecedores, sem restrição de volume: (a) antes da otimização (b) depois da otimização. . . . . . . . . . . . . . . . . . . . . 99

5.35 Irradiações $\left(W / m^{2}\right)$ para a maximização da irradiação através da distribuição de aquecedores, com restrição de volume de 30\%: (a) antes da otimização (b) depois da otimização. . . . . . . . . . . . . . . . . . . 100 


\section{Lista de Tabelas}

2.1 Requisitos para aplicação da Lei de Kirchhoff. . . . . . . . . . . . . . . . . 25

B.1 Fatores de forma calculados analiticamente para as paredes de um confinamento de dimensão $L \times L \times L$. . . . . . . . . . . . . . . . . . . . . . 122

B.2 Porcentagem de erro médio no cálculo dos fatores de forma das paredes de um confinamento de dimensão $L \times L \times L$. . . . . . . . . . . . . . . . . . . 122

B.3 Fatores de forma calculados analiticamente para as paredes de um confinamento de dimensão $0,4 \times 0,5 \times 0,3$ m . . . . . . . . . . . . . . . . 123

B.4 Porcentagem de erro médio no cálculo dos fatores de forma das paredes de um confinamento de dimensão $0,4 \times 0,5 \times 0,3$ m. . . . . . . . . . . . . 124

B.5 Média aritmética dos fluxos de calor sobre todas as paredes para o primeiro benchmark. . . . . . . . . . . . . . . . . 125

B.6 Porcentagem de erro médio no cálculo das radiosidades sobre todas as paredes para o primeiro benchmark. . . . . . . . . . . . . . . . 125

B.7 Porcentagem de erro médio no cálculo das variáveis desconhecidas do segundo benchmark, modelado com 2400 elementos. . . . . . . . . . . . . . 127

B.8 Porcentagem de erro médio no cálculo das variáveis desconhecidas do segundo benchmark, modelado com 5400 elementos. . . . . . . . . . . . . . 128

B.9 Porcentagem de erro médio no cálculo das variáveis desconhecidas do segundo benchmark, modelado com 9600 elementos. . . . . . . . . . . . . . 128

B.10 Porcentagem de erro médio no cálculo das variáveis desconhecidas do segundo benchmark, modelado com 15000 elementos. . . . . . . . . . . . . 129

B.11 Verificação do princípio da conservação da energia, através da equação (2.90), para o segundo benchmark. . . . . . . . . . . . . . . . . . . . 129 


\section{Lista de Siglas}

DFE Domínio Fixo Estendido

MEF Método dos Elementos Finitos

MOT Método da Otimização Topológica

MMA Method of Moving Asymptotes

OT Otimização Topológica 


\section{Lista de Símbolos}

\begin{tabular}{|c|c|}
\hline$A$ & área, $m^{2}$ \\
\hline$C$ & contorno de uma área \\
\hline$c_{0}$ & velocidade da luz, $\mathrm{m} / \mathrm{s}$ \\
\hline$E, \boldsymbol{E}$ & poder emissivo, $W / m^{2}$; vetor de emissões \\
\hline$F_{i j}, \boldsymbol{F}$ & fator de forma; matriz de fatores de forma \\
\hline$G, G$ & irradiação, $W / m^{2}$; vetor de irradiações \\
\hline$h$ & constante de Planck \\
\hline$I, \boldsymbol{I}$ & intensidade de radiação, $W / m^{2} . s r ;$ matriz identidade \\
\hline$J$ & radiosidade, $W / m^{2} ;$ Jacobiano \\
\hline$J$ & vetor de radiosidades \\
\hline$k$ & constante de Boltzmann \\
\hline $\boldsymbol{K}$ & $\begin{array}{l}\text { matriz de rigidez para determinação das temperaturas e fluxos } \\
\text { de calor }\end{array}$ \\
\hline$K_{R}$ & matriz de rigidez para determinação das radiosidades \\
\hline$L$ & comprimento, $m$ \\
\hline$N$ & número de superfícies em um confinamento \\
\hline$N_{p g}$ & número de pontos de Gauss \\
\hline$n$ & número de segmentos de linha reta que compõem uma superfície \\
\hline $\mathbf{n}$ & vetor normal a uma superfície \\
\hline$p$ & penalizador \\
\hline$Q$ & taxa de transferência de energia, $W$ \\
\hline$q, \boldsymbol{q}$ & fluxo de calor, $W / m^{2}$; vetor de fluxos de calor \\
\hline$r, \theta, \phi$ & coordenadas esféricas \\
\hline$\vec{s}$ & versor \\
\hline$T, \overline{\mathbf{T}}$ & $\begin{array}{l}\text { temperatura, } K \text {; vetor de temperaturas elevadas à quarta } \\
\text { potência }\end{array}$ \\
\hline$W$ & peso da quadratura de Gauss \\
\hline$x, y, z$ & coordenadas retangulares \\
\hline$z_{p}$ & coordenadas dos pontos de Gauss \\
\hline
\end{tabular}

Letras Gregas

continua... 


$\begin{array}{ll}\alpha & \text { absortividade } \\ \gamma & \text { variável de projeto } \\ \delta & \text { delta de Kronecker } \\ \varepsilon & \text { emissividade } \\ \operatorname{diag}(\varepsilon) & \text { matriz diagonal de emissividades } \\ \theta & \text { ângulo de zênite, rad } \\ \lambda & \text { comprimento de onda, } \mu m \\ \rho & \text { refletividade } \\ \sigma & \text { constante de Stefan-Boltzmann } \\ \phi & \text { ângulo de azimute, } r a d \\ \tau & \text { transmissividade } \\ \Omega & \text { domínio de projeto } \\ \omega & \text { ângulo sólido, sr }\end{array}$

Subscritos

$\begin{array}{ll}\text { abs } & \text { radiação absorvida } \\ b & \text { corpo negro } \\ e & \text { emissão } \\ i & \text { radiação incidente; designação geral de espécie } \\ j & \text { designação geral de espécie } \\ r, \text { ref } & \text { radiação refletida } \\ \theta & \text { direcional } \\ \lambda & \text { espectral }\end{array}$




\section{Introdução}

A ocorrência prioritária de transferência de calor por radiação térmica pode ser verificada em diferentes níveis de temperatura e condições de ambiente. A altas temperaturas, por exemplo, a condução e a convecção têm atuação secundária e a radiação térmica representa a principal forma de troca de calor, como pode ser notado no funcionamento dos altos fornos de indústrias siderúrgicas e na geração de vapor em usinas nucleares. A importância deste modo de transferência de calor também pode ser constatada à temperatura ambiente. Em projetos de conforto térmico de locais sujeitos a baixa convecção forçada, a radiação térmica passa a ter papel essencial na modelagem da troca de calor destes ambientes. Já na ausência de um meio físico para transferência de calor, a radiação é a única forma de um sistema transferir energia térmica para o ambiente. Desta forma, o desenvolvimento de satélites e equipamentos que orbitam a Terra ou exploram o espaço representa um excelente campo de aplicação de alta tecnologia, cuja viabilidade reside, em parte, no pleno entendimento teórico e prático do fenômeno de radiação térmica.

De construções robustas como alto fornos a delicadas aplicações espaciais, para todas as aplicações industriais em que a radiação térmica toma parte, há uma atual e importante necessidade de inovação na metodologia de projeto destes equipamentos. Neste sentido, a otimização topológica representa uma ferramenta sistemática para a concepção e desenvolvimento de estruturas sujeitas a trocas por radiação térmica, uma vez que permite liberdade de distribuição de material dentro de um domínio inicial, de forma a tornar possível a adição ou remoção de material de uma determinada região do domínio de projeto, criando ou desfazendo fronteiras, produzindo assim resultados não óbvios. O seu uso para tais fins, apesar de ainda pouco explorado, representa um enorme campo aberto de aplicações e soluções, bem como uma rica fonte de economia de recursos. 


\subsection{Radiação Térmica}

Do ponto de vista da teoria clássica, que considera o comportamento eletromagnético da onda, todos os corpos emitem constantemente energia na forma de radiação eletromagnética. A radiação térmica nada mais é que um trecho do espectro eletromagnético capaz de induzir mudança de temperatura no corpo em que incide. Desta forma, a transferência de energia por radiação térmica não precisa de um meio físico para ocorrer (ao contrário da condução e da convecção, ela pode perfeitamente acontecer no vácuo), o que a torna significante em aplicações espaciais, como satélites ou veículos espaciais.

A modelagem da radiação térmica pode ser trabalhosa e complicada. Uma das razões para isto é que o estado deste fenômeno não pode ser representado, para um dado intervalo de tempo e um ponto do espaço de propagação, por um único vetor (isto é, uma única direção de quantidade) (PLANCK, 1914), como por exemplo, acontece na condução de calor, em que se obtém esta representação através da Lei de Fourier. Na radiação térmica, todos os raios que em um dado instante passam por um ponto do meio de propagação são perfeitamente independentes entre si. Portanto, para se determinar completamente o estado da radiação térmica, a intensidade de radiação precisa ser conhecida em todas as direções (que são infinitas em número) que passam pelo ponto analisado (PLANCK, 1914). Outra complicação é que, tanto para a condução quanto para a convecção, a equação do balanço de energia depende apenas das condições locais de temperatura do material: para a primeira, interessam as derivadas locais de temperatura do material; para a segunda, são essenciais as condições na vizinhança do local que está sendo considerado na análise. Mas para a radiação térmica, como já discutido, a energia é transmitida entre superfícies separadas sem a necessidade de um meio de propagação entre estas.

Por fim, é importante citar que existem sérias dificuldades em se determinar com acurácia os parâmetros físicos que fazem parte da modelagem da transferência de calor em cavidades $^{1}$. As dificuldades advêm do fato de que as propriedades e parâmetros nos sólidos dependem de muitas variáveis, como do nível de polimento e rugosidade da superfície, pureza do material, temperatura e comprimento de onda da radiação. Isto limita a acurácia numérica, mesmo para problemas com soluções conhecidas.

\footnotetext{
${ }^{1} \mathrm{O}$ termo cavidade também é encontrado na literatura especializada como sinônimo para confinamento.
} 


\subsection{Método da Otimização Topológica}

O método da otimização topológica (MOT) é uma ferramenta computacional que permite gerar estruturas otimizadas através da distribuição de material no interior de um domínio de projeto. Na sua implementação tradicional, o método combina algoritmos de otimização e um método numérico de modelagem física do fenômeno analisado, como o método dos elementos finitos (MEF). Assim, a partir de um domínio de projeto inicialmente discretizado em elementos finitos, avalia-se o comportamento físico da estrutura e, por meio dos algoritmos de otimização, busca-se a melhor distribuição de material que atenda aos requisitos de projeto da estrutura (BENDSØE; SIGMUND, 2003).

A implementação do algoritmo de otimização topológica é baseada num conjunto de etapas necessárias para a obtenção de uma solução otimizada. Estas etapas podem ser empregadas em projetos de engenharia nos quais o fenômeno de radiação térmica se faz presente. A sequência das etapas aplicadas ao problema de otimização é conceitualmente representada na Figura 1.1, onde são apresentadas duas superfícies que fazem parte de um confinamento sujeito à transferência de calor por radiação.

(a) Domínio inicial

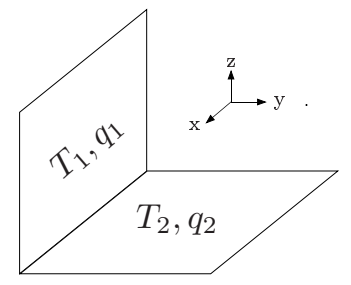

(f) Fabricação (b) Discretização

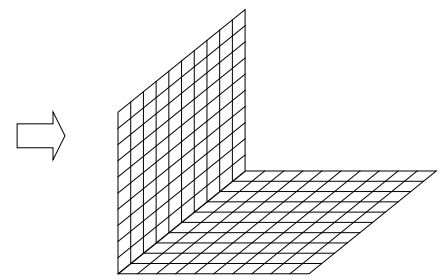

(e) Verificação

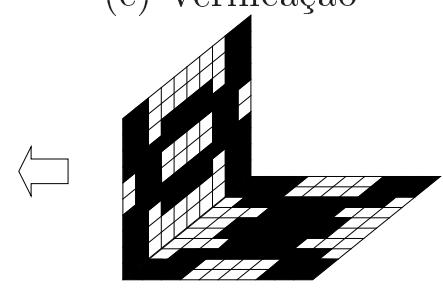

(c) Otimização topológica
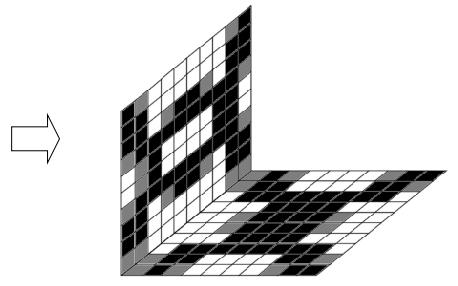

(d) Pós-processamento

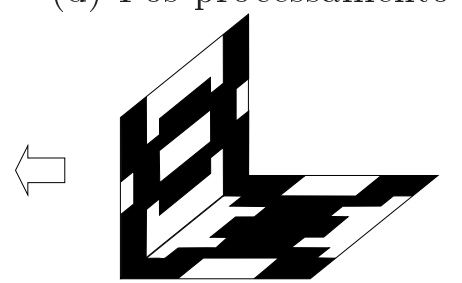

Figura 1.1: Conjunto de etapas para aplicação da otimização topológica em um problema de radiação térmica ocorrendo em confinamento.

A primeira etapa (Figura 1.1a) consiste em definir o domínio fixo estendido (DFE), o qual é limitado pelos pontos de aplicação de carregamento e condições de contorno, como, por exemplo, fluxo de calor e temperatura. É neste domínio que a estrutura otimizada será projetada, por isso é importante definir um DFE que contenha, no mínimo, a estrutura original que será otimizada. A segunda etapa (Figura 1.1b) envolve a discretização do DFE em elementos finitos. Na terceira etapa (Figura 1.1c), os dados obtidos através do MEF, juntamente com os parâmetros de otimização, são inseridos no algoritmo de 
otimização topológica que, iterativamente, distribui o material no interior do DFE até que a função objetivo do problema seja minimizada (ou maximizada) e se obtenha a solução otimizada da estrutura. A quarta etapa (Figura 1.1d) consiste na interpretação da solução otimizada oferecida pelo MOT. Conforme indicado pela Figura 1.1c, esta solução é composta por elementos em cor escura (totalmente preenchidos), cores claras (ausência de material) e cores intermediárias, conhecidas como "escala de cinza". Esta escala de cinza é um fenômeno que deriva da formulação adotada no MOT e deve ser minimizada para não dificultar a interpretação dos resultados, bem como inviabilizar a fabricação da estrutura (BRUNS; TORTORELLI, 2001; GUEST; PRÉVOST; BELYTSCHKO, 2004). Ainda na fase de interpretação da solução otimizada, pode ocorrer a presença de regiões com distribuição de material semelhante a um "tabuleiro de xadrez", resultado este conhecido como instabilidade de tabuleiro (CARDOSO; FONSECA, 2003; SIGMUND; PETERSSON, 1998), que geralmente inviabiliza a fabricação de uma estrutura resultante de otimização estrutural. Contudo, na otimização de estruturas sujeitas à radiação térmica este padrão de resultado não aparece. Nesta etapa de projeto, a interpretação dos resultados pode provocar apenas pequenas alterações na estrutura, já que os elementos que contêm materiais intermediários são eliminados.

Após a interpretação da solução otimizada, inicia-se a quinta etapa (Figura 1.1e), que consiste no pós-processamento da nova topologia. Nesta etapa, a estrutura sintetizada é avaliada através do MEF, para se verificar o valor da função objetivo após as alterações realizadas na estrutura durante a fase de interpretação. Finalmente, a última etapa consiste na fabricação da estrutura otimizada.

\subsection{Breve Revisão Bibliográfica}

A bibliografia que trata da aplicação do método da otimização topológica no projeto de estruturas sujeitas à radiação térmica é escassa. Em uma das poucas referências encontradas, Bruns (2007) explorou esta ferramenta para o projeto de micro-aletas de refrigeração sujeitas à troca de calor não linear. Este trabalho, de maneira indireta e simplificada, aborda o fenômeno da radiação, linearizada através de um coeficiente de transferência de calor similar ao utilizado pela lei de resfriamento de Newton (INCROPERA et al., 2007).

Por outro lado, o projeto de estruturas que compõem o interior de confinamentos tem sido exaustivamente abordado através de outras ferramentas de projeto. Modelos para o projeto de sistemas onde a radiação térmica é importante podem ser obtidos a partir da perspectiva de problemas inversos (HOWELL; EZEKOYE; MORALES, 2000; DAUN 
et al., 2006; KOWSARY; POOLADVAND; POURSHAGHAGHY, 2007). Esta técnica permite, por exemplo, determinar a distribuição de fluxo de calor de um aquecedor que satisfaça simultaneamente uma desejada distribuição de temperatura e fluxo de calor sobre um domínio de projeto sujeito a trocas de calor convectiva e radiativa (FRANÇA; EZEKOYE; HOWELL, 2001).

Métodos heurísticos também são frequentemente encontrados na literatura como ferramenta para o projeto de confinamentos sujeitos a trocas térmicas ocorrendo a altas temperaturas (TAJOURI; El Hitti; NEMER, 2011). A literatura, por exemplo, apresenta resultados, obtidos através da utilização de algoritmo genético, da localização otimizada de aquecedores no interior de fornos (SAFAVINEJAD et al., 2009; AMIRI et al., 2011), de modo que determinada área deste confinamento possua uma desejada distribuição de temperatura e fluxo de calor. Outra determinação possível através da utilização deste método é das propriedades emissivas das paredes de um confinamento (KIM et al., 2004).

O método que talvez mais se aproxime do escopo deste trabalho de mestrado, e que apresenta inúmeras referências na literatura, é o que leva em consideração a determinação dos gradientes das funções objetivos investigadas para utilização em otimizações matemáticas (DAUN; HOWELL; MORTON, 2003a). Através desta abordagem, a geometria de confinamentos (DAUN; HOWELL; MORTON, 2003b; DAUN; MORTON; HOWELL, 2003; FAKHRABADI; KOWSARY, 2009) ou o perfil de potência de aquecedores em fornos (HOWELL et al., 2003; DAUN; HOWELL; MORTON, 2004; RAHMANI et al., 2010) podem ser obtidos de maneira otimizada. Para uma discussão mais segmentada e aprofundada das referências pesquisadas para este trabalho, consultar seção 4.2.

\subsection{Motivação}

Qualquer modificação em estruturas que trocam calor por radiação térmica, no sentido de economizar material ou aperfeiçoar o gerenciamento de energia de um processo, pode representar uma considerável economia de recursos financeiros e um avanço no desenvolvimento de práticas sustentáveis. Neste amplo campo de pesquisa e inovação tecnológica, a otimização topológica apresenta-se como uma ferramenta de alto desempenho para o projeto e a fabricação de estruturas sujeitas a trocas radiantes mais eficientes.

Um ramo industrial que demonstra diretamente o quão essencial é o estudo da radiação térmica e o diferencial que representa dominar a aplicação da OT ao seu maquinário é a siderurgia. As elevadas temperaturas dos altos fornos utilizados na indústria siderúrgica tornam a radiação térmica uma importante forma de troca de calor em todo o processo. 
A OT, neste caso específico, pode contribuir para geração de resultados inovadores na distribuição dos materiais que revestem estes fornos. Vê-se assim a importância da utilização de tecnologia que apresente resultados diferenciados, uma vez que, além de ser altamente lucrativo, este setor abastece outros grandes segmentos, como o automobilístico, a construção civil e o setor de transportes.

A aplicação da otimização topológica em estruturas sujeitas à troca de calor radiante representa uma metodologia nova, escassamente explorada na literatura e, como visto no parágrafo anterior, tem aplicação pertinente e direta na redução de custos de uma indústria de faturamento alto e de importância amplamente conhecida. Nestas constatações residem as principais motivações deste mestrado. Acredita-se assim que, neste contexto, o presente trabalho possa contribuir para o desenvolvimento de um método que permita a distribuição sistemática de materiais refletores ou de aquecedores no interior de confinamentos submetidos à radiação térmica. Seguindo este raciocínio, o assunto que será discutido nas próximas linhas é atual, motivo de grande interesse na comunidade científica internacional e de potencial utilidade na indústria.

\subsection{Objetivos}

O presente trabalho tem como objetivo desenvolver uma metodologia para o projeto de estruturas que trocam calor por radiação térmica no interior de confinamentos utilizando o método da otimização topológica como ferramenta de otimização. A modelagem dos fenômenos estudados é feita através do método dos elementos finitos e é implementada por meio de código próprio, utilizando-se o Matlab ${ }^{\circledR}$. Desta forma, espera-se verificar resultados potenciais da aplicação da otimização topológica nesta área.

Os objetivos específicos deste mestrado são:

- distribuir de maneira sistemática material refletor de radiação térmica sobre o domínio estudado;

- distribuir de maneira sistemática aquecedores sobre o domínio estudado;

- extremizar a irradiação de calor em áreas específicas da estrutura modelada;

- minimizar a temperatura em áreas específicas da estrutura modelada. 


\subsection{Otimizar para que, a solução não é óbvia?}

Antes de prosseguir para o próximo capítulo, sugere-se uma breve reflexão, que possivelmente um leitor mais experiente em otimização possa ter aventado após a leitura das seções 1.4 e 1.5: a distribuição de um material com eventual valor de refletividade maior do que os valores iniciais dos materiais que recobrem as superficies do interior de um confinamento, através da otimização topológica, não seria uma tarefa óbvia?

Tome-se como exemplo de projeto a maximização da radiação que chega até uma determinada área deste sistema. Dados os valores iniciais de refletividade das superfícies do interior do confinamento, para alcançar-se o objetivo de maximização proposto, não bastaria que todas as superficies do interior deste confinamento fossem completamente revestidas com um material de refletividade superior? Uma resposta intuitiva para tal questionamento seria mais do que suficiente para tornar irrelevante este trabalho, já que um dos papéis da otimização é de justamente tornar a metodologia de projeto deste tipo de estrutura sistemática, uma vez que ela não seja ordinária.

Indagações deste tipo, entretanto, podem mostrar-se bastante ingênuas sob a ótica da modelagem da radiação térmica no interior de confinamentos. Nas palavras de Siegel e Howell (2002) fica fácil de compreender o porquê:

A complex radiative exchange occurs inside the enclosure as radiation leaves a surface, travels to others surfaces, is partially reflected, and is then rereflected many times within the enclosure with partial absorption at each contact with a surface. It would be complicated to follow the beams of radiation as they undergo this process.

Portanto, fica claro que, mesmo tratando-se de uma simples mudança de refletividade sobre uma superfície qualquer do confinamento, a tarefa de prever a influência desta modificação na distribuição da radiação que chega até determinada área deste sistema não é necessariamente trivial, muito menos óbvia. Outros conceitos e evidências que corroboram esta afirmação ainda serão apresentados no decorrer deste texto. 


\section{Radiação Térmica: Abordagem Analítica}

Neste capítulo, serão mostrados e discutidos os principais fundamentos envolvidos na modelagem analítica da transferência de calor por radiação. O início, que engloba as seções de 2.1.1 a 2.1.3, se dará pela abordagem de conceitos mais diretamente relacionados com este trabalho de mestrado, como a definição das propriedades de absortividade e refletividade, a Lei de Kirchhoff, a definição do fator de forma e a simplificação para corpos cinzas das estruturas que serão estudadas. Por fim, na seção 2.1.4, desenvolve-se como exemplo a solução analítica da troca radiante em um confinamento tridimensional, sujeito a condições de contorno de temperatura e fluxo de calor prescritos.

\subsection{Conceitos Fundamentais}

Qualquer material ou substância que está a uma temperatura maior que zero Kelvin emite energia eletromagnética em pacotes discretos de energia chamados fótons (ROHSENOW; HARTNETT; CHO, 1998). O fóton é o quantum da radiação eletromagnética e a partícula elementar mediadora da força eletromagnética. A energia do fóton é igual a $h v=h c / \lambda$, em que $h$ é a constante de Planck, $c$ a velocidade da luz, $v$ e $\lambda$ são a frequência e comprimento de onda da energia emitida, respectivamente. A radiação térmica é um tipo de radiação eletromagnética associada com um intervalo de temperatura contido entre 30 e $30000 \mathrm{~K}$ e com um comprimento de onda contido no intervalo de 0,1 a $100 \mu \mathrm{m}$ (ROHSENOW; HARTNETT; CHO, 1998), como mostra a Figura 2.1.

Para a maior parte das aplicações em Engenharia, contudo, o interesse reside em uma faixa de radiação cujo comprimento de onda varia de $0,4 \mu m$ (contido na região do ultravioleta) a $15 \mu \mathrm{m}$ (contido na região do infravermelho). Os fótons, cuja energia corresponde a este intervalo de comprimento de onda/temperatura, são capazes de mudar o estado de energia discreta de vibração, rotação e eletrônica de átomos e moléculas do material em que incidem, e, desta forma, mudar a energia interna e a correspondente temperatura deste material. Como resultado disso, a energia é transferida de um corpo 
mais quente para outro mais frio através da radiação térmica (ROHSENOW; HARTNETT; CHO, 1998).

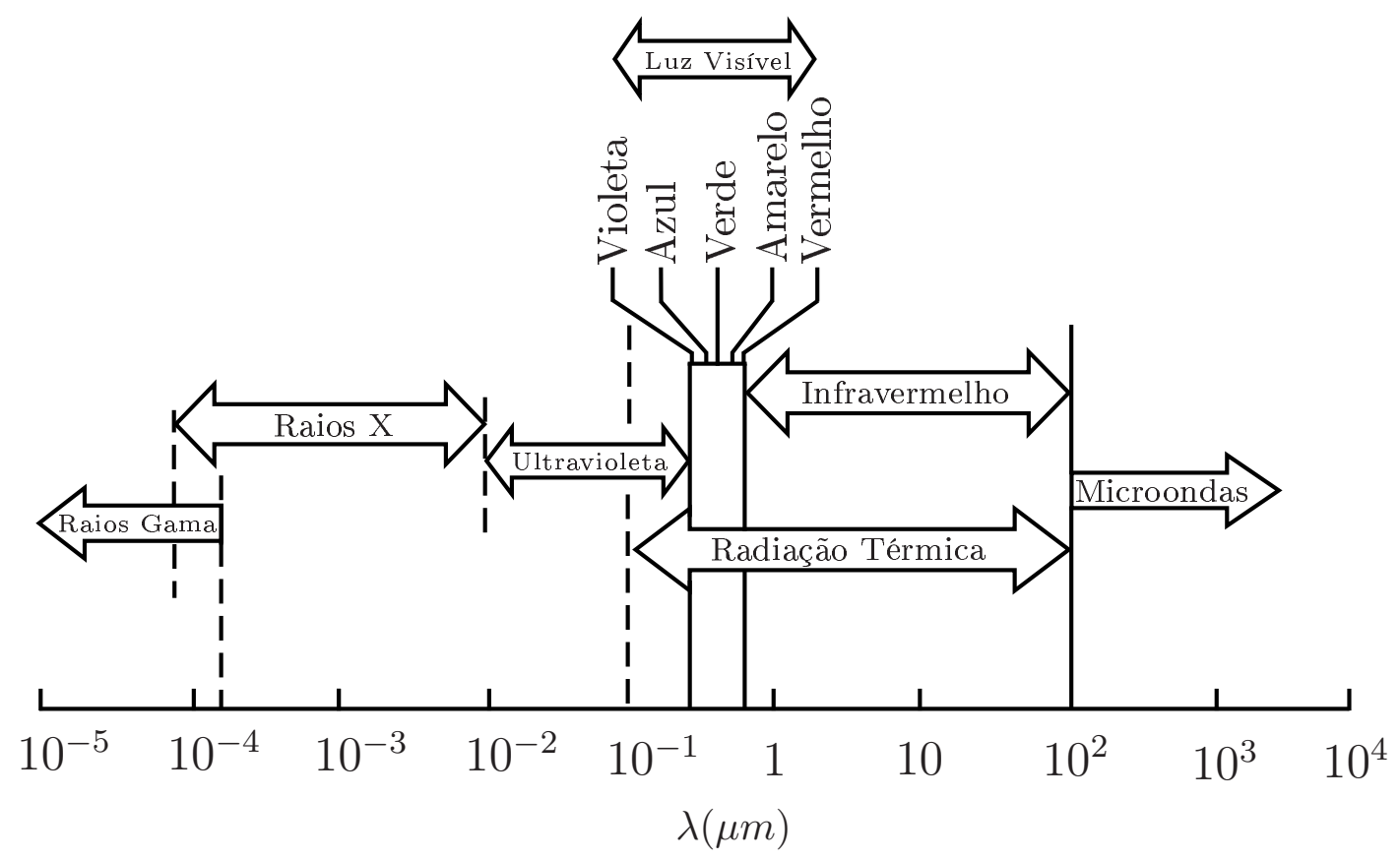

Figura 2.1: Espectro eletromagnético da radiação.

\subsubsection{Emissão, Irradiação e Radiosidade}

A Figura 2.2 mostra três tipos de fenômenos ocorrendo na superfície de uma estrutura sujeita à transferência de calor por radiação: a emissão, a irradiação e a radiosidade. O entendimento, a relação e a formulação matemática destes fenômenos são de essencial importância para a definição, mais adiante, da estratégia de modelagem da interação térmica entre superfícies que trocam calor por radiação no interior de confinamentos que este trabalho utilizará. No exemplo 2.1.4.6, será verificada a aplicação destes conceitos, ao solucionar-se o problema de troca térmica no interior de um confinamento tridimensional.

Antes disso, entretanto, faz-se necessária a discussão de algumas definições geométricas básicas para o entendimento da troca radiante. Somente a partir daí faz-se um detalhamento sobre a intensidade de radiação, que permitirá entender como o fluxo de radiação associado a uma área infinitesimal depende da direção e do comprimento de onda. Utilizando estes conceitos serão então analisados, mais genericamente, os fenômenos de superfícies que estão diretamente ligados ao que se entende por transferência de calor por radiação ${ }^{1}$.

\footnotetext{
${ }^{1}$ De agora em diante, a expressão "radiação térmica" será reduzida para "radiação", por se entender não existir motivos, dado o escopo deste trabalho, de continuar com esta diferenciação.
} 


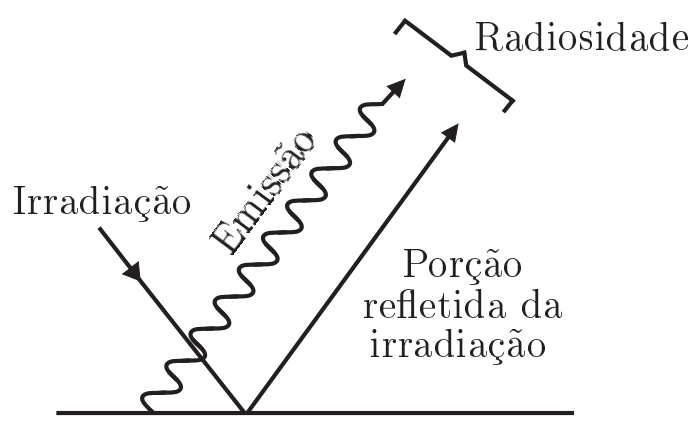

Figura 2.2: Fenômenos que ocorrem em uma superfície sujeita à radiação.

\subsubsection{Definições Geométricas}

A princípio, é interessante entender como a radiação emitida por uma superfície se propaga no espaço tridimensional. Para isso são utilizadas definições obtidas a partir de um sistema de coordenadas esféricas. O ângulo sólido formado entre $d A_{1}$ e uma pequena superfície diferencial $d A_{n}$ através do qual a radiação passa é representado por $d w$ e é um conceito bastante importante, que será retomado futuramente na seção 2.1.4.1, quando forem definidos os fatores de forma.

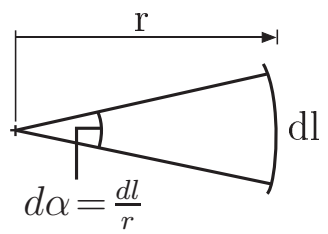

(a)

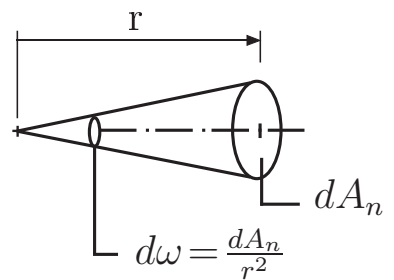

(b)

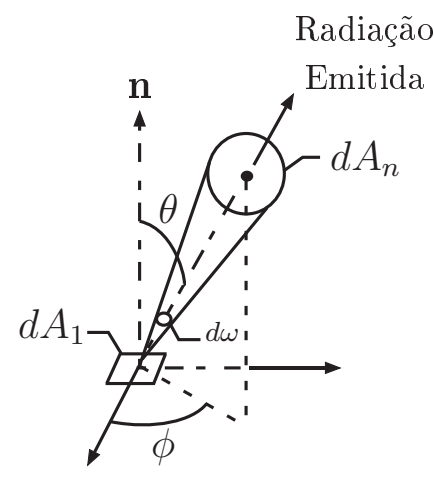

(c)

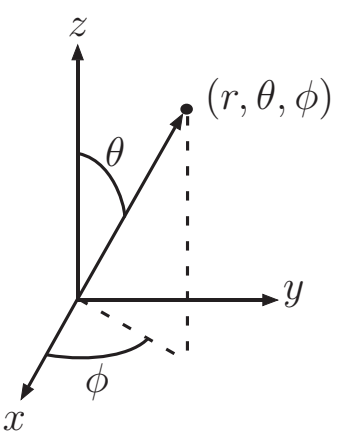

(d)

Figura 2.3: (a) Ângulo plano (b) ângulo sólido (c) emissão de radiação a partir de uma área diferencial $d A_{1}(\mathrm{~d})$ sistema de coordenadas esféricas.

O ângulo sólido possui um paralelo com o ângulo plano: ambos representam uma 
razão. O ângulo plano diferencial $d \alpha$, analogamente ao sólido, é definido pela região entre os raios de um círculo e é medido, em radianos (rad), como a razão entre o elemento de comprimento de arco $d l$ no círculo e o raio $r$ do círculo, como pode ser observado na Figura 2.3a. Uma vez que se trata de um fenômeno que ocorre no espaço tridimensional, define-se o ângulo sólido diferencial $d w$, medido em esterorradiano (sr), como o ângulo com o vértice no centro de uma esfera e que subentende na superfície desta esfera uma área $d A_{n}$, medida pelo quadrado do raio da esfera (INCROPERA et al., 2007), como pode ser visto na Figura 2.4. Assim:

$$
d w=\frac{d A_{n}}{r^{2}}
$$

Tome-se como referência um elemento de área $d A_{1}$, emitindo radiação em uma determinada direção. Essa direção de emissão pode ser definida através dos ângulos de zênite e azimutal, $\theta$ e $\phi$, respectivamente, em um sistema de coordenadas esféricas (Figura 2.3d). A área retangular $d A_{n}$ é normal à direção $(\theta, \phi)$ e da Figura 2.4 percebe-se

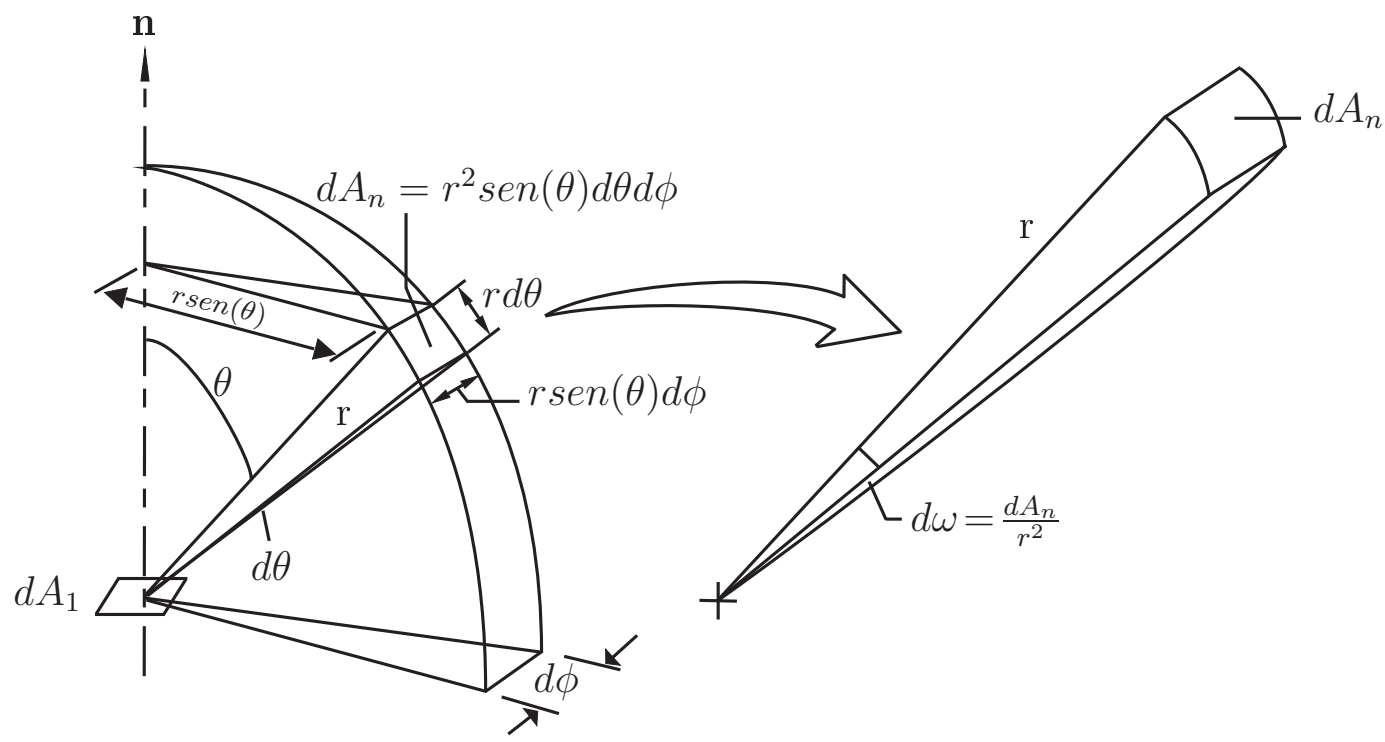

Figura 2.4: Ângulo sólido subtendido por $d A_{n}$ em um ponto em $d A_{1}$, no sistema de coordenadas esférico.

que ela pode ser calculada como $r d \theta \times r \operatorname{sen}(\theta) d \phi$. Assim, $d A_{n}=r^{2} \operatorname{sen}(\theta) d \theta d \phi$ para uma superfície esférica. O ângulo sólido fica então definido como:

$$
d w=\operatorname{sen}(\theta) d \theta d \phi
$$

Quando a área infinitesimal $d A_{1}$ for opaca, a radiação pode ser emitida em qualquer direção definida por um hemisfério hipotético que envolve esta área. O ângulo sólido para este exemplo pode ser obtido integrando a equação (2.2) nos limites $\phi=0$ a $\phi=2 \pi$ e 
$\theta=0$ a $\theta=\pi / 2$. Assim, o ângulo sólido, em esterorradianos ( $s r)$, fica:

$$
\int d w=\int_{0}^{2 \pi} \int_{0}^{\pi / 2} \operatorname{sen}(\theta) d \theta d \phi=2 \pi \int_{0}^{\pi / 2} \operatorname{sen}(\theta) d \theta=2 \pi
$$

Esta abordagem hemisférica utilizada para descrição da emissão de radiação é clássica e será adotada como padrão neste texto.

\subsubsection{Emissão}

Uma vez introduzida a ideia geométrica por trás da emissão de radiação, este conceito pode ser explorado de forma mais específica. Max Planck, no seu livro The Theory of Heat Radiation (PLANCK, 1914), define a emissão de radiação de uma forma bastante interessante. Para ele, somente partículas materiais, e não volumes geométricos ou superfícies, podem emitir radiação. Em suas palavras:

The creation of a heat ray is generally denoted by the word emission. According to the principle of the conservation of energy, emission always takes place at the expense of other forms of energy (heat, chemical or electric energy, etc.) and hence it follows that only material particles, not geometrical volumes or surfaces, can emit heat rays. It is true that for the sake of brevity we frequently speak of the surface of a body as radiating heat to the surroundings, but this form of expression does not imply that the surface actually emits heat rays. Strictly speaking, the surface of a body never emits rays, but rather it allows part of the rays coming from the interior to pass through. The other part is reflected inward and according as the fraction transmitted is larger or smaller the surface seems to emit more or less intense radiations.

A despeito de qualquer uso de linguagem, é necessário, pra todos os efeitos, quantificar a radiação emitida. A grandeza que está diretamente envolvida neste processo é a intensidade de radiação. Este efeito direcional é particularmente importante, uma vez que, na modelagem de um problema térmico que ocorre em um confinamento, caso em que a radiação é um fenômeno pertinente, o interesse está em saber, em cada estrutura, para onde vão os raios emitidos e de onde vêm os raios recebidos. Mais adiante, no exemplo do confinamento tridimensional que será resolvido no item 2.1.4.6, ficará clara a necessidade de entender o equilíbrio térmico em cada uma das paredes que o constituem, ou seja, o fluxo líquido de calor em cada superfície, resultado do balanço entre a quantidade de radiação emitida e a quantidade de radiação recebida.

Considere agora a taxa de emissão de radiação oriunda $d A_{1}$ que passa através de $d A_{n}$. Esta quantidade pode ser expressa por meio da intensidade espectral $I_{\lambda, e}$ e é definida 
como a taxa na qual a energia radiante é emitida, associada a um comprimento de onda $\lambda$ na direção $(\theta, \phi)$, por unidade de área da superfície emissora normal a essa direção, por unidade de ângulo sólido em torno dessa direção e por unidade do intervalo de comprimento de onda $d \lambda$ em torno de $\lambda$ (INCROPERA et al., 2007). A área utilizada para definir a intensidade é o componente de $d A_{1}$ perpendicular à direção da radiação, de forma que esta projeção é dada por $d A_{1} \cos (\theta)$. Assim, a intensidade espectral é dada, em $W / m^{2} . s r . \mu m$, por:

$$
I_{\lambda, e}(\lambda, \theta, \phi)=\frac{d Q}{d A_{1} \cos (\theta) d w d \lambda}
$$

em que $(d Q / d \lambda)=d Q_{\lambda}$ é a taxa, dada em $W / \mu m$, que se pretende determinar (quantidade de radiação de comprimento de onda $\lambda$ emitida por $d A_{1}$ que passa através de $d A_{n}$ ). Rearranjando a equação (2.4), tem-se:

$$
d Q_{\lambda}=I_{\lambda, e}(\lambda, \theta, \phi) \cos (\theta) d A_{1} d w
$$

Através da equação (2.5) é possível calcular a taxa na qual a radiação emitida por uma superfície se propaga na região do espaço definido pelo ângulo sólido $d w$ em torno da direção $(\theta, \phi)$. A partir da equação anterior e da equação (2.2), consegue-se determinar o fluxo de radiação espectral por unidade de área da superfície emissora $d A_{1}$ :

$$
d q_{\lambda}=I_{\lambda, e}(\lambda, \theta, \phi) \cos (\theta) \operatorname{sen}(\theta) d \theta d \phi
$$

Se conhecida a distribuição espectral e direcional, ou seja, o valor de $I_{\lambda, e}(\lambda, \theta, \phi)$, esta equação permite calcular o fluxo de calor associado com a emissão em qualquer ângulo sólido finito ou sobre qualquer intervalo de comprimento de onda finito. Para fins de cálculo da transferência de calor por radiação, é necessário integrar a expressão (2.6) em todas as direções. Como exemplo, é proposto o cálculo do fluxo de calor espectral associado com a emissão para um hemisfério hipotético que envolve a área infinitesimal $d A_{1}$, conforme mostra a Figura 2.5. Assim:

$$
E_{\lambda}(\lambda)=q_{\lambda}(\lambda)=\int_{0}^{2 \pi} \int_{0}^{\pi / 2} I_{\lambda, e}(\lambda, \theta, \phi) \cos (\theta) \operatorname{sen}(\theta) d \theta d \phi
$$

O ângulo sólido para este exemplo pode ser obtido da mesma forma que na equação (2.2). O fluxo total de calor associado com a emissão em todas as direções e em todos os comprimentos de onda, conhecido também por poder emissivo hemisférico, é dado por:

$$
E=\int_{0}^{\infty} E_{\lambda}(\lambda) d \lambda
$$

Uma das hipóteses que será adotada no tratamento da radiação neste texto é de que as superfícies das estruturas analisadas são difusas (ou emissores difusos). Isto é importante, 


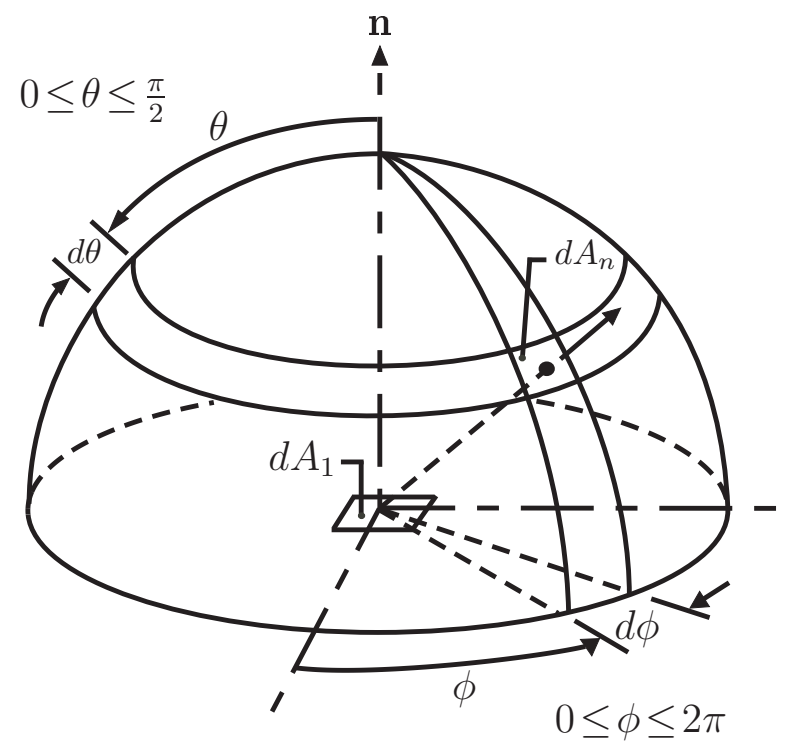

Figura 2.5: Emissão a partir de um elemento de área diferencial $d A_{1}$ para um hemisfério hipotético centrado em um ponto de $d A_{1}$.

pois simplifica a modelagem do problema, uma vez que a intensidade da radiação emitida torna-se independente da direção $(\theta, \phi)$. Desta forma, $I_{\lambda, e}(\lambda, \theta, \phi)=I_{\lambda, e}(\lambda)$ e refazendo a integral da equação (2.7), tem-se a emissão dependendo apenas do comprimento de onda:

$$
E_{\lambda}(\lambda)=\pi I_{\lambda, e}(\lambda)
$$

Equivalentemente, a equação do poder emissivo hemisférico (2.8) fica:

$$
E=\int_{0}^{\infty} \int_{0}^{2 \pi} \int_{0}^{\pi / 2} I_{\lambda, e}(\lambda, \theta, \phi) \cos (\theta) \operatorname{sen}(\theta) d \theta d \phi d \lambda=\pi I_{e}
$$

em que $I_{e}$ é a intensidade total da radiação emitida.

\subsubsection{Irradiação}

Até aqui, concentrou-se em analisar a radiação fruto da emissão de uma superfície. Porém, como já comentado anteriormente, este trabalho tem interesse em determinar o balanço térmico nas estruturas que serão analisadas na modelagem do fenômeno de radiação em confinamentos. Desta forma, é primordial voltar o olhar para a radiação incidente sobre uma superfície, como mostra a Figura 2.6.

A irradiação pode ser originária da reflexão, da emissão ou de ambos os fenômenos ocorrendo ao mesmo tempo em outras superfícies, como é possível observar na Figura 2.2. Analogamente à emissão, a radiação incidente terá distribuição espectral e direcional determinada pela intensidade espectral $I_{\lambda, i}(\lambda, \theta, \phi)$. Esta grandeza é definida como a taxa na qual a energia radiante de comprimento de onda $\lambda$ é incidente a partir da direção $(\theta, \phi)$, por unidade de área da superfície interceptadora normal a essa direção, por unidade de 


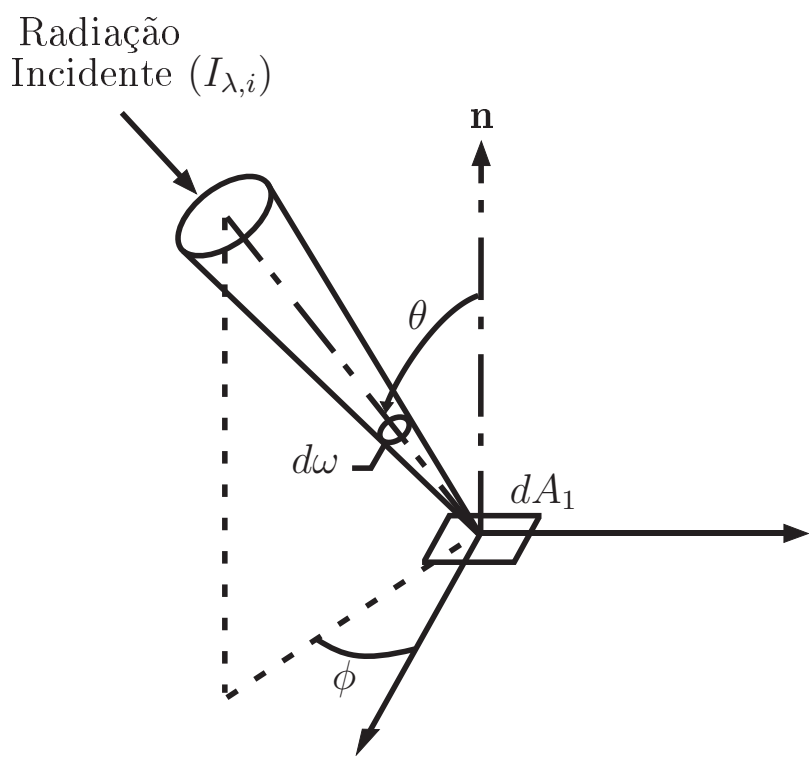

Figura 2.6: Direção natural da radiação incidente.

ângulo sólido em torno dessa direção e por unidade do intervalo de comprimento de onda $d \lambda$ em torno de $\lambda$ (INCROPERA et al., 2007).

Pode-se então, como já foi feito no item 2.1.1.2, calcular o fluxo de radiação incidente $G_{\lambda}$, dado em $\left(W / m^{2} . \mu m\right)$ e conhecido por irradiação espectral. Este fluxo é definido como a taxa na qual radiação de comprimento de onda $\lambda$ é incidente em uma superfície, por unidade de área de superfície e por unidade de intervalo de comprimento de $d_{\lambda}$ em torno de $\lambda$. Assim:

$$
G_{\lambda}(\lambda)=\int_{0}^{2 \pi} \int_{0}^{\pi / 2} I_{\lambda, i}(\lambda, \theta, \phi) \cos (\theta) \operatorname{sen}(\theta) d \theta d \phi
$$

Se integrada em todos os comprimentos de onda e em todas as direções, a irradiação total $G\left(W / m^{2}\right)$ é dada por:

$$
G=\int_{0}^{\infty} G_{\lambda}(\lambda) d \lambda
$$

Se a radiação incidente é independente de $\theta$ e $\phi$, ou seja, difusa, tem-se:

$$
G_{\lambda}(\lambda)=\pi I_{\lambda, i}(\lambda)
$$

e, portanto:

$$
G=\int_{0}^{\infty} \int_{0}^{2 \pi} \int_{0}^{\pi / 2} I_{\lambda, i}(\lambda, \theta, \phi) \cos (\theta) \operatorname{sen}(\theta) d \theta d \phi d \lambda=\pi I_{i}
$$

\subsubsection{Radiosidade}

As definições de emissão e irradiação já foram dadas, de forma que resta apenas definir o que seria a radiosidade. Da Figura 2.2, nota-se que este fluxo refere-se a toda energia radiante que deixa a superfície analisada, seja por emissão, seja por reflexão. 
Neste sentido, geralmente a radiosidade é diferente da emissão. A radiosidade espectral $J_{\lambda}\left(W / m^{2} \cdot \mu m\right)$ representa a taxa na qual a radiação de comprimento de onda $\lambda$ deixa uma área unitária da superfície, por unidade de intervalo de comprimento de $d_{\lambda}$ em torno de $\lambda$ (INCROPERA et al., 2007). Como isto corresponde à radiação que deixa a superfície em todas as direções, ela está relacionada à intensidade associada com a emissão e a reflexão, $I_{\lambda, e+r}(\lambda, \theta, \phi)$, pela expressão:

$$
J_{\lambda}(\lambda)=\int_{0}^{2 \pi} \int_{0}^{\pi / 2} I_{\lambda, e+r}(\lambda, \theta, \phi) \cos (\theta) \operatorname{sen}(\theta) d \theta d \phi
$$

Se a superfície emitir e refletir difusamente, $I_{\lambda, e+r}$ é independente da direção e vale:

$$
J_{\lambda}(\lambda)=\pi I_{\lambda, e+r}(\lambda)
$$

Portanto:

$$
J=\int_{0}^{\infty} \int_{0}^{2 \pi} \int_{0}^{\pi / 2} I_{\lambda, e+r}(\lambda, \theta, \phi) \cos (\theta) \operatorname{sen}(\theta) d \theta d \phi d \lambda=\pi I_{e+r}
$$

Através de definições geométricas e da apresentação dos conceitos de emissão, irradiação e radiosidade, foi discutido o conteúdo básico para o entendimento dos fenômenos de superfície que podem ocorrer no interior de um confinamento sujeito à troca de calor por radiação. Porém, como esses fenômenos são modelados em superfícies reais? No intuito de iniciar o esclarecimento desta dúvida, define-se, a seguir, a radiação de corpo negro.

\subsubsection{Radiação de Corpo Negro}

Antes de serem mostrados alguns conceitos relacionados à radiação de corpo negro, um questionamento é pertinente: por que estudar a radiação em um sistema totalmente idealizado, como é o caso de um corpo negro, se o que se pretende aqui é justamente a modelagem de sistemas reais, de forma a obter-se um modelo que possa ser robustamente utilizado para fins de engenharia? Existem algumas possíveis respostas para esta pergunta, mas a que talvez seja mais relevante para este trabalho é que a propriedade radiante conhecida como emissividade, que permitirá tratar as superfícies que aqui serão analisadas como próximas da realidade, é definida tomando como referência a radiação de corpo negro. Além disso, através da emissividade, como será visto em 2.1.3.5, determina-se outra propriedade, a refletividade, de bastante interesse na otimização topológica desenvolvida neste trabalho. Desta forma, um aprofundamento neste assunto se faz necessário.

Uma discussão pertinente feita no livro Thermal Radiation Heat Transfer (SIEGEL; HOWELL, 2002) e que remete às palavras de Max Planck citadas no item 2.1.1.2, é a 
de que a interação entre a energia radiante incidente e a superfície de um corpo não é resultado apenas das propriedades desta superfície, mas depende igualmente do volume de material abaixo desta superfície. Por exemplo, um metal altamente polido geralmente refletirá praticamente toda a radiação incidente, mas a radiação que passa para o corpo será fortemente absorvida e convertida em energia interna. Assim, este metal possui forte tendência a absorção interna, mesmo que seja um absorvedor medíocre de radiação incidente. Um não metal pode exibir um comportamento oposto. Não metais permitem que uma porção substancial do feixe de radiação incidente penetrem no material (pequena refletividade de superfície), mas uma espessura de material maior é requerida, em relação aos metais, para que haja absorção de radiação e conversão em energia interna. Para ser um bom absorvedor de energia incidente, o corpo precisa então ter uma baixa refletividade de superficie e uma alta absorção interna de radiação. Um corpo negro tem zero de reflexão de superficie e absorção de energia interna completa.

Em outras palavras, um corpo negro é um corpo ideal que permite que toda a radiação incidente penetre nele (sem reflexão de energia). Além disso, ele absorve internamente toda a radiação (sem transmissão de energia). Isto é verdade para todos os comprimentos de ondas e todas as direções (SIEGEL; HOWELL, 2002). Curiosamente, o nome "corpo negro" tem origem no fato de que bons absorvedores de luz visível aparentam ter a cor preta, apesar do olho humano não ser necessariamente um bom indicador para este tipo de fenômeno (SIEGEL; HOWELL, 2002).

Três características principais definem um corpo negro (INCROPERA et al., 2007):

- um corpo negro absorve toda a radiação incidente, independente do comprimento de onda e direção;

- para uma temperatura e comprimento de onda prescritos, nenhuma superfície pode emitir mais energia que um corpo negro (emissor perfeito);

- apesar de a radiação emitida por um corpo negro ser função do comprimento de onda e da temperatura, ela é independente da direção. Isto quer dizer que o corpo negro é um emissor difuso.

Essas características contundentes tornam o corpo negro um referencial idealizado para o tratamento da radiação. Assim, a partir dele, medir-se-á o comportamento da radiação em superfícies reais.

Nos dois itens que se seguem, procura-se clarificar como um corpo idealizado emite energia. Este é classicamente um preâmbulo seguido para a definição da emissão em corpos não negros. 


\subsubsection{Lei de Planck}

A expressão que dá a magnitude da intensidade de radiação emitida por um corpo negro em cada um dos comprimentos de onda não pode ser deduzida através de argumentos termodinâmicos. Na verdade, a pesquisa sobre esta equação levou Planck a investigações e hipóteses que originaram a teoria quântica (SIEGEL; HOWELL, 2002). Foi mostrado pelos argumentos quânticos de Planck (PLANCK, 1901) e verificado experimentalmente que, para um corpo negro, a intensidade espectral é dada por:

$$
I_{\lambda, b}(\lambda, T)=\frac{2 h c_{0}^{2}}{\lambda^{5}\left[\exp \left(\frac{h c_{0}}{\lambda k T}\right)-1\right]}
$$

em que $h=6,626 \times 10^{-34} J . s$ e $k=1,38065156 \times 10^{-23} J / K$ (PODESTA et al., 2013) são as constantes universais de Planck e Boltzmann, respectivamente; $c_{0}=2,998 \times 10^{8} \mathrm{~m} / \mathrm{s}$ é a velocidade da luz no vácuo e $T$ é a temperatura absoluta do corpo negro, medida em Kelvin. Uma vez que o corpo negro é um emissor difuso, conclui-se da equação (2.9) que o poder emissivo espectral será:

$$
E_{\lambda, b}(\lambda, T)=\pi I_{\lambda, b}(\lambda, T)=\frac{C_{1}}{\lambda^{5}\left(\exp \left(\frac{C_{2}}{\lambda T}\right)-1\right)}
$$

em que a constante $C_{1}=2 \pi h c_{0}^{2}=3,742 \times 10^{8} W \cdot \mu^{4} / m^{2}$ e a constante $C_{2}=\left(h c_{0} / k\right)=$ $1,439 \times 10^{4} \mu K$. A equação (2.19) é conhecida como a Distribuição espectral de Planck.

\subsubsection{Lei de Stefan-Boltzmann}

Após a definição do poder emissivo espectral de um corpo negro, é interessante determinar a intensidade de radiação total emitida por um corpo negro, que inclui a radiação em todos os comprimentos de onda. A intensidade de radiação emitida em um pequeno intervalo de comprimento de onda $d_{\lambda}$ é dada por $I_{\lambda, b} d \lambda$. Integrando em todo o intervalo de comprimento de onda, tem-se a intensidade total:

$$
I_{b}=\int_{0}^{\infty} I_{\lambda, b}(\lambda, T) d \lambda
$$

Essa equação é avaliada fazendo a substituição da equação da distribuição espectral de Plank (2.19) e pela transformação de variáveis $\zeta=C_{2} / \lambda T$. Assim:

$$
\begin{aligned}
I_{b} & =\int_{0}^{\infty} \frac{2 C_{1}}{\lambda^{5}\left(\exp \left(\frac{C_{2}}{\lambda T}\right)-1\right)} d \lambda= \\
& =\int_{0}^{\infty}\left(\frac{C_{2}}{\lambda T}\right)^{5}\left(\frac{T}{C_{2}}\right)^{5} \frac{2 C_{1}}{e^{C_{2} / \lambda T}-1}\left(\frac{\lambda T}{C_{2}}\right)^{2}\left(\frac{-C_{2}}{T}\right) d\left(\frac{C_{2}}{\lambda T}\right)= \\
& =\frac{2 C_{1} T^{4}}{C_{2}^{4}} \int_{0}^{\infty} \frac{\zeta^{3}}{e^{\zeta}-1} d \zeta
\end{aligned}
$$


A integral desta equação é dada por:

$$
I_{b}=\frac{2 C_{1} T^{4}}{C_{2}^{4}} \frac{\pi^{4}}{15}
$$

Reagrupando (2.22), tem-se:

$$
I_{b}=\frac{\sigma}{\pi} T^{4}
$$

em que $\sigma=\frac{2 C_{1} \pi^{5}}{15 C_{2}^{4}}=5,67051 \times 10^{-8} \mathrm{~W} /\left(\mathrm{m}^{2} . K^{4}\right)$ é denominada de constante de Stefan-Boltzmann. O poder emissivo hemisférico total de um corpo negro radiando no vácuo fica então:

$$
E_{b}=\int_{0}^{\infty} E_{\lambda, b}(\lambda) d \lambda=\int_{0}^{\infty} \pi I_{\lambda, b}(\lambda) d \lambda=\sigma T^{4}
$$

Por essa emissão ser difusa, segue da equação (2.10) que a intensidade total associada com a emissão do corpo negro é:

$$
I_{b}=\frac{E_{b}}{\pi}
$$

O resultado apresentado em (2.24), supreendentemente simples, define a Lei de Stefan-Boltzmann e será importante para definir-se, a seguir, a emissão de superfícies reais.

\subsubsection{Radiação em Superfícies Reais}

Conceitos aplicáveis à radiação em corpos ideais foram suficientemente discutidos nas seções anteriores. A partir de agora, será estudado como adequá-los à radiação em corpos não negros. O comportamento ideal do corpo negro serve como base de comparação para a performance de um corpo real. Assim, é necessário quantificar os desvios que estes corpos apresentam em relação ao corpo negro para definir a dependência espectral, direcional e de temperatura de suas propriedades.

Muitos são os fatores que influenciam o comportamento de corpos reais, como por exemplo: composição, acabamento da superfície, temperatura, comprimento de onda da radiação, ângulo em que a radiação é emitida ou interceptada, distribuição espectral da radiação incidente e se o corpo é opaco. Nem todos serão levados em conta, mas será dada atenção à dependência espectral, direcional e de temperatura das propriedades emissividade, absortividade e refletividade. A propriedade transmissividade $(\tau)$ será negligenciada, uma vez que o escopo deste trabalho não prevê o estudo do que acontece no interior das estruturas analisadas, apenas e tão somente em suas superfícies. 


\subsubsection{Emissividade}

A habilidade de uma superfície em emitir radiação em comparação com a emissão ideal feita por um corpo negro é definida como emissividade (ROHSENOW; HARTNETT; CHO, 1998). Em outras palavras, a emissividade especifica quão eficazmente um corpo é capaz de radiar energia se comparado a um corpo negro (SIEGEL; HOWELL, 2002). Em uma representação algébrica, tem-se:

$$
\varepsilon=\frac{\text { radiação emitida por uma superfície real }}{\text { radiação emitida por um corpo negro à mesma temperatura }}
$$

Assim, um corpo real a uma temperatura $T$ não emite radiação segundo a Lei de Stefan-Boltzmann $\left(E_{b}=\sigma T^{4}\right)$, mas como uma fração $\varepsilon$ desta emissão. Fica claro, portanto, que a radiação espectral emitida por uma superfície real difere da distribuição de Planck dada por (2.19).

A definição da emissividade direcional espectral $\varepsilon_{\lambda, \theta}(\lambda, \theta, \phi, T)$ de uma superfície a uma temperatura $T$ é dada como a razão entre a intensidade de radiação emitida no comprimento de onda $\lambda$ e na direção de $\theta$ e $\phi$ e a radiação emitida por um corpo negro nos mesmos valores de $T$ e $\lambda$. Logo:

$$
\varepsilon_{\lambda, \theta}(\lambda, \theta, \phi, T)=\frac{I_{\lambda, e}(\lambda, \theta, \phi, T)}{I_{\lambda, b}(\lambda, T)}
$$

Para a maioria dos fins de engenharia, contudo, é desejável trabalhar-se com propriedades que representam médias direcionais. Retome-se, portanto, a análise da Figura 2.5, considerando a média obtida pela integração da quantidade de radiação direcional e espectral de uma semi-esfera em torno de $d A_{1}$. A radiação espectral emitida pela unidade de superfície de área em todas as direções de todo o hemisfério pode ser determinada pela integração da energia espectral, como feito em (2.7):

$$
E_{\lambda}(\lambda, T)=\int_{0}^{2 \pi} \int_{0}^{\pi / 2} I_{\lambda, e}(\lambda, \theta, \phi, T) \cos (\theta) \operatorname{sen}(\theta) d \theta d \phi
$$

Esta equação pode ser reescrita utilizando a relação (2.27):

$$
E_{\lambda}(\lambda, T)=I_{\lambda, b}(\lambda, T) \int_{0}^{2 \pi} \int_{0}^{\pi / 2} \varepsilon_{\lambda, \theta}(\lambda, \theta, \phi, T) \cos (\theta) \operatorname{sen}(\theta) d \theta d \phi
$$

A razão entre a equação anterior e a emissão de um corpo negro (equação (2.19)) define 
a emissividade espectral hemisférica:

$$
\begin{aligned}
\varepsilon_{\lambda}(\lambda, T)=\frac{E_{\lambda}(\lambda, T)}{E_{\lambda, b}(\lambda, T)} & =\frac{I_{\lambda, b}(\lambda, T) \int_{0}^{2 \pi} \int_{0}^{\pi / 2} \varepsilon_{\lambda, \theta}(\lambda, \theta, \phi, T) \cos (\theta) \operatorname{sen}(\theta) d \theta d \phi}{\pi I_{\lambda, b}(\lambda, T)}= \\
& =\frac{1}{\pi} \int_{0}^{2 \pi} \int_{0}^{\pi / 2} \varepsilon_{\lambda, \theta}(\lambda, \theta, \phi, T) \cos (\theta) \operatorname{sen}(\theta) d \theta d \phi
\end{aligned}
$$

A emissividade hemisférica total, que representa uma média sobre todas as direções e comprimentos possíveis, é dada pela substituição das equações (2.8) e (2.30):

$$
\varepsilon(T)=\frac{E(T)}{E_{b}(T)}=\frac{\int_{0}^{\infty} \varepsilon_{\lambda}(\lambda, T) E_{\lambda, b}(\lambda, T) d \lambda}{\sigma T^{4}}
$$

Fica claro que uma superfície real emite radiação como uma porcentagem da emissão de um corpo negro, de tal forma que a propriedade emissividade $\varepsilon$ possui valores entre 0 e 1.

Ainda restam duas propriedades a serem vistas: a absortividade e a refletividade, propriedades de grande interesse para a formulação do problema térmico da otimização topológica.

\subsubsection{Absortividade}

"Raios" de calor são destruídos pela absorção (PLANCK, 1914). Sempre que há absorção, o raio de calor passando através do meio em questão é "enfraquecido" em uma fração de sua intensidade. De acordo com o princípio da conservação da energia, portanto, a energia proveniente da radiação ou é absorvida ou é refletida. A absortividade é a propriedade que retrata justamente esse "enfraquecimento" da energia, pois define a fração da radiação incidente que é absorvida pela superfície (ROHSENOW; HARTNETT; CHO, 1998). Em uma representação algébrica, tem-se:

$$
\alpha=\frac{\text { irradiação absorvida }}{\text { irradiação incidente }}
$$

Se comparada à emissividade, algumas dificuldades adicionais são introduzidas na definição da absortividade, porque as características direcionais e espectrais da radiação incidente precisam ser consideradas.

A absortividade direcional espectral $\alpha_{\lambda, \theta}(\lambda, \theta, \phi)$ de uma superfície é definida como a fração da intensidade espectral incidente na direção de $\theta$ e $\phi$ que é absorvida pela superfície. Logo:

$$
\alpha_{\lambda, \theta}(\lambda, \theta, \phi)=\frac{I_{\lambda, i, a b s}(\lambda, \theta, \phi)}{I_{\lambda, i}(\lambda, \theta, \phi)}
$$

A dependência da temperatura foi desprezada na expressão anterior, porque ela é pequena 
para a maior parte das propriedades radiativas espectrais.

Tal qual visto no item 2.1.3.1, para fins de engenharia é interessante trabalhar com propriedades de superfície que representam médias direcionais. Considere então a absortividade hemisférica espectral $\alpha_{\lambda}$, fração da energia espectral que é absorvida da radiação espectral incidente e oriunda de todas as direções nas redondezas de um hemisfério. Das expressões (2.11) e (2.33), vale:

$$
\alpha_{\lambda}(\lambda)=\frac{G_{\lambda, a b s}(\lambda)}{G_{\lambda}(\lambda)}=\frac{\int_{0}^{2 \pi} \int_{0}^{\pi / 2} \alpha_{\lambda, \theta}(\lambda, \theta, \phi) I_{\lambda, i}(\lambda, \theta, \phi) \cos (\theta) \operatorname{sen}(\theta) d \theta d \phi}{\int_{0}^{2 \pi} \int_{0}^{\pi / 2} I_{\lambda, i}(\lambda, \theta, \phi) \cos (\theta) \operatorname{sen}(\theta) d \theta d \phi}
$$

Se a radiação incidente for difusamente distribuída e $\alpha_{\lambda, \theta}$ for independente de $\phi$, a equação anterior pode ser reduzida a:

$$
\alpha_{\lambda}(\lambda)=2 \int_{0}^{\pi / 2} \alpha_{\lambda, \theta}(\lambda, \theta) \cos (\theta) \operatorname{sen}(\theta) d \theta
$$

Finalmente, define-se a absortividade hemisférica total $\alpha$, que representa a fração da energia incidente que é absorvida, oriunda de todas as direções (que compõem a semi-esfera) e em todos os comprimentos de onda:

$$
\alpha=\frac{G_{a b s}}{G}=\frac{\int_{0}^{\infty} \int_{0}^{2 \pi} \int_{0}^{\pi / 2} \alpha_{\lambda, \theta}(\lambda, \theta, \phi) I_{\lambda, i}(\lambda, \theta, \phi) \cos (\theta) \operatorname{sen}(\theta) d \theta d \phi d \lambda}{\int_{0}^{\infty} \int_{0}^{2 \pi} \int_{0}^{\pi / 2} I_{\lambda, i}(\lambda, \theta, \phi) \cos (\theta) \operatorname{sen}(\theta) d \theta d \phi d \lambda}
$$

Assim, constata-se que a absortividade tem forte dependência da distribuição espectral da radiação incidente, da sua distribuição direcional e da natureza da superfície.

A seguir, é feita a análise da última propriedade principal deste capítulo: a refletividade. Os conceitos que serão discutidos nesta seção são de determinante importância para a compreensão do problema de otimização apresentado mais adiante, no item 4.4 .

\subsubsection{Refletividade}

As propriedades refletivas de uma superfície são mais complicadas de ser especificadas que a emissividade ou a absortividade. Isto se deve ao fato de que a energia refletida não depende somente do ângulo que a energia incidente faz com a superfície, mas também da direção de reflexão considerada para a energia refletida (SIEGEL; HOWELL, 2002), como mostra a Figura 2.7. Este caráter bidirecional da refletividade será aqui evitado, uma vez que optou-se por trabalhar com uma medida que representa uma média integrada sobre a semiesfera associada com a radiação refletida, e dessa forma, as informações relativas à distribuição direcional dessa radiação passam a ser negligenciáveis. Em outras palavras, 

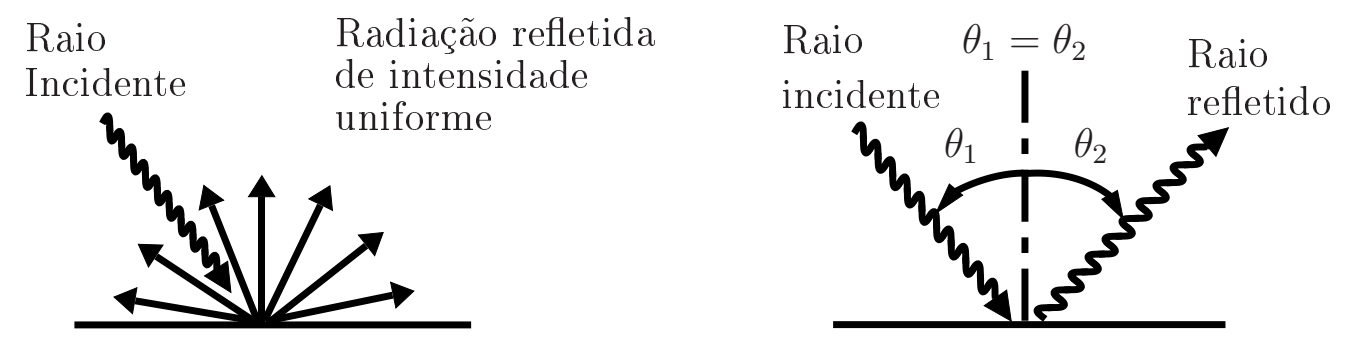

Figura 2.7: Reflexão difusa e especular.

o tratamento especular da radiação não será abordado neste texto.

Discutidas estas questões iniciais, pode-se caracterizar melhor o que é a refletividade: esta propriedade radiante define a fração da energia incidente que é refletida pela superfície (ROHSENOW; HARTNETT; CHO, 1998). Em uma representação algébrica, tem-se:

$$
\rho=\frac{\text { irradiação refletida }}{\text { irradiação incidente }}
$$

Desta forma, é possível explanar o conceito de refletividade direcional espectral $\rho_{\lambda, \theta}(\lambda, \theta, \phi)$ de uma superfície, definida como a fração da intensidade espectral incidente na direção de $\theta$ e $\phi$ que é refletida pela superfície (INCROPERA et al., 2007). Assim:

$$
\rho_{\lambda, \theta}(\lambda, \theta, \phi)=\frac{I_{\lambda, i, r e f}(\lambda, \theta, \phi)}{I_{\lambda, i}(\lambda, \theta, \phi)}
$$

A refletividade hemisférica espectral $\rho_{\lambda}$ é então definida como a fração da irradiação espectral que é refletida pela superfície. Logo:

$$
\rho_{\lambda}=\frac{G_{\lambda, r e f}(\lambda)}{G_{\lambda}(\lambda)}=\frac{\int_{0}^{2 \pi} \int_{0}^{\pi / 2} \rho_{\lambda, \theta}(\lambda, \theta, \phi) I_{\lambda, i}(\lambda, \theta, \phi) \cos (\theta) \operatorname{sen}(\theta) d \theta d \phi}{\int_{0}^{2 \pi} \int_{0}^{\pi / 2} I_{\lambda, i}(\lambda, \theta, \phi) \cos (\theta) \operatorname{sen}(\theta) d \theta d \phi}
$$

A refletividade hemisférica total $\rho$ pode então ser determinada como:

$$
\rho=\frac{G_{r e f}}{G}=\frac{\int_{0}^{\infty} \int_{0}^{2 \pi} \int_{0}^{\pi / 2} \rho_{\lambda, \theta}(\lambda, \theta, \phi) I_{\lambda, i}(\lambda, \theta, \phi) \cos (\theta) \operatorname{sen}(\theta) d \theta d \phi d \lambda}{\int_{0}^{\infty} \int_{0}^{2 \pi} \int_{0}^{\pi / 2} I_{\lambda, i}(\lambda, \theta, \phi) \cos (\theta) \operatorname{sen}(\theta) d \theta d \phi d \lambda}
$$

A partir das diversas definições possíveis para a refletividade, uma importante hipótese é estabelecida e será utilizada para todas as modelagens de radiação apresentadas neste trabalho: as superfícies analisadas são aproximadas como difusas. Desta forma, independente da direção da radiação incidente, a intensidade da radiação refletida não dependerá do ângulo de reflexão. Essa hipótese é extremamente razoável para a maioria das aplicações em engenharia (INCROPERA et al., 2007). 


\subsubsection{Relação entre Propriedades Radiantes da Superfície}

Uma importante relação algébrica pode ser obtida em superfícies opacas através da manipulação das propriedades radiantes absortividade e refletividade. A partir do princípio da conservação de energia, analisa-se a incidência de radiação neste tipo de superfície. A radiação que chega a uma estrutura opaca ou é absorvida ou refletida, de forma que para um dado comprimento de onda, vale:

$$
G_{\lambda}=G_{\lambda, a b s}+G_{\lambda, r e f}
$$

Reescrevendo, tem-se:

$$
G_{\lambda}=\alpha_{\lambda} G_{\lambda}+\rho_{\lambda} G_{\lambda}
$$

Logo, vale:

$$
1=\alpha_{\lambda}+\rho_{\lambda}
$$

Similarmente, para a radiação incidente considerada em todos os comprimentos de onda e em todas as direções, vale:

$$
1=\alpha+\rho
$$

A equação (2.44) é bastante relevante, pois estabelece uma simples e direta relação para a determinação das propriedades radiantes que ditam o destino da radiação incidente em uma superfície opaca.

A próxima seção complementará a equação (2.44), ao tornar claro como é possível relacionar-se absortividade e refletividade à emissividade dos materiais.

\subsubsection{Lei de Kirchhoff}

A Lei de Kirchhoff permite entender a relação que existe entre as capacidades de emissão e absorção de um corpo. Através de um balanço efetuado quando há equilíbrio termodinâmico em um confinamento, pode ser mostrado que a emissividade direcional espectral é igual a absortividade direcional espectral. Assim:

$$
\varepsilon_{\lambda, \theta}=\alpha_{\lambda, \theta}
$$

Isto é verdade porque $\varepsilon_{\lambda, \theta}$ e $\alpha_{\lambda, \theta}$ são propriedades inerentes da superfície. Em outras palavras, elas são independentes das distribuições espectral e direcional das radiações emitidas e incidentes (INCROPERA et al., 2007).

A expressão (2.45) é conhecida como Lei de Kirchhoff e pode ser utilizada em outras relações entre a absortividade e emissividade de um corpo. Para tanto, algumas restrições 
Tabela 2.1: Requisitos para aplicação da Lei de Kirchhoff.

\begin{tabular}{|l|l|}
\hline Relação & Restrições \\
\hline I: $\varepsilon_{\lambda, \theta}=\alpha_{\lambda, \theta}$ & Nenhuma \\
\hline II: $\varepsilon_{\lambda}=\alpha_{\lambda}$ & $\begin{array}{l}\text { Radiação incidente possui intensidade igual em todos os } \\
\text { ângulos, ou } \varepsilon_{\lambda, \theta} \text { e } \alpha_{\lambda, \theta} \text { são independentes do ângulo }\end{array}$ \\
\hline III: $\varepsilon_{\theta}=\alpha_{\theta}$ & $\begin{array}{l}\text { Radiação incidente tem distribuição espectral proporcional } \\
\text { a de um corpo negro na mesma temperatura da superfície, } \\
\text { ou } \varepsilon_{\lambda, \theta} \text { e } \alpha_{\lambda, \theta} \text { são independentes do comprimento de onda }\end{array}$ \\
\hline IV: $\varepsilon=\alpha$ & Uma restrição do item II e outra do item III \\
\hline
\end{tabular}

precisam ser obedecidas, como mostra a Tabela 2.1. Assim, uma consequência da aplicação da Lei de Kirchhoff sobre a equação (2.44), assumindo a hipótese $I V$ como verdadeira, será que:

$$
\alpha+\rho=1 \rightarrow \rho=1-\varepsilon
$$

Os cálculos de transferência de calor desenvolvidos mais adiante serão fortemente simplificados ao assumir-se o item $I V$ da Tabela 2.1 como hipótese válida.

\subsubsection{A Superfície Cinza e Difusa}

A superfície cinza pode ser definida como aquela em que $\alpha_{\lambda}$ e $\varepsilon_{\lambda}$ são independentes de $\lambda$, considerando toda a região do espectro da irradiação e da emissão de superfície. Já a superfície em que $\alpha_{\lambda, \theta}$ e $\varepsilon_{\lambda, \theta}$ são independentes tanto de $\theta$ quanto de $\lambda$ é chamada de superfície cinza e difusa: difusa por causa da independência direcional e cinza por causa da independência do comprimento de onda. Constantemente serão adotadas essas condições para as superfícies analisadas, por isso a importância da discussão desta hipótese. Isto facilitará os cálculos e permitirá boas aproximações.

\subsubsection{Transferência de Calor por Radiação entre Superfícies}

A determinação da transferência de calor por radiação entre superfícies é requerida em diversas áreas, como já mencionado na Introdução (seção 1) deste trabalho. A partir de 1960, o estudo nesse nicho sofreu uma intensificação devido aos avanços tecnológicos em sistemas em que a radiação é bastante significativa (SIEGEL; HOWELL, 2002). Como exemplos destes sistemas podem ser citados: o controle de temperatura em satélites, a transferência de calor em sistemas propulsores nucleares e dispositivos para coleta e utilização da energia solar.

Nesta seção, muitas das definições vistas até aqui são aplicadas, principalmente as relacionadas às propriedades radiantes e à emissão, irradiação e radiosidade, porém agora 
com ênfase na modelagem da troca térmica ocorrendo no interior de um confinamento formado por superfícies cinzas e difusas. Também é dada atenção minuciosa aos fatores de forma, um importante conceito geométrico envolvido neste processo.

\subsubsection{Fatores de Forma: Integral na Área}

Uma das complexidades no cálculo da transferência de calor por radiação entre superfícies se deve às relações geométricas que quantificam como as superfícies "vêem" umas as outras. Isto resulta em integrações da troca radiante nas áreas finitas envolvidas no processo de transferência de calor. Assim, neste item, é apresentada uma medida responsável por esta condição geométrica: os fatores de forma.

O fator de forma difuso $F_{i j}$, ou simplesmente fator de forma, é definido como a fração da radiação uniforme e difusa que deixa uma superfície $i$ e é interceptada pela superfície j (SIEGEL; HOWELL, 2002). Em uma representação algébrica, tem-se:

$$
F_{i j}=\frac{\text { fração da radiação que deixa superfície } i \text { e encontra a superfície } j}{\text { total de radiação emitida pela superfície } i}
$$

Para desenvolver uma expressão geral de $F_{i j}$, considere duas superfícies quaisquer $A_{i}$ e $A_{j}$, que estão a temperaturas $T_{i}$ e $T_{j}$, orientadas de forma arbitrária, como mostra a Figura 2.8 .

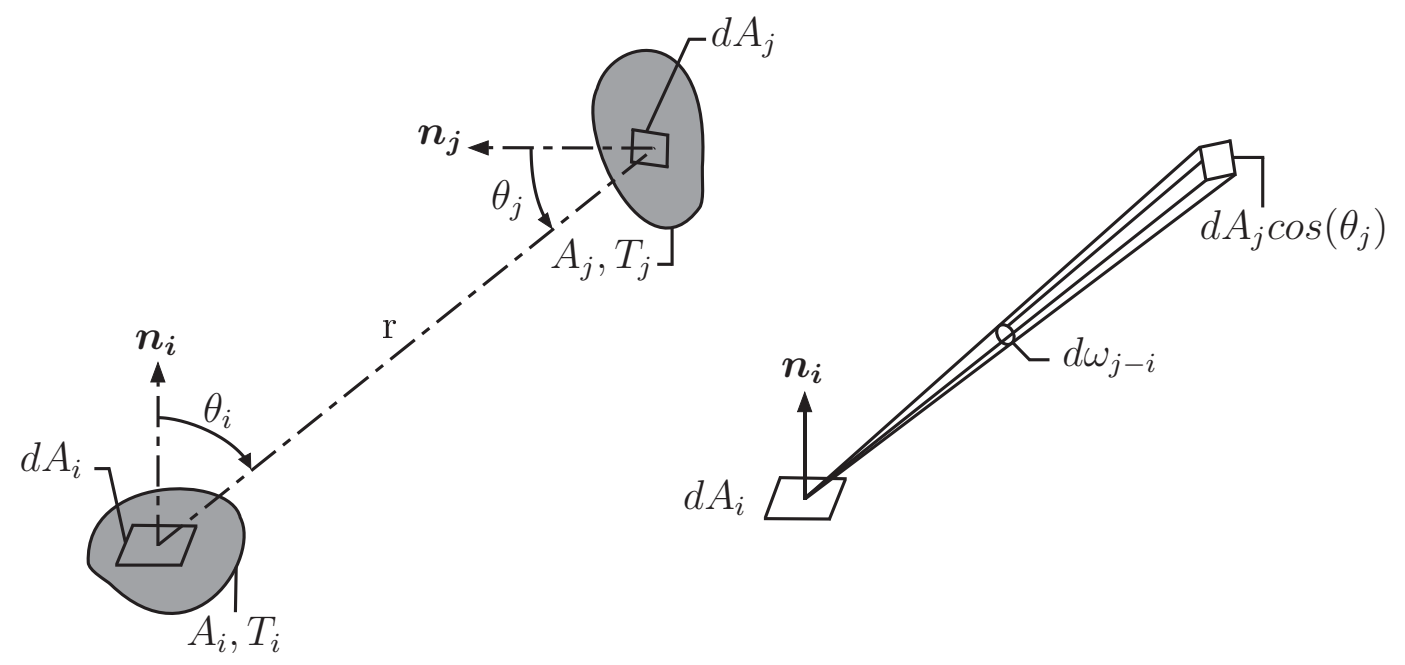

Figura 2.8: Fatores de forma associados com a troca radiante entre as superfícies diferenciais $d A_{i}$ e $d A_{j}$.

As áreas diferenciais em cada superfície, $d A_{i}$ e $d A_{j}$, são conectadas por uma reta de comprimento $r$, que forma os ângulos polares $\theta_{i}$ e $\theta_{j}$, respectivamente, em relação aos vetores normais das superfícies $\left(\boldsymbol{n}_{\boldsymbol{i}}\right.$ e $\left.\boldsymbol{n}_{\boldsymbol{j}}\right)$. Os valores de $r, \theta_{i}$ e $\theta_{j}$ variam com a posição das áreas $A_{i}$ e $A_{j}$.

Da definição de irradiação dada no item 2.1.1.3 e da equação (2.5), a taxa na qual a 
radiação deixa $d A_{i}$ e é interceptada por $d A_{j}$ vale:

$$
d Q_{i \rightarrow j}=I_{e+r, i} \cos \left(\theta_{i}\right) d A_{i} d w_{j-i}
$$

em que $I_{e+r, i}$ é intensidade de radiação emitida e refletida por $i$ que chega até $j, d w_{j-i}$ é o ângulo sólido subtendido por $d A_{j}$ quando visto de $d A_{i}$. Como $d w_{j-i}=\left(\cos \left(\theta_{j}\right) d A_{j}\right) / r_{i j}{ }^{2}$ (equação (2.1)), segue que:

$$
d Q_{i \rightarrow j}=I_{e+r, i} \frac{\cos \left(\theta_{i}\right) \cos \left(\theta_{j}\right)}{r_{i j}^{2}} d A_{i} d A_{j}
$$

Se for admitido que a superfície $i$ emite e reflete de maneira difusa, vale a substituição segundo a equação (2.17):

$$
d Q_{i \rightarrow j}=J_{i} \frac{\cos \left(\theta_{i}\right) \cos \left(\theta_{j}\right)}{\pi r_{i j}^{2}} d A_{i} d A_{j}
$$

Integrando nas duas superfícies $\left(d A_{i}\right.$ e $\left.d A_{j}\right)$, obtém-se a taxa total na qual a radiação deixa a superfície $i$ e é interceptada pela superfície $j$ :

$$
Q_{i \rightarrow j}=J_{i} \int_{A_{i}} \int_{A_{j}} \frac{\cos \left(\theta_{i}\right) \cos \left(\theta_{j}\right)}{\pi r_{i j}^{2}} d A_{i} d A_{j}
$$

em que é feita a hipótese de que a radiosidade $J_{i}$ é uniforme sobre a superfície $A_{i}$. Da definição do fator de forma como a fração da radiação uniforme e difusa que deixa a superfície $A_{i}$ e é interceptada pela superfície $A_{j}$, tem-se:

$$
F_{i j}=\frac{Q_{i \rightarrow j}}{A_{i} J_{i}}
$$

Logo, da substituição das duas relações anteriores, vale:

$$
F_{i j}=\frac{1}{A_{i}} \int_{A_{i}} \int_{A_{j}} \frac{\cos \left(\theta_{i}\right) \cos \left(\theta_{j}\right)}{\pi r_{i j}^{2}} d A_{i} d A_{j}
$$

Equivalentemente, é interessante determinar a fração de radiação que deixa a superfície $A_{j}$ e atinge a superfície $A_{i}$. Assim:

$$
F_{j i}=\frac{1}{A_{j}} \int_{A_{i}} \int_{A_{j}} \frac{\cos \left(\theta_{i}\right) \cos \left(\theta_{j}\right)}{\pi r_{j i}^{2}} d A_{i} d A_{j}
$$

As relações (2.53) e (2.54) representam a forma clássica de definição algébrica dos fatores de forma. Porém, elas são computacionalmente custosas, como mostrado por Shapiro (1985) e Rao e Sastri (1996). Neste sentido, é imperativo tornar este cálculo mais rápido e menos custoso. Para isso, é utilizado neste trabalho a abordagem que define os fatores de forma através de uma integral de linha no contorno, ao invés de uma integral dupla na área. 


\subsubsection{Fatores de Forma: Integral no Contorno}

É imperativo tornar o custo da integração para a determinação dos fatores de forma menor. A aplicação do teorema de Stokes na equação (2.53) permite reduzir a integral dupla sobre uma superfície de área para uma integral dupla de linha no contorno desta área, que é geralmente mais simples e rápida (SPARROW, 1963). Assim:

$$
F_{i j}=\frac{1}{2 \pi A_{i}} \oint_{C_{i}} \oint_{C_{j}}\left[\ln \left(r_{i j}\right) d x_{i} d x_{j}+\ln \left(r_{i j}\right) d y_{i} d y_{j}+\ln \left(r_{i j}\right) d z_{i} d z_{j}\right]
$$

em que $C_{i}$ e $C_{j}$ representam os contornos das áreas $A_{i}$ e $A_{j}$, respectivamente. Os comprimentos infinitesimais destes contornos são dados por $d x$, $d y$ e $d z$ e a distância entre eles é dada por $r_{i j}$. Similarmente à equação (2.54), faz-se:

$$
F_{j i}=\frac{1}{2 \pi A_{j}} \oint_{C_{i}} \oint_{C_{j}}\left[\ln \left(r_{j i}\right) d x_{i} d x_{j}+\ln \left(r_{j i}\right) d y_{i} d y_{j}+\ln \left(r_{j i}\right) d z_{i} d z_{j}\right]
$$

Alguns fatores de forma foram determinados analiticamente e se encontram publicados na literatura, como feito em (SIEGEL; HOWELL, 2002). Para esta dissertação, dois casos são de interesse especial, pois estes servirão de benchmarks para o cálculo numérico dos fatores de forma de um confinamento tridimensional analisado em 2.1.4.6: o de retângulos alinhados paralelos e o de retângulos perpendiculares com uma aresta em comum, como mostra a Figura 2.9.

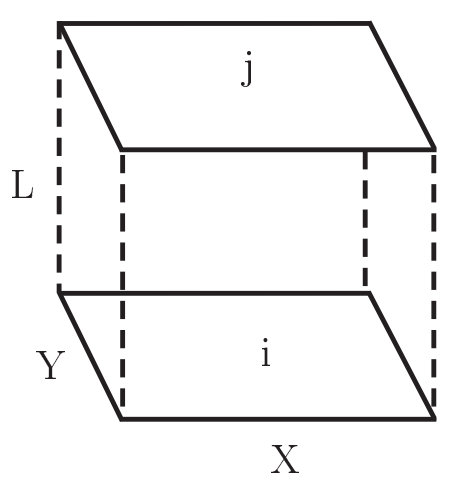

(a)

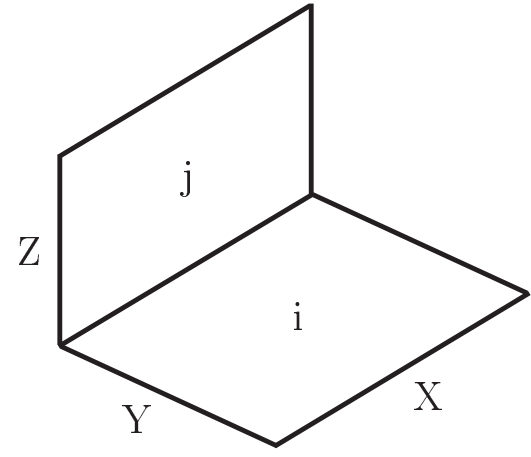

(b)

Figura 2.9: (a) Retângulos alinhados paralelamente (b) retângulos perpendicularmente intersectantes.

Para o caso de retângulos alinhados paralelamente, o resultado da integral (2.55) vale 
(SIEGEL; HOWELL, 2002):

$$
\begin{aligned}
F_{i j} & =\frac{2}{\pi \overline{X Y}}\left\{\ln \left[\frac{\left(1+\bar{X}^{2}\right)\left(1+\bar{Y}^{2}\right)}{1+\bar{X}^{2}+\bar{Y}^{2}}\right]^{1 / 2}+\bar{X}\left(1+\bar{Y}^{2}\right)^{1 / 2} a \tan ^{-1}\left(\frac{\bar{X}}{\left(1+\bar{Y}^{2}\right)^{1 / 2}}\right)+\right. \\
& \left.+\bar{Y}\left(1+\bar{X}^{2}\right)^{1 / 2} a \tan ^{-1}\left(\frac{\bar{Y}}{\left(1+\bar{X}^{2}\right)^{1 / 2}}\right)-\bar{X} a \tan ^{-1}(\bar{X})-\bar{Y} a \tan ^{-1}(\bar{Y})\right\}
\end{aligned}
$$

em que $\bar{X}=X / L$ e $\bar{Y}=Y / L$. Para o caso de retângulos perpendiculares com uma aresta em comum, o resultado da integral (2.55) vale (SIEGEL; HOWELL, 2002):

$$
\begin{aligned}
F_{j i} & =\frac{1}{\pi W}\left\{W \operatorname{atan}^{-1}\left(\frac{1}{W}\right)+\operatorname{Hatan}^{-1}\left(\frac{1}{H}\right)-\left(H^{2}+W^{2}\right)^{1 / 2} a^{-1 a n}\left(\frac{1}{\left(H^{2}+W^{2}\right)^{1 / 2}}\right)+\right. \\
& \left.+\frac{1}{4} \ln \left(\frac{\left(1+W^{2}\right)\left(1+H^{2}\right)}{1+H^{2}+W^{2}}\left[\frac{W^{2}\left(1+H^{2}+W^{2}\right)}{\left(1+W^{2}\right)\left(W^{2}+H^{2}\right)}\right]^{W^{2}} \times\left[\frac{H^{2}\left(1+H^{2}+W^{2}\right)}{\left(1+H^{2}\right)\left(W^{2}+H^{2}\right)}\right]^{H^{2}}\right)\right\}
\end{aligned}
$$

em que $H=Z / X$ e $W=Y / X$.

As equações (2.55) e (2.56) podem ser utilizadas para determinar os fatores de forma associados com quaisquer duas superfícies que são emissoras e refletoras difusas e têm radiosidades uniformes. Aliadas à esta formulação no contorno, serão discutidas a seguir algumas operações algébricas que tornam possível acelerar o cálculo dos fatores de forma em ambientes confinados.

\subsubsection{3 Álgebra dos Fatores de Forma}

Algumas relações podem ser obtidas através do manejo das equações (2.55) e (2.56), de maneira a facilitar o cálculo dos fatores de forma. De uma forma bem direta, é possível perceber que, destas duas expressões, vale:

$$
A_{i} F_{i j}=A_{j} F_{j i}
$$

A equação anterior é conhecida como relação de reciprocidade e é bastante útil para determinação de um fator de forma a partir do conhecimento de outro.

Outra relação amplamente utilizada no cálculo dos fatores de forma apresentados neste trabalho está relacionada à conservação da energia no interior de uma cavidade. Suponha que a superfície $i$ esteja completamente envolvida por $N$ outras superfícies, como mostrado na Figura 2.10. Neste caso, toda a energia que deixa $i$ deve encontrar alguma das outras 


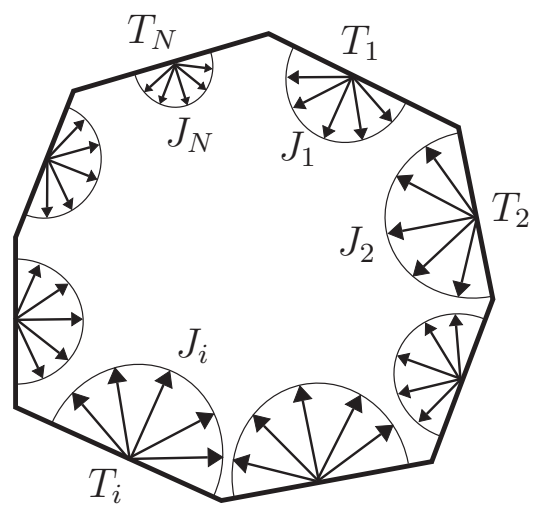

Figura 2.10: Troca de calor por radiação em uma cavidade.

superfícies que a envolvem, podendo-se escrever:

$$
F_{i 1}+F_{i 2}+F_{i 3}+\ldots+F_{i i}+\ldots+F_{i N}=\sum_{j=1}^{N} F_{i j}=1
$$

Essa regra é mera consequência da conservação da energia que deixa a superfície $i$. O fator de forma $F_{i i}$ diz respeito à fração de energia que deixa a superfície $i$ e é interceptada por ela mesma. Isto ocorre quando $i$ é uma estrutura côncava. Por outro lado, para superfícies planas ou convexas, como as que são analisadas neste texto, $F_{i i}=0$. A relação (2.60) é amplamente empregada para aferir os fatores de forma calculados numericamente, como feito no Apêndice B.1.

Uma vez que será utilizado o método dos elementos finitos para modelar o problema da troca radiante (seção 3.2), existem ainda duas relações algébricas que valem a pena ser mencionadas. A primeira delas diz respeito à natureza aditiva dos fatores de forma para uma superfície subdividida, como a mostrada na Figura 2.11. Se considerada a radiação

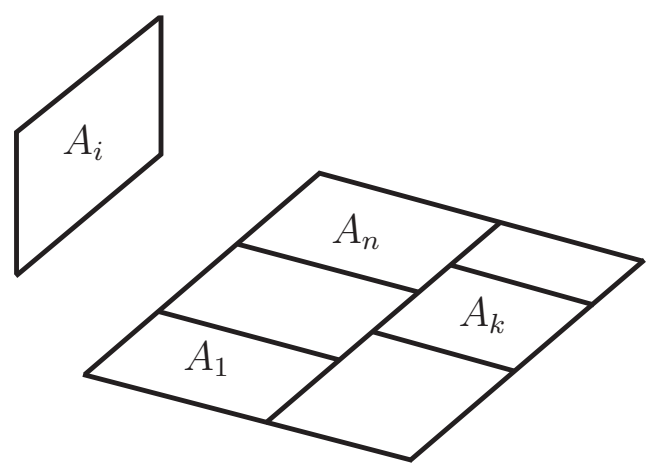

Figura 2.11: Áreas utilizadas para ilustrar a relações dos fatores de forma (2.61) e (2.63).

saindo da superfície $i$ e chegando na superfície $j$, que é dividida em $n$ elementos, fica claro que:

$$
F_{i(j)}=\sum_{k=1}^{n} F_{i k}
$$


em que o parênteses em torno do subscrito $j$ indica que esta é uma superfície composta, de tal forma que $(j)$ é equivalente à soma das superfícies $(1,2, \ldots, k, \ldots, n)$. Esta relação mostra que a radiação que intercepta uma superfície composta é a soma da radiação que chega a cada uma da partes que compõem esta superfície.

Imagine agora a subdivisão da superfície irradiadora. Multiplicando a equação (2.61) por $A_{i}$, e aplicando a relação de reciprocidade (2.59), tem-se:

$$
A_{j} F_{(j) i}=\sum_{k=1}^{n} A_{k} F_{k i}
$$

$\mathrm{Ou}$

$$
F_{(j) i}=\frac{\sum_{k=1}^{n} A_{k} F_{k i}}{\sum_{k=1}^{n} A_{k}}
$$

Para calcular os fluxos de calor e as temperaturas no exemplo do confinamento tridimensional que será mostrado no item 2.1.4.6, um total de $N^{2}$ fatores de forma são necessários. Esta exigência se torna clara quando estes coeficientes geométricos são matricialmente dispostos, como abaixo:

$$
\left[\begin{array}{cccc}
F_{11} & F_{12} & \ldots & F_{1 N} \\
F_{21} & F_{22} & \ldots & F_{2 N} \\
\vdots & \vdots & \ddots & \vdots \\
F_{N 1} & F_{N 2} & \ldots & F_{N N}
\end{array}\right]
$$

Contudo, não se faz necessária a determinação de todos estes fatores. Isto porque um total de $N$ fatores de forma podem ser obtidos das $N$ equações associadas com a aplicação da regra do somatório (relação (2.60)) para cada uma das superfícies da cavidade. Além disso, $N(N-1) / 2$ fatores de forma podem ser obtidos das $N(N-1) / 2$ aplicações da relação de reciprocidade (2.59). Desta forma, são necessários determinar diretamente

$$
\left[N^{2}-N-\frac{N(N-1)}{2}\right]=\frac{N(N-1)}{2}
$$

fatores de forma. A regra anterior pode ser aplicada apenas quando todas as superfícies "veem" umas às outras. Se somente $M$ superfícies puderem "ver-se" reciprocamente, então são necessários (ROHSENOW; HARTNETT; CHO, 1998)

$$
\frac{N(N-3)}{2}+M
$$

fatores de forma.

Quando os valores de certos fatores de forma em uma cavidade são conhecidos apenas 
de forma aproximada, algumas restrições podem ser impostas aos fatores de forma a fim de refiná-los numericamente, através da utilização da relação de reciprocidade e da relação do somatório (relação de conservação). Métodos para estes fins estão amplamente descritos nas referências (SOWELL; O'BRIEN, 1972), (LARSEN; HOWELL, 1986) e (LEERSUM, 1989).

\subsubsection{Troca Radiante entre Superfícies que são Opacas, Cinzas e Difusas no Interior de Confinamentos}

A modelagem da transferência de calor por radiação no interior de confinamentos é amplamente utilizada para fins de engenharia, como no projeto de fornos e do interior de satélites, e pode ser facilmente encontrada na literatura especializada no assunto (SPARROW; CESS, 1978; SIEGEL; HOWELL, 2002). Um exemplo deste tipo de cavidade pode ser visto na Figura 2.12.

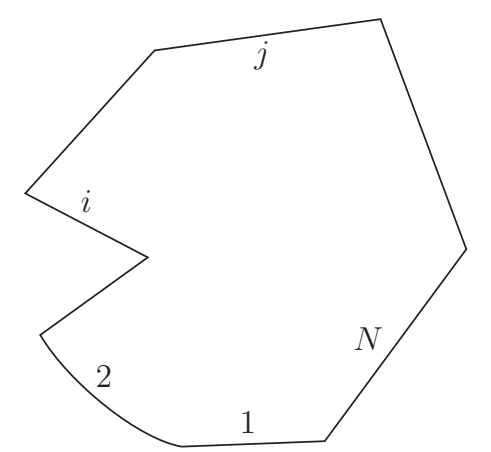

Figura 2.12: Confinamento composto por $N$ superfícies, mostrado em seção transversal (SIEGEL; HOWELL, 2002).

Muitas são as abordagens possíveis para a determinação do fenômeno discutido neste texto (CLARK; KORYBALSKI, 1974). Gebhart (1961), por exemplo, apresenta um método que se baseia na análise da energia que é absorvida pelas superfícies do confinamento. Apesar de bastante similar, a técnica que será utilizada neste texto é a Net-Radiation Method, desenvolvida por Poljak e que é reproduzida com clareza em (SIEGEL; HOWELL, 2002). Contudo, antes da apresentação propriamente dita do método, algumas hipóteses precisam ser feitas. Daqui em diante, será admitido que para qualquer modelagem, seja ela analítica ou numérica, as superfícies que formam a cavidade são:

- isotérmicas e possuem radiosidade e irradiação uniformes;

- opacas (não transmitem energia, ou seja, $\tau=0$ );

- difusas (radiação emitida, refletida ou incidente não orientada);

- cinzas (absortividade e emissividade independentes do comprimento de onda); 
- o meio no qual há troca de calor é transparente, ou seja, não absorve, reflete ou emite radiação.

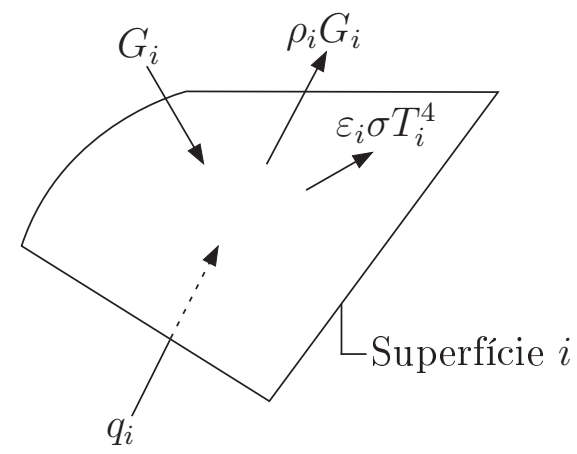

Figura 2.13: Energia incidente e que deixa uma superfície $i$ de uma cavidade (SIEGEL; HOWELL, 2002).

Ao analisar o efeito líquido das interações radiativas ocorrendo dentro de um ambiente de confinamento, o Net-Radiation Method permite determinar três grandezas básicas do sistema: a temperatura, o fluxo de calor líquido e a radiosidade para cada superfície. Dos conceitos discutidos no item 2.1.1 e do balanço térmico representado pela Figura 2.13, é possível deduzir-se duas equações fundamentais para a formulação deste método. A primeira relação vem do fato que a taxa de transferência de calor $Q_{i}$ (ou o fluxo de calor $q_{i}$ ) pode ser definida como a diferença entre a radiosidade e a irradiação ocorrendo em $i$. Desta forma:

$$
Q_{i}=q_{i} A_{i}=A_{i}\left(J_{i}-G_{i}\right)
$$

Uma segunda relação advém da definição de radiosidade, que diz que a taxa de energia que deixa uma superfície $i$ é composta pela energia emitida e refletida. Assim:

$$
J_{i}=\varepsilon_{i} \sigma T_{i}^{4}+\rho_{i} G_{i}=\varepsilon_{i} \sigma T_{i}^{4}+\left(1-\varepsilon_{i}\right) G_{i}
$$

As equações (2.67) e (2.68) permitem entender como a transferência de calor por radiação acontece na superfície de uma estrutura $i$ que compõe um confinamento qualquer. Mas, especificamente para a equação (2.67), ainda falta determinar matematicamente a irradiação $G_{i}$, de forma que as duas equações anteriores possam ser manipuladas e, assim, formarem um sistema de equações em que as incógnitas sejam os valores desconhecidos de temperatura, fluxo de calor e radiosidade. Desta forma, retomando o conceito de irradiação dado em 2.1.1.3, que diz que a radiação que chega até uma superfície $i$ pode ser originária da reflexão, da emissão ou de ambos os fenômenos ocorrendo ao mesmo tempo em todas as superfícies que compõem o interior da cavidade, tem-se:

$$
A_{i} G_{i}=A_{1} J_{1} F_{1 i}+A_{2} J_{2} F_{2 i}+\cdots+A_{j} J_{j} F_{j i}+\cdots+A_{i} J_{i} F_{i i}+\cdots+A_{N} J_{N} F_{N i}
$$

Da relação de reciprocidade (2.59), a equação anterior pode ser reescrita de forma que a 
única área que apareça seja $A_{i}$ :

$$
A_{i} G_{i}=A_{i} F_{i 1} J_{1}+A_{i} F_{i 2} J_{2}+\cdots+A_{i} F_{i j} J_{j}+\cdots+A_{i} F_{i i} J_{i}+\cdots+A_{i} F_{i N} J_{N}
$$

e a irradiação que incide sobre a superfície pode então ser algebricamente definida por:

$$
G_{i}=\sum_{j=1}^{N} F_{i j} J_{j}
$$

A equações (2.67), (2.68) e (2.71) formam relações simultâneas para $q_{i}, T_{i}, J_{i}$ e $G_{i}$ em cada superfície. Seguindo o objetivo inicial de formulação de um procedimento de solução, é interessante notar que (2.68) e (2.71) possibilitam duas expressões diferentes para a definição da irradiação $G_{i}$. Assim, suas substituições em (2.67) fornecem duas equações de balanço de calor para $q_{i}$, em termos de $T_{i}$ e $J_{i}$ :

$$
\left\{\begin{array}{l}
\frac{Q_{i}}{A_{i}}=q_{i}=\frac{\varepsilon_{i}}{1-\varepsilon_{i}}\left(\sigma T_{i}^{4}-J_{i}\right) \\
\frac{Q_{i}}{A_{i}}=q_{i}=J_{i}-\sum_{j=1}^{N} F_{i j} J_{j}=\sum_{j=1}^{N} F_{i j}\left(J_{i}-J_{j}\right)
\end{array}\right.
$$

Em um breve exercício mental, imagine que as equações (2.72) e (2.73) possam ser escritas para cada uma das $N$ superfícies de um confinamento. Isto gera $2 N$ equações para $2 N$ incógnitas. As radiosidades $J$ serão $N$ das incógnitas; as incógnitas remanescentes consistirão dos fluxos de calor $q$ e das temperaturas $T$, dependendo de como as condições de contorno foram definidas para o problema. Depois de determinadas, as radiosidades podem ser eliminadas para gerar $N$ equações relacionando $N$ variáveis desconhecidas de $q$ e $T$. A montagem deste sistema linear pode ser iniciada isolando-se a radiosidade $J_{i}$ na equação (2.72):

$$
J_{i}=\sigma T_{i}^{4}-\frac{1-\varepsilon_{i}}{\varepsilon_{i}} q_{i}
$$

A equação (2.74) é então substituída em (2.73), resultando na seguinte expressão para a superfície $i$ :

$$
\begin{aligned}
& -\frac{Q_{1}}{A_{1}} F_{i 1} \frac{1-\varepsilon_{1}}{\varepsilon_{1}}-\frac{Q_{2}}{A_{2}} F_{i 2} \frac{1-\varepsilon_{2}}{\varepsilon_{2}}-\cdots+\frac{Q_{i}}{A_{i}}\left(\frac{1}{\varepsilon_{i}}-F_{i i} \frac{1-\varepsilon_{i}}{\varepsilon_{i}}\right)-\cdots-\frac{Q_{N}}{A_{N}} F_{i N} \frac{1-\varepsilon_{N}}{\varepsilon_{N}}= \\
& =-F_{i 1} \sigma T_{1}^{4}-F_{i 2} \sigma T_{2}^{4}-\cdots+\left(1-F_{i i}\right) \sigma T_{i}^{4}-\cdots-F_{i N} \sigma T_{N}{ }^{4}= \\
& =F_{i 1} \sigma\left(T_{i}^{4}-T_{1}^{4}\right)+F_{i 2} \sigma\left(T_{i}^{4}-T_{2}^{4}\right)+\cdots+F_{i N} \sigma\left(T_{i}^{4}-T_{N}{ }^{4}\right)
\end{aligned}
$$

A expressão anterior pode ser escrita em forma de somatório:

$$
\sum_{j=1}^{N}\left[\frac{\delta_{i j}}{\varepsilon_{j}}-F_{i j}\left(\frac{1-\varepsilon_{j}}{\varepsilon_{j}}\right)\right] \frac{Q_{j}}{A_{j}}=\sum_{j=1}^{N}\left(\delta_{i j}-F_{i j}\right) \sigma T_{j}^{4}=\sum_{j=1}^{N} F_{i j} \sigma\left(T_{i}^{4}-T_{j}^{4}\right)
$$


em que, para cada superfície correspondente, $i$ assume os valores de $i=1,2, \ldots, N$ e o delta de Kronecker é definido como:

$$
\delta_{i j}= \begin{cases}1, & \text { quando } i=j \\ 0, & \text { quando } i \neq j\end{cases}
$$

Assim, quando as temperaturas das superfícies forem prescritas, o lado direito da equação (2.76) é conhecido e haverá $N$ equações simultâneas para os valores desconhecidos de taxa de transferência de calor $Q_{i}$ (ou fluxo de calor $\frac{Q_{i}}{A_{i}}$ ). Pode ocorrer ainda que os fluxos de calor para algumas superfícies sejam prescritos e as temperaturas, portanto, precisem ser determinadas. Um total de $\mathrm{N}$ incógnitas em $Q$ e $T$ permanecem e a expressão (2.76) fornecerá o número necessário de relações para a determinação destas variáveis desconhecidas. Todo este processo ficará mais claro no item 2.1.4.5, quando será montado, passo-a-passo, um sistema de equações para determinação das temperaturas, fluxos de calor e radiosidades no interior de um confinamento.

\subsubsection{Método Passo-a-Passo para Modelagem da Troca Radiante entre Superfícies no Interior de Confinamentos}

O objetivo deste item é montar um método passo-a-passo para resolução de problemas envolvendo radiação no interior de confinamentos, através de uma abordagem analítica, levando em consideração as hipóteses admitidas anteriormente em 2.1.4.4 para cada superfície, que são (SIEGEL; HOWELL, 2002):

1. a temperatura é uniforme;

2. as propriedades das superfícies são uniformes;

3. as superfícies são opacas $(\tau=0)$ e difusas $(\varepsilon=\alpha=1-\rho)$;

4. toda energia é emitida e refletida difusamente;

5. os fluxos de energia incidente e refletido são uniformes em cada superfície.

Para isto, é necessário dispor organizadamente as equações que foram apresentadas na seção 2.1.4.4. Como ficará claro quando o problema do confinamento tridimensional do item 2.1.4.6 for resolvido, isto é extremamente importante, uma vez que o aumento na quantidade de superfícies que constituem a cavidade pode tornar o problema indesejavelmente complexo.

Problemas que envolvem a transferência de calor entre as superfícies que formam uma cavidade podem envolver a determinação do fluxo de calor radiativo líquido $q_{i}$, caso a 
temperatura associada com a superfície $i, T_{i}$, for conhecida, ou envolver uma determinação da temperatura $T_{i}$, se $q_{i}$ for prescrito (SIEGEL; HOWELL, 2002). Em ambos os casos, faz-se necessário o cálculo das radiosidades. Neste trabalho, também será utilizada esta abordagem. Desta forma, dividem-se as $N$ superfícies que compõem a cavidade em:

- superfícies com temperaturas conhecidas: $1 \leq i \leq N_{1}$;

- superfícies com fluxos de calor conhecidos: $\left(N_{1}+1\right) \leq i \leq N$.

Tendo identificado as superfícies desta forma, o primeiro passo é desenvolvido a seguir:

$1^{o}$ Passo: o primeiro passo a ser dado consiste na determinação dos fatores de forma entre as superfícies. A correta determinação destes coeficientes geométricos é de extrema importância para a precisão dos resultados que se pretende obter (FEINGOLD, 1966). Para isso é possível utilizar resultados analíticos de configurações geométricas comuns, como os sugeridos pelas relações (2.57) e (2.58), ou consultar em catálogos e referências, como (SPARROW; CESS, 1978), (SIEGEL; HOWELL, 2002), (ROHSENOW; HARTNETT; CHO, 1998), (DAVIES, 1984), (VASINA; CHEKSHIN, 1998), (BROCKMANN, 1994), (DEIVEEGAN et al., 2004), (WALTON, 2002), (NARAYANA, 1998), (ABISHEK; RAMANUJAM; KATTE, 2007), (HAMilTON; MORGAN, 1952), (FEINGOLD, 1966) e on-line em (HOWELL, 2012). De maneira geral, porém, pode-se dizer que o primeiro passo consiste na resolução da integral dada por (2.55), seja de maneira analítica ou numérica. As relações de (2.59) a (2.61), de uso altamente recomendável quando o número de superfícies que compõem a cavidade for elevado, também podem ajudar na determinação dos fatores de forma. Assim, uma matriz de fatores de forma como a dada por (2.64) é montada:

$$
F_{i j}=\frac{1}{2 \pi A_{i}} \oint_{C_{i}} \oint_{C_{j}}\left[\ln (r) d x_{i} d x_{j}+\ln (r) d y_{i} d y_{j}+\ln (r) d z_{i} d z_{j}\right] \rightarrow\left[\begin{array}{cccc}
F_{11} & F_{12} & \ldots & F_{1 N} \\
F_{22} & F_{22} & \ldots & F_{2 N} \\
\vdots & \vdots & \ddots & \vdots \\
F_{N 1} & F_{N 2} & \ldots & F_{N N}
\end{array}\right]
$$

Uma maneira indireta de verificar se os valores obtidos para os fatores de forma são coerentes obedece à lei da conservação de energia e, a partir da relação (2.60), se

$$
\sum_{k=1}^{n} F_{i j}(1, k)=1
$$

for verdadeiro, os valores obtidos para o primeiro elemento do confinamento estarão provavelmente corretos. A repetição desta verificação para todas as linhas da matriz (2.64) é extremamente recomendável antes de se prosseguir para o próximo passo. 
$2^{o}$ Passo: o segundo passo consiste na determinação dos valores das radiosidades $J_{i}$ para cada superfície. Substituindo a equação (2.71) na equação (2.68), tem-se:

$$
J_{i}=\varepsilon_{i} \sigma T_{i}^{4}+\left(1-\varepsilon_{i}\right) \sum_{j=1}^{N} F_{i j} J_{j} \quad\left(1 \leq i \leq N_{1}\right)
$$

Apenas as radiosidades das superfícies que possuem temperatura prescrita podem ser determinadas pela equação (2.78). Para as superfícies que possuem fluxo de calor prescrito, é preciso substituir a equação (2.71) na equação (2.67), obtendo-se:

$$
J_{i}=\frac{Q_{i}}{A_{i}}+G_{i}=\frac{Q_{i}}{A_{i}}+\sum_{j=1}^{N} F_{i j} J_{j} \quad\left(N_{1}+1\right) \leq i \leq N
$$

As equações (2.78) e (2.79) podem ser reescritas da seguinte forma (STASIEK, 1988):

$$
\sum_{j=1}^{N} \mathrm{X}_{i j} J_{j}=\Omega_{i} \quad(1 \leq i \leq N)
$$

em que

$$
\left\{\begin{array}{lr}
\mathrm{X}_{i j}=\delta_{i j}-\left(1-\varepsilon_{i}\right) F_{i j} & \left(1 \leq i \leq N_{1}\right) \\
\mathrm{X}_{i j}=\delta_{i j}-F_{i j} & \left(N_{1}+1\right) \leq i \leq N
\end{array}\right.
$$

$\mathrm{e}$

$$
\left\{\begin{array}{lr}
\Omega_{i}=\varepsilon_{i} \sigma T_{i}^{4} & \left(1 \leq i \leq N_{1}\right) \\
\Omega_{i}=\frac{Q_{i}}{A_{i}} & \left(N_{1}+1\right) \leq i \leq N
\end{array}\right.
$$

Os coeficientes $\mathrm{X}_{\mathrm{ij}}$ formam a matriz $\mathbf{X}$, que pela sua inversão fornece a matriz $\mathbf{\Psi}=\mathbf{X}^{-\mathbf{1}}$. Logo, as radiosidades de todas as superfícies podem ser calculadas por:

$$
J_{i}=\sum_{j=1}^{N_{1}} \Psi_{i j} \sigma T_{j}^{4}+\sum_{j=\left(N_{1}+1\right)}^{N} \Psi_{i j} \frac{Q_{j}}{A_{j}} \quad(1 \leq i \leq N)
$$

$3^{o}$ Passo: no terceiro passo, determinam-se as temperaturas e fluxos térmicos desconhecidos. Para as $N_{1}$ primeiras superfícies, onde são conhecidas as temperaturas, pode-se substituir diretamente a equação (2.85) na equação (2.72) para se obter os fluxos de calor:

$$
q_{i}=\sum_{j=1}^{N_{1}} \Lambda_{i j} \sigma T_{j}^{4}-\frac{\varepsilon_{i}}{1-\varepsilon_{i}} \sum_{j=\left(N_{1}+1\right)}^{N} \Psi_{i j} \frac{Q_{j}}{A_{j}} \quad\left(1 \leq i \leq N_{1}\right)
$$

em que

$$
\Lambda_{i j}=\frac{\varepsilon_{i}}{1-\varepsilon_{i}}\left(\delta_{i j}-\Psi_{i j}\right)
$$

Para as superfícies restantes, $\left(N_{1}+1\right) \leq i \leq N$, onde são conhecidos os fluxos térmicos, isola-se a temperatura na equação (2.72) e substitui-se a equação (2.85) nesta, resultando 
em:

$$
T_{i}=\left[\frac{1}{\sigma}\left(\sum_{j=1}^{N_{1}} \Psi_{i j} \sigma T_{j}^{4}+\sum_{j=\left(N_{1}+1\right)}^{N} \phi_{i j} \frac{Q_{j}}{A_{j}}\right)\right]^{\frac{1}{4}} \quad\left(N_{1}+1\right) \leq i \leq N
$$

em que

$$
\phi_{i j}=\left(\frac{1-\varepsilon_{i}}{\varepsilon_{i}}\right) \delta_{i j}+\Psi_{i j}
$$

$4^{\circ}$ Passo: no quarto e último passo, estabelece-se um padrão para verificação dos resultados, baseado na primeira lei da termodinâmica, que consiste em averiguar se a soma das taxas de transferência de calor calculadas é igual a zero (SIEGEL; HOWELL, 2002), ou seja:

$$
\sum_{i=1}^{N} Q_{i}=\sum_{i=1}^{N} q_{i} A_{i}=0
$$

Uma vez atendida a equação (2.90), garante-se que os resultados satisfazem o princípio de conservação da energia, o que caracteriza um excelente indicativo de uma boa modelagem do fenômeno analisado.

O método passo-a-passo apresentado nesta seção tem a função de auxiliar na aferição do método numérico que será apresentado na seção 3.2 (resultados desta aferição encontram-se discutidos no Apêndice B.2) e será utilizado para a solução do exemplo de um confinamento tridimensional, como apresentado a seguir.

\subsubsection{Exemplo: Confinamento Tridimensional}

A modelagem da troca radiante em um confinamento tridimensional foi frequentemente citada como exemplo ao longo deste texto. Ela é bastante importante, porque além de permitir a discussão de muito dos conceitos já apresentados, servirá de benchmark para os resultados da modelagem numérica utilizando o método dos elementos finitos que será implementada mais a frente, na seção 3.2.

O problema em questão consiste em determinar os fluxos de calor nas superfícies de 1 a 4 e as temperaturas nas superfícies 5 e 6 do confinamento tridimensional representado pela Figura 2.14. A emissividade de cada superfície, bem como as condições de contorno de temperatura e de fluxo de calor são dadas por:

$$
\left\{\begin{array} { l } 
{ \varepsilon _ { p _ { 1 } } = 0 , 9 } \\
{ \varepsilon _ { p _ { 2 } } = 0 , 7 } \\
{ \varepsilon _ { p _ { 3 } } = 0 , 8 } \\
{ \varepsilon _ { p _ { 4 } } = 0 , 3 } \\
{ \varepsilon _ { p _ { 5 } } = 0 , 9 } \\
{ \varepsilon _ { p _ { 6 } } = 0 , 9 }
\end{array} \quad \left\{\begin{array} { l } 
{ T _ { p _ { 1 } } = 5 0 0 \mathrm { K } } \\
{ T _ { p _ { 2 } } = 8 0 0 \mathrm { K } } \\
{ T _ { p _ { 3 } } = 1 0 0 0 \mathrm { K } } \\
{ T _ { p _ { 4 } } = 1 2 0 0 \mathrm { K } }
\end{array} \quad \left\{\begin{array}{l}
q_{p_{5}}=0 \\
q_{p_{6}}=0
\end{array}\right.\right.\right.
$$




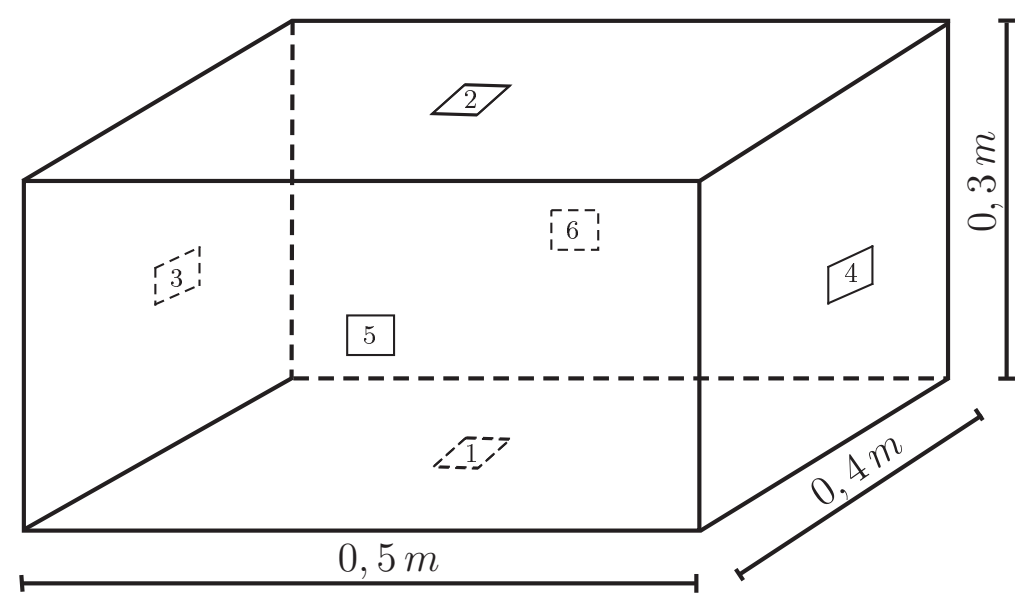

Figura 2.14: Ilustração do confinamento tridimensional.

Seguindo o método desenvolvido no item 2.1.4.5, no primeiro passo, os fatores de forma são calculados utilizando as equações (2.57) e (2.58) e a matriz dos fatores de forma é montada como em (2.64):

$$
\mathbf{F}=\left[\begin{array}{cccccc}
0 & 0,3163 & 0,2514 & 0,2514 & 0,2547 & 0,2547 \\
0,3163 & 0 & 0,2514 & 0,2514 & 0,2547 & 0,2547 \\
0,1508 & 0,1508 & 0 & 0,1168 & 0,1522 & 0,1522 \\
0,1508 & 0,1508 & 0,1168 & 0 & 0,1522 & 0,1522 \\
0,1910 & 0,1910 & 0,1902 & 0,1902 & 0 & 0,1864 \\
0,1910 & 0,1910 & 0,1902 & 0,1902 & 0,1864 & 0
\end{array}\right]
$$

É interessante observar que a somatória de todas as linhas da matriz $\boldsymbol{F}$ deve ser igual a 1. Assim, para a primeira linha desta matriz, vale: $\sum_{k=1}^{6} F_{i j}(1, k)=1$, respeitando o princípio da conservação da energia, como exigido em (2.60). Esta rápida verificação, apesar de não representar o único modo, é uma maneira extremamente eficaz para averiguar se os valores dos fatores de forma calculados estão corretos e, portanto, será extensamente utilizada para validar os resultados obtidos no Apêndice B.1.

No segundo passo, monta-se a matriz $\mathbf{X}$, através das relações 1.76 e 1.77 e a inverte-se, para o cálculo da matriz $\Psi$ :

$$
\mathbf{X}=\left[\begin{array}{cccccc}
1,1111 & -0,0351 & -0,0279 & -0,0279 & -0,0283 & -0,0283 \\
-0,1356 & 1,4286 & -0,1077 & -0,1077 & -0,1091 & -0,1091 \\
-0,0377 & -0,0377 & 1,2500 & -0,0292 & -0,0380 & -0,0380 \\
-0,3520 & -0,3520 & -0,2726 & 3,3333 & -0,3550 & -0,3550 \\
-0,1910 & -0,1910 & -0,1902 & -0,1902 & 1,0000 & -0,1864 \\
-0,1910 & -0,1910 & -0,1902 & -0,1902 & -0,1864 & 1,0000
\end{array}\right]
$$


A matriz $\Psi=\mathrm{X}^{-1}$ vale:

$$
\Psi=\left[\begin{array}{llllll}
0,9267 & 0,0398 & 0,0248 & 0,0088 & 0,0344 & 0,0344 \\
0,1534 & 0,7517 & 0,0700 & 0,0248 & 0,0973 & 0,0973 \\
0,0929 & 0,0681 & 0,8240 & 0,0150 & 0,0656 & 0,0656 \\
0,3076 & 0,2254 & 0,1400 & 0,3270 & 0,2172 & 0,2172 \\
0,4130 & 0,3026 & 0,2099 & 0,0745 & 1,1301 & 0,2872 \\
0,4130 & 0,3026 & 0,2099 & 0,0745 & 0,2872 & 1,1301
\end{array}\right]
$$

As radiosidades, de acordo com a equação (2.85), podem então ser determinadas:

$$
\mathbf{J}=\left[\begin{array}{c}
6646,04 \\
24895,69 \\
50398,56 \\
52709,22 \\
29153,73 \\
29153,73
\end{array}\right] W / m^{2}
$$

Agora prossegue-se para o terceiro passo. Com a ajuda das equações (2.86) e (2.88), determinam-se os valores de fluxo de calor e de temperatura desconhecidos:

$$
\mathbf{T}=\left[\begin{array}{c}
500,00 \\
800,00 \\
1000,00 \\
1200,00 \\
846,77 \\
846,77
\end{array}\right] K \quad \mathbf{q}=\left[\begin{array}{c}
-27918,42 \\
-3896,05 \\
25221,75 \\
27802,36 \\
0,00 \\
0,00
\end{array}\right] \mathrm{W} / \mathrm{m}^{2}
$$

Para uma verificação preliminar dos resultados, faz-se como sugerido no quarto passo da seção 2.1.4.5. Desta forma, tem-se:

$$
\left\{\begin{array}{l}
q_{p_{1}} A_{p_{1}}+q_{p_{2}} A_{p_{2}}+q_{p_{3}} A_{p_{3}}+q_{p_{4}} A_{p_{4}}=0 \\
-27918,4 \times 0,2-3896,0 \times 0,2+25221,7 \times 0,12+27802,3 \times 0,12=0
\end{array}\right.
$$

Este exemplo finaliza a extensa, mas essencial discussão dos conceitos analíticos que permeiam a determinação do problema de transferência de calor por radiação em superfícies que constituem o interior de um confinamento. Um método robusto para a abordagem deste fenômeno foi apresentado, de forma que a seguir, o interesse recairá em transpor este método para o mundo numérico/computacional, através do uso da quadratura de Gauss e do método dos elementos finitos. 


\section{Radiação Térmica: Abordagem Numérica}

Transita-se agora para a modelagem numérica/computacional da troca radiante no interior de confinamentos. Assim, através de uma técnica de quadratura será apresentada a solução numérica para o cálculo dos fatores de forma em superfícies planas e não obstruídas, dada analiticamente pela equação (2.55), e por meio do método dos elementos finitos será possível determinar as radiosidades, temperaturas e fluxos de calor desconhecidos, como apresentado analiticamente na seção 2.1.4.5.

\subsection{Cálculo Numérico dos Fatores de Forma}

Nas seções 2.1.4.1 e 2.1.4.2 foram introduzidas formulações analíticas dos fatores de forma. Discute-se agora a abordagem numérica do cálculo desses coeficientes e o caminho percorrido que levou o autor a escolher, dentre as muitas opções possíveis, a técnica utilizada neste trabalho.

Antes de prosseguir, contudo, faz-se necessário justificar o não uso das formulações propostas no trabalho de Ehlert e Smith (1993). Este artigo trata justamente do problema de determinação dos fatores de forma entre superfícies planas paralelas e perpendiculares, abordado nesta dissertação. A opção por não reproduzi-lo foi adotada por acreditar-se que a metodologia que será apresentada na seção 3.1.3 é mais genérica, sendo inclusive aplicável à determinação dos fatores de forma entre superfícies côncavas, sem a presença de uma superfície obstruidora entre estas.

\subsubsection{Breve Revisão Bibliográfica}

Muitos são os métodos possíveis de serem utilizados para determinação numérica dos fatores de forma. Dentre os mais tradicionalmente citados pela literatura, destacam-se os métodos do Hemi-Cubo, de Monte Carlo, Método de Projeção de Nusselt e Ray Tracing.

Ao preterir-se a equação (2.53) em função da equação (2.55), procurava-se tornar o 
cálculo dos fatores de forma mais simples e menos custoso. Mas essa escolha, a priori, pode não parecer tão óbvia, uma vez que uma pouco criteriosa busca nas referências bibliográficas que tratam do assunto indica justamente a utilização da equação (2.53) como correta abordagem. Isto porque, em um trabalho que se propõe a fazer uso do MEF para a modelagem da troca radiante em confinamentos, é natural imaginar que um artigo como (CHUNG; KIM, 1982) seja indicado como referência imediata na determinação numérica dos fatores de forma. Todavia, explorando melhor a ampla literatura que trata do assunto, encontram-se nas palavras de Ambirajan e Venkateshan (1993), que os valores dos resultados obtidos por Chung e Kim (1982) para o cálculo dos fatores de forma entre retângulos alinhados paralelos e entre retângulos com uma aresta em comum possuem significativo erro, mesmo com a utilização de uma malha refinada. Até mesmo os valores analíticos que o artigo utiliza como base de comparação, baseados no trabalho de Hamilton e Morgan (1952), apresentam erros consideráveis, como indicado em (FEINGOLD, 1966). Fica claro, portanto, que para uma correta e econômica abordagem numérica do cálculo dos fatores de forma é essencial a utilização da equação (2.55).

Segundo Ambirajan e Venkateshan (1993), mesmo que os fatores de forma representem apenas uma aproximação do comportamento direcional real de uma superfície, seria errado admitir que se pode trabalhar com valores imprecisos desses fatores geométricos. Como demonstra Feingold (1966), este tipo de erro seria potencialmente ampliado no tratamento da radiação em cavidades. Desta forma, deve-se evitar a conclusão de que, porque simplificações no cálculo da troca de calor por radiação foram estabelecidas e porque as superfícies reais modeladas não respeitam exatamente à Lei de Beer-Lambert, é cabível prescindir de calcular com precisão os fatores de forma.

Rao e Sastri (1996) estabelecem uma análise comparativa de precisão e de tempo na determinação de fatores de forma em configurações estruturais clássicas, como as presentes na Figura 2.9, através de quadraturas de Gauss de várias ordens. Este artigo, que pode ser visto como um método dos elementos finitos para a integral de linha, mostra que esta integral precisa de uma quadratura de ordem menor para obter a mesma acurácia que o método sugerido por Chung e Kim (1982) e, portanto, é mais atrativa que o método dos elementos finitos para a integral na área.

Shapiro (1985) apresenta um interessante estudo sobre o tempo de execução e porcentagem de erro entre as estimações numéricas das equações (2.53) e (2.55) no caso de dois retângulos diretamente opostos (Figura 2.9a). Este estudo mostra que, se forem divididos cada um dos quatro segmentos de linha que formam o retângulo sobre o qual realiza-se a integral em $n$ divisões, serão criados $4 n$ nós ao redor do contorno e $n^{2}$ nós para a superfície de área. Assim, são necessárias $\left(114 n^{4}+86 n^{2}\right)$ operações para a integral na 
área e $\left(464 n^{2}+24 n\right)$ operações para a integral na linha, o que prova computacionalmente a eficiência desta última integral em relação à primeira.

Apesar de numericamente mais rápida de ser integrada, a equação (2.55) apresenta uma importante restrição: no caso de uma intersecção entre duas estruturas, como na Figura 2.9b, a distância $r$ torna-se nula e o logaritmo natural passa a não ser definido. Ambirajan e Venkateshan (1993) evitam o tratamento numérico desta restrição ao definirem a integral analítica para qualquer borda reta intersectante entre duas superfícies, dada por:

$$
\Delta F_{i j}=\frac{1}{2 \pi A_{i}} L_{c}^{2}\left(1,5-\ln \left(L_{c}\right)\right)
$$

em que $L_{c}$ é o comprimento da aresta em comum (borda intersectante). A relação (3.1) representa a contribuição do elemento que está na aresta em comum entre as duas superfícies para o fator de forma total. Esta formulação, de extrema simplicidade, uma vez que só depende do comprimento da aresta em comum, foi bastante utilizada para obtenção dos resultados apresentados no Apêndice B.1.

Como é possível constatar, a literatura disponibiliza uma série de discussões e de métodos numéricos para a determinação dos fatores de forma em cavidades. A técnica que é explorada nesta dissertação é a empregada classicamente para a determinação numérica de integrais quando o MEF é aplicado ao fenômeno analisado: a quadratura de Gauss.

\subsubsection{Aproximação Numérica da Integral no Contorno}

No item 3.1.1, foi visto que a equação (2.55) é a mais adequada para a determinação dos fatores de forma. Mas antes de aproximá-la numericamente e aplicar a quadratura de Gauss, é interessante observar como pode se dar o seu manuseio. Rao e Sastri (1996) apresentam um exemplo bastante elucidativo, ao considerarem dois elementos de linha no contorno de duas superfícies, como mostra a Figura 3.1.

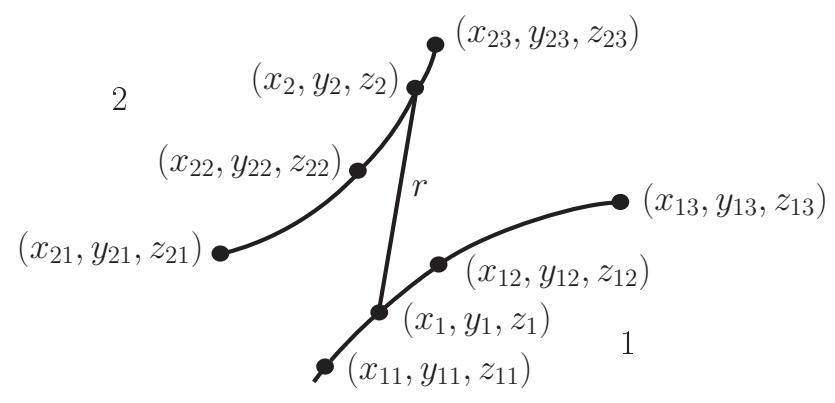

Figura 3.1: Esquema que mostra 3 pontos em cada linha para a aplicação da integral no contorno.

Três pontos são marcados em cada um dos elementos. Para esta situação, a equação 
(2.55) pode ser expandida como:

$$
\begin{aligned}
\Delta F_{12}=\frac{1}{2 \pi A_{1}} & {\left[\int_{x_{11}}^{x_{13}} \int_{x_{21}}^{x_{23}} \ln \left(r_{12}\right) d x_{1} d x_{2}+\right.} \\
& +\int_{y_{11}}^{y_{13}} \int_{y_{21}}^{y_{23}} \ln \left(r_{12}\right) d y_{1} d y_{2}+ \\
& \left.+\int_{z_{11}}^{z_{13}} \int_{z_{21}}^{z_{23}} \ln \left(r_{12}\right) d z_{1} d z_{2}\right]
\end{aligned}
$$

em que $r_{12}=\sqrt{\left(x_{1}-x_{2}\right)^{2}+\left(y_{1}-y_{2}\right)^{2}+\left(z_{1}-z_{2}\right)^{2}}$ e $\Delta F_{12}$ é contribuição da integral de linha dos dois elementos considerados. O fator de forma $F_{12}$, portanto, é dado como a soma de contribuições como esta, de cada elemento (segmento de linha) na superfície 1 para cada elemento na superfície 2.

Vista a manipulação analítica da integral no contorno, pode-se determinar sua forma numérica. Uma possível aproximação pode ser encontrada em (SHAPIRO, 1985; KAKUTA et al., 2001). Ao dividir os contornos $C_{i}$ e $C_{j}$, que delimitam as áreas $A_{i}$ e $A_{j}$, em $n$ segmentos finitos de linha reta $\left(\vec{s}_{i}\right.$ e $\left.\vec{s}_{j}\right)$, a equação $(2.55)$ pode ser numericamente aproximada por:

$$
F_{i j}=\frac{1}{2 \pi A_{i}} \sum_{i=1}^{n} \sum_{j=1}^{n} \ln \left(r_{i j}\right) \vec{s}_{i} \cdot \vec{s}_{j}
$$

em que $\vec{s}_{i} \cdot \vec{s}_{j}$ representa o produto escalar entre os versores $\vec{s}_{i}: i=1,2, \ldots, n$ e $\vec{s}_{j}: j=$ $1,2, \ldots, n$, localizados ao longo dos contornos.

Geralmente, a literatura disponibiliza a formulação numérica para a equação dos fatores de forma como apresentada em (3.3). Mas, em uma primeira análise, alguns detalhes no trato desta equação podem passar desapercebidos. Seu manuseio, portanto, será demonstrado através de um curto exemplo, como feito por Davies (2004).

Considere duas superfícies finitas 1 e 2 , de áreas $2 x_{1} \times 2 y_{1}$ e $2 x_{2} \times 2 z_{2}$, posicionadas em cantos opostos de um prisma retangular $X \times Y \times Z$, como mostra a Figura 3.2. Como o contorno $C_{1}$, da superfície 1 , não possui componente em $z$ e o contorno $C_{2}$, da superfície 2 , não possui componente em $y$, somente termos do tipo $x_{1} x_{2}$ serão contabilizados na análise. Desta forma, a equação (3.3) para este exemplo fica:

$$
\begin{aligned}
F_{12} & =\frac{1}{2 \pi A_{1}} \sum \ln \left(r_{i j}\right)\left(2 x_{1}\right)\left(2 x_{2}\right)= \\
& =\ln \sqrt{X^{2}+\left(Y+y_{1}\right)^{2}+\left(Z-z_{2}\right)^{2}}\left(+2 x_{1}\right)\left(+2 x_{2}\right)+ \\
& +\ln \sqrt{X^{2}+\left(Y+y_{1}\right)^{2}+\left(Z+z_{2}\right)^{2}}\left(+2 x_{1}\right)\left(-2 x_{2}\right)+ \\
& +\ln \sqrt{X^{2}+\left(Y-y_{1}\right)^{2}+\left(Z-z_{2}\right)^{2}}\left(-2 x_{1}\right)\left(+2 x_{2}\right)+ \\
& +\ln \sqrt{X^{2}+\left(Y-y_{1}\right)^{2}+\left(Z+z_{2}\right)^{2}}\left(-2 x_{1}\right)\left(-2 x_{2}\right)
\end{aligned}
$$




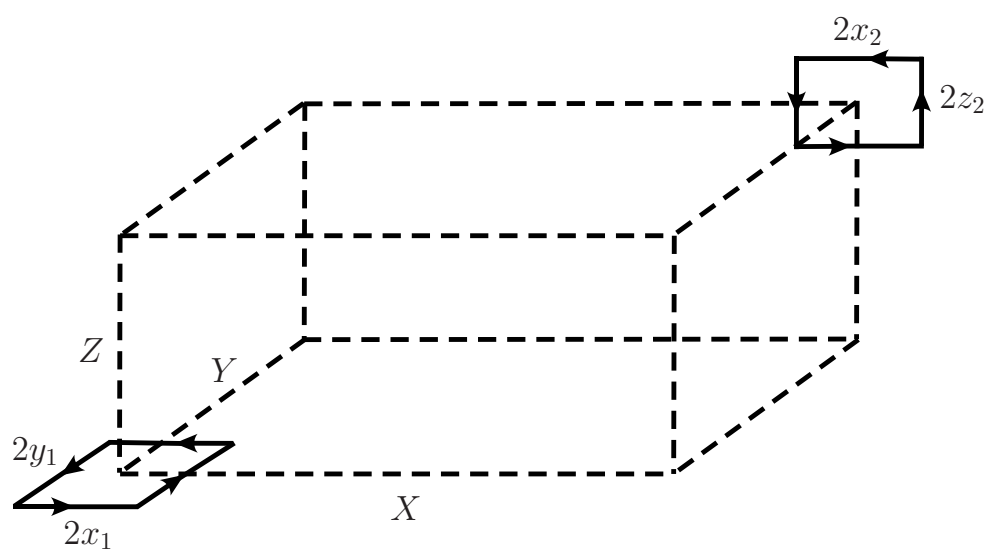

Figura 3.2: Exemplo do cálculo do fator de forma entre duas áreas finitas através da equação (3.3).

Essa soma pode ser consideravelmente simplificada, se for admitido que:

1. cada dimensão das superfícies for muito pequena se comparada com sua distância de separação $R=\left(X^{2}+Y^{2}+Z^{2}\right)^{1 / 2}$;

2. aproximações tais quais $u \ll 1,1 /(1-u) \approx 1+u$ e, portanto, $\ln (1+u) \approx u$ são válidas.

Este breve exemplo permite ilustrar como é feita a determinação numérica dos fatores de forma utilizando a equação (3.3). A seguir, a quadratura de Gauss é aplicada a esta relação.

\subsubsection{Quadratura de Gauss Aplicada à Integral no Contorno}

A quadratura de Gauss é uma técnica padrão de quadratura, como o método de Simpson ou o método trapeizoidal, e é frequentemente utilizada como ferramenta de integração numérica quando um fenômeno físico é modelado através do método dos elementos finitos. Assim, por meio da aplicação desta técnica à aproximação numérica dada pela equação (3.3), obtém-se a quadratura de Gauss da Integral do Contorno que define os fatores de forma (CHECCHI; STRAGAPEDE; GROSSETIE, 1991):

$$
F_{i j}=\frac{1}{2 \pi A_{i}} \sum_{e l_{i}=1}^{n_{i}} \sum_{p_{i}=1}^{N_{p g}} W_{p_{i}} J_{e l_{i}} \sum_{e l_{j}=1}^{n_{j}} \sum_{p_{j}=1}^{N_{p g}} W_{p_{j}} J_{e l_{j}} \ln \left[r_{p_{i} p_{j}}\left(z_{p_{i}}, z_{p_{j}}\right)\right] \vec{s}_{i} \cdot \vec{s}_{j}
$$

em que $n_{i}$ e $n_{j}$ representam as respectivas quantidades de segmentos (ou elementos de linha) em que os contornos das superfícies $i$ e $j$ foram divididos e $N_{p g}$ define o número de pontos de Gauss utilizados. Os pesos da integração são referenciados através de $W_{p_{i}}$ e $W_{p_{j}}$ e os Jacobianos das transformações de coordenadas, calculados nos elementos de 
linha $e l_{i}$ e $e l_{j}$, respectivamente por $J_{e l_{i}}$ e $J_{e l_{j}}$. Como nesta aplicação da quadratura de Gauss utiliza-se um mapeamento linear das coordenadas locais para as do domínio físico, os valores de Jacobiano valem metade do comprimento do segmento de linha. A distância, $r_{p_{i} p_{j}}$, é agora calculada entre os pontos de Gauss $z_{p_{i}}$ e $z_{p_{j}}$ e o produto escalar entre os versores $\vec{s}_{i}$ e $\vec{s}_{j}$ é resultado das orientações de parametrização dos contornos $C_{i}$ e $C_{j}$ (de acordo o Teorema de Stokes, os contornos de integração devem ser percorridos no sentido anti-horário. Em um confinamento, obviamente, os elementos de linha têm orientação direcionada para o interior do mesmo, uma vez que é aí onde ocorrem as trocas de calor).

Tendo apresentado a quadratura de Gauss que aproxima a integral dos fatores de forma, é possível partir para a formulação em elementos finitos do problema da transferência de calor no interior de confinamentos.

\subsection{Método dos Elementos Finitos aplicado à Troca de Calor Radiante em Confinamentos}

O método dos elementos finitos é uma ferramenta bastante eficaz para o tratamento do fenômeno de transferência de calor no interior de cavidades e largamente utilizada na comunidade científica para estes fins (OSNES, 1983; BENIM, 1988; KEAVEY, 1988; BORNSIDE et al., 1990; HECKBERT; WINGET, 1991; ZOLTI, 1991; KUPPURAO; DERBY, 1993; KISSELEV; ROBERTI; PERONA, 1994; DAURELLE; OCCELLI; JAEGER, 1999; GOULD, 2000; BERGHEAU; POTIER, 2001; AN et al., 2005; HOGAN; GARTLING, 2008; WIDMER, 2010; REDDY; GARTLING, 2010). Desta forma, são tratados nesta seção os principais temas relacionados ao MEF radiativo e ao seu equacionamento matricial. Para um detalhamento no tratamento variacional do fenômeno, consultar o Apêndice A.

\subsubsection{Construção da Matriz de Fatores de Forma}

Antes de se prosseguir para a definição matricial das medidas de interesse no trato de um confinamento sujeito à troca de calor radiativa, o leitor deve estar atento ao fato de que os fatores de forma, tal qual apresentados na seção 3.1.3, são definidos em pontos de Gauss. Estes, por sua vez, estão localizados sobre contornos (no caso deste mestrado, em segmentos de linha) que descrevem o domínio de integração, como mostra a Figura 3.3. Já os valores de radiosidade, temperatura e fluxo de calor que são utilizados e determinados neste texto estão distribuídos uniformemente sobre a área de um elemento finito (no caso deste trabalho, elementos finitos retangulares).

Para se obter uma matriz como a dada por (2.64), que relaciona os valores de fatores 


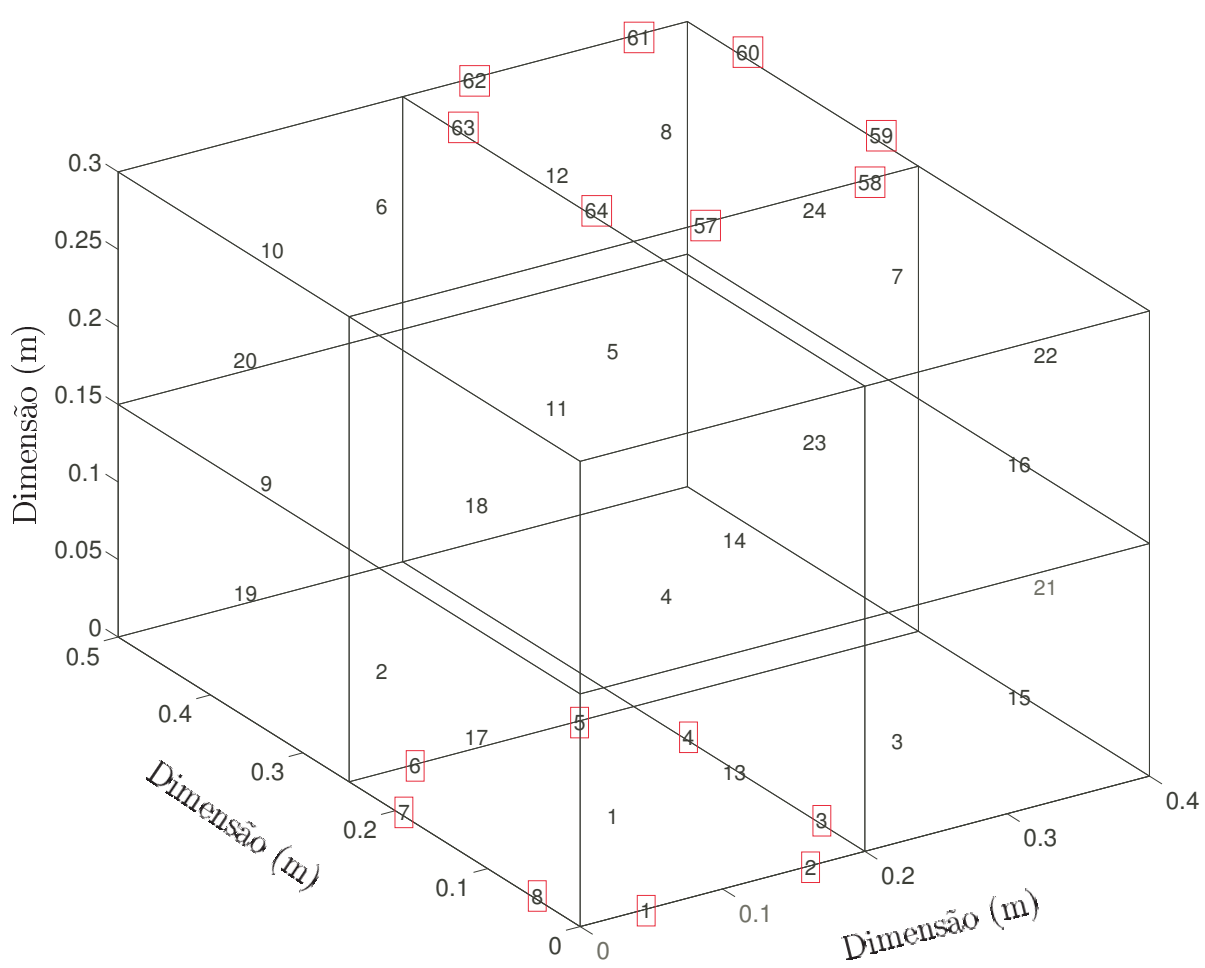

Figura 3.3: Distribuição de pontos de Gauss sobre a malha de elementos finitos para o cálculo dos fatores de forma em um confinamento.

de forma calculados nos diversos elementos finitos retangulares que compõem a malha do confinamento, faz-se necessária uma aglomeração dos valores obtidos nos pontos de Gauss em torno destes elementos. A Figura 3.3 demonstra esta situação para o uso de 2 pontos de Gauss por contorno: para o cálculo do fator de forma entre os elementos finitos 1 e $8, F_{18}$, é necessário que sejam somadas todas as contribuições individuais dos fatores de forma calculados entres os pontos de Gauss de 1 a 8 e os pontos de Gauss de 57 a 64, de forma a se ter:

$$
\begin{aligned}
F_{18} & =\left(F_{18}^{1,57}+F_{18}^{1,58}+\ldots+F_{18}^{1,64}\right)+\left(F_{18}^{2,57}+F_{18}^{2,58}+\ldots+F_{18}^{2,64}\right)+\ldots+ \\
& +\left(F_{18}^{8,57}+F_{18}^{8,58}+\ldots+F_{18}^{8,64}\right)
\end{aligned}
$$

Esta mesma estratégia deve ser adotada no caso da utilização de qualquer outro tipo de elemento finito que possa vir a compor a malha que representa o confinamento, bem como no caso da utilização de mais pontos de Gauss.

\subsubsection{Formulação Matricial para Cálculo das Radiosidades}

A formulação matricial para a determinação das radiosidades que é utilizada neste trabalho é bastante similar ao método das radiosidades descrito em (COHEN; GREENBERG, 1985; GREENBERG; COHEN; TORRANCE, 1986). A diferença reside basicamente na inclusão das condições de contorno de fluxo de calor prescrito, de forma que as radiosidades 
são calculadas seguindo a mesma lógica utilizada na Seção 2.1.4.5. Assim, o sistema de equações lineares dado pela equação (2.80) é matricialmente definido como:

$$
\mathbf{K}_{\mathbf{R}} \mathbf{J}=\mathbf{E}
$$

em que $\boldsymbol{K}_{\boldsymbol{R}}$ é a matriz de rigidez (HECKBERT; WINGET, 1991; HOGAN; GARTLING, 2008), $\boldsymbol{J}$ o vetor de radiosidades e $\boldsymbol{E}$ o vetor de emissões.

A construção da matriz de rigidez e do vetor de emissões segue o mesmo padrão utilizado nas definições analíticas das equações de (2.81) a (2.84). Assim, se a temperatura for prescrita, vale:

$$
\left\{\begin{aligned}
K_{R_{i j}} & =\delta_{i j}-\left(1-\varepsilon_{i}\right) F_{i j} \\
E_{i} & =\varepsilon_{i} \sigma T_{i}^{4}
\end{aligned}\right.
$$

e se o fluxo de calor for prescrito, vale:

$$
\left\{\begin{aligned}
K_{R_{i j}} & =\delta_{i j}-F_{i j} \\
E_{i} & =q_{i}
\end{aligned}\right.
$$

É importante relembrar que os valores $F_{i j}$ são retirados de uma matriz de fatores de forma organizada como (2.64) e o Delta de Kronecker $\delta_{i j}$ é o mesmo utilizado na seção 2.1.4.5.

A determinação das radiosidades a partir da (3.6) permite calcular as irradiações através da seguinte equação:

$$
\mathbf{G}=\mathbf{F} \mathbf{J}
$$

\subsubsection{Formulação Matricial para Cálculo das Temperaturas e Fluxos de Calor}

O equacionamento discreto do problema de radiação no interior de uma cavidade é baseado na equação (2.76) (forma indicial) e pode ser expresso na forma matricial por (REDDY; GARTLING, 2010):

$$
[\mathbf{I}-\mathbf{F}(\mathbf{I}-\operatorname{diag}(\boldsymbol{\varepsilon}))] \mathbf{q}=(\mathbf{I}-\mathbf{F}) \operatorname{diag}(\boldsymbol{\varepsilon}) \sigma \overline{\mathbf{T}}
$$

em que $\boldsymbol{I}$ é uma matriz identidade, $\mathbf{F}$ é a matriz dos fatores de forma dada tal qual em (2.64), diag $(\varepsilon)$ é uma matriz diagonal formada pelas emissividades das superfícies, q é o 
vetor que contém os fluxos de calor e o vetor de temperaturas $\overline{\mathbf{T}}$ é dado por:

$$
\overline{\mathbf{T}}=\left[\begin{array}{c}
T_{1}{ }^{4} \\
T_{2}{ }^{4} \\
\vdots \\
T_{N}{ }^{4}
\end{array}\right]
$$

A equação (3.12) pode ser rearranjada de forma a torná-la mais próxima do formato clássico utilizado em elementos finitos, que é:

$$
K \overline{\mathbf{T}}=\mathrm{q}
$$

Assim, faz-se:

$$
\left\{(\mathbf{I}-\mathbf{F})[\mathbf{I}-(\mathbf{I}-\operatorname{diag}(\boldsymbol{\varepsilon})) \mathbf{F}]^{-1} \operatorname{diag}(\boldsymbol{\varepsilon}) \sigma\right\} \overline{\mathbf{T}}=\mathbf{q}
$$

em que a matriz de rigidez pode ser escrita como:

$$
\mathbf{K}=(\mathbf{I}-\mathbf{F})[\mathbf{I}-(\mathbf{I}-\operatorname{diag}(\boldsymbol{\varepsilon})) \mathbf{F}]^{-1} \operatorname{diag}(\boldsymbol{\varepsilon}) \sigma
$$

Fica claro, a partir do equacionamento (3.15), que o fenômeno que se pretende modelar forma um sistema de equações simultâneas lineares para a determinação das temperaturas e dos fluxos de calor na superfície das estruturas analisadas. Mas qual a abordagem a ser escolhida para a solução deste sistema de equações? Esta pergunta pode até ter muitas respostas, porém, para este trabalho, a seleção adequada da metodologia de solução é de extrema importância, pois afeta diretamente na formulação da função objetivo de minimização da temperatura e o cálculo dos seus gradientes, como será visto em 4.4.2.

O método escolhido começa pela rotulação das variáveis conhecidas, como feito abaixo:

$$
\left\{\begin{array}{l}
\theta: \text { conjunto de elementos com temperaturas conhecidas } \\
h: \text { conjunto de elementos com fluxos de calor conhecidos }
\end{array}\right.
$$

Em outra palavras, os elementos finitos que são referenciados por $\theta$ possuem todos fluxos de calor desconhecidos e os que são referenciados por $h$ possuem temperaturas desconhecidas. A alocação correta destes conjuntos na matriz de rigidez e no vetor de fluxos de calor permite o cálculo das temperaturas desconhecidas. Para tanto, faz-se:

$$
\overline{\mathbf{T}}(h)=\left\{\mathbf{K}(h, h)^{-1}[\mathbf{q}(h)-\mathbf{K}(h, \theta) \overline{\mathbf{T}}(\theta)]\right\}
$$

em que o vetor de temperaturas desconhecidas $\mathbf{T}(h)$, calculado sobre um conjunto de 
elementos com fluxos de calor desconhecidos de dimensão $N_{h}$, é dado como:

$$
\mathbf{T}(h)=\left[\begin{array}{l}
\bar{T}\left(h_{1}\right)^{\frac{1}{4}} \\
\bar{T}\left(h_{2}\right)^{\frac{1}{4}} \\
\vdots \\
\bar{T}\left(h_{N_{h}}\right)^{\frac{1}{4}}
\end{array}\right]
$$

Somente a partir da obtenção das temperaturas desconhecidas $\mathbf{T}(h)$ é que os fluxos de calor desconhecidos podem ser calculados. Assim, faz-se:

$$
\mathbf{q}(\theta)=\mathbf{K}(\theta,:) \overline{\mathbf{T}}
$$

em que o símbolo de dois pontos significa que todas as colunas da matriz de rigidez são utilizadas. Para uma verificação preliminar dos resultados de fluxo de calor obtidos através da equação (3.20), sugere-se seguir o mesmo método adotado no quarto passo apresentado na seção 2.1.4.5, que consiste em averiguar se a somatória dos valores das taxas de transferência de calor de todos os elementos finitos utilizados para descrever o confinamento se aproxima de zero.

Dois Benchmarks com a finalidade de aferição da implementação do método dos elementos finitos estão disponíveis no Apêndice B.2, incluindo a solução numérica do confinamento tridimensional apresentado em 2.1.4.6.

Tendo-se discutido todo o ferramental analítico e numérico necessário para análise do problema proposto neste trabalho, é possível agora concentrar-se na discussão da aplicação do método da otimização topológica para o caso da transferência de calor por radiação no interior de confinamentos. 


\section{Otimização Topológica Aplicada à Transferência de Calor Radiante}

\subsection{Introdução}

O conceito de otimização está presente em diversas áreas do conhecimento, como por exemplo, na Economia, Medicina, Biologia, Física, Química e principalmente nas Engenharias. Um processo de otimização consiste na busca sistemática (através de algoritmo numérico) e racionalizada (consistente com as teorias da área aplicada) de uma solução otimizada, dentro de um espaço de soluções possíveis, de modo a alcançar um ou mais objetivos e atender restrições de um problema qualquer.

(a)

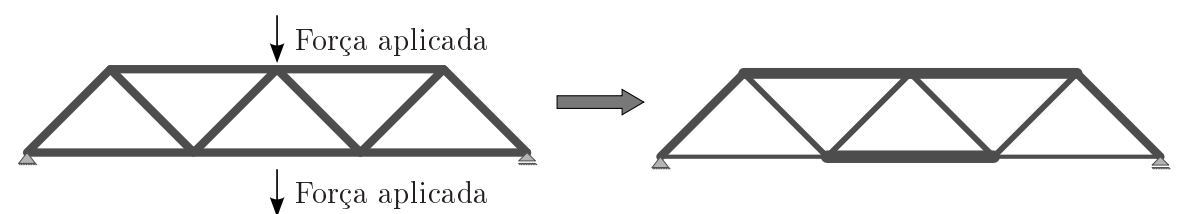

(b)

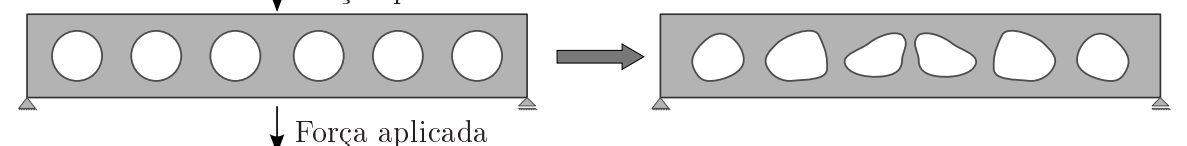

(c)

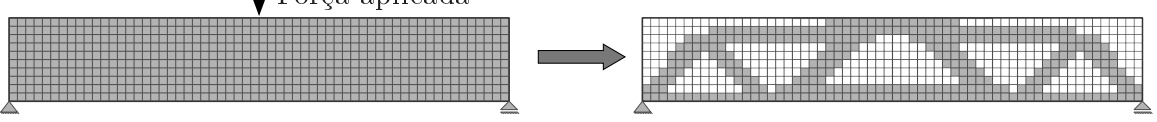

Figura 4.1: Exemplo clássico de 3 categorias de otimização estrutural: (a) otimização paramétrica (b) otimização de forma (c) otimização topológica (AMIGO, 2013).

Quando se fala de otimização aplicada aos diferentes campos dentro da Engenharia, três tipos básicos de abordagem são possíveis a fim de se obter um resultado otimizado: as otimizações paramétrica, de forma e a topológica, como mostra a Figura 4.1, para um exemplo clássico de otimização estrutural frequentemente encontrado na literatura (AMIGO, 2013).

Na otimização paramétrica, assume-se uma forma pré-definida para a estrutura e tomam-se como variáveis de projeto um ou mais parâmetros da estrutura (HAFTKA; GURDAL, 1992). A Figura 4.2 ilustra este tipo de otimização para uma superfície estendida (aleta), em que a área da seção transversal e o comprimento de cada cilindro 
são considerados como variáveis de projeto. Neste caso conceitual, o problema de otimização consiste na determinação dos valores otimizados da área da seção transversal e do comprimento de cada barra que maximizam a transferência de calor por radiação a partir de uma restrição de volume total da estrutura.

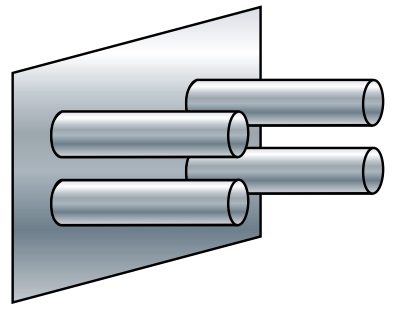

(a) Estrutura inicial.

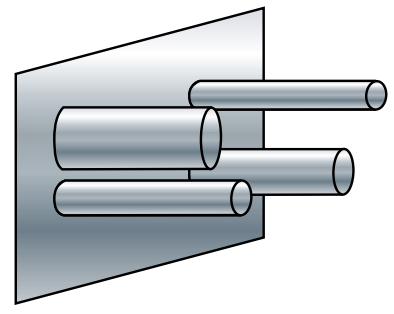

(b) Estrutura otimizada.

Figura 4.2: Otimização paramétrica da área da seção transversal de dissipadores de calor.

Em uma rápida análise das bibliografias relacionadas com aplicação da otimização paramétrica a estruturas que trocam calor por radiação, diversas referências são encontradas. Para uma fonte mais rica no detalhamento de otimizações paramétricas aplicadas aos mais diferentes formatos de superfícies estendidas, consultar (KRAUS; AZIZ; WELTY, 2002). No que tange ao projeto de cavidades, o trabalho de Wieckert (2005) apresenta resultados de eficiência térmica de um reator solar como função da variação dos parâmetros geométricos e físicos das cavidades que o constituem. Já o artigo publicado por Shuai, Xia e Tan (2008) apresenta resultados da eficiência radiativa de seis modelos clássicos de cavidades receptoras de energia solar, através da variação de parâmetros como a distância focal.

$\mathrm{Na}$ otimização de forma, aplicada principalmente em superfícies contínuas, os contornos externos da estrutura são parametrizados por curvas (splines, por exemplo), em que os parâmetros dessas curvas representam as variáveis de projeto na otimização (HAFTKA; GRANDHI, 1986; HAFTKA; GURDAL, 1992). Esta técnica é mais genérica que a otimização paramétrica, uma vez que a forma externa da estrutura é alterada. A Figura 4.3 apresenta um exemplo de otimização de forma aplicada a tubos microaletados utilizados para intensificação da troca de calor no interior de caldeiras (BERGLES, 2002). Para a verificação da aplicação desta ferramenta em aletas que compõem um radiador embarcado em veículos espaciais, consultar (HULL et al., 2006).

A literatura também apresenta estudos da aplicação da otimização de forma na modificação dos contornos de cavidades submetidas à transferência de calor radiante. Dentre os trabalhos existentes na área, o realizado por Farahmand, Payan e Sarvari (2012) demonstra resultados interessantes na otimização dos pontos de controle de curvas B-Spline, através do uso de algoritmo genético, para o projeto de cavidades 


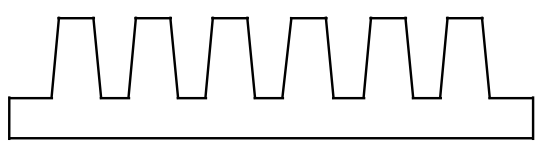

(a) Estrutura inicial.

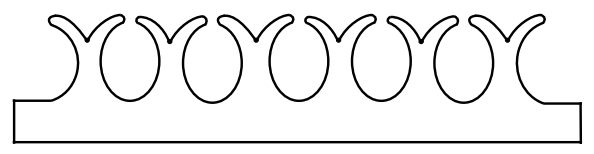

(b) Estrutura otimizada.

Figura 4.3: Otimização de forma da superfície interna de uma caldeira com o objetivo de aumentar a troca de calor convectiva (BERGLES, 2002).

bidimensionais, compostas por superfícies cinzas e difusas. O artigo procura desenvolver uma metodologia para a determinação do formato de uma cavidade em função da distribuição de fluxo de calor e temperatura previamente determinadas. Seguindo a mesma linha, o trabalho de Fakhrabadi e Kowsary (2009) parametriza uma cavidade através do uso de NURBS (non uniform rational basis spline) e modela o problema de troca radiante aplicando uma técnica de análise em área infinitesimal, desenvolvida por Daun e Hollands (2001). O método dos gradientes simplificados (SCGM, na sigla em inglês) é então aplicado para determinação dos pontos de controle das curvas que constituem uma cavidade bidimensional, dado o objetivo de aumentar a emissividade aparente da estrutura. Mais sobre o tema pode ainda ser encontrado nos trabalhos de Rukolaine (2010), Tan, Zhao e Liu (2011), Marston, Daun e Collins (2011).

Finalmente, a última abordagem, apresentada na Figura 4.4, consiste na técnica de otimização topológica, que é definida como um método iterativo baseado na distribuição de material em um dominio de projeto fixo, com o objetivo de extremizar uma função custo sujeita às restriçôes inerentes do problema (BENDSøE; SIGMUND, 2003). Esta técnica pode ser aplicada tanto em estruturas contínuas, quanto em discretas (BENDSøE, 1995; BENDSØE; SIGMUND, 2003). Em estruturas discretas, formadas por treliças ou barras, busca-se a melhor distribuição espacial destes componentes ou uma melhor conectividade entre eles. Em estruturas contínuas, busca-se a melhor distribuição de material a partir de variáveis de projeto que indicam a existência ou não de material em regiões do domínio (BENDSøE, 1995; BENDSØE; SIGMUND, 2003). Assim, em estruturas sólidas, a otimização topológica permite determinar características como número, localização e formato de buracos ou a conectividade do domínio de projeto (BENDSØE; SIGMUND, 2003).

Na otimização topológica, a procura pela distribuição ótima de material é realizada através de um algoritmo computacional que combina um método de otimização (para solução do problema de otimização, composto de uma função objetivo e suas restrições) com um método numérico, como o método dos elementos finitos, utilizado para a modelagem física do problema (BENDSøE; SIGMUND, 2003). A partir de um domínio de projeto discretizado em elementos finitos (subdomínios), associa-se a cada elemento um valor de densidade, de modo que a distribuição de material no interior do domínio de projeto possa ser representada pelo conjunto das densidades formado por cada elemento. 
Como exemplo de aplicação desta técnica de otimização, a Figura 4.4a apresenta a situação de uma placa submetida a geração uniforme de calor no seu centro, com temperatura $T=0{ }^{\circ} \mathrm{C}$ prescrita em toda fronteira do domínio, como pode ser visto em (GAO et al., 2008). Neste problema, o objetivo é determinar a geometria da estrutura que maximiza a dissipação de calor considerando um volume máximo de material. A topologia otimizada da estrutura é apresentada na Figura 4.4b, em que a região escura representa material condutor e a região clara indica ausência de material.

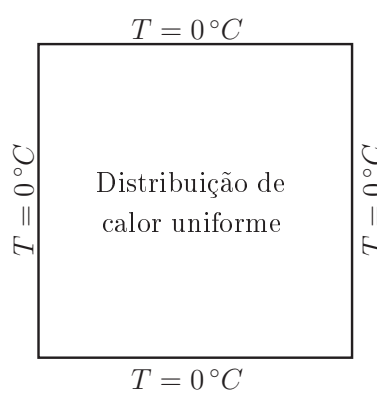

(a) Placa com geração de calor uniformemente distribuída.

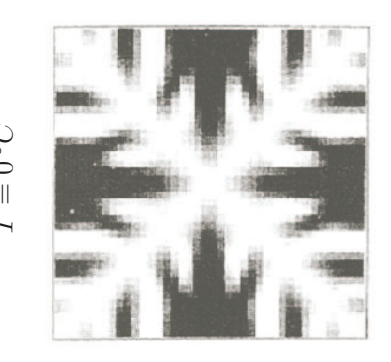

(b) Topologia otimizada.

Figura 4.4: Otimização topológica aplicada ao projeto de um dissipador de calor no interior de uma estrutura uniformemente aquecida (GAO et al., 2008).

Dentre as abordagens de otimização citadas, a técnica de otimização topológica é a mais genérica, uma vez que ela não requer uma estrutura inicial ou mesmo parâmetros da geometria para fornecer uma topologia otimizada (BENDSøE, 1989). Por apresentar tamanha robustez e confiabilidade, acredita-se que esta ferramenta deva ser mais aprofundadamente explorada para o projeto do interior de confinamentos sujeitos à troca radiante, uma vez que tão poucos trabalhos tratam do assunto.

\subsection{Revisão Bibliográfica da Otimização de Confinamentos sujeitos à Radiação}

A bibliografia referente à aplicação da OT em problemas de transferência de calor por radiação no interior de confinamentos é escassa, de modo que a seguir é feita uma revisão de trabalhos que de alguma forma estão relacionados a este tema.

\subsubsection{Otimização Topológica}

A otimização topológica consiste num método que permite projetar estruturas de acordo com um determinado critério (leia-se: função objetivo e suas restrições), como, por exemplo, maximização da irradiação. Esta técnica foi inicialmente proposta 
com a publicação do artigo Generating optimal topologies in structural design using a homogenization method, de Bendsøe e Kikuchi (1988), em que os autores apresentam um método baseado na parametrização das propriedades microestruturais do material, conhecido por método da homogeneização. O desenvolvimento desta técnica foi inspirado principalmente no trabalho de (CHENG; OLHOFF, 1981), quando os primeiros estudos sobre modelos de materiais baseados em microestrutura começaram a ser realizados.

A utilização do conceito de microestrutura representa, no problema de otimização topológica, uma maneira de relaxação do funcional (variação da função) que indica se há ou não presença de material no interior de um elemento finito (KOHN; STRANG, 1986a, 1986b, 1986c). Com os trabalhos de Bendsøe (1989) e Rozvany, Zhou e Birker (1992), uma maneira alternativa ao método da homogeneização é apresentada para se realizar a relaxação do variacional por meio de um modelo de material baseado na distribuição de densidades. Este modelo, juntamente com os trabalhos de Suzuki e Kikuchi (1991) e Olhoff, Bendsøe e Rasmussen (1991), favoreceu a difusão do método da otimização topológica e motivou a realização de diversos trabalhos acadêmicos que contribuíram para a consolidação do MOT como uma eficiente técnica de otimização estrutural.

Amplamente empregado para fins estruturais, como no clássico problema de maximização da rigidez (BENDSøE; KIKUCHI, 1988; BENDSøE, 1995; SIGMUND, 2001), o MOT também pode ser aplicado para a resolução de problemas térmicos. Um dos primeiros estudos voltado a características exclusivamente térmicas de uma dada estrutura é o publicado por Bendsøe e Sigmund (2003). Neste estudo, o MOT é empregado para maximizar a dissipação de energia térmica gerada de maneira uniforme e sem dependência estrutural, sobre uma placa quadrada, em que suas laterais estão em condição adiabática, exceto em um pequeno trecho (ver Figura 4.5). Como resultado para este problema, tem-se uma estrutura com aspecto semelhante à raiz de uma planta (tree like), resultado este comumente utilizado como benchmark em trabalhos relacionados a problemas de dissipação térmica.

Ainda no que tange a aplicação do MOT a problemas térmicos, Bruns (2007) explorou esta ferramenta para o projeto de micro-aletas de refrigeração sujeitas à troca de calor não linear, com o objetivo de diminuição da temperatura de base destas superfícies estendidas. Este trabalho, de maneira indireta e simplificada, aborda o fenômeno da radiação, linearizado através de um coeficiente de transferência de calor similar ao utilizado pela lei de resfriamento de Newton (INCROPERA et al., 2007). Para um domínio de projeto que possui condutividade térmica $k$, coeficiente de convecção $h$, geração de calor uniforme na parte inferior e temperatura ambiente do fluido de $0^{\circ}$, Bruns (2007) obteve um resultado similar ao formato de árvore apresentado na Figura 4.5, quando sujeito a uma restrição 


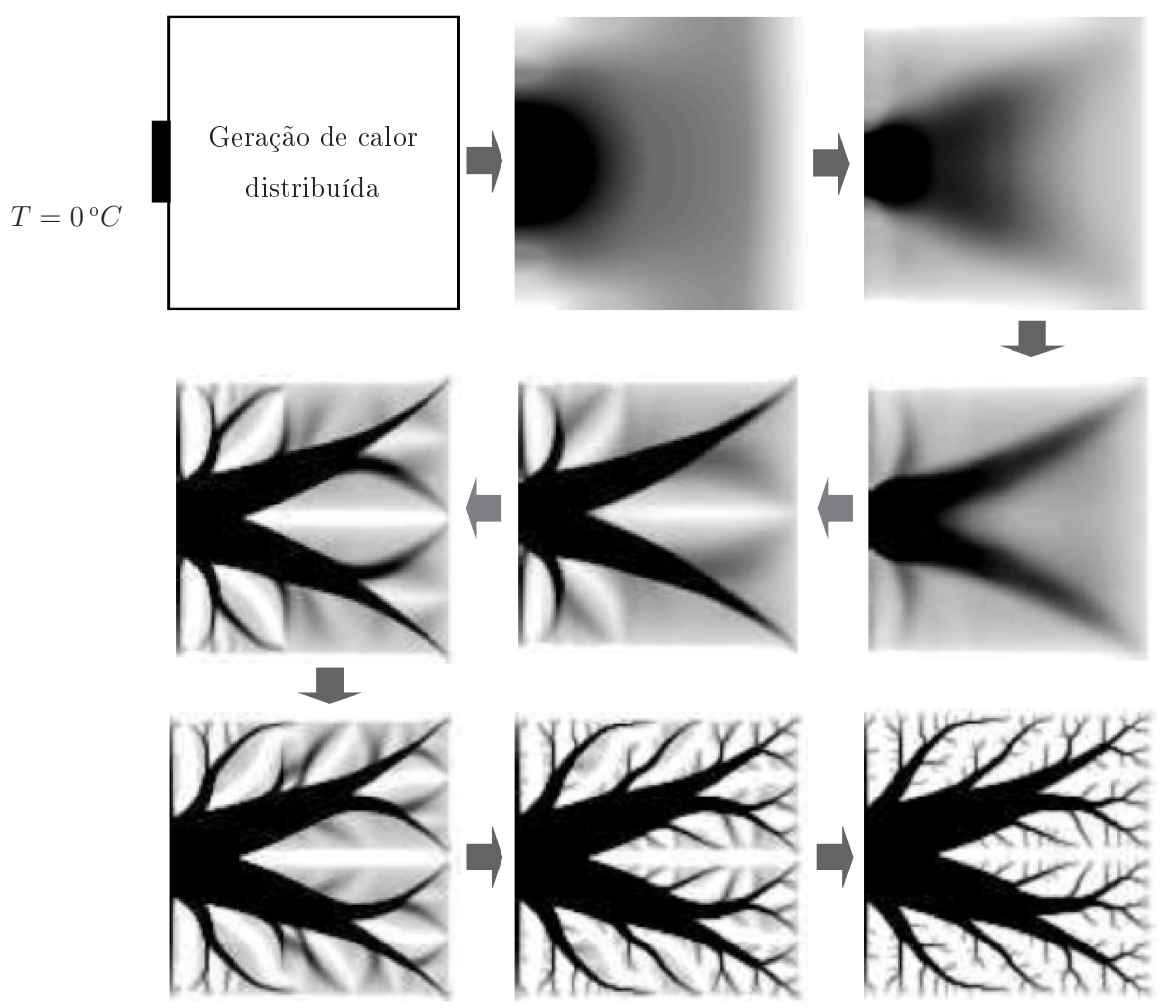

Figura 4.5: Exemplo de aplicação do MOT em um problema de dissipação térmica (BENDSØE; SIGMUND, 2003).

de distribuição de material de 30\%. Este resultado é reproduzido na Figura 4.6

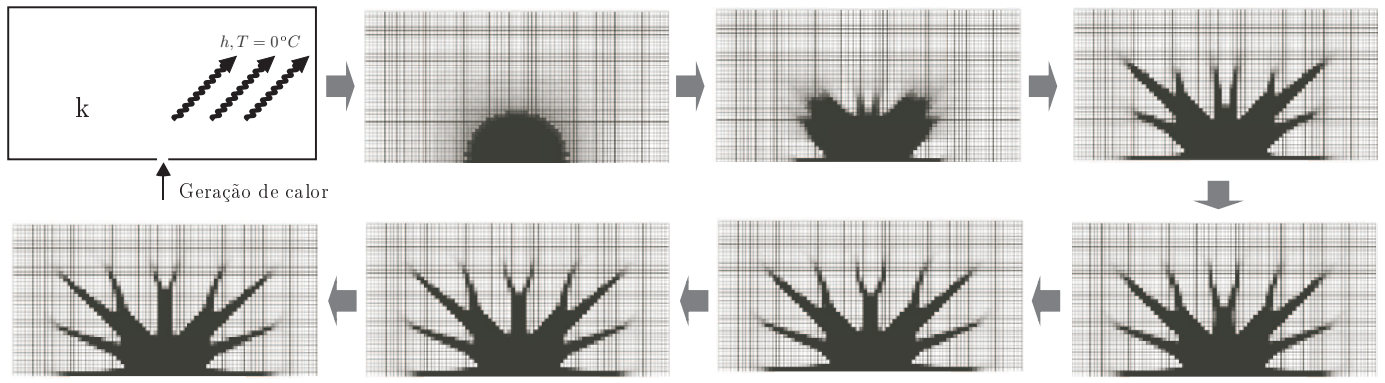

Figura 4.6: Exemplo da aplicação do MOT para o projeto de micro-aletas de refrigeração sujeitas à convecção (BRUNS, 2007).

Mesmo contando com um vasto ferramental de busca de artigos acadêmicos, o autor deste texto enfrentou séria dificuldade em encontrar fontes que tratassem diretamente da aplicação do MOT no projeto de estruturas que trocam calor por radiação no interior de confinamentos. Por outro lado, foram encontradas na literatura vastas discussões utilizando outros métodos e abordagens para o projeto de confinamentos sujeitos à troca radiante que possibilitam um prévio entendimento do fenômeno que se deseja estudar neste trabalho. A seguir, algumas destas referências bibliográficas são brevemente analisadas. 


\subsubsection{Problemas Inversos e Métodos Heurísticos}

O desenvolvimento de uma metodologia mais estruturada e eficiente do que a técnica de projeto por tentativa e erro é fato recente na construção de cavidades submetidas à troca de calor radiante. Uma visão corriqueiramente presente na literatura é dada sob a ótica dos problemas inversos e inúmeros são os artigos publicados na área (HOWELL; EZEKOYE; MORALES, 2000; FRANÇA; EZEKOYE; HOWELL, 2001; ERTURK; EZEKOYE; HOWELL, 2002; DAUN; HOWELL; MORTON, 2003a; SARVARI; HOWELL; MANSOURI, 2003; SARVARI; MANSOURI; HOWELL, 2003a, 2003b; LEDUC; MONCHOUX; THELLIER, 2004; SARVARI, 2005; POURSHAGHAGHY et al., 2006; MOSSI et al., 2008; PAYAN; SARVARI; AJAM, 2009; SCHNEIDER et al., 2009; BAYAT; MEHRABAN; SARVARI, 2010; HOFFMANN et al., 2010; CHOPADE et al., 2011b; AMIRI; MANSOURI; COELHO, 2013), mas uma discussão aprofundada desta metodologia e dos trabalhos que a utilizam foge ao escopo desta dissertação. Contudo, um breve estudo de (FEDOROV; LEE; VISKANTA, 1998; HOWELL et al., 2003; DAUN; HOWELL, 2005; DAUN et al., 2006) permite identificar definições úteis para uma análise prévia do problema de OT, dadas principalmente através da apresentação de modelos de funções objetivo e do cálculo de suas sensibilidades.

Métodos heurísticos também são frequentemente utilizados no projeto de cavidades sujeitas à troca de calor radiante. Quando as variáveis de projeto envolvidas na construção destas estruturas são discretas, como, por exemplo, melhor localização, número ideal e potência dos aquecedores, ou mesmo quando se deseja estudar o efeito térmico (distribuição de fluxo e de temperatura) do posicionamento destes aquecedores dentro de cavidades compostas por superfícies difusas ou especulares, artigos como (PORTER et al., 2006; SAFAVINEJAD et al., 2009; AMIRI et al., 2011; CASSOL et al., 2011; CHOPADE et al., 2011b, 2011a, 2012a, 2012b) podem representar uma boa fonte de consulta. Ainda nesta linha de projeto, resultados comparativos para o uso dos métodos meta-heurísticos recozimento simulado (simulated annealing), algoritmo genético e busca tabu na definição das propriedades de aquecedores para obtenção de perfil de temperatura específico em uma superfície de projeto são discutidos em (TAJOURI; El Hitti; NEMER, 2011). Por fim, como visto em 4.1, estes métodos também permitem a modificação da geometria de cavidades (SARVARI, 2007; FARAHMAND; PAYAN; SARVARI, 2012) e de aletas de radiadores de calor (HULL et al., 2006).

Cabe ressaltar, contudo, que apesar da aparente eficiência dos métodos heurísticos no tratamento de variáveis discretas, métodos que não envolvam o cálculo de gradientes não são recomendados na otimização topológica (SIGMUND, 2011). A despeito do que é propagandeado, a utilização destes métodos na OT não implica na obtenção de um projeto globalmente ótimo. Além disso, há uma limitação no número de elementos 
finitos envolvida na aplicação destes métodos, o que pode gerar uma modelagem física mais pobre do problema analisado. Isto porque com um número alto de elementos, as permutações necessárias para a aplicação deste tipo de método podem recair em um regime astronômico. É errôneo, ainda, acreditar que o uso de gradientes torna o problema mais difícil de ser implementado e não permite gerar projetos com formatos discretos (SIGMUND, 2011).

Os artigos discutidos nesta seção, tanto os vinculados a problemas inversos, quanto a métodos heurísticos, influenciaram o presente trabalho principalmente na maneira como o problema de otimização é proposto. Ou seja, estes artigos ajudaram o autor na formulação de funções objetivo que encontrassem o mínimo de respaldo na literatura especializada no assunto (para um tratamento pormenorizado da definição destas funções, consultar seção 4.4). A seguir, é feita uma revisão bibliográfica sobre a técnica de otimização mais próxima da proposta por esta dissertação: o método dos gradientes.

\subsubsection{Método dos Gradientes}

Os requisitos térmicos para o projeto de cavidades sujeitas à transferência de calor por radiação dependem de uma seleção apropriada da geometria da cavidade, das propriedades radiantes dos materiais utilizados e do meio participante. Fatores discretos, como localização e potência dos painéis aquecedores também precisam ser levados em consideração (CHOPADE et al., 2011a), como previamente mostrado em 4.2.2.

A metodologia de projeto por tentativa e erro é um procedimento iterativo não controlável, mas que pode ser visivelmente melhorado através de uma rotina de otimização, como é feito na otimização topológica. Assim, o número de iterações necessárias para o processo de projeto é fortemente reduzido (e consequentemente o tempo de projeto): primeiro, pelo cálculo das sensibilidades do sistema em relação a cada variável de projeto, e depois pela utilização destas informações para se fazer mudanças sistemáticas na configuração do confinamento a cada iteração (DAUN; HOWELL; MORTON, 2003b).

Nesta linha de pesquisa, o artigo (TORTORELLI; HABER; LU, 1989) utiliza multiplicadores de Lagrange e a teoria da convolução para formular sensibilidades para um funcional que caracteriza o desempenho de sistemas térmicos transientes e não lineares, modelagem esta que contempla fluxos de calor originários de troca radiante.

Ainda sob o ponto de vista teórico, a tese (DAUn, 2003) e o artigo (DAUN; HOWELL; MORTON, 2003a) apresentam uma ampla e rica discussão do método dos gradientes aplicado à troca de calor radiante em cavidades. A modelagem do fenômeno, a estruturação do problema de otimização e suas sensibilidades (até segunda ordem), 
além de exemplos de aplicação podem ser encontrados nestes trabalhos. Mais casos da utilização desta técnica são apresentados em (HOWELL et al., 2003) e em (DAUN; HOWELL; MORTON, 2003b). Neste último artigo, é discutida uma metodologia para o projeto de cavidades bidimensionais, representadas de forma paramétrica por B-Splines, cujas paredes são difusas e a modelagem do fenômeno é feita através de uma análise de área infinitesimal, técnica frequentemente utilizada em trabalhos similares (DAUN; HOLLANDS, 2001). Há ainda uma comparação de custo computacional e eficiência entre algoritmos de programação não linear, como o descida íngreme, método de Newton e o método de quasi-Newton. Em (DAUN; HOWELL; MORTON, 2004), os autores sugerem uma metodologia de projeto para aquecedores que são construídos para gerar calor uniforme, através do cálculo das sensibilidades de temperatura transiente.

Uma discussão de interesse para o presente trabalho, e que pode ser encontrada em (DAUN; HOWELL; MORTON, 2003a), trata da comparação entre métodos inversos e de otimização. A solução do problema de otimização de cavidades sujeitas à radiação utilizando níveis de regularização das equações mal postas que podem descrevê-lo faz parte de uma abordagem de projeto tipicamente inversa (HOWELL; EZEKOYE; MORALES, 2000), e se encontra brevemente discutida na seção 4.2.2. Entretanto, uma desvantagem significativa deste método reside na dificuldade em se impor restrições de projeto e, por este motivo, soluções de regularização frequentemente incluem regiões de fluxo de calor negativo sobre os aquecedores. Esta condição não corresponde a uma realidade prática no projeto de fornos e por isso estas regiões são forçadas a ser adiabáticas, prejudicando a qualidade da solução (DAUN; HOWELl; MORTON, 2004). Neste sentido, métodos de otimização como a OT estão naturalmente aptos a acomodar restrições de projeto, o que representa uma vantagem visível, pois conseguem fazer com que os fluxos de calor sobre as superfícies dos aquecedores fiquem entre uma faixa de operação específica.

Outra aplicabilidade frequentemente encontrada na literatura para a utilização do método dos gradientes no projeto de cavidades submetidas à troca radiante concerne à cura de pinturas em fornos. Em (MEHDIPOUR et al., 2010), o referido método é utilizado para projetar painéis aquecedores para a cura de pintura da representação bidimensional de uma carroceria de automóvel que se desloca dentro de um forno, submetido a temperaturas que variam com o tempo. Nesta linha de pesquisa, mais exemplos e discussões relativas à cura de pintura em fornos podem ser encontrados em (MEHDIPOUR; AGHANAJAFI, 2010; ASHRAFIZADEH; MEHDIPOUR; AGHANAJAFI, 2012; MEHDIPOUR; AGHANAJAFI; ASHRAFIZADEH, 2012; MEHDIPOUR et al., 2012).

Por fim, um dos objetivos de projeto pretendido neste trabalho de mestrado, que consiste na distribuição de material refletor de radiação com o objetivo de minimização 
da temperatura em uma determinada região do interior de um confinamento, é tratado na literatura através do método dos gradientes conjugados (LIU; TAN; YU, 1999, 2001). Nestes artigos, a partir de uma abordagem tipicamente paramétrica de otimização, as emissividades nas paredes de um confinamento são determinadas através de uma análise inversa do problema de radiação com o objetivo de determinação de um perfil de temperatura sobre o domínio de projeto.

Uma breve revisão bibliográfica abordando o tema principal deste texto foi apresentada nesta seção. Muito do que foi discutido teve o intuito de ambientar o leitor em relação às diversas nuances de pesquisa dentro da área de otimização de estruturas sujeitas à troca de calor por radiação em confinamentos. A partir da próxima seção, o foco será integral em trabalhar os conceitos e minúcias da OT aplicada a este tema.

\subsection{Conceitos Teóricos}

Na seção 4.1 foi introduzida a definição de otimização topológica. Esta técnica de otimização é sedimentada em dois conceitos teóricos principais: o dominio fixo estendido e o modelo de material. A seguir, estes fundamentos são discutidos em detalhes.

\subsubsection{Domínio Fixo Estendido}

O domínio fixo estendido (DFE) é a região do espaço, limitada pelos pontos de apoio e condições de contorno, onde a estrutura otimizada será formada. Durante o processo de otimização, o MOT irá remover e adicionar materiais no interior do DFE até que a distribuição otimizada de materiais seja encontrada, definindo portanto, a geometria da estrutura.

$\mathrm{Na}$ implementação numérica deste trabalho, o domínio fixo estendido é discretizado em elementos finitos e este modelo permanece constante durante o processo de otimização, sendo alterada apenas a distribuição de material em cada elemento. Esta característica faz com que as derivadas de uma função objetivo $G$ possam facilmente ser calculadas através da expressão:

$$
\frac{\partial}{\partial \gamma_{n}} \int_{\Omega} G d \Omega=\int_{\Omega} \frac{\partial G}{\partial \gamma_{n}} d \Omega
$$

em que $\gamma_{n}$ representa a variável de projeto definida após a discretização do DFE e $G$ é uma função derivável. 


\subsubsection{Modelo de material}

As propriedades efetivas para materiais isótropos, através de relaxação, podem ser expressas da seguinte maneira:

$$
C(x)=\chi(x) C_{0}
$$

em que $C_{0}$ é a propriedade básica do material a ser distribuído (por exemplo, a refletividade) e $\chi(x)$ é a função discreta que caracteriza, em cada ponto $x$ do domínio de projeto, a estrutura a ser otimizada. Matematicamente, a função $\chi(x)$ pode ser escrita da seguinte forma :

$$
\chi(x)=\left\{\begin{array}{lll}
1, & \text { se } & x \in \Omega_{d} \\
0, & \text { se } & x \in \Omega \backslash \Omega_{d}
\end{array}\right.
$$

sendo $\Omega_{d}$ a região onde há presença de material, inserida num domínio $\Omega$, conforme ilustrado na Figura 4.7.

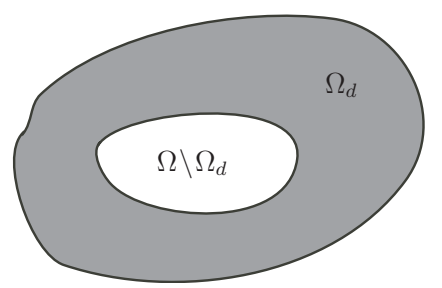

Figura 4.7: Domínio de projeto do MOT.

Porém, ao se trabalhar com a função discreta $\chi(x)$ o problema de otimização não apresenta solução única (máximo ou mínimo global), uma vez que esta se torna dependente da discretização do domínio de projeto $\Omega$. Desta forma, a função discreta é substituída por uma função contínua, que faz a relaxação do problema de distribuição de material e permite valores intermediários entre 0 e 1 para representar as propriedades do material no domínio de projeto. A princípio, propriedades com valores intermediários não teriam um significado físico, sendo apenas decorrentes do recurso matemático para relaxação do problema.

O modelo de material é um recurso matemático que permite relaxar o problema da distribuição de material no interior do dominio de projeto, de modo que seja possivel trabalhar com um problema discreto de maneira contínua (BENDSØE; KIKUCHI, 1988). Em outras palavras, ao invés de se trabalhar com variáveis de projeto que possuam valores discretos (0 e 1), a relaxação permite trabalhar com valores intermediários destas variáveis. Assim, a partir desses valores intermediários, obtêm-se as propriedades efetivas entre os materiais, que podem ser, por exemplo, ar (ausência de material) ou sólido (presença de material). 
Existem diversos modelos de materiais disponíveis na literatura que podem ser implementados no MOT: modelos baseados em microestruturas, como por exemplo materiais laminados rank-1 e rank-2 (HASSANI; HINTON, 1999), e modelos artificiais baseados em densidades, como por exemplo o SIMP (solid isotropic material with penalization) (BENDSøE; SIGMUND, 2003). O método das densidades é um modelo de material que consiste numa equação que define as propriedades efetivas do material a partir de valores de densidades (variáveis de projeto) em cada ponto do domínio e das propriedades do material base. Esta equação é dada por:

$$
C(\mathbf{x})=\gamma(\mathbf{x}) C_{0}
$$

em que $\gamma(\mathbf{x})^{1}$ pode ser interpretada como uma função de distribuição contínua de densidades, com $0 \leq \gamma(\mathbf{x}) \leq 1$ e $\mathbf{x} \in \Omega$. Com isso, a densidade do material pode variar de um valor próximo de 0 (para evitar problemas numéricos), que indica ausência de material, até o valor 1, que indica total presença de material e que, portanto, assume as propriedades do material base.

A relaxação do problema através da ocorrência de valores intermediários para a variável de projeto $\gamma(\mathbf{x})$ pode resultar em soluções com regiões formadas por materiais com propriedades intermediárias. Como citado anteriormente, valores intermediários para a variável de projeto e, por conseguinte, para as propriedades físicas do material, não apresentam a priori um significado físico, sendo apenas consequência da formulação matemática. O excesso de valores intermediários para $\gamma(\mathbf{x})$ pode dificultar a interpretação dos resultados e inviabilizar o processo de fabricação da estrutura otimizada.

Para minimizar o excesso de valores intermediários de $\gamma(\mathbf{x})$, problema conhecido como escala de cinza, tais valores são penalizados da seguinte maneira (BENDSØE; KIKUCHI, 1988; MLEJNEK, 1992; BENDSøE; SIGMUND, 2003):

$$
C(\mathbf{x})=\gamma(\mathbf{x})^{p} C_{0}
$$

em que $p$ é o fator de penalização das densidades intermediárias. É importante notar que valores relativamente altos para o penalizador $p$ podem aproximar o problema contínuo do problema discreto, retornando ao caso de unicidade de solução devido à aproximação da natureza discreta da variável de projeto.

No presente trabalho, o SIMP que será utilizado é uma simples extensão do modelo introduzido pela equação (4.5). Esta extensão é apresentada em (CARBONARI; SILVA; NISHIWAKI, 2007) para três tipos de materiais, mas aqui será simplificada para apenas

\footnotetext{
${ }^{1}$ As densidades, ou variáveis de projeto, são referenciadas por $\gamma$, ao invés da clássica notação $\rho$, para evitar qualquer associação conceitual com a propriedade radiante refletividade.
} 
dois tipos, como mostrado abaixo:

$$
\rho_{i}=\gamma_{i}^{p} \rho_{m}+\left(1-\gamma_{i}^{p}\right) \rho_{0}
$$

Conforme este modelo, representado no gráfico da Figura 4.8, a propriedade de interesse não é interpolada entre presença ou não presença de material, mas sim entre presença de material (propriedade refletividade inicial $\rho_{0}$ do elemento), caso $\gamma_{i}$ seja zero, e presença de material que se deseja distribuir (material com nova refletividade $\rho_{m}$ ), caso $\gamma_{i}$ seja unitário. É possível perceber através da equação (4.6) que o penalizador $p$ age, de acordo com o valor de $\gamma_{i}$, no sentido de aproximar a propriedade refletividade $\rho_{i}$ de $\rho_{m}$ ou de $\rho_{0}$, de forma a evitarem-se valores intermediários que não são de interesse para o problema de otimização topológica da transferência de calor por radiação em confinamentos abordado neste trabalho.

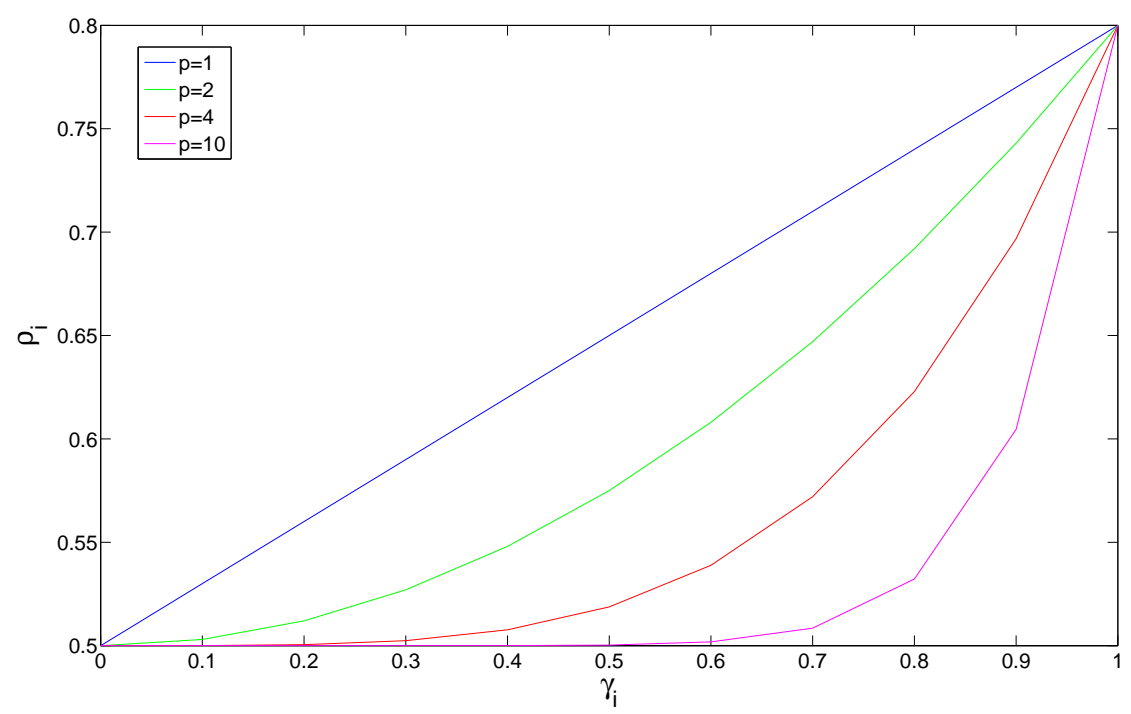

Figura 4.8: Gráficos da função dada em (4.6), que define o modelo de material, para diferentes valores de penalização. $\mathrm{O}$ valor de $\rho_{0}=0,5$ e de $\rho_{m}=0,8$.

Um outro modelo de material, com a finalidade de distribuição de aquecedores (regiões com fluxo de calor prescrito) no interior de confinamentos, é explorado nesta dissertação. Também baseado no modelo clássico do SIMP (BENDSøE; KIKUCHI, 1988; MLEJNEK, 1992; BENDSøE; SIGMUND, 2003) e nas equações de (3.6) a (3.10), a ideia central para o desenvolvimento deste modelo é entender que, da forma como a troca de calor radiante no interior de confinamentos é modelada neste trabalho, os elementos finitos ou possuem temperatura prescrita ou fluxo de calor prescrito. Desta forma, as variáveis de projeto passam a ser ponderadoras das condições de contorno. Assim, para o sistema de equações lineares dado por (3.6), os elementos da matriz de rigidez $\boldsymbol{K}_{\boldsymbol{R}}$ podem ser escritos 
como:

$$
K_{R_{i j}}=\delta_{i j}-\left(1-\varepsilon_{i}\right)^{1-\gamma_{i}^{p}} F_{i j}
$$

em que

$$
\left\{\begin{array}{l}
\gamma_{i}=0 \rightarrow K_{i j}=\delta_{i j}-\left(1-\varepsilon_{i}\right) F_{i j} \text { (temperatura prescrita) } \\
\left.\gamma_{i}=1 \rightarrow K_{i j}=\delta_{i j}-F_{i j} \text { (aquecedor }\right)
\end{array}\right.
$$

Da mesma forma, os elementos do vetor de emissões $\boldsymbol{E}$ podem ser ponderados como:

$$
E_{i}=\left(1-\gamma_{i}^{p}\right) \varepsilon_{i} \sigma T_{i}^{4}+\gamma_{i}^{p} q_{i}
$$

em que

$$
\left\{\begin{array}{l}
\gamma_{i}=0 \rightarrow E_{i}=\varepsilon_{i} \sigma T_{i}^{4} \text { (temperatura prescrita) } \\
\gamma_{i}=1 \rightarrow E_{i j}=q_{i} \text { (aquecedor) }
\end{array}\right.
$$

A correta manipulação das variáveis de projeto utilizadas neste modelo de material permite identificar se, no final do processo de otimização, o elemento finito estará sujeito à condição de contorno de temperatura ou de fluxo de calor, sendo considerado neste último caso um aquecedor.

Os principais conceitos teóricos que definem a otimização topológica foram discutidos nesta seção. É importante o leitor se familiarizar plenamente com as definições de domínio fixo estendido e do modelo de material, pois estas ideias são essenciais para o entendimento da formulação do problema de otimização topológica apresentada a seguir.

\subsection{Formulação do Problema de Otimização Topológica aplicada à Troca Radiante em Confinamentos}

O fenômeno de transferência de calor por radiação em confinamentos foi exaustivamente abordado, de maneira analítica e também numérica nos capítulos 2 e 3 . Todo este prelúdio teórico terá desfecho nesta seção, em que finalmente serão apresentados os tópicos de maior interesse para este trabalho de mestrado: a definição da função objetivo e o cálculo dos seus gradientes em relação às variáveis de projeto. Juntos, estas definições determinam o problema de otimização topológica aplicada à troca radiante em confinamentos.

\subsubsection{Função Objetivo de Extremização da Irradiação}

Uma das formulações do problema de otimização topológica propostas neste trabalho tem interesse em investigar a extremização do fluxo de radiação que chega até uma 
determinada região do interior de um confinamento, dada uma possivel restrição no volume de material refletor a ser distribuido no interior deste confinamento. Essa medida, como visto em 2.1.1.3, chama-se irradiação e pode ser representada pela equação (2.71), reproduzida abaixo:

$$
G_{i}=\sum_{j=1}^{N} F_{i j} J_{j}
$$

Ou seja, o fluxo de irradiação que chega até uma determinada superfície $i$ que compõe o confinamento analisado é resultado da somatória de todas as radiosidades do sistema, ponderadas pelos respectivos fatores de forma.

O estudo da maximização da irradiação é importante no projeto de fornos, em que se deseja que determinada área tenha máxima incidência de radiação. Outro segmento que tem interesse neste tipo de abordagem é o do projeto de coletores solares. Desta forma, a função objetivo de maximização da irradiação sobre um determinado domínio pode ser formulada como:

$$
\begin{gathered}
\underset{\gamma}{\operatorname{Maximizar}:} \quad G \\
\text { tal que }: 0 \leq \gamma_{i} \leq 1, i=1, \ldots, N \\
\qquad(\gamma)=\sum_{i=1}^{N} \gamma d \Omega \leq V_{s}
\end{gathered}
$$

As motivações para se estudar a minimização da irradiação são claramente diferentes. O umbilical de uma plataforma de petróleo, a bateria de um carro ou os dispositivos eletrônicos no interior de um computador, todas estas diferentes aplicações de engenharia tem em comum o fato de que sua eficiência e/ou durabilidade são prejudicadas pelo alto nível de radiação térmica presente no ambiente em que operam. Tomando esta fragilidade como motivação de projeto, optou-se também por estudar confinamentos que apresentam a necessidade de minimização da irradiação que chega até uma determinada região do seu interior. A abordagem proposta diferencia-se da tradicional técnica de blindagem de radiação (INCROPERA et al., 2007), pois além de obviamente não estar interessada na minimização do fluxo líquido de calor, permite analisar a interação de muitas superfícies trocando calor ao mesmo tempo e permite identificar de forma sistemática o melhor local do domínio de projeto para se distribuir material refletor, o que gera, portanto, soluções mais robustas e detalhadas. A formulação da função objetivo de minimização da irradiação é equivalente à dada por (4.13). Assim, tem-se:

$$
\begin{gathered}
\underset{\gamma}{\operatorname{Minimizar}:} \quad G \\
\text { tal que }: 0 \leq \gamma_{i} \leq 1, i=1, \ldots, N \\
V(\gamma)=\sum_{i=1}^{N} \gamma d \Omega \leq V_{s}
\end{gathered}
$$


Na próxima seção é apresentada uma proposição de função objetivo que procura entender qual a maneira otimizada de se distribuir material refletor, de forma que determinada região do interior de um confinamento tenha sua temperatura minimizada.

\subsubsection{Função Objetivo de Minimização da Temperatura}

A mesma motivação utilizada para definir o problema de minimização da irradiação na seção 4.4.1 é aqui retomada para o caso em que se deseja minimizar a temperatura de determinada região de um confinamento sujeito à troca radiante. Esta necessidade se torna clara, quando percebe-se que, na prática, uma grande gama de processos industriais tem a temperatura como principal variável de controle. Ambientes de manufatura que comportam processos químicos, como os de cura de pintura, são um exemplo disto. Outra área que representa uma aplicação direta desta linha de projeto é a de conforto térmico, principalmente em ambientes onde prevalece a convecção natural.

Assim, a segunda função objetivo discutida neste trabalho procura elucidar qual a melhor forma de se minimizar a temperatura em uma região específica do interior de um confinamento através da distribuição de material refletor. Desta forma, o foco recai no cálculo da temperatura sobre o domínio de projeto. A determinação deste grau de liberdade pode ser dada pela equação (3.18), convenientemente reproduzida abaixo:

$$
\overline{\mathbf{T}}(h)=\left\{\mathbf{K}^{-1}[\mathbf{q}(h)-\mathbf{K}(h, \theta) \overline{\mathbf{T}}(\theta)]\right\}
$$

Assim, utilizando-se a mesma abordagem adotada para a definição de (4.14), a função objetivo de minimização da temperatura pode ser escrita como:

$$
\begin{gathered}
\underset{\gamma}{\operatorname{Minimizar}:} \quad T \\
\text { tal que }: 0 \leq \gamma_{i} \leq 1, i=1, \ldots, N \\
V(\gamma)=\sum_{i=1}^{N} \gamma d \Omega \leq V_{s}
\end{gathered}
$$

A última proposição de função objetivo, apresentada a seguir, procura estabelecer uma abordagem para a distribuição otimizada de aquecedores no interior de um confinamento. Isto é feito com o propósito de maximizar a irradiação que chega a uma região específica deste domínio de projeto. 


\subsubsection{Função Objetivo de Distribuição de Aquecedores para Maximização da Irradiação}

Uma trivial demanda no projeto de fornos se preocupa em entender qual o número otimizado de aquecedores a ser utilizado e onde estes devem estar posicionados de forma a se ter um funcionamento mais eficiente deste equipamento. É comum encontrar na literatura resultados que respondem a este questionamento através de métodos de otimização que não utilizam a informação de gradientes (AMIRI et al., 2011). Entretanto, através do modelo de material para distribuição de aquecedores, proposto na seção 4.3.2, o projeto de fornos que tenham por finalidade a maximização da irradiação em uma região do seu interior passa a também ser possível através da otimização topológica.

A função objetivo de distribuição de aquecedores se utiliza do modelo de material que é descrito pelas equações de (4.7) a (4.12) no intuito de maximizar a irradiação que chega a uma determinada região no interior de um confinamento. Esta função objetivo pode ser dada como:

$$
\begin{gathered}
\text { Distribuir aquecedores para maximizar } G \\
\text { tal que }: 0 \leq \gamma_{i} \leq 1, \quad i=1, \ldots, N \\
V(\gamma)=\sum_{i=1}^{N} \gamma_{i} d \Omega \leq V_{s}
\end{gathered}
$$

Foram apresentadas quatro funções objetivo para a aplicação da otimização topológica no projeto do interior de confinamentos sujeitos à radiação. Para que essa técnica de otimização esteja suficientemente abordada neste texto, as sensibilidades destas funções precisam ser definidas, como feito a seguir.

\subsubsection{Gradientes das Funções Objetivo de Extremização da Irradiação}

Os gradientes, ou sensibilidades, de uma função objetivo descrevem como esta função se comporta em relação às mudanças das variáveis de projeto e são uma importante informação a ser fornecida ao otimizador MMA (SVANBERG, 1987). Neste sentido, a derivada da função objetivo de maximização da irradiação (4.13) em relação à $\gamma_{i}$ pode ser dada como:

$$
\frac{\partial \mathbf{G}}{\partial \gamma_{i}}=\mathbf{F} \frac{\partial \mathbf{J}}{\partial \gamma_{i}}
$$

já que a otimização modifica apenas a distribuição de material sobre as superfícies que compõem o interior do confinamento e não sua geometria em si (por isso $\frac{\partial \mathbf{F}}{\partial \gamma_{i}}=0$ ). A derivada das radiosidades utilizadas na equação (4.17) é calculada a partir da equação 
(3.6), isolando-se $\boldsymbol{J}$ :

$$
\begin{gathered}
\mathbf{J}=\mathbf{K}_{\mathbf{R}}{ }^{-1} \mathbf{E} \\
\frac{\partial \mathbf{J}}{\partial \gamma_{i}}=\mathbf{K}_{\mathbf{R}}{ }^{-1}\left(\frac{\partial \mathbf{E}}{\partial \gamma_{i}}-\frac{\partial \mathbf{K}_{\mathbf{R}}}{\partial \gamma_{i}} \mathbf{J}\right)
\end{gathered}
$$

Desta forma, a partir da equação (4.17), a derivada das irradiações em relação às variáveis de projeto pode ser dada como:

$$
\frac{\partial \mathbf{G}}{\partial \gamma_{i}}=\mathbf{F}\left[\mathbf{K}_{\mathbf{R}}{ }^{-1}\left(\frac{\partial \mathbf{E}}{\partial \gamma_{i}}-\frac{\partial \mathbf{K}_{\mathbf{R}}}{\partial \gamma_{i}} \mathbf{J}\right)\right]
$$

A maximização da irradiação em uma região específica do domínio de projeto, neste texto, é tratada basicamente como a maximização da soma das irradiações nos elementos que descrevem esta área. A partir desta abordagem, define-se um vetor linha $\mathbf{f}_{D}$ de dimensão $1 \times N$, com valor 1 nas posições dos elementos que descrevem a região que o projetista deseja maximizar a irradiação e zero no restante. Assim, através da aplicação do método adjunto (CHOI; KIM, 2004), a derivada da soma das irradiações nos elementos de interesse pode ser reescrita como:

$$
\frac{\partial \mathbf{G}}{\partial \gamma_{i}}=\boldsymbol{\lambda}_{\boldsymbol{R}}\left(\frac{\partial \mathbf{E}}{\partial \gamma_{i}}-\frac{\partial \mathbf{K}_{\mathbf{R}}}{\partial \gamma_{i}} \mathbf{J}\right)
$$

em que o vetor coluna $\boldsymbol{\lambda}_{\boldsymbol{R}}$ é dado por:

$$
\lambda_{\boldsymbol{R}}=\left(\mathbf{K}_{\mathbf{R}}^{T}\right)^{-1}\left(\mathbf{f}_{D} \mathbf{F}\right)^{T}
$$

Uma vez que a derivada das emissões em elementos com fluxo de calor prescrito é nula, como mostra a equação (3.10), faz-se necessário somente o cálculo das sensibilidades das emissões nos elementos que possuem temperatura prescrita. Assim, da equação (3.8), tem-se:

$$
\frac{\partial \mathbf{E}_{i}}{\partial \gamma_{i}}=-\left(p \gamma_{i}^{p-1} \rho_{m}-p \gamma_{i}^{p-1} \rho_{0}\right) \sigma \overline{\mathbf{T}}\left(\theta_{i}\right)
$$

Ou seja, o vetor coluna $\frac{\partial \mathbf{E}}{\partial \gamma_{i}}$ somente tem derivada na posição $i$, nas outras posições esta derivada é nula.

A derivada da matriz de rigidez deste problema é igualmente nula nos elementos que possuem fluxo de calor prescrito, como pode-se induzir da equação (3.9). Desta forma, a partir da equação (3.7), a derivada da matriz de rigidez para elementos com temperatura 
prescrita é dada por:

$$
\frac{\partial \mathbf{K}_{\mathbf{R}}}{\partial \gamma_{i}}=-\left(p \gamma_{i}^{p-1} \rho_{m}-p \gamma_{i}^{p-1} \rho_{0}\right)\left[\begin{array}{cccc}
0 & 0 & \cdots & 0 \\
\vdots & \vdots & \ddots & \vdots \\
F_{i 1} & F_{i 2} & \cdots & F_{i N} \\
\vdots & \vdots & \ddots & \vdots \\
0 & 0 & \cdots & 0
\end{array}\right]
$$

Desta forma, a matriz $\frac{\partial \mathbf{K}_{\mathbf{R}}}{\partial \gamma_{i}}$ somente tem derivadas na linha $i$, nas outras linhas as derivadas são nulas.

Os gradientes da função objetivo de minimização da irradiação (4.14) são analogamente calculados. A única diferença consiste no sinal dos valores de $\frac{\partial \mathbf{G}}{\partial \gamma_{i}}$, que para efeitos de utilização do MMA (SVANBERG, 1987) são negativos na maximização da irradiação e positivos na minimização da mesma.

\subsubsection{Gradientes da Função Objetivo de Minimização da Temperatura}

A medida da variação da temperatura em relação às variáveis de projeto no interior de um confinamento está diretamente relacionada ao caminho percorrido para se deduzir à equação (3.18). Seguindo esta linha de raciocínio, o passo anterior à determinação das temperaturas desconhecidas é descrito a seguir:

$$
\mathbf{K}(h, h) \overline{\mathbf{T}}(h)=\mathbf{q}(h)-\mathbf{K}(h, \theta) \overline{\mathbf{T}}(\theta)
$$

Derivando-se a equação (4.25) em relação à $\gamma_{i}$, tem-se:

$$
\frac{\partial \mathbf{K}(h, h)}{\partial \gamma_{i}} \overline{\mathbf{T}}(h)+\mathbf{K}(h, h) \frac{\partial \overline{\mathbf{T}}(h)}{\partial \gamma_{i}}=-\frac{\partial \mathbf{K}(h, \theta)}{\partial \gamma_{i}} \overline{\mathbf{T}}(\theta)
$$

uma vez que as derivadas de $\frac{\partial \mathbf{q}(h)}{\partial \gamma_{i}}$ e $\frac{\partial \overline{\mathbf{T}}(\theta)}{\partial \gamma_{i}}$ são nulas $(\mathbf{q}(h)$ e $\overline{\mathbf{T}}(\theta)$ representam condições de contorno prescritas). Logo, a derivada das temperaturas em relação às variáveis de projeto pode ser dada como:

$$
\frac{\partial \overline{\mathbf{T}}(h)}{\partial \gamma_{i}}=-\mathbf{K}(h, h)^{-1}\left(\frac{\partial \mathbf{K}(h, \theta)}{\partial \gamma_{i}} \overline{\mathbf{T}}(\theta)+\frac{\partial \mathbf{K}(h, h)}{\partial \gamma_{i}} \overline{\mathbf{T}}(h)\right)
$$

A minimização da temperatura em uma região específica do domínio de projeto, neste texto, é tratada basicamente como a minimização da soma das temperaturas nos elementos que descrevem esta área. A partir desta abordagem, define-se um vetor linha $\mathbf{f}_{D}$ de dimensão $1 \times N$, com valor 1 nas posições dos elementos que descrevem a região que o 
projetista deseja minimizar a temperatura e zero no restante. Assim, através da aplicação do método adjunto (CHOI; KIM, 2004), a derivada da soma das temperaturas nos elementos de interesse pode ser definida como:

$$
\frac{\partial \overline{\mathbf{T}}(h)}{\partial \gamma_{i}}=-\boldsymbol{\lambda}^{T}\left(\frac{\partial \mathbf{K}(h,:)}{\partial \gamma_{i}}\left\{\begin{array}{l}
\overline{\mathbf{T}}(h) \\
\overline{\mathbf{T}}(\theta)
\end{array}\right\}\right)
$$

em que $\boldsymbol{\lambda}$ é dado por:

$$
\boldsymbol{\lambda}=\left(\mathbf{K}(h, h)^{T}\right)^{-1}\left(\mathbf{f}_{D}(h)\right)^{T}
$$

A derivada de $\frac{\partial \mathbf{T}(h)}{\partial \gamma_{i}}$ é então dada por:

$$
\frac{\partial \mathbf{T}(h)}{\partial \gamma_{i}}=\left[\begin{array}{c}
\frac{1}{4 T\left(h_{1}\right)^{3}} \frac{\partial \bar{T}\left(h_{1}\right)}{\partial \gamma_{i}} \\
\frac{1}{4 T\left(h_{2}\right)^{3}} \frac{\partial \frac{\partial T}{\left.\partial h_{2}\right)}}{\partial \gamma_{i}} \\
\vdots \\
\frac{1}{4 T\left(h_{N_{h}}\right)^{3}} \frac{\partial \bar{T}\left(h_{N_{h}}\right)}{\partial \gamma_{i}}
\end{array}\right]
$$

Para a utilização da equação (4.28), falta definir a variação da matriz de rigidez em relação às variáveis de projeto nas posições que correspondem a fluxo de calor prescrito. Isto é feito, primeiramente, aplicando-se a relação (2.46) à matriz de rigidez (3.16):

$$
\mathbf{K}=(\mathbf{I}-\mathbf{F})[\mathbf{I}-\operatorname{diag}(\boldsymbol{\rho}) \mathbf{F}]^{-1} \operatorname{diag}(1-\boldsymbol{\rho}) \sigma
$$

Só então as derivadas podem ser calculadas:

$$
\frac{\partial \mathbf{K}}{\partial \gamma_{i}}=\sigma(\mathbf{I}-\mathbf{F})[\mathbf{I}-\operatorname{diag}(\boldsymbol{\rho}) \mathbf{F}]^{-1} \frac{\partial \operatorname{diag}(1-\boldsymbol{\rho})}{\partial \gamma_{i}}\left\{-\mathbf{F}[\mathbf{I}-\operatorname{diag}(\boldsymbol{\rho}) \mathbf{F}]^{-1} \operatorname{diag}(1-\boldsymbol{\rho})+\mathbf{I}\right\}
$$

em que $\frac{\partial \operatorname{diag}(1-\boldsymbol{\rho})}{\partial \gamma_{i}}$ é uma matriz de dimensão $N \times N$, preenchida com zeros e que exclusivamente na posição $\left[\frac{\partial \operatorname{diag}(1-\boldsymbol{\rho})}{\partial \gamma_{i}}\right]_{i i}$ vale

$$
-\left(p \gamma_{i}^{p-1} \rho_{m}-p \gamma_{i}^{p-1} \rho_{0}\right)
$$

Para determinação de $\frac{\partial \mathbf{K}(h,:)}{\partial \gamma_{i}}$ basta acessar a matriz (4.32), nas posições das linhas, com o conjunto dos elementos que possuem fluxo de calor conhecidos.

\subsubsection{Gradientes das Função Objetivo de Distribuição de Aquecedores para Maximização da Irradiação}

O posicionamento otimizado de aquecedores no interior de um confinamento sujeito à troca radiante é um problema tipicamente abordado por métodos de otimização que não utilizam informações dos gradientes das funções objetivo (PORTER et al., 2006; SAFAVINEJAD et al., 2009; AMIRI et al., 2011). Mas como discutido em 4.2.2, para fins 
de otimização topológica, este tipo de tratamento deve ser evitado.

Desta forma, para a função objetivo (4.4.3), a derivada da soma das irradiações nos elementos que formam a região alvo da otimização é igualmente dada pela equação (4.21), novamente reproduzida para fins de conveniência:

$$
\frac{\partial \mathbf{G}}{\partial \gamma_{i}}=\boldsymbol{\lambda}_{\boldsymbol{R}}\left(\frac{\partial \mathbf{E}}{\partial \gamma_{i}}-\frac{\partial \mathbf{K}_{\mathbf{R}}}{\partial \gamma_{i}} \mathbf{J}\right)
$$

Porém, no caso em questão as sensibilidades da matriz de rigidez $\mathbf{K}_{\mathbf{R}}$ em relação às variáveis de projeto são obtidas através da derivação da equação (4.7), como abaixo:

$$
\frac{\partial \mathbf{K}_{\mathbf{R}}}{\partial \gamma_{i}}=p \gamma_{i}^{p-1} \ln \left(1-\varepsilon_{i}\right)\left(1-\varepsilon_{i}\right)^{1-\gamma_{i}{ }^{p}}\left[\begin{array}{cccc}
0 & 0 & \cdots & 0 \\
\vdots & \vdots & \ddots & \vdots \\
F_{i 1} & F_{i 2} & \cdots & F_{i N} \\
\vdots & \vdots & \ddots & \vdots \\
0 & 0 & \cdots & 0
\end{array}\right]
$$

Desta forma, a matriz $\frac{\partial \mathbf{K}_{\mathbf{R}}}{\partial \gamma_{i}}$ somente tem derivadas na linha $i$. Já as derivadas do vetor de emissões E são obtidas a partir da equação (4.10):

$$
\frac{\partial \mathbf{E}_{i}}{\partial \gamma_{i}}=p \gamma_{i}^{p-1}\left(q_{i}-\sigma T_{i}^{4}\right)
$$

Ou seja, o vetor coluna $\frac{\partial \mathbf{E}}{\partial \gamma_{i}}$ somente tem derivada na posição $i$.

A apresentação das funções objetivo e dos gradientes destas representaram os últimos conceitos necessários para aplicação da otimização topológica ao projeto do interior de confinamentos sujeitos à troca radiante. Apenas uma breve exposição dos passos utilizados neste processo separa o leitor de resultados que demonstram o potencial desta ferramenta.

\subsection{Implementação do Algoritmo de Otimização Topológica}

Como qualquer outra ferramenta convencional de otimização, a otimização topológica utiliza um processo iterativo para alcançar uma configuração de projeto final, de forma que o desempenho da estrutura modificada é analisado a cada iteração. Se a nova configuração não satisfaz os requisitos de projeto, ela é modificada e novamente avaliada. Este processo é repetido até que uma resposta satisfatória seja obtida (HOWELL et al., 2003).

A eficiência deste processo e a qualidade do resultado final dependem do quanto o desempenho da estrutura otimizada melhora a cada iteração. Técnicas de otimização, tal qual a OT, modificam as variáveis de projeto baseadas nas informações de sensibilidade 
utilizando algoritmos numéricos, que procuram maximizar a qualidade dos resultados entre iterações sucessivas. Consequentemente, técnicas de otimização requerem muito menos iterações do que o método de tentativa e erro (HOWELL et al., 2003).

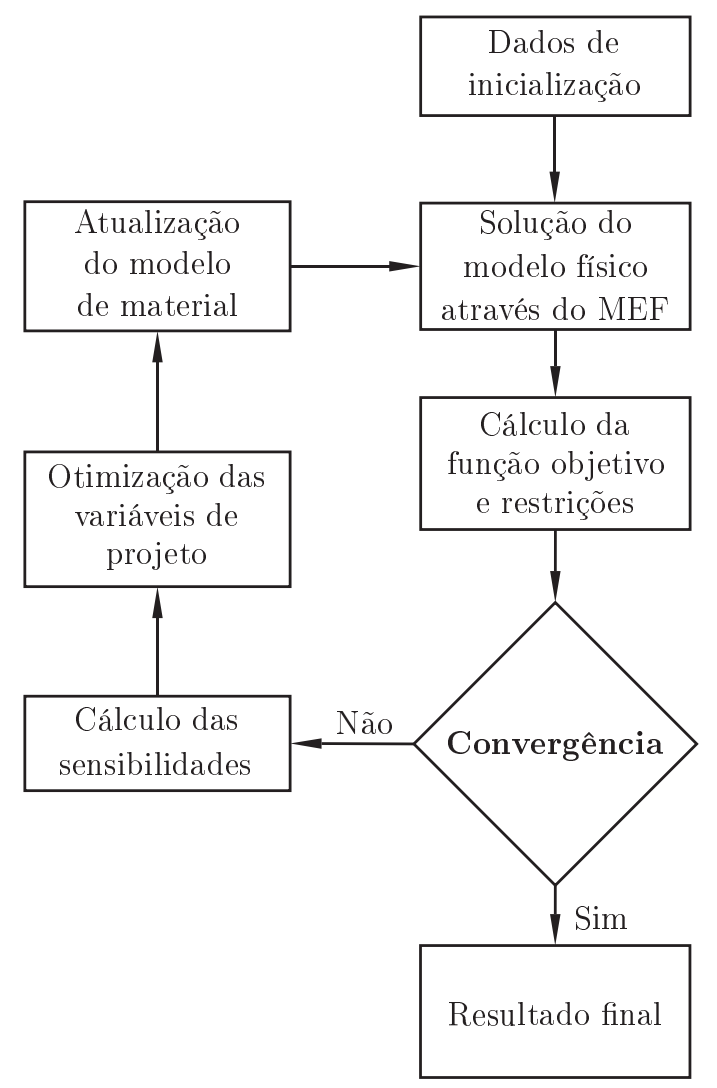

Figura 4.9: Passos seguidos durante a otimização topológica utilizando o Matlab ${ }^{\circledR}$.

O laço, que conecta o solucionador do problema físico (o "solver" de MEF) ao otimizador topológico, segue passos definidos, como pode ser visto no fluxograma da Figura 4.9. Inicialmente, definem-se os dados de entrada do problema de otimização, tais como: malha de elementos finitos, fatores de forma, condições de contorno e valores iniciais das variáveis de projeto. Em seguida, obtém-se a solução do problema físico utilizando o MEF, calcula-se a função objetivo e as restrições do problema para, somente então, verificar-se a convergência da função objetivo. Se ocorrer a convergência, obtém-se uma dentre as muitas possíveis soluções otimizadas para o problema. Soluções otimizadas intermediárias são encontradas (ou seja, máximos ou mínimos locais), pois o problema a ser otimizado somente possui máximo ou mínimo global se a função objetivo que o define for convexa (HAFTKA; GURDAL, 1992), o que pode ser comprovado apenas de maneira analítica. Caso não haja convergência, calculam-se as sensibilidades (gradientes) da função objetivo, que são dados de entrada para o otimizador. Com a solução fornecida pelo otimizador, atualiza-se a distribuição de material e resolve-se novamente o problema físico. Este ciclo se repete até que uma convergência para função objetivo seja alcançada.

É importante frisar que, neste trabalho, toda a modelagem física do fenômeno 
estudado, bem como a estruturação do algoritmo de OT, são implementados através de códigos próprios, escritos em linguagem Matlab ${ }^{\circledR}$. 


\section{Resultados}

Neste capítulo, resultados obtidos através das diversas funções objetivo propostas na seção 4.4 são apresentados e discutidos através de exemplos como o mostrado na Figura 5.1, em que o domínio de projeto possui regiões com temperatura ou fluxo de calor (aquecedores, por exemplo) prescrito, além de uma área alvo onde deseja-se extremizar uma função objetivo previamente definida.

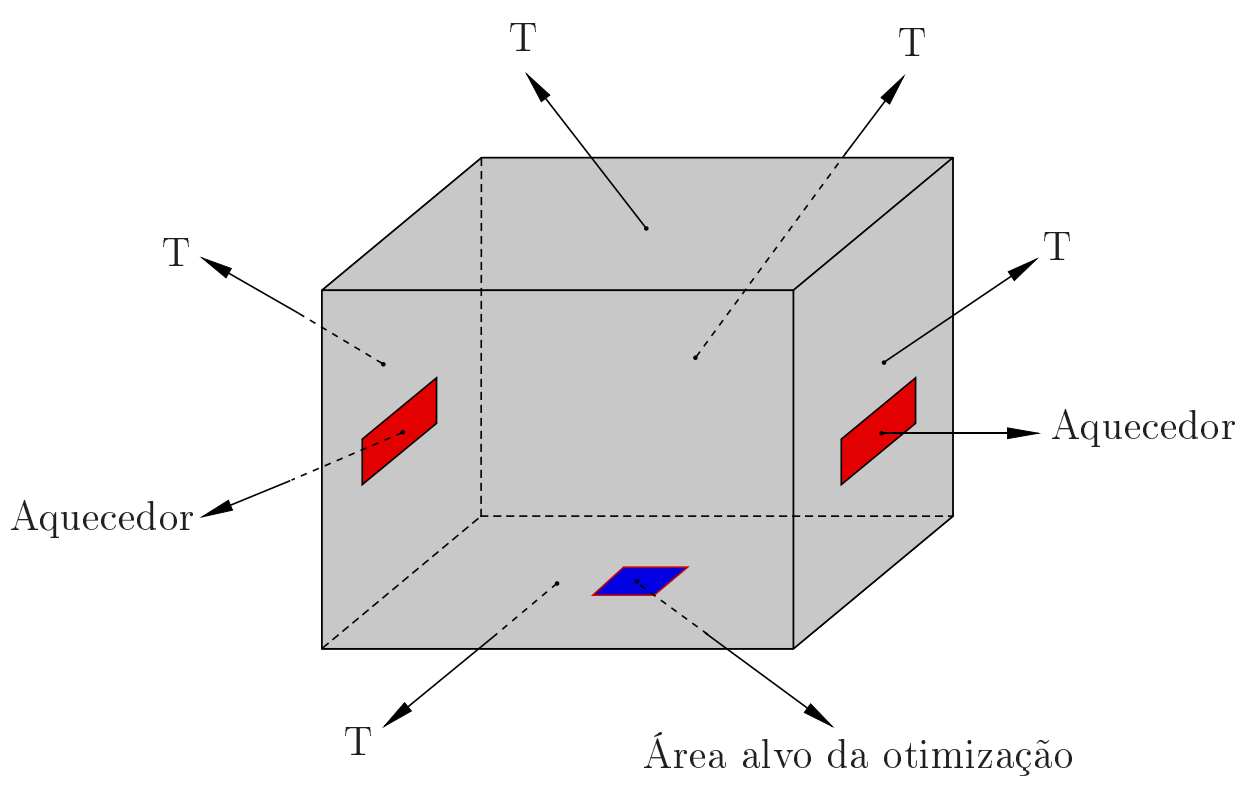

Figura 5.1: Exemplo de domínio de projeto e suas possíveis condições de contorno.

Para todos os tipos de problemas abordados foi utilizado o método da continuação (BENDSøE; SIGMUND, 2003), variando $p$ de 1 a no máximo 5, através de intervalos unitários. Também foram geradas figuras da distribuição final das variáveis de projeto, das medidas otimizadas (radiosidades ou temperaturas) e gráficos de convergência da função objetivo. As áreas alvo, onde deseja-se extremizar a irradiação ou minimizar-se a temperatura, estão delimitadas por um retângulo vermelho. Para fins de melhorar a visualização dos resultados, os confinamentos analisados foram abertos (unfolded), como o modelo na Figura 5.2 mostra. A numeração presente nesta figura, utilizada para orientar as paredes do interior de um confinamento, será adotada como padrão em todo este capítulo. 

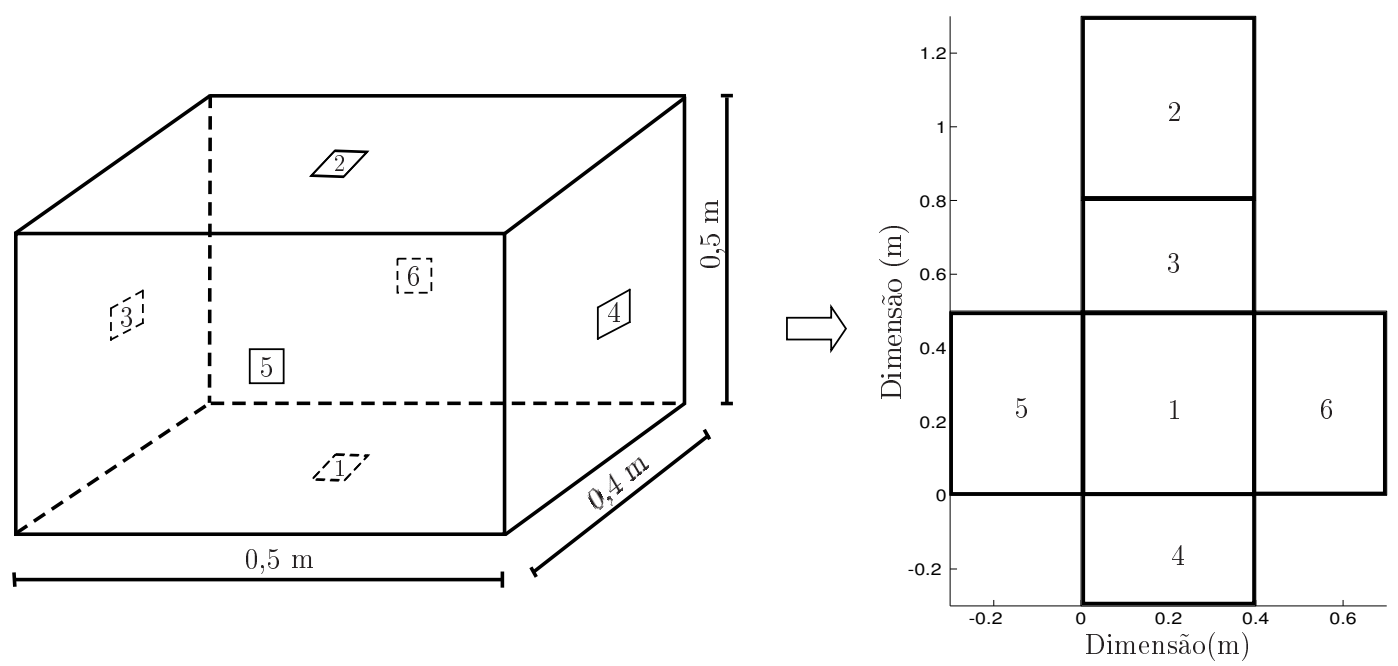

Figura 5.2: Abertura de um confinamento para fins de visualização dos resultados.

A maioria dos exemplos estudados utiliza condições de contorno de temperatura e fluxo de calor homogêneos sobre as paredes dos interiores dos confinamentos analisados. Esse tipo de abordagem possui a vantagem de ser computacionalmente simples de implementar, mas pode ser limitadora, na medida que favorece a obtenção de resultados discretos, principalmente em casos de não aplicação de uma restrição de volume. Desta forma, em um primeiro momento, o leitor poderia ter a impressão de que a otimização paramétrica seria uma ferramenta tão eficiente quanto a otimização topológica para a solução dos problemas estudados nesta dissertação. No intuito de distinguir o potencial da otimização topológica de outras ferramentas de otimização e, ao mesmo tempo, cobrir uma necessidade de projeto (a de que o projetista possua deveras uma limitação na quantidade de material que poderá empregar), resultados com restrição de volume também são apresentados.

\subsection{Maximização da Irradiação}

Como visto na seção 4.4.1, o estudo da maximização da irradiação é, apenas para citar um exemplo, importante no projeto de fornos, em que se deseja que determinada área tenha máxima incidência de radiação. A função objetivo de maximização da irradiação será diferentemente discutida através de três casos: no primeiro caso, a intenção é mostrar o potencial da otimização topológica como ferramenta de projeto para confinamentos sujeitos à troca radiante; no segundo caso, o problema do confinamento tridimensional discutido em 2.1.4.6 é revisitado; por fim, no terceiro caso, um confinamento semelhante a um forno elétrico é estudado. Somente para esta função objetivo tal abordagem será tomada.

Para todos estes casos, as emissividades (e consequentemente as refletividades) iniciais 
de cada parede interior ao confinamento são as mesmas utilizadas no exemplo resolvido no item 2.1.4.6, ou seja:

$$
\left\{\begin{array} { l } 
{ \varepsilon _ { p _ { 1 } } = 0 , 9 } \\
{ \varepsilon _ { p _ { 2 } } = 0 , 7 } \\
{ \varepsilon _ { p _ { 3 } } = 0 , 8 } \\
{ \varepsilon _ { p _ { 4 } } = 0 , 3 } \\
{ \varepsilon _ { p _ { 5 } } = 0 , 9 } \\
{ \varepsilon _ { p _ { 6 } } = 0 , 9 }
\end{array} \quad \left\{\begin{array}{l}
\rho_{p_{1}}=0,1 \\
\rho_{p_{2}}=0,3 \\
\rho_{p_{3}}=0,2 \\
\rho_{p_{4}}=0,7 \\
\rho_{p_{5}}=0,1 \\
\rho_{p_{6}}=0,1
\end{array}\right.\right.
$$

Dois confinamentos de tamanhos diferentes foram escolhidos para acomodar os exemplos estudados nesta seção. As áreas alvos em cada um deles, onde se deseja maximizar a irradiação, são delimitadas por um retângulo vermelho como pode ser visualizado na Figura 5.3.

(a)

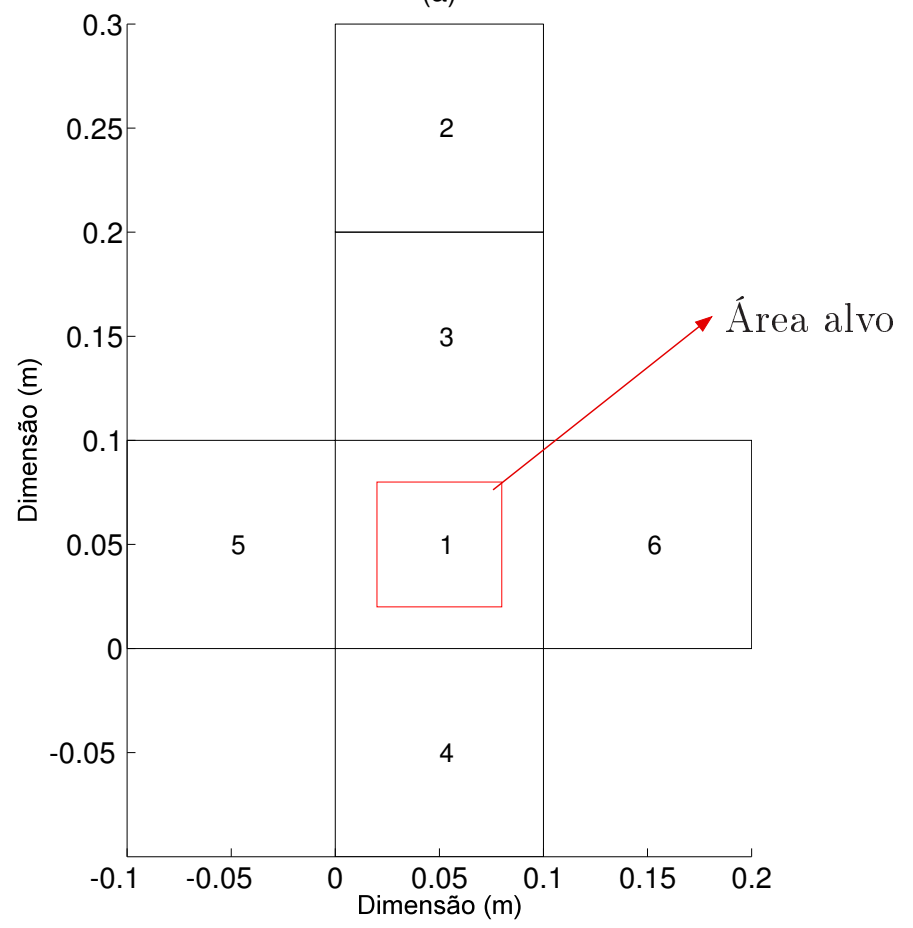

(b)

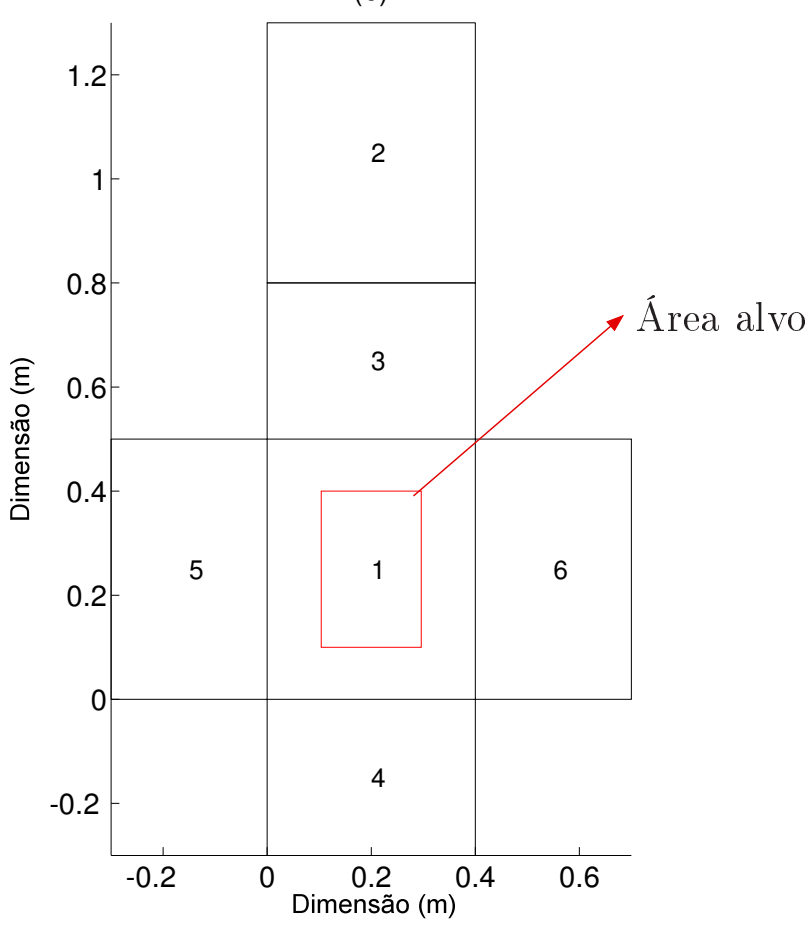

Figura 5.3: Áreas alvo da maximização da irradiação: (a) para um confinamento de dimensão $0,1 \times 0,1 \times 0,1 \mathrm{~m}$ (b) para um confinamento de dimensão $0,4 \times 0,5 \times 0,3 \mathrm{~m}$.

É interessante notar que regiões com fluxo de calor prescrito não precisam fazer parte do domínio de projeto em casos de extremização da irradiação. Isto porque a radiosidade nestas regiões é insensível a mudanças nas variáveis de projeto, como indicam as equações (2.79), (3.9) e (3.10). A exclusão destes elementos do processo de otimização é uma excelente maneira de economizar recurso computacional e foi adotada para geração dos resultados apresentados a seguir. Por opção do autor, a área alvo da otimização também não é considerada para o tipo de problema em questão. 


\subsubsection{Caso 1}

Este primeiro caso tem o claro e exclusivo objetivo de mostrar o diferencial da otimização topológica como ferramenta de projeto. Desta forma, pretende-se distinguir os resultados possíveis de se obter através deste método dos resultados possíveis de se obter através da otimização de forma e, principalmente, da otimização paramétrica. Para todos os outros casos, todavia, isto será feito através da imposição de uma restrição de volume ao projeto analisado, como já comentado no início deste capítulo.

Um projetista experiente tende a esperar que um padrão de solução para o projeto do interior de confinamentos submetidos à radiação, através da utilização da otimização topológica, seja baseado em uma distribuição de material não necessariamente intuitiva ou bem comportada sobre este dominio de projeto. Para a obtenção deste tipo de resultado, faz-se necessário que as condições de contorno de temperatura do problema sejam mais heterogêneas (menos discretas). Levando em conta este aspecto, o primeiro caso analisado pode ser enunciado como:

- objetivo: maximização da radiação que chega até o retângulo vermelho apresentado na Figura 5.3a, através da distribuição irrestrita de material de refletividade igual a 0,8 ;

- onde: no interior de um confinamento de dimensões $0,1 \times 0,1 \times 0,1 \mathrm{~m}$, malhado com 15000 elementos finitos retangulares;

- condições: sujeito a uma distribuição inicial de temperatura $(K)$ nas paredes de 1 a 4 definida segundo a Figura 5.4. As paredes 5 e 6 estão coloridas de branco, cor não presente na escala de cores utilizada, pois são áreas com fluxos de calor prescritos e iguais a zero.

O gráfico de convergência da função objetivo de maximização da irradiação para o caso analisado pode ser visto na Figura 5.5. Fica claro através deste gráfico que uma convergência bem comportada foi obtida, mesmo para um número pequeno de iterações, e que há pouca variação entre o valor da função objetivo obtido na última iteração de otimização e após o pós-processamento do resultado ( $0,1 \%$ de diferença).

As distribuições final e pós-processada das variáveis de projeto podem ser vistas na Figura 5.6. A última iteração produziu um resultado praticamente discreto, com mínima presença de cinza. Este resultado, obtido sem restrição de volume, serve ainda para corroborar a discussão realizada no item 1.6, mostrando que a solução otimizada para o problema em questão não se resume à substituição completa dos materiais de menor 


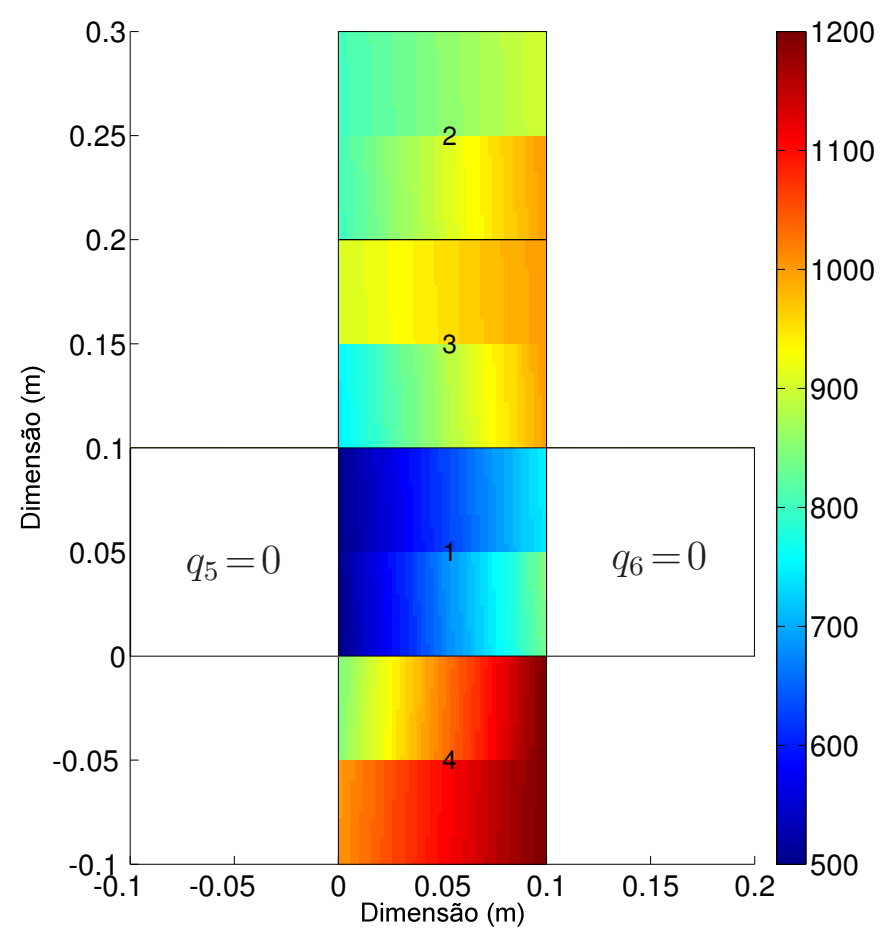

Figura 5.4: Condições de contorno de temperatura $(K)$ das paredes de 1 a 4 e de fluxo de calor $\left(W / m^{2}\right)$ das paredes 5 e 6 , para o primeiro caso de maximização da irradiação.

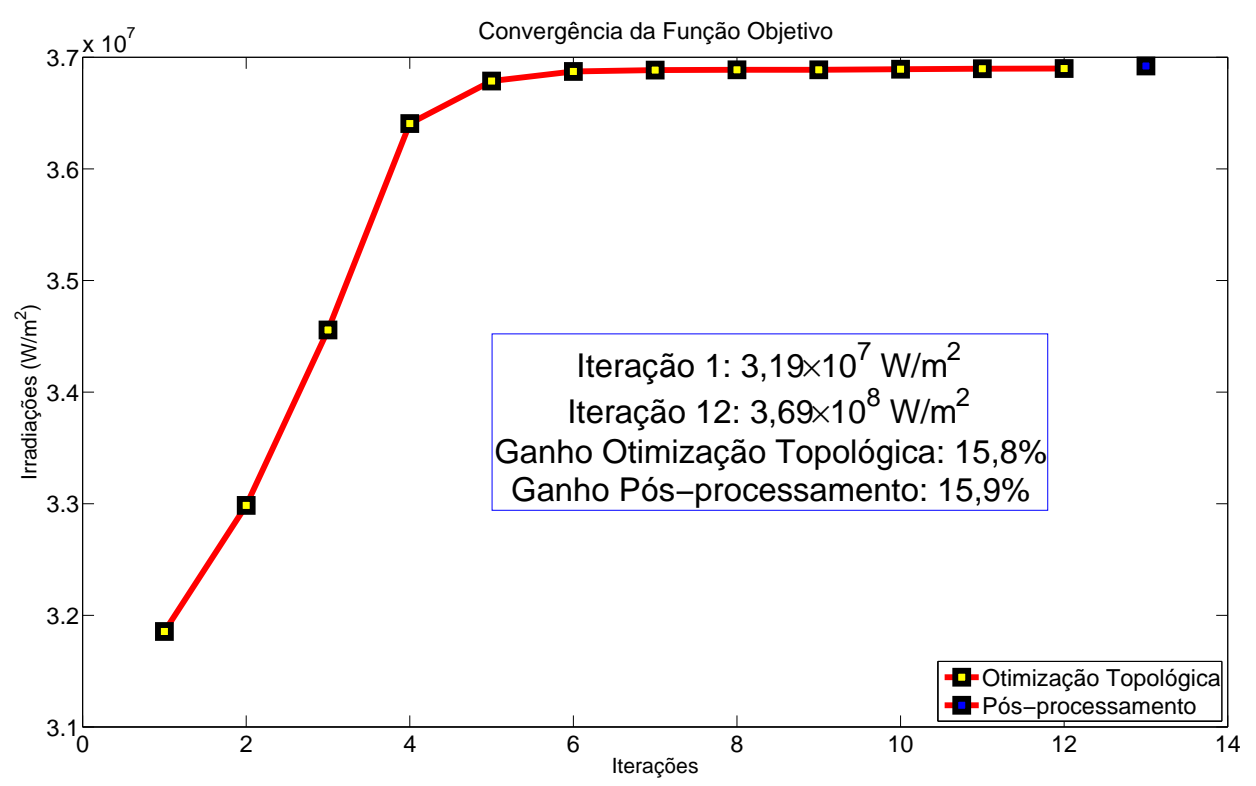

Figura 5.5: Convergência da função objetivo para o primeiro caso de maximização da irradiação.

refletividade por um de maior refletividade, como pode ser visto na Figura 5.7, cuja barra de cores representa os valores da propriedade em questão.

Finalizando este primeiro caso, o leitor pode observar ainda, na Figura 5.8, a diferença entre a distribuição de irradiações sobre o domínio de projeto antes e depois do processo de otimização topológica. A região delimitada pelo retângulo vermelho teve um aumento 
(a)

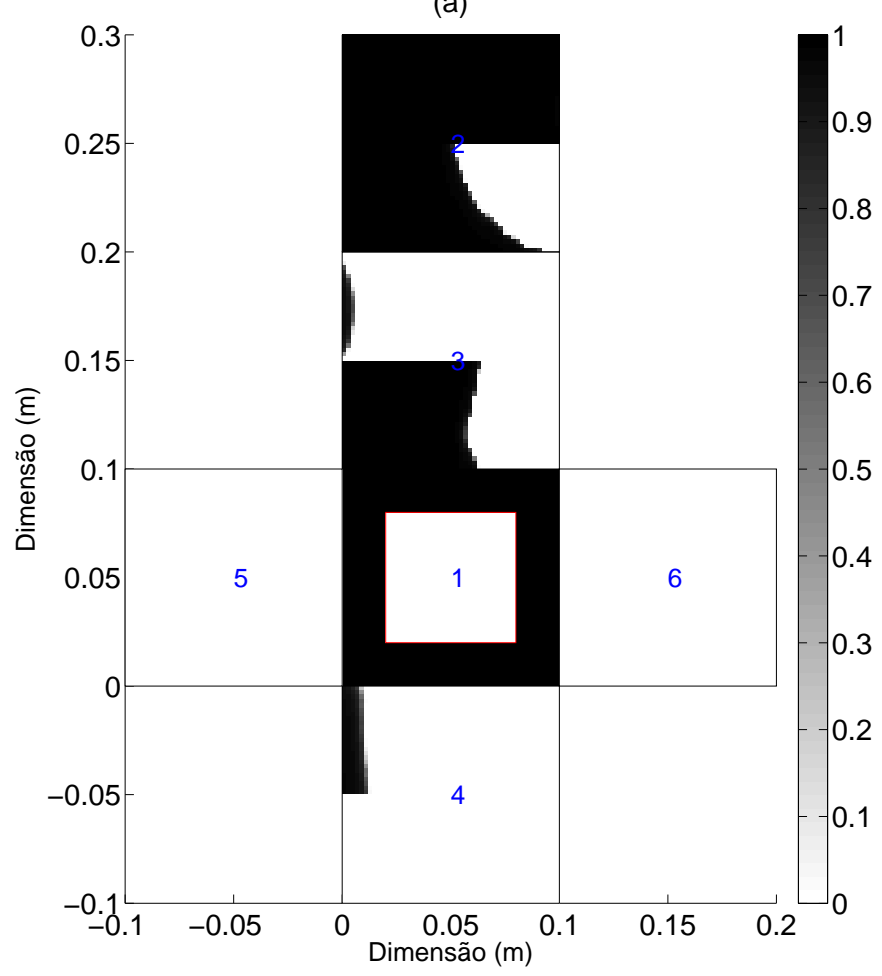

(b)

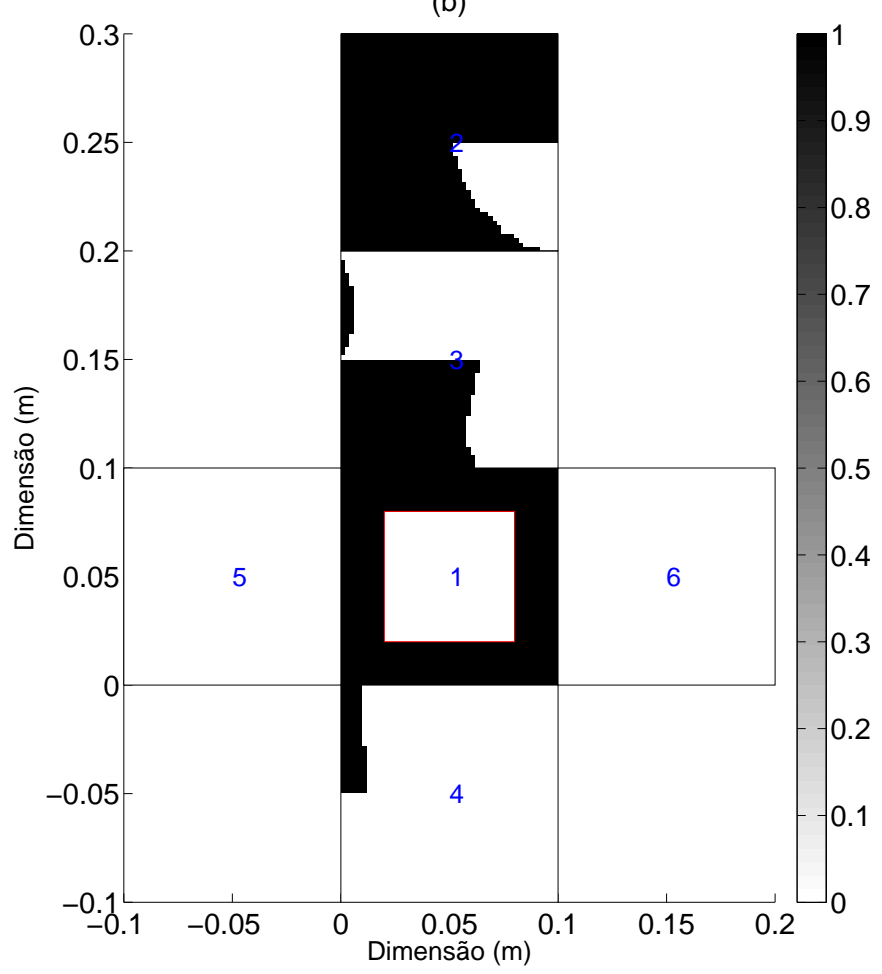

Figura 5.6: Distribuição das variáveis de projeto para o primeiro caso de maximização da irradiação: (a) última iteração do processo de otimização (b) pós-processamento.

(a)

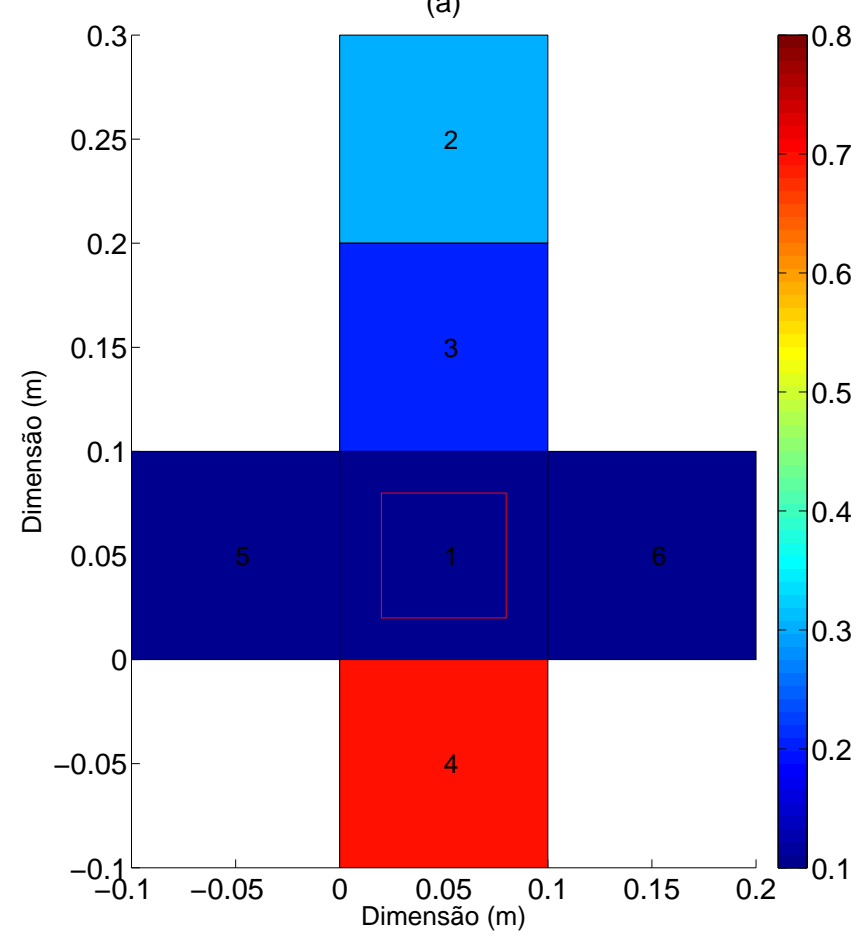

(b)

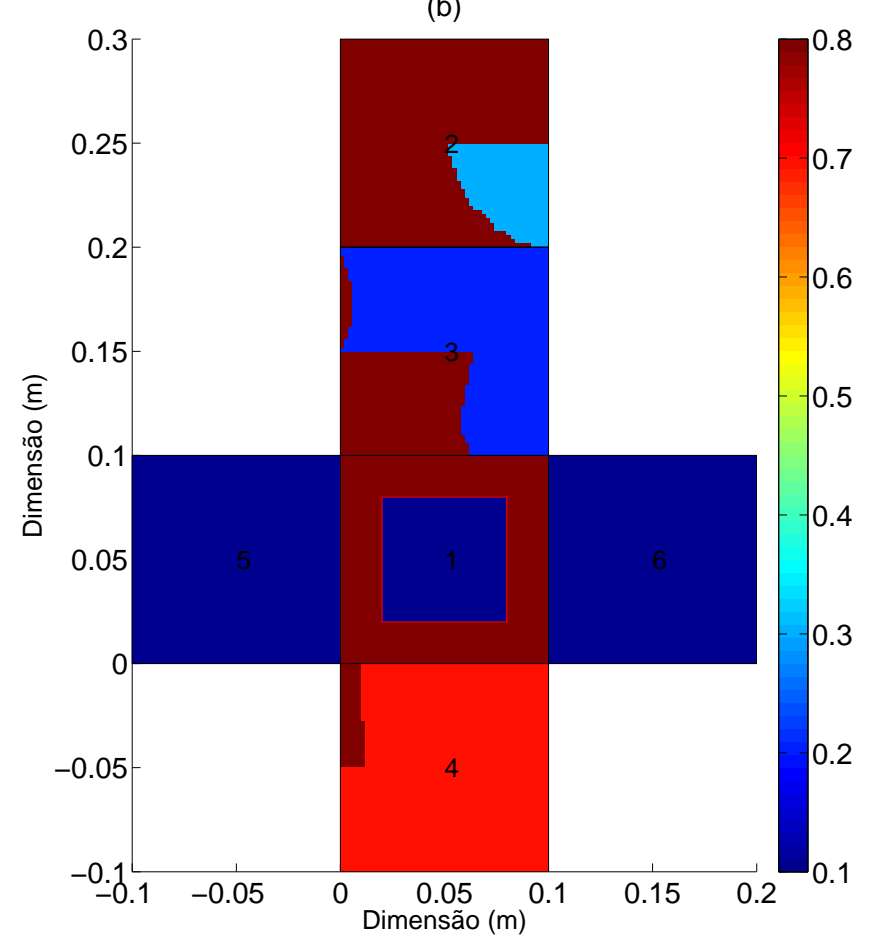

Figura 5.7: Distribuição de material de refletividade igual a 0,8 para o primeiro caso de maximização da irradiação: (a) domínio de projeto inicial (b) domínio de projeto otimizado. 
de quase $16 \%$ na intensidade de incidência de radiação.

A seguir, o exemplo do confinamento tridimensional, fundamental para as discussões analíticas e numéricas realizadas nos capítulos 2 e 3, é novamente abordado.
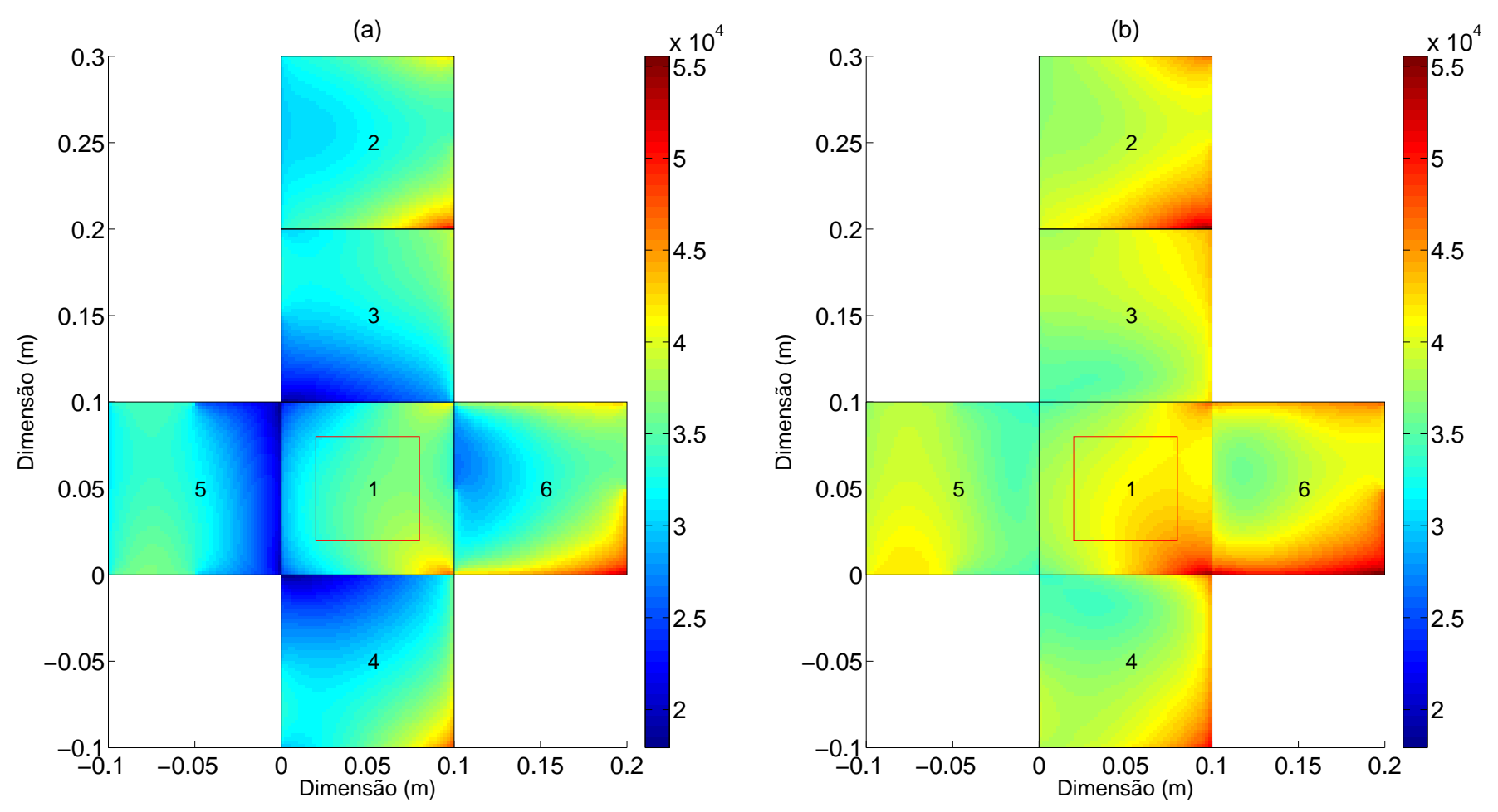

Figura 5.8: Irradiações $\left(W / m^{2}\right)$ para o primeiro caso de maximização da irradiação: (a) antes da otimização (b) depois da otimização.

\subsubsection{Caso 2}

O segundo caso revisita o exemplo de confinamento tridimensional anteriormente discutido no item 2.1.4.6. Para este caso, o projeto pretendido pode ser enunciado como:

- objetivo: maximização da radiação que chega até o retângulo vermelho apresentado na Figura 5.3b, através da distribuição restrita (30\% do volume total) ou irrestrita de material de refletividade igual a 0,8 ;

- onde: no interior de um confinamento de dimensões $0,4 \times 0,5 \times 0,3 \mathrm{~m}$, malhado com 15000 elementos finitos retangulares;

- condições: sujeito a condições de contorno de temperatura e fluxo de calor tal qual definidas no item 2.1.4.6 e abaixo novamente reproduzidas: 


$$
\left\{\begin{array} { l } 
{ T _ { p _ { 1 } } = 5 0 0 \mathrm { K } } \\
{ T _ { p _ { 2 } } = 8 0 0 \mathrm { K } } \\
{ T _ { p _ { 3 } } = 1 0 0 0 \mathrm { K } } \\
{ T _ { p _ { 4 } } = 1 2 0 0 \mathrm { K } }
\end{array} \quad \left\{\begin{array}{l}
q_{p_{5}}=0 \\
q_{p_{6}}=0
\end{array}\right.\right.
$$

Os gráficos de convergência da função objetivo de maximização da irradiação para o segundo problema, com e sem restrição de volume, podem ser vistos na Figura 5.9. Em ambos os casos, convergências bem comportadas foram obtidas e poucas variações entre os valores das funções objetivo obtidos nas últimas iterações de otimização e após o pós-processamento dos resultados são verificados (0\% para o caso sem restrição de volume e $0,1 \%$ de diferença para o caso com restrição). A descontinuidade observada na Figura 5.9b corresponde a uma transição do método da continuação. Um número maior de iterações para o processo de otimização com restrição de $30 \%$ de volume é necessário para fins de eliminação de regiões cinzas sobre o domínio de projeto.
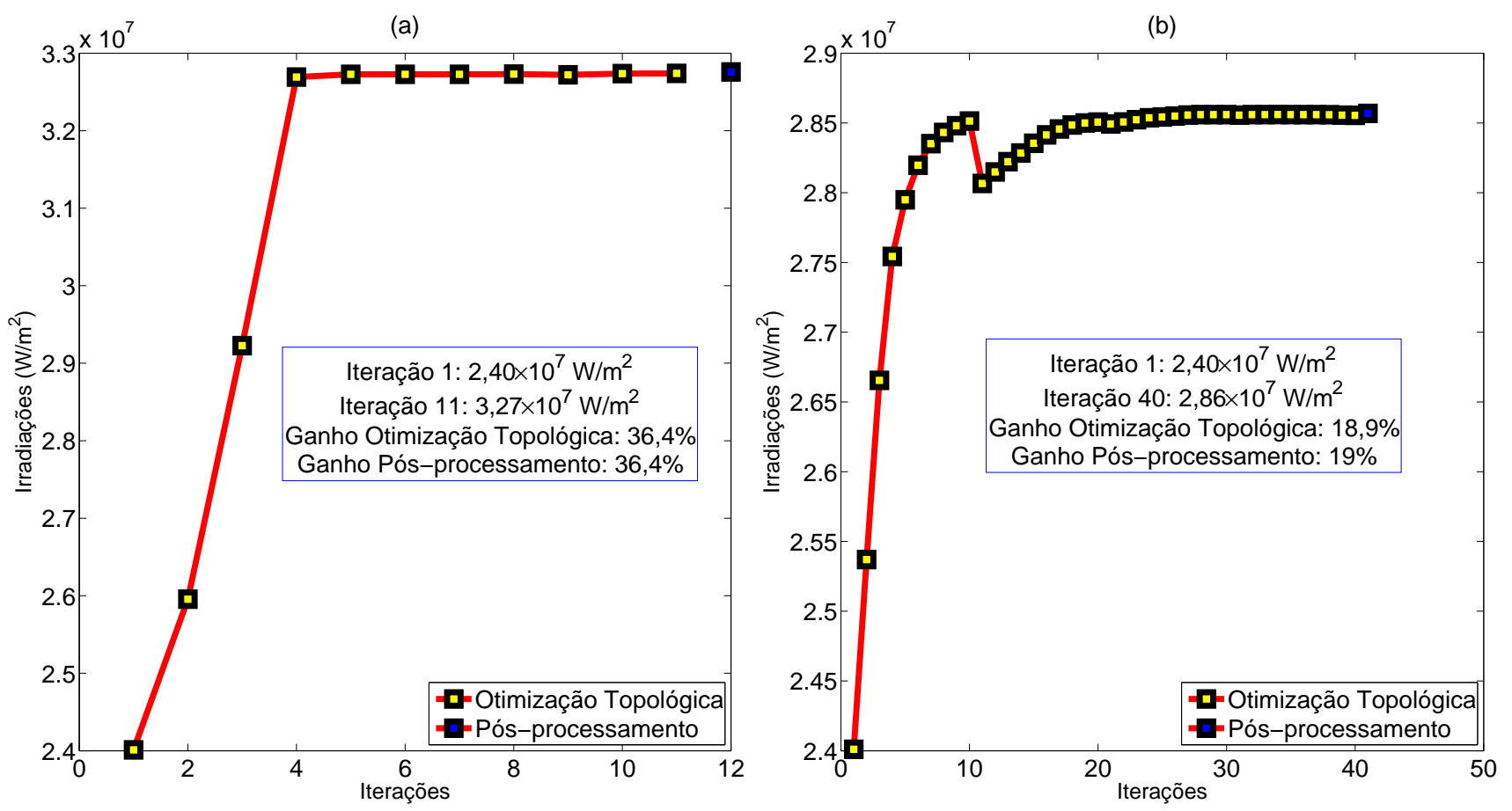

Figura 5.9: Convergência da função objetivo para o segundo caso de maximização da irradiação: (a) sem restrição de volume (b) com restrição de volume de $30 \%$.

As distribuições das variáveis de projeto, na última iteração do processo de otimização, podem ser visualizadas na Figura 5.10. Fica claro que resultados praticamente discretos foram obtidos para as simulações com e sem restrição de volume, de forma que julgou-se desnecessário mostrar os resultados pós-processados. Estes resultados, obtidos com e sem restrição de volume, servem ainda para corroborar a discussão realizada no item 1.6, mostrando que as soluções otimizadas para o problema em questão não se resumem a 
substituição completa dos materiais de menor refletividade por um de maior refletividade, como pode ser visto na Figura 5.11, cuja barra de cores representa os valores da propriedade em questão.

(a)

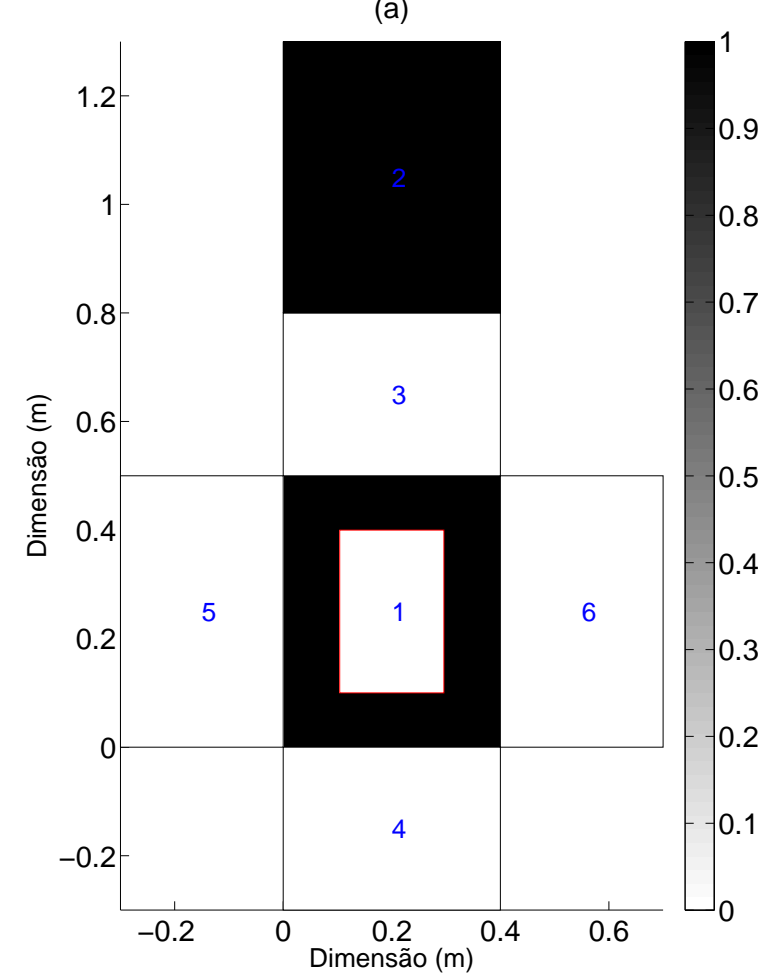

(b)

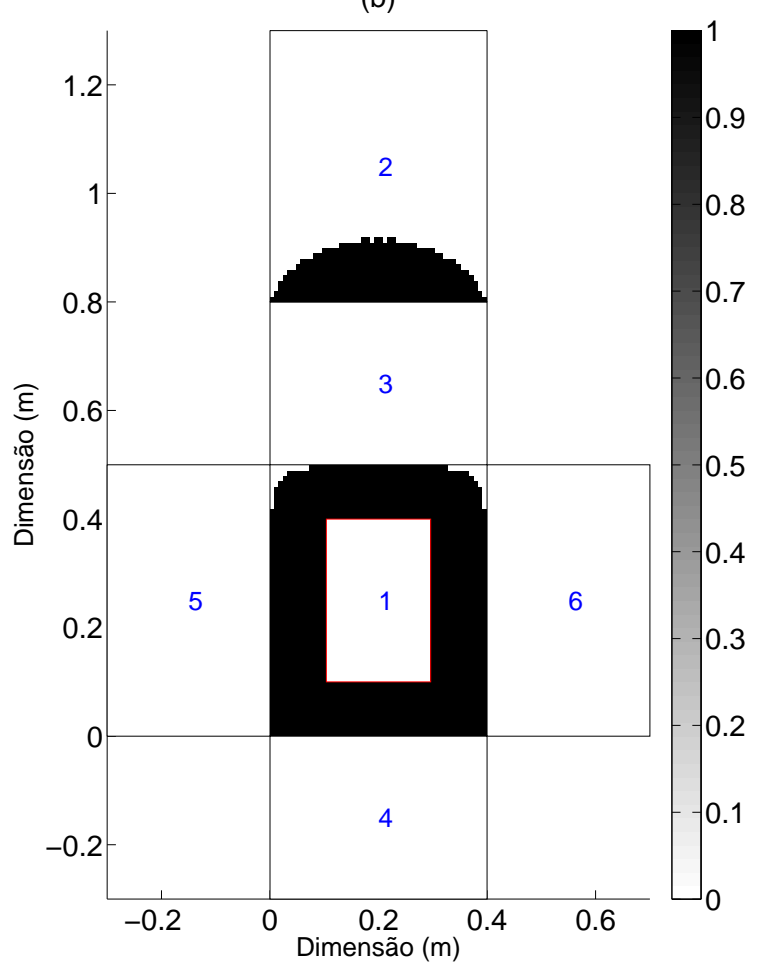

Figura 5.10: Distribuição das variáveis de projeto para o segundo caso de maximização da irradiação na última iteração do processo de otimização topológica: (a) sem restrição de volume (b) com restrição de volume de $30 \%$.

Finalizando este segundo exemplo, é possível visualizar nas Figuras 5.12 e 5.13 as diferenças entre as distribuições de irradiações sobre o domínio de projeto antes e depois do processo de otimização topológica, para os casos sem e com restrição de volume, respectivamente. A região delimitada pelo retângulo vermelho na Figura 5.12a teve um significativo aumento de 36,4\% na intensidade de incidência de radiação para o caso sem restrição de volume. Já para o caso com restrição de 30\% de volume na distribuição de material de refletividade 0,8 , a intensidade de radiação que chega até o retângulo vermelho teve um aumento de quase $19 \%$ após o processo de otimização topológica, resultado este também bastante satisfatório.

A seguir, o terceiro e último exemplo procura verificar a aplicação dos conhecimentos discutidos neste texto para o projeto de um confinamento que emula o interior simplificado de um forno elétrico. 
(a)

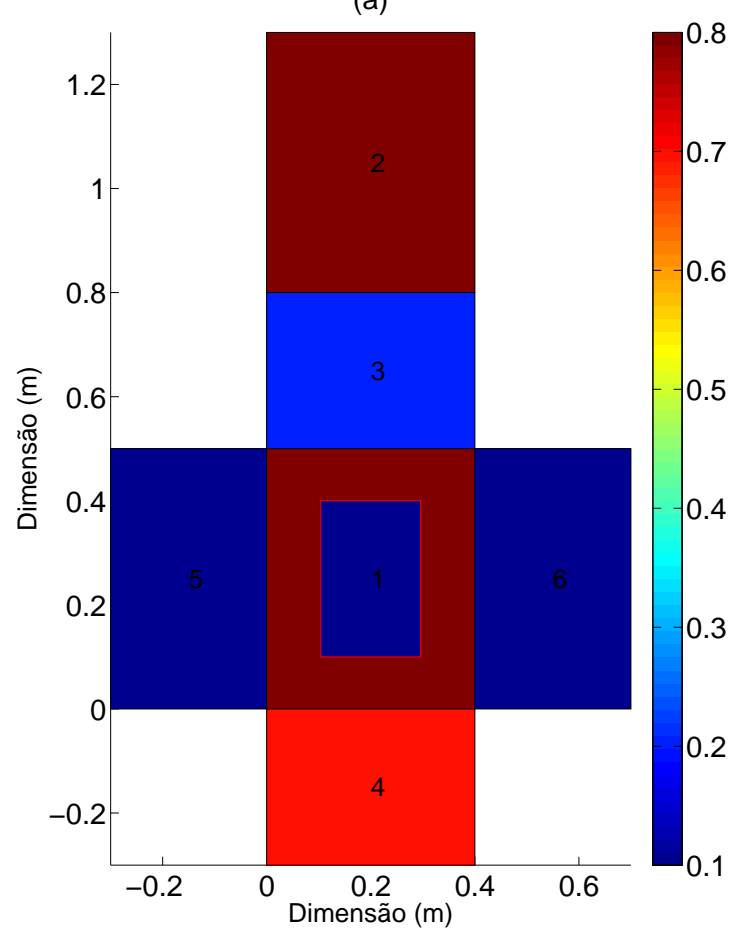

(b)

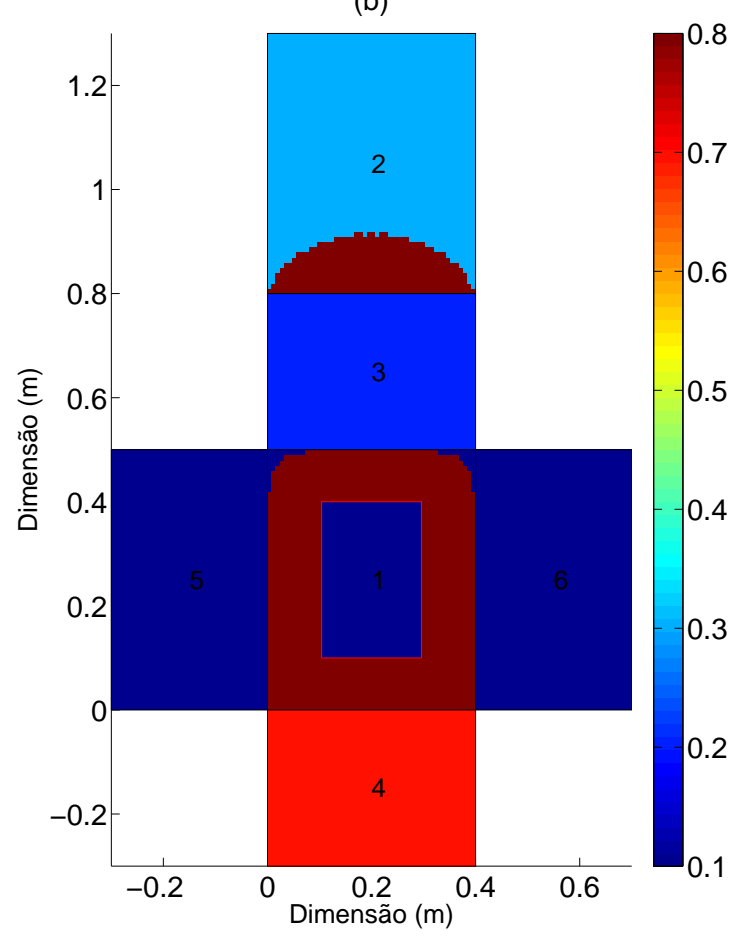

Figura 5.11: Distribuição de material de refletividade igual a 0,8 para o segundo caso de maximização da irradiação: (a) sem restrição de volume (b) com restrição de volume de $30 \%$.

(a)

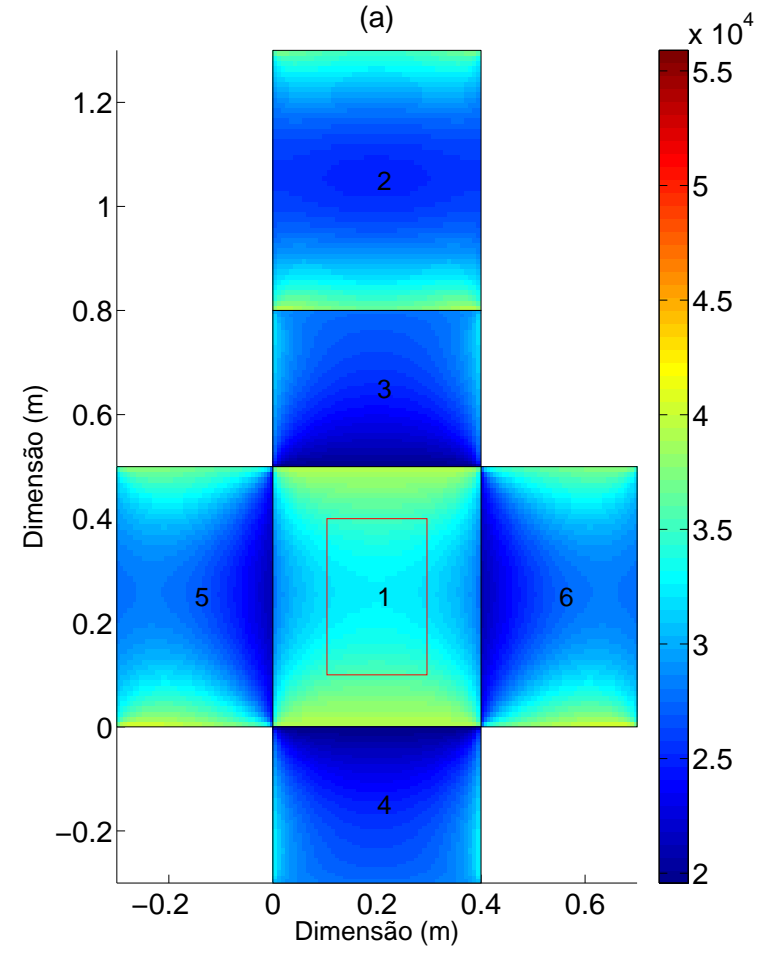

(b)

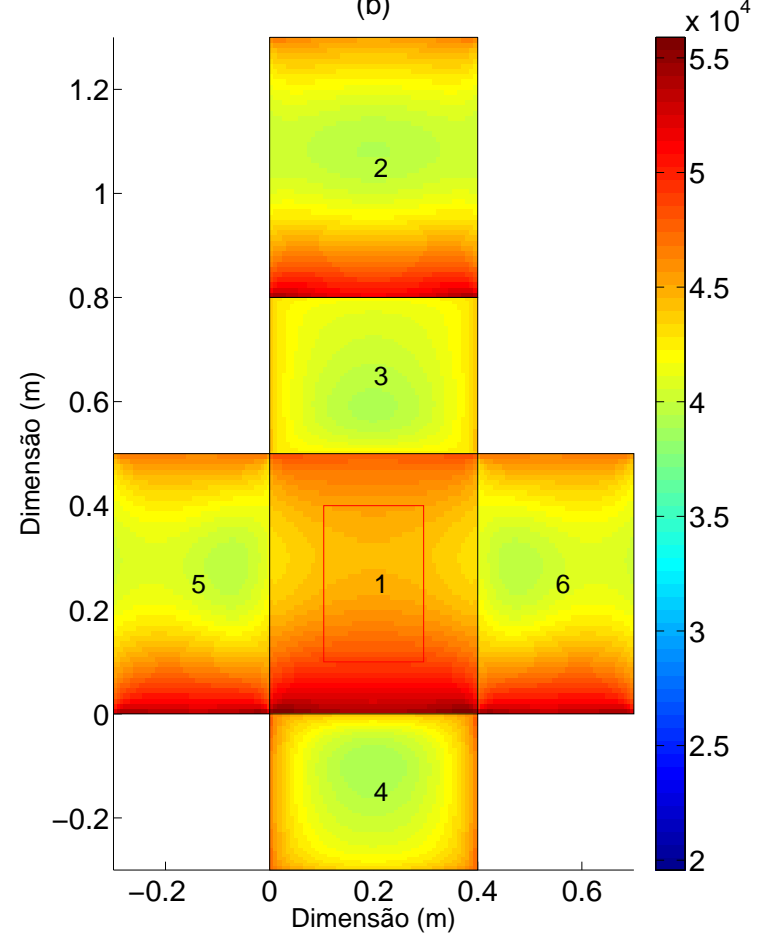

Figura 5.12: Irradiações $\left(W / m^{2}\right)$ para o segundo caso de maximização da irradiação, sem restrição de volume: (a) antes da otimização (b) depois da otimização. 
(a)

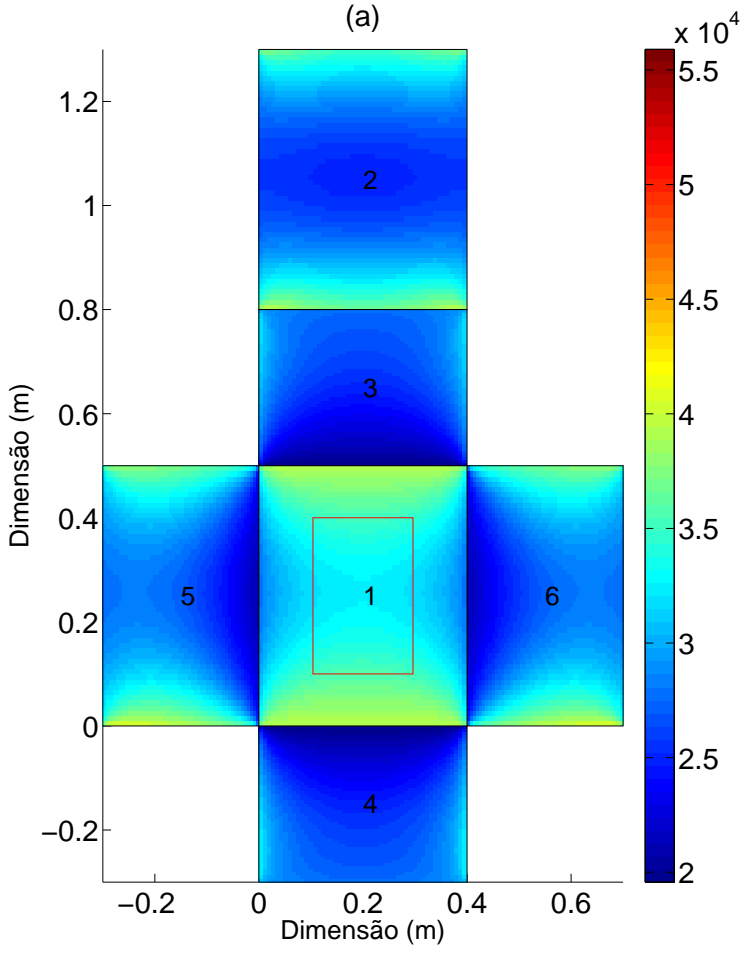

(b)

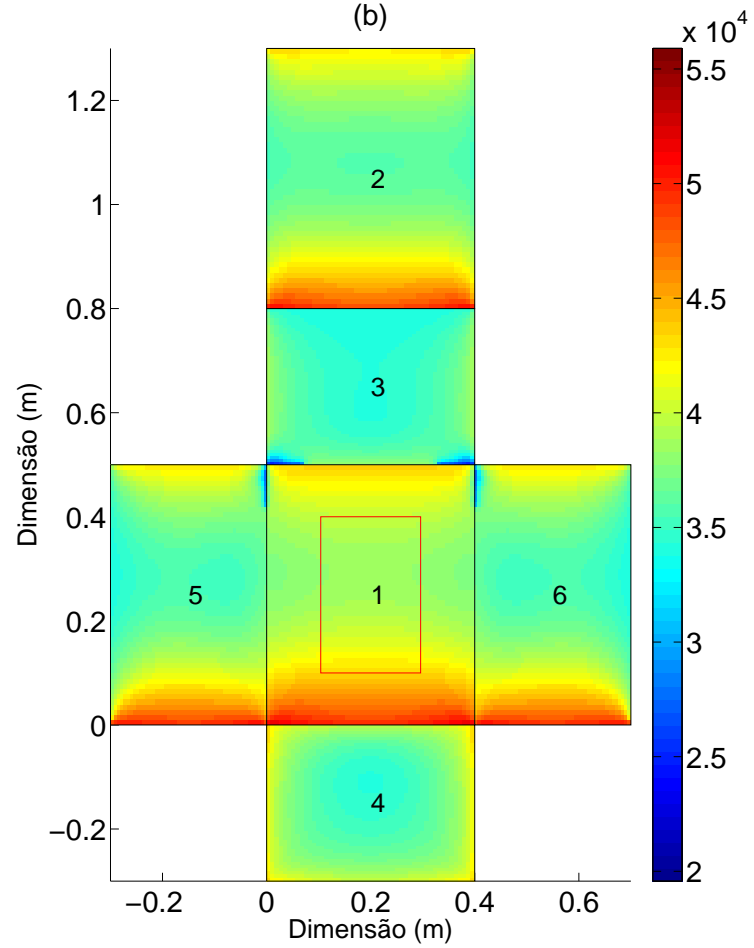

Figura 5.13: Irradiações $\left(W / m^{2}\right)$ para o segundo caso de maximização da irradiação, com restrição de volume de 30\%: (a) antes da otimização (b) depois da otimização.

\subsubsection{Caso 3}

O terceiro caso procura reproduzir um ambiente similar ao de um forno elétrico. Desta forma, aquecedores, representados por retângulos azuis na Figura 5.14, são posicionados nas paredes laterais de um confinamento. Para este caso, o projeto pretendido pode ser enunciado como:

- objetivo: maximização da radiação que chega até o retângulo vermelho apresentado na Figura 5.3b, através da distribuição restrita (40\% do volume total) ou irrestrita de material de refletividade igual a 0,8 ;

- onde: no interior de um confinamento de dimensões $0,4 \times 0,5 \times 0,3 \mathrm{~m}$, malhado com 15000 elementos finitos retangulares;

- condições: sujeito a condições de contorno de temperatura $(K)$ e fluxo de calor $\left(W / m^{2}\right)$ definidas de acordo com a Figura 5.14.

Os gráficos de convergência da função objetivo de maximização da irradiação para o terceiro problema, com e sem restrição de volume, podem ser vistos na Figura 5.15. Em ambos os casos, convergências bem comportadas foram obtidas e poucas variações entre os valores das funções objetivo obtidos nas últimas iterações de otimização e após 


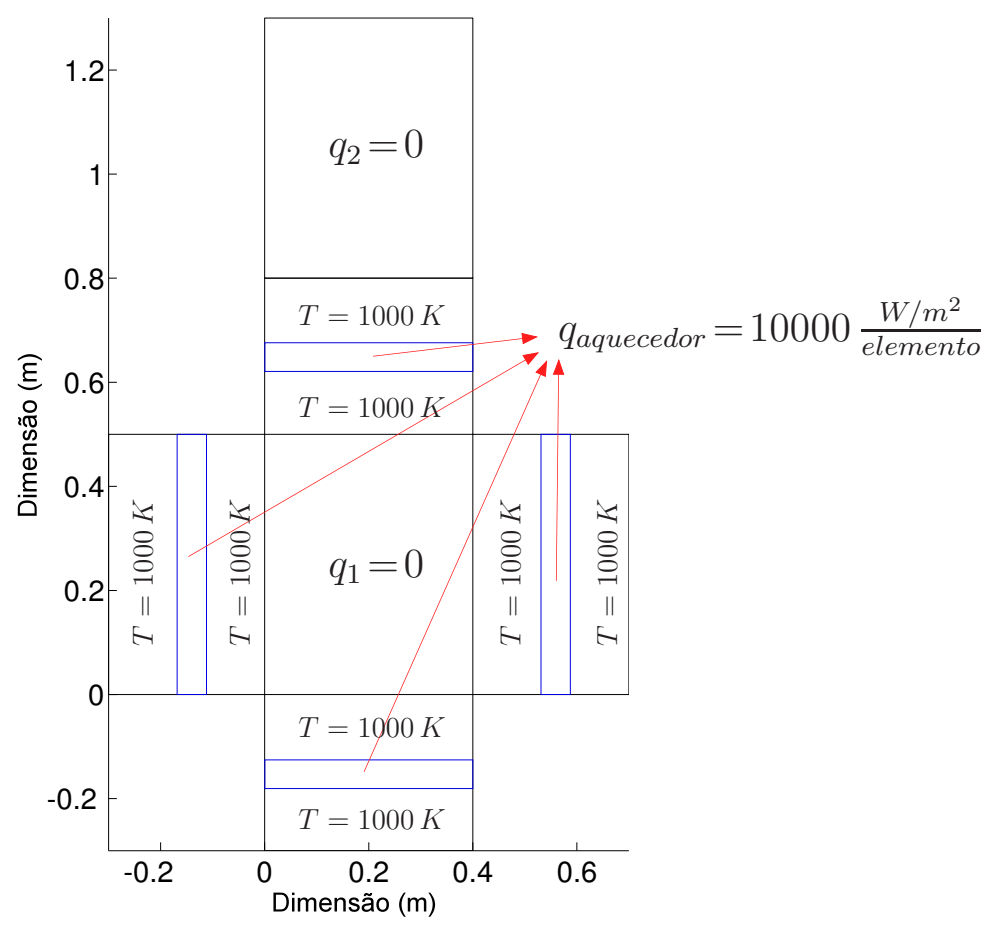

Figura 5.14: Condições de contorno de temperatura $(K)$ e de fluxo de calor $\left(W / m^{2}\right)$ para o terceiro caso de maximização da irradiação.

o pós-processamento dos resultados são verificados (0,11\% para o caso sem restrição de volume e $0,1 \%$ de diferença para o caso com restrição). A descontinuidade observada na Figura 5.15b corresponde a uma transição do método da continuação. Um número maior de iterações para o processo de otimização com restrição de $40 \%$ de volume é necessário para fins de eliminação de regiões cinzas sobre o domínio de projeto.

As distribuições das variáveis de projeto e das refletividades, na última iteração do processo de otimização, podem ser visualizadas nas Figuras 5.16 e 5.17, respectivamente. Nesta última figura, a barra de cores representa os valores da propriedade refletividade. Como é possível observar, resultados praticamente discretos foram obtidos para as simulações com e sem restrição de volume, de forma que julgou-se desnecessário mostrar os resultados pós-processados. Para o projeto em questão, o resultado obtido sem restrição de volume preenche todo o domínio de projeto considerado (lembrando, como visto no início deste capítulo, que áreas com fluxo de calor prescrito não fazem parte deste domínio), o que não necessariamente, como discutido nos dois casos anteriores, é um padrão de solução. O resultado obtido com restrição de volume de $40 \%$ apresenta uma distribuição de material claramente não óbvia, o que mostra, entre muitos possíveis aspectos, a eficiência virtual da otimização topológica para fins de projeto do interior de fornos elétricos.

É possível visualizar nas Figuras 5.18 e 5.19 as diferenças entre as distribuições de irradiações sobre o domínio de projeto antes e depois do processo de otimização topológica, para os casos sem e com restrição de volume, respectivamente. A região delimitada 

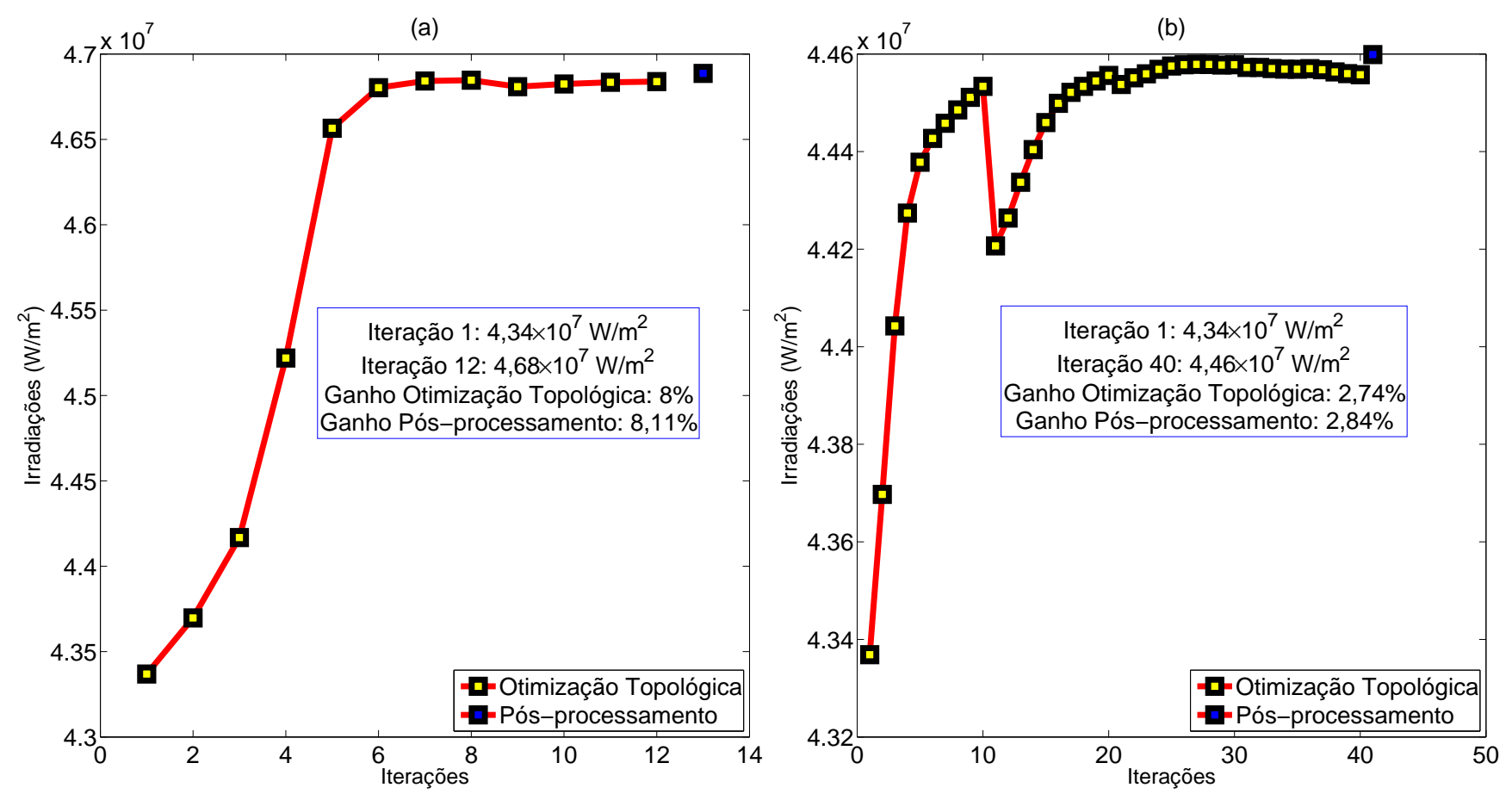

Figura 5.15: Convergência da função objetivo para o terceiro caso de maximização da irradiação: (a) sem restrição de volume (b) com restrição de volume de $40 \%$.

(a)

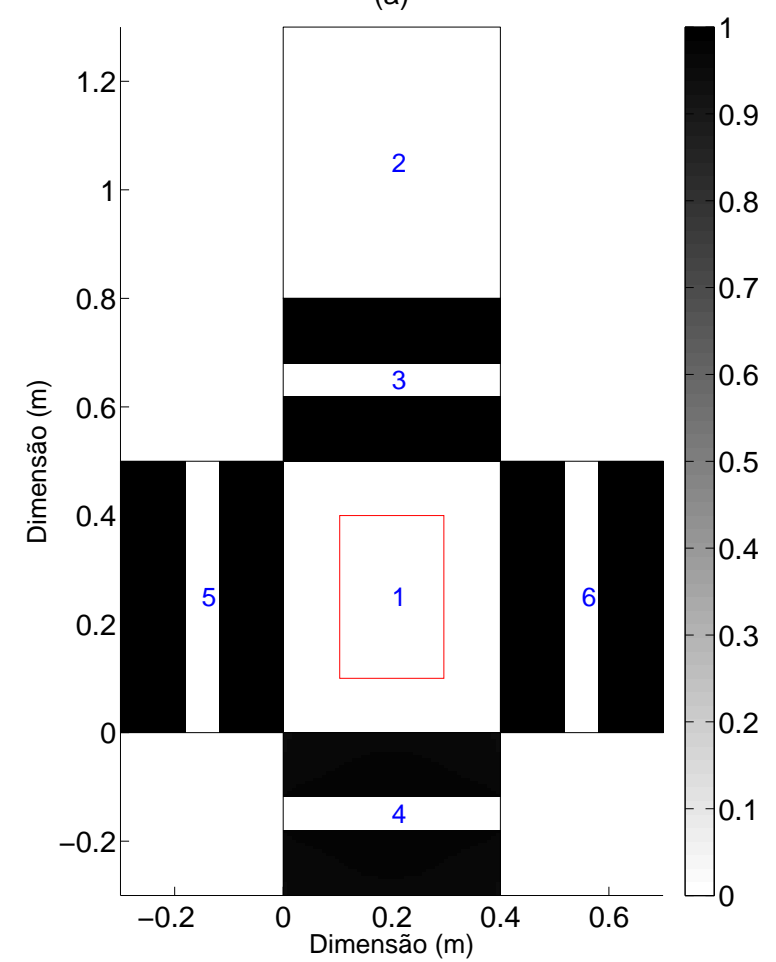

(b)

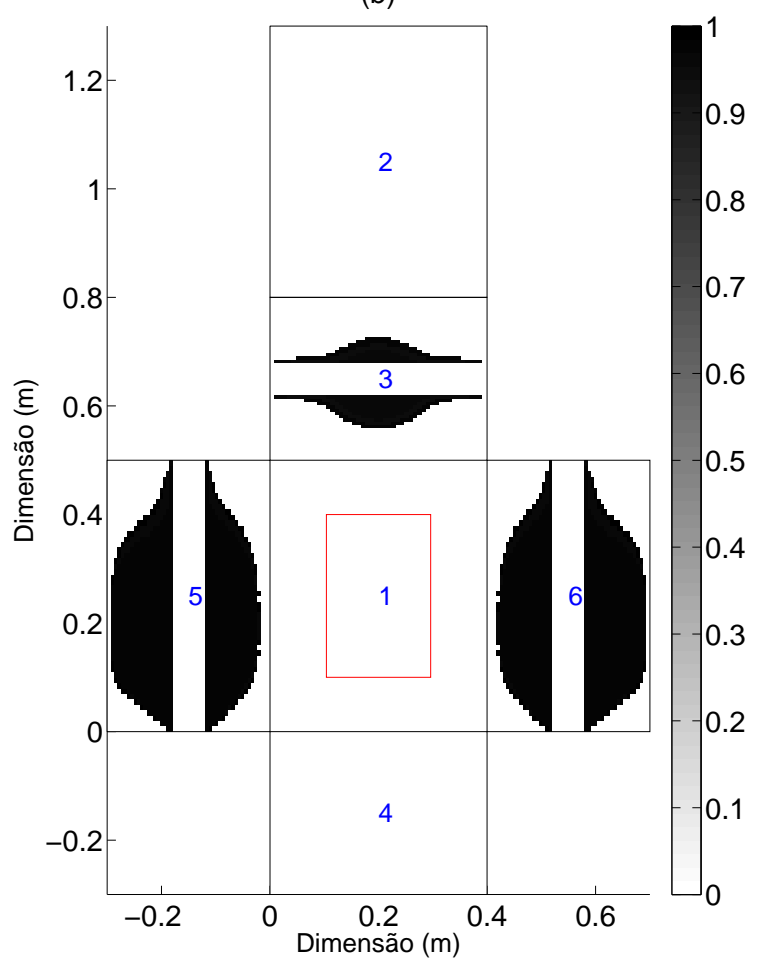

Figura 5.16: Distribuição das variáveis de projeto para o terceiro caso de maximização da irradiação na última iteração do processo de otimização topológica: (a) sem restrição de volume (b) com restrição de volume de $40 \%$.

pelo retângulo vermelho na Figura 5.18a teve um aumento de 8,11\% na intensidade de incidência de radiação para o caso sem restrição de volume. Já para o caso com restrição de $40 \%$ de volume na distribuição de material de refletividade 0,8 , a intensidade de radiação 
(a)

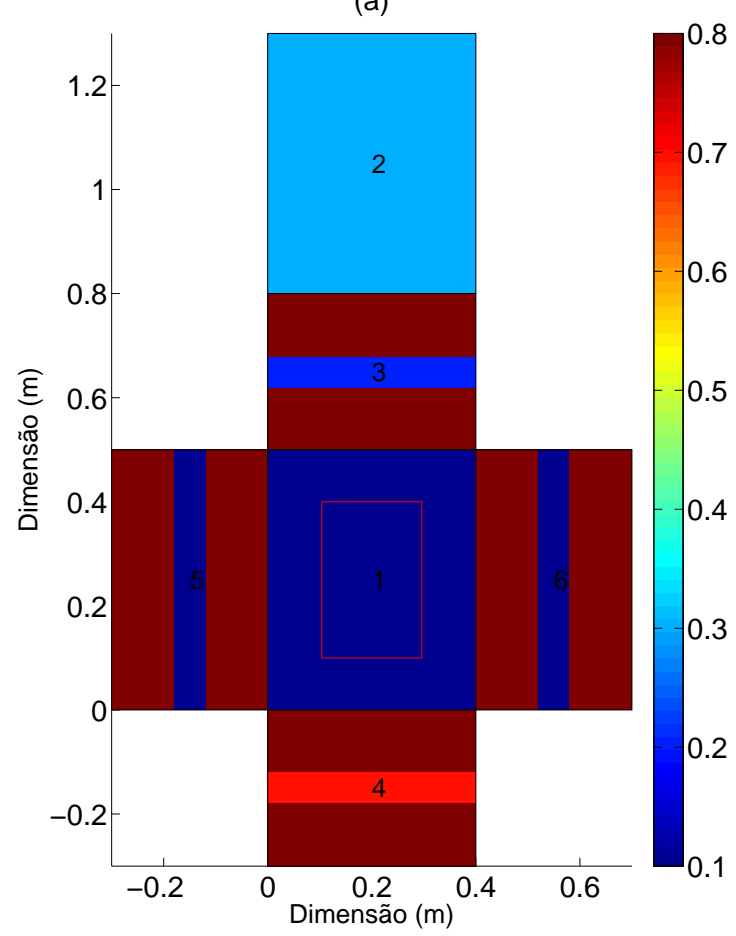

(b)

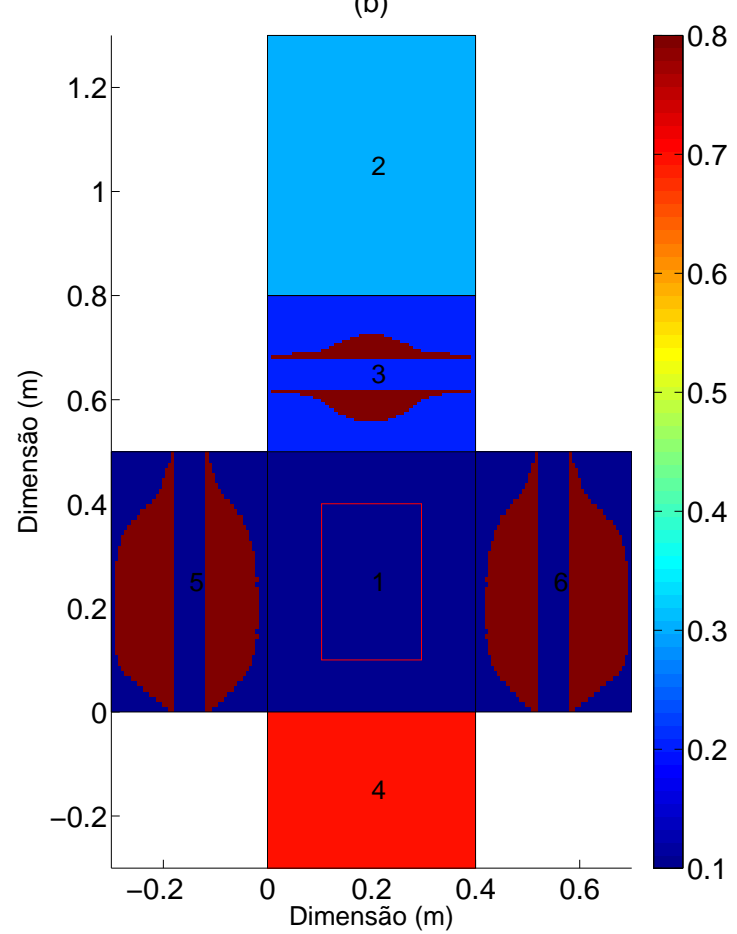

Figura 5.17: Distribuição de material de refletividade igual a 0,8 para o terceiro caso de maximização da irradiação: (a) sem restrição de volume (b) com restrição de volume de $40 \%$.

que chega até o retângulo vermelho teve um aumento de 2,84\% após o pós-processamento da otimização topológica, resultados satisfatórios para este tipo de projeto.

O terceiro exemplo tratou do projeto de fornos elétricos. Este tipo de forno produz calor por efeito Joule, o que exige um consumo significativo de energia elétrica. Neste sentido, uma modificação que contribua para melhorar a eficiência energética deste processo representa uma clara economia no custo de operação. Fica evidente, pelos resultados apresentados, que a otimização topológica, além de permitir soluções customizadas, também é capaz de projetar o interior de fornos elétricos que apresentem economia no consumo de energia elétrica.

\subsection{Minimização da Irradiação}

Algumas aplicações de engenharia, como dispositivos eletrônicos e baterias, têm em comum o fato de que sua eficiência e/ou durabilidade são prejudicadas pelo alto nível de radiação térmica presente no ambiente em que operam. Admitindo-se a necessidade de proteção da radiação que chega a equipamentos como estes, o projeto pretendido nesta seção pode ser enunciado como:

- objetivo: minimização da radiação que chega até o retângulo vermelho apresentado 

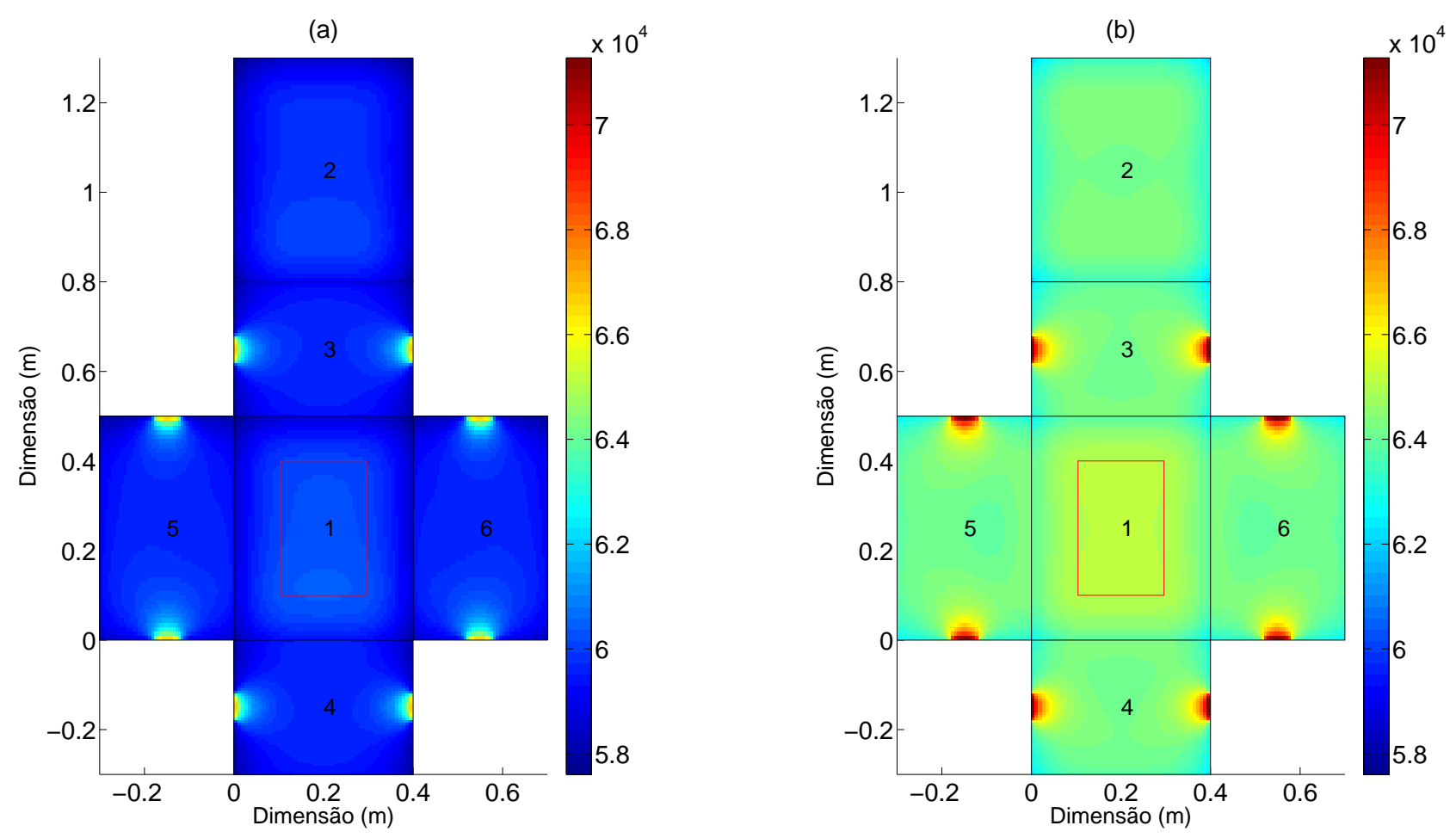

Figura 5.18: Irradiações $\left(W / m^{2}\right)$ para o terceiro caso de maximização da irradiação, sem restrição de volume: (a) antes da otimização (b) depois da otimização.
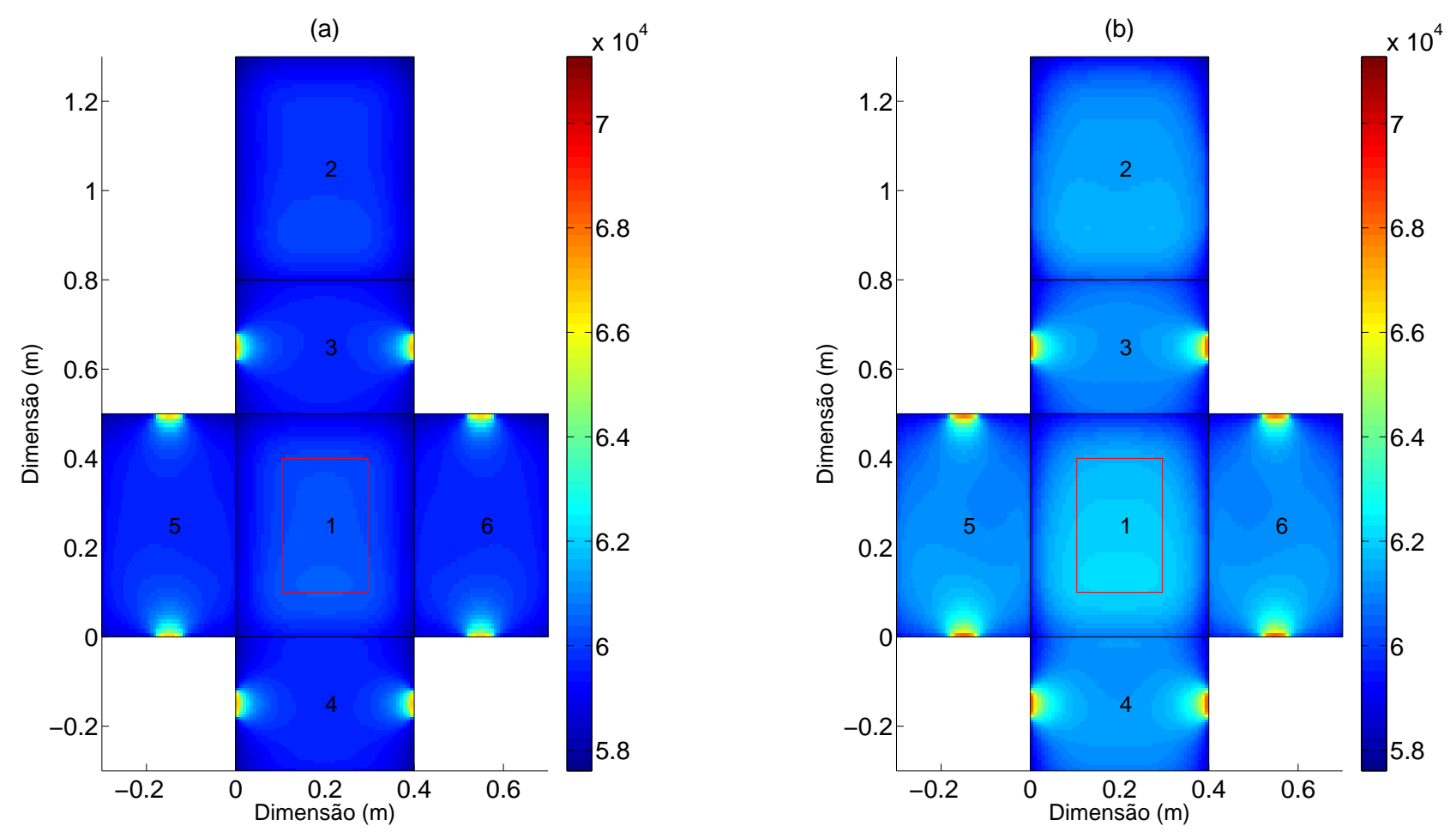

Figura 5.19: Irradiações $\left(W / m^{2}\right)$ para o terceiro caso de maximização da irradiação, com restrição de volume de 40\%: (a) antes da otimização (b) depois da otimização.

na Figura 5.20, através da distribuição restrita (10\% do volume total) ou irrestrita 
de material de refletividade igual a 0,7 ;

- onde: no interior de um confinamento de dimensões $0,1 \times 0,1 \times 0,1 \mathrm{~m}$, malhado com 15000 elementos finitos retangulares;

- condições: paredes que formam o interior do confinamento com as propriedades refletivas dadas por $\boldsymbol{\rho}=\{0,6 ; 0,4 ; 0,2 ; 0,3 ; 0,5 ; 0,6\}$ e condições de contorno definidas como na Figura 5.20.

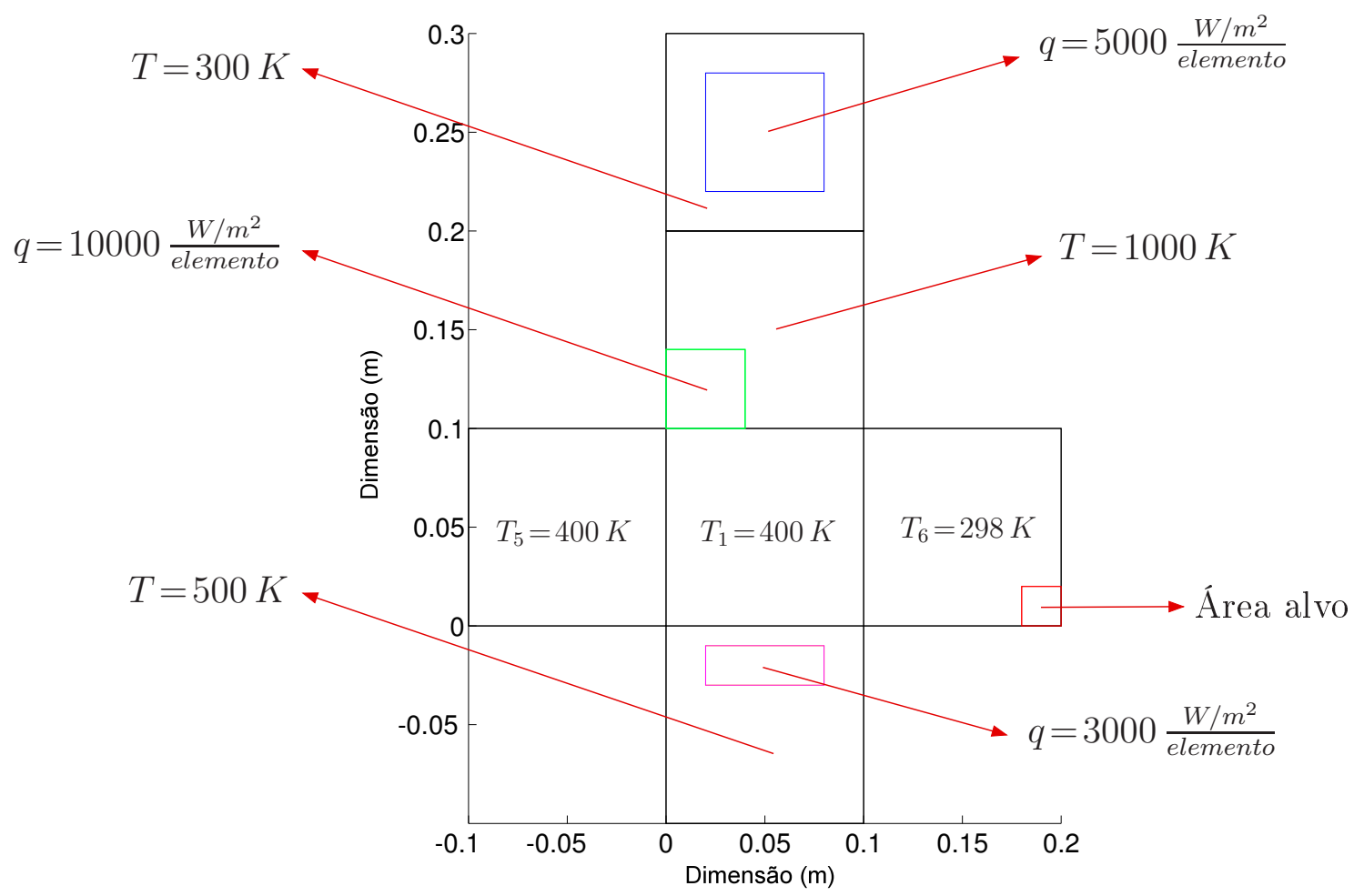

Figura 5.20: Condições de contorno de temperatura $(K)$ e de fluxo de calor $\left(\mathrm{W} / \mathrm{m}^{2}\right)$ para o caso de minimização da irradiação.

Os gráficos de convergência da função objetivo de minimização da irradiação, com e sem restrição de volume, podem ser vistos na Figura 5.21. Em ambos os casos, convergências bem comportadas foram obtidas e poucas variações entre os valores das funções objetivo obtidos nas últimas iterações de otimização e após o pós-processamento dos resultados são verificados ( $0,1 \%$ para o caso sem restrição de volume e $0,4 \%$ de diferença para o caso com restrição). A descontinuidade observada na Figura 5.21b corresponde a uma transição do método da continuação. Um número maior de iterações para o processo de otimização com restrição de $10 \%$ de volume é necessário para fins de eliminação de regiões cinzas sobre o domínio de projeto.

As distribuições das variáveis de projeto, na última iteração do processo de otimização, podem ser visualizadas na Figura 5.22. Fica claro que resultados praticamente discretos foram obtidos para as simulações com e sem restrição de volume, de forma que julgou-se 

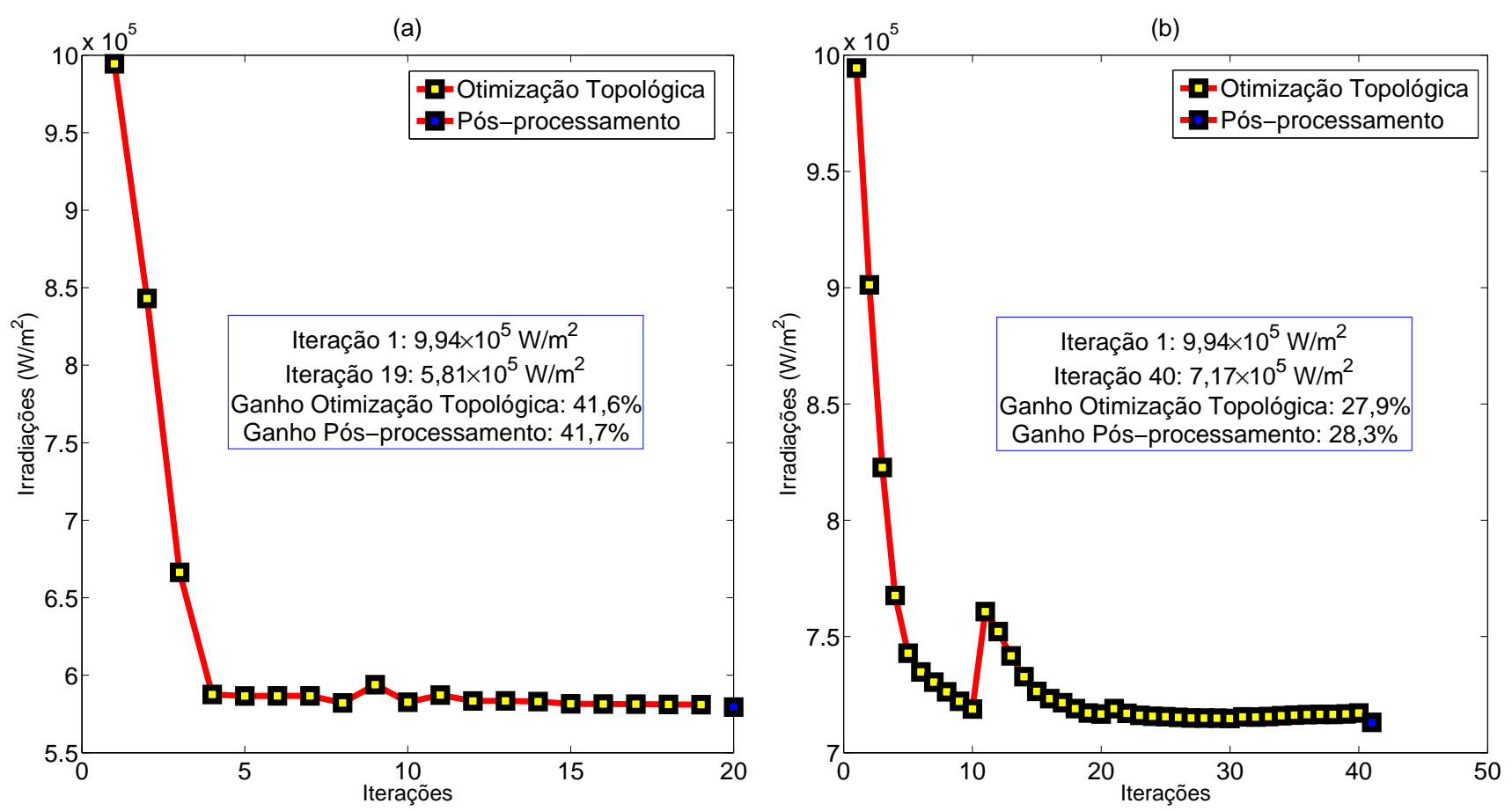

Figura 5.21: Convergência da função objetivo para o segundo caso de minimização da irradiação: (a) sem restrição de volume (b) com restrição de volume de $10 \%$.

desnecessário mostrar os resultados pós-processados. Estes resultados, obtidos com e sem restrição de volume, apresentam uma distribuição de material que sob muitos aspectos pode ser considerada não óbvia, uma vez que para proteger a região alvo da minimização de irradiação, não distribuiu-se sobre ela um material de maior refletividade, como fica claro na Figura 5.23, cuja barra de cores representa os valores da propriedade em questão.

Finalizando este exemplo, é possível visualizar nas Figuras 5.24 e 5.25 as diferenças entre as distribuições de irradiações sobre o domínio de projeto antes e depois do processo de otimização topológica, para os casos sem e com restrição de volume, respectivamente. A região delimitada pelo retângulo vermelho na Figura 5.25a teve uma significativa diminuição de 41,7\% na intensidade de incidência de radiação para o caso sem restrição de volume. Já para o caso com restrição de 10\% de volume na distribuição de material de refletividade 0,7 , a intensidade de radiação que chega até o retângulo vermelho teve uma diminuição de 28,3\% após o processo de otimização topológica, resultado este também bastante satisfatório.

\subsection{Minimização da Temperatura}

O trabalho em ambientes confinados sujeitos à intensa troca de calor por radiação é extremamente desgastante e prejudicial à saúde. Procurando priorizar uma demanda 
(a)

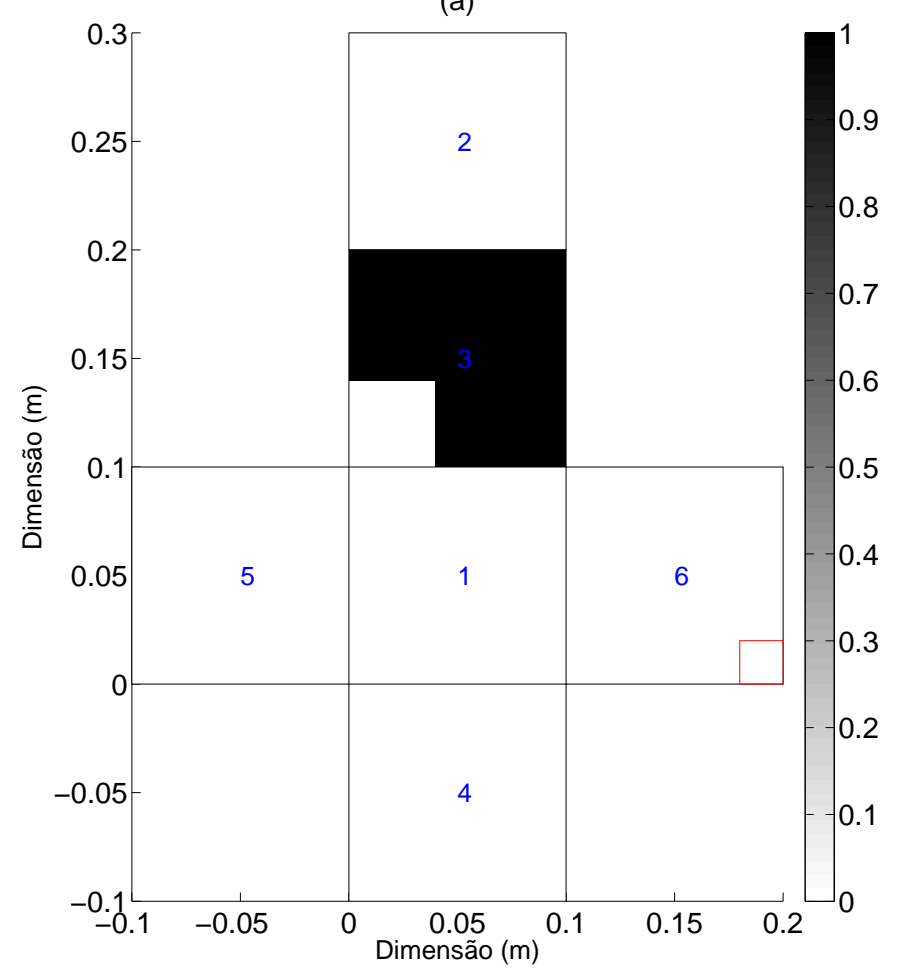

(b)

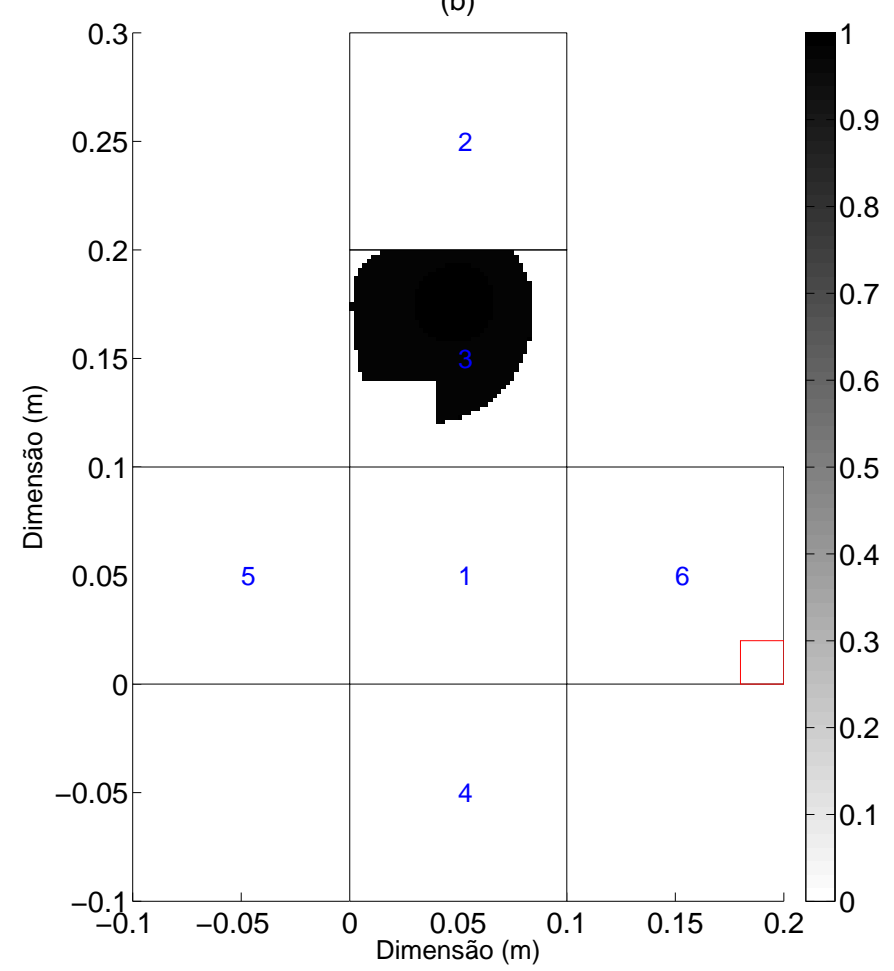

Figura 5.22: Distribuição das variáveis de projeto para o caso de minimização da irradiação na última iteração do processo de otimização topológica: (a) sem restrição de volume (b) com restrição de volume de $10 \%$.

(a)

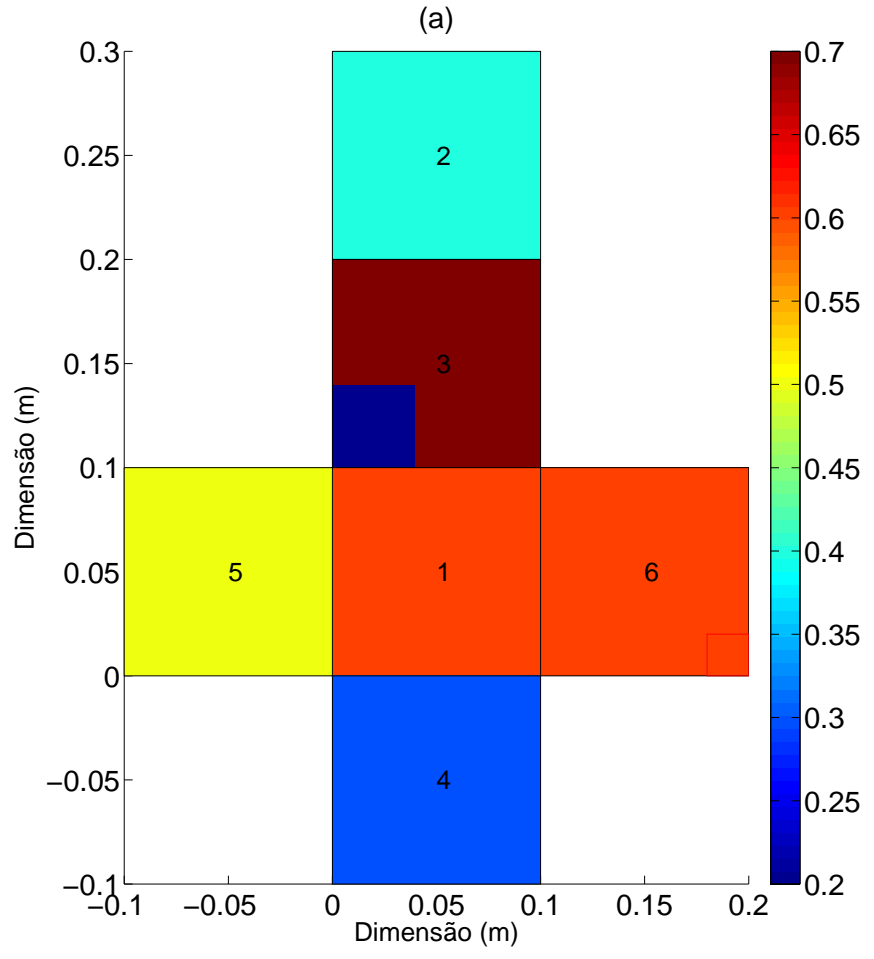

(b)

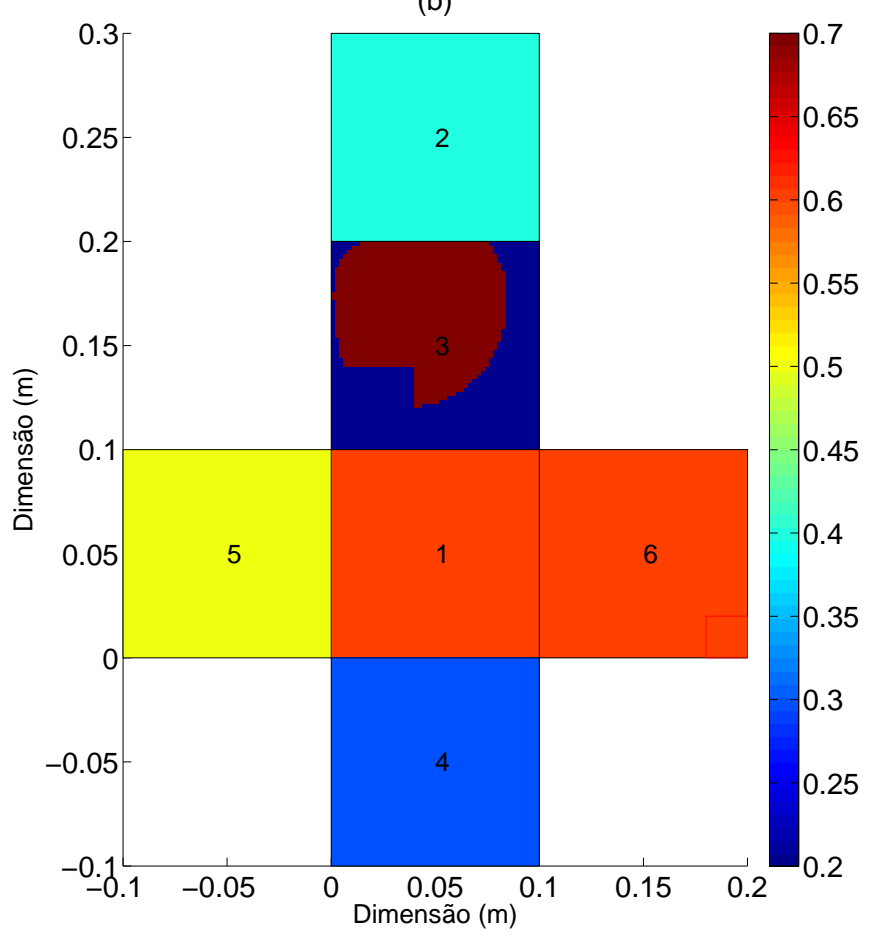

Figura 5.23: Distribuição de material de refletividade igual a 0,7 para o caso de minimização da irradiação: (a) sem restrição de volume (b) com restrição de volume de $10 \%$. 

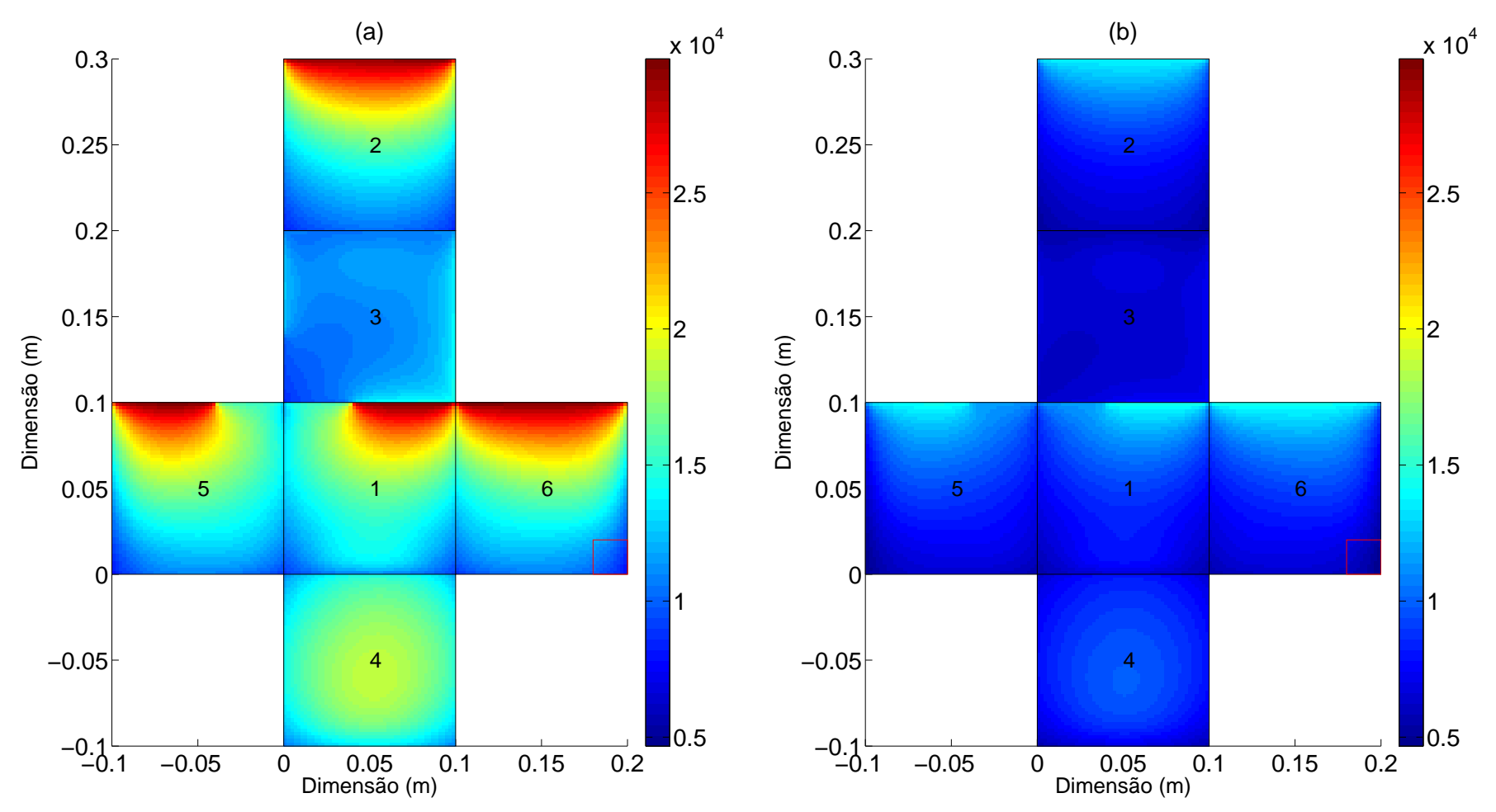

Figura 5.24: Irradiações $\left(W / m^{2}\right)$ para o caso de minimização da irradiação, sem restrição de volume: (a) antes da otimização (b) depois da otimização.
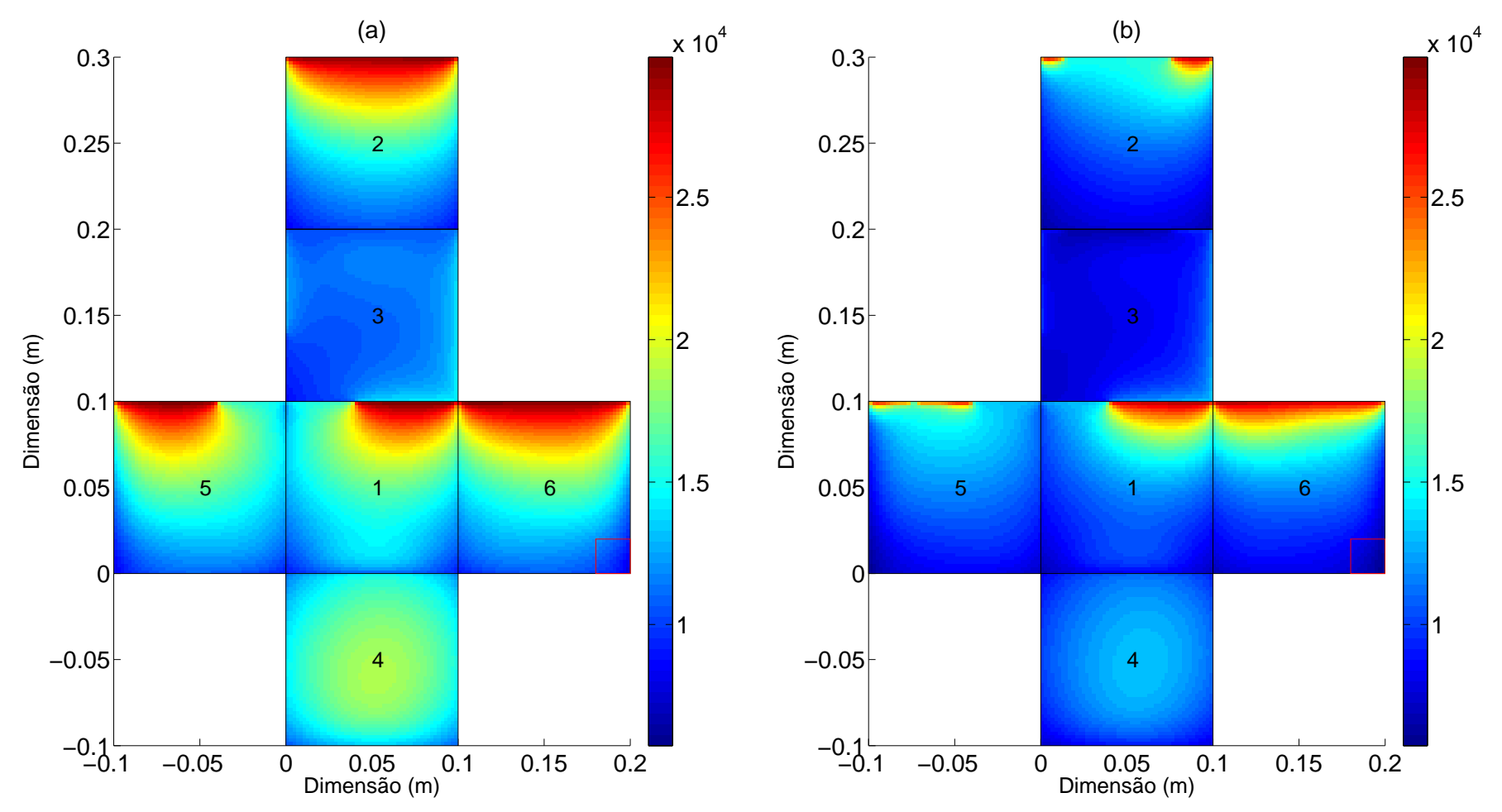

Figura 5.25: Irradiações $\left(W / m^{2}\right)$ para o caso de minimização da irradiação, com restrição de volume de 10\%: (a) antes da otimização (b) depois da otimização.

por conforto térmico/proteção de radiação em ambientes como este, o projeto pretendido 
nesta seção pode ser enunciado como:

- objetivo: minimização da temperatura que chega até o retângulo vermelho apresentado na Figura 5.26, através da distribuição restrita (30\% do volume total) ou irrestrita de material de refletividade igual a 0,8 ;

- onde: no interior de um confinamento de dimensões $0,1 \times 0,1 \times 0,1 \mathrm{~m}$, malhado com 9600 elementos finitos retangulares (menos elementos que nos problemas anteriores, pois o custo computacional de análise da função objetivo em questão é maior);

- condições: paredes que formam o interior do confinamento com as propriedades refletivas dadas por $\boldsymbol{\rho}=\{0,7 ; 0,7 ; 0,5 ; 0,5 ; 0,6 ; 0,6\}$ e condições de contorno definidas como na Figura 5.26.

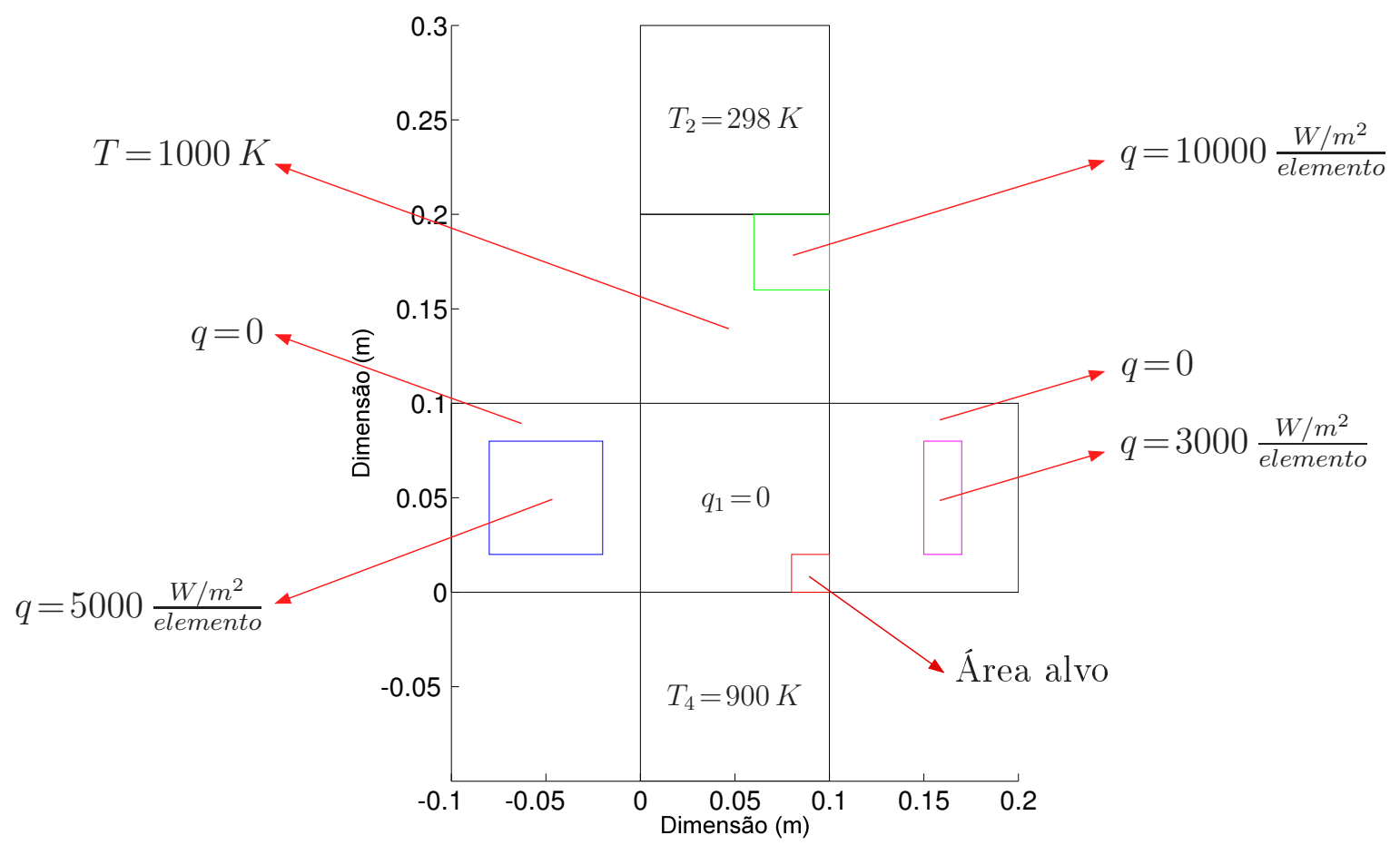

Figura 5.26: Condições de contorno de temperatura $(K)$ e de fluxo de calor $\left(W / m^{2}\right)$ para o caso de minimização da temperatura.

Os gráficos de convergência da função objetivo de minimização da irradiação, com e sem restrição de volume, podem ser visualizados na Figura 5.27. Em ambos os casos, convergências bem comportadas foram obtidas e poucas variações (apenas 0,02\% de diferença) entre os valores das funções objetivo obtidos nas últimas iterações de otimização e após o pós-processamento dos resultados são verificados. A descontinuidade observada na Figura 5.27b corresponde a uma transição do método da continuação. Um número maior de iterações para o processo de otimização com restrição de $30 \%$ de volume é necessário para fins de eliminação de regiões cinzas sobre o domínio de projeto. 

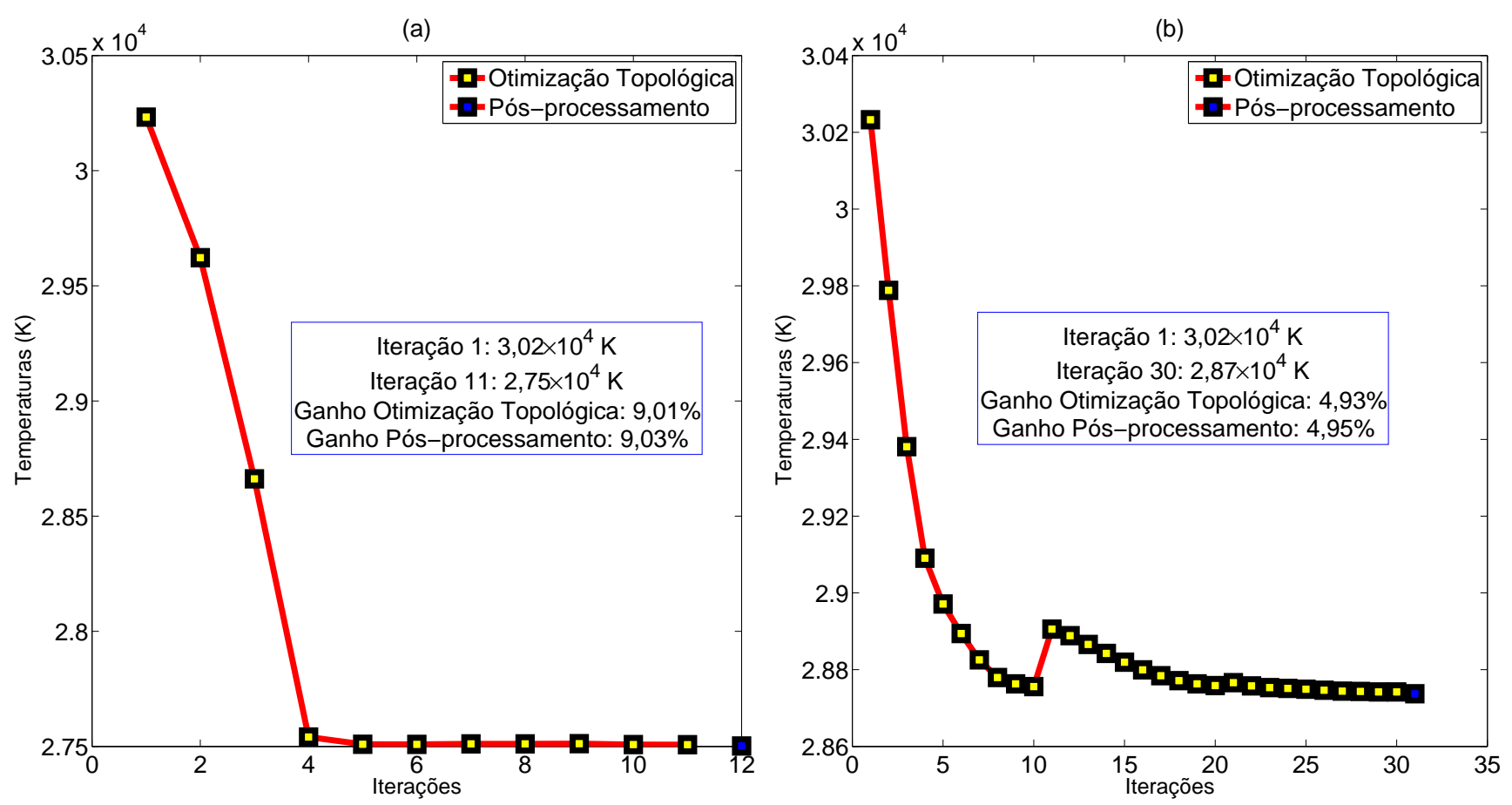

Figura 5.27: Convergência da função objetivo para o caso de minimização da temperatura: (a) sem restrição de volume (b) com restrição de volume de $30 \%$.

As distribuições das variáveis de projeto, na última iteração do processo de otimização, podem ser visualizadas na Figura 5.28. Fica claro que resultados praticamente discretos foram obtidos para as simulações com e sem restrição de volume, de forma que julgou-se desnecessário mostrar os resultados pós-processados. Estes resultados, obtidos com e sem restrição de volume, apresentam uma distribuição de material que sob muitos aspectos pode ser considerada não óbvia, uma vez que para proteger a região alvo da minimização de temperatura, não distribuiu-se sobre ela um material de maior refletividade, como fica claro na Figura 5.29, cuja barra de cores representa os valores da propriedade refletividade.

Finalizando este exemplo, é possível visualizar nas Figuras 5.30 e 5.31 as diferenças entre as distribuições de temperaturas sobre o domínio de projeto antes e depois do processo de otimização topológica, para os casos sem e com restrição de volume, respectivamente. A região delimitada pelo retângulo vermelho na Figura 5.31a teve uma queda de 9,03\% na intensidade de temperatura para o caso sem restrição de volume. Já para o caso com restrição de $30 \%$ de volume na distribuição de material de refletividade 0,8, a intensidade de temperatura sobre o retângulo vermelho teve uma queda de 4,95\% após o processo de otimização topológica, resultado este também bastante satisfatório. 
(a)

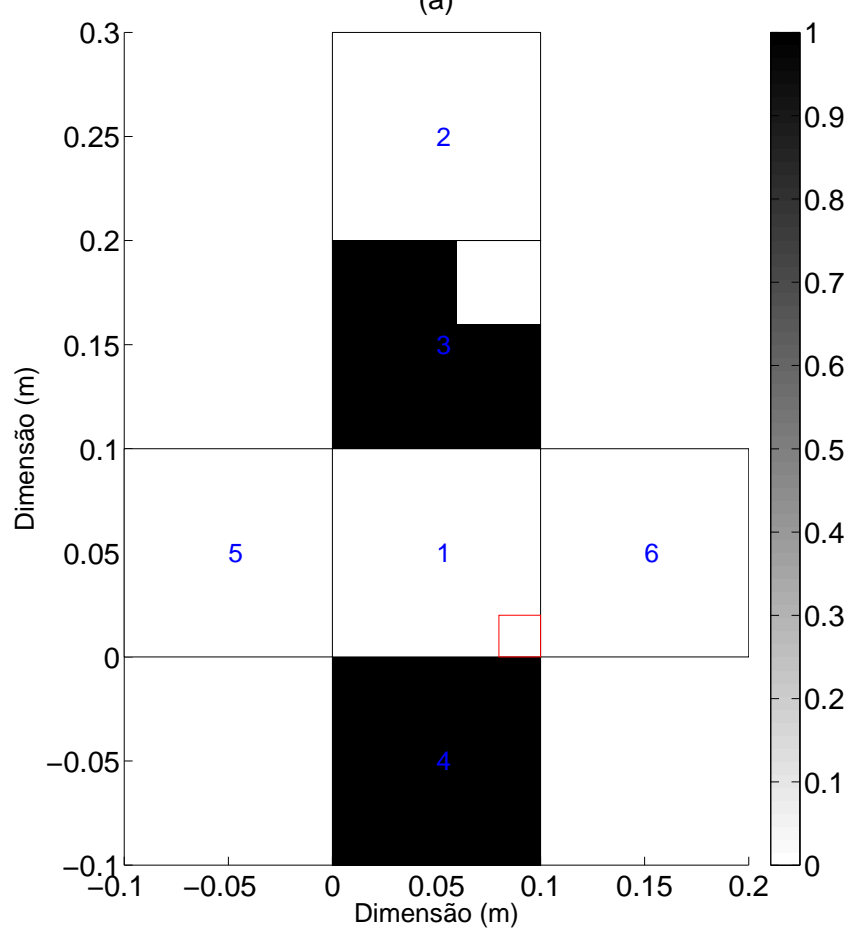

(b)

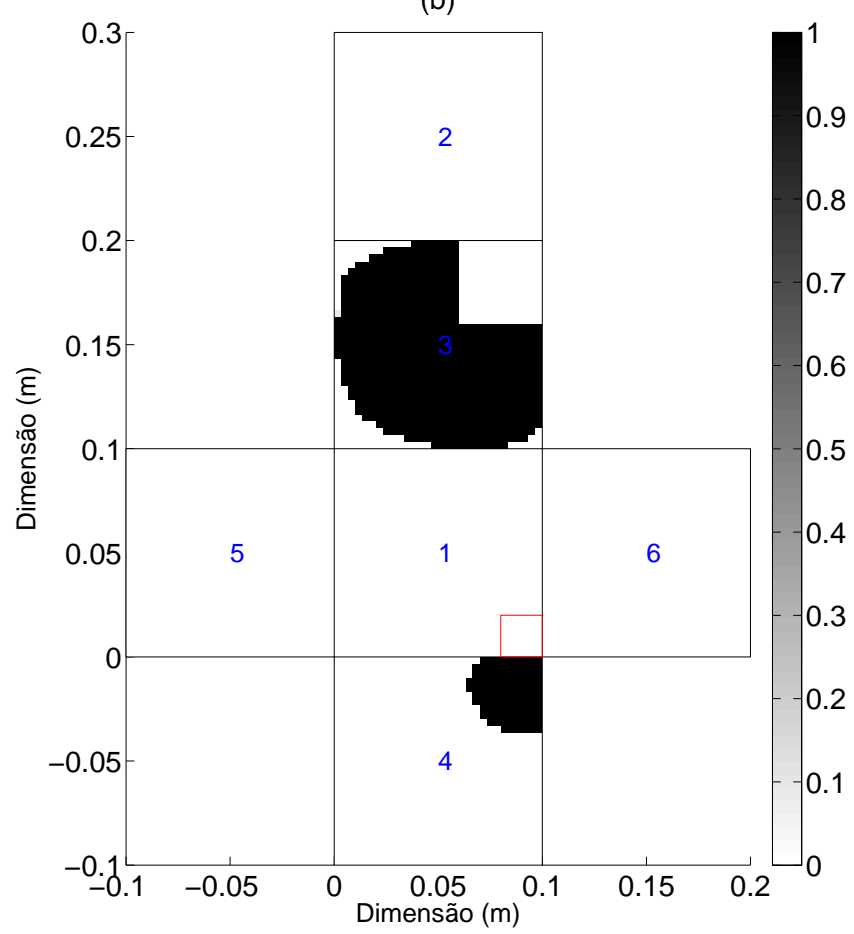

Figura 5.28: Distribuição das variáveis de projeto para o caso de minimização da temperatura na última iteração do processo de otimização topológica: (a) sem restrição de volume (b) com restrição de volume de $30 \%$.

(a)

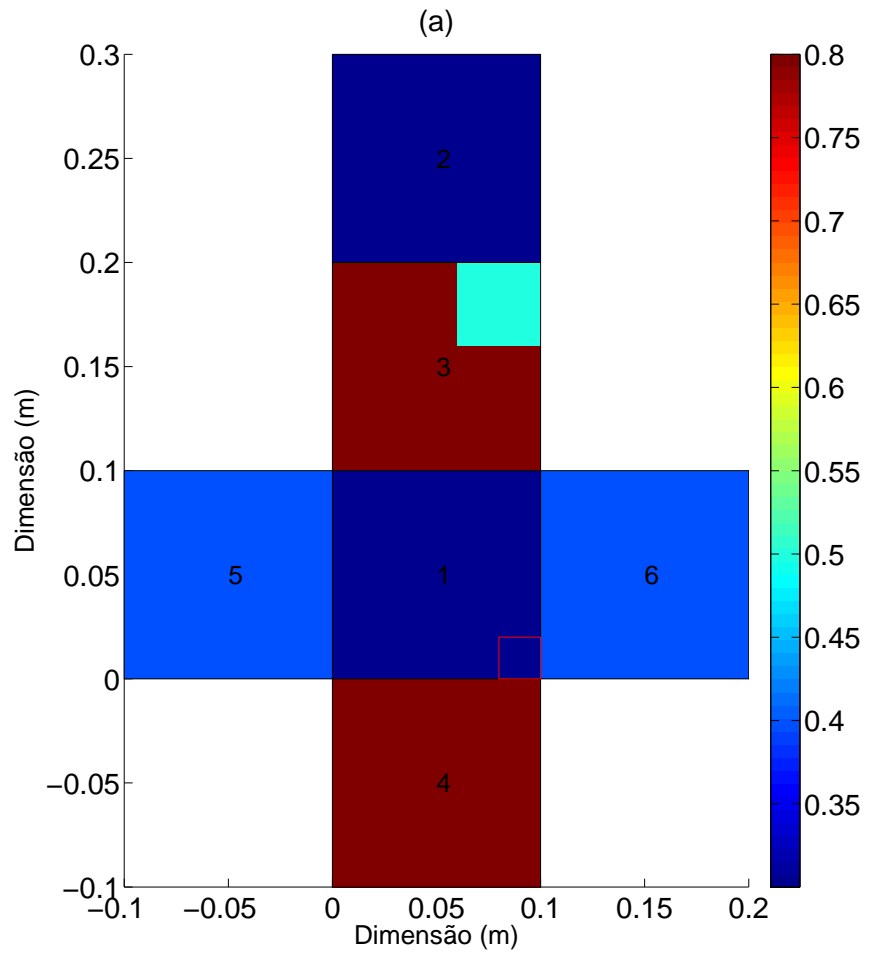

(b)

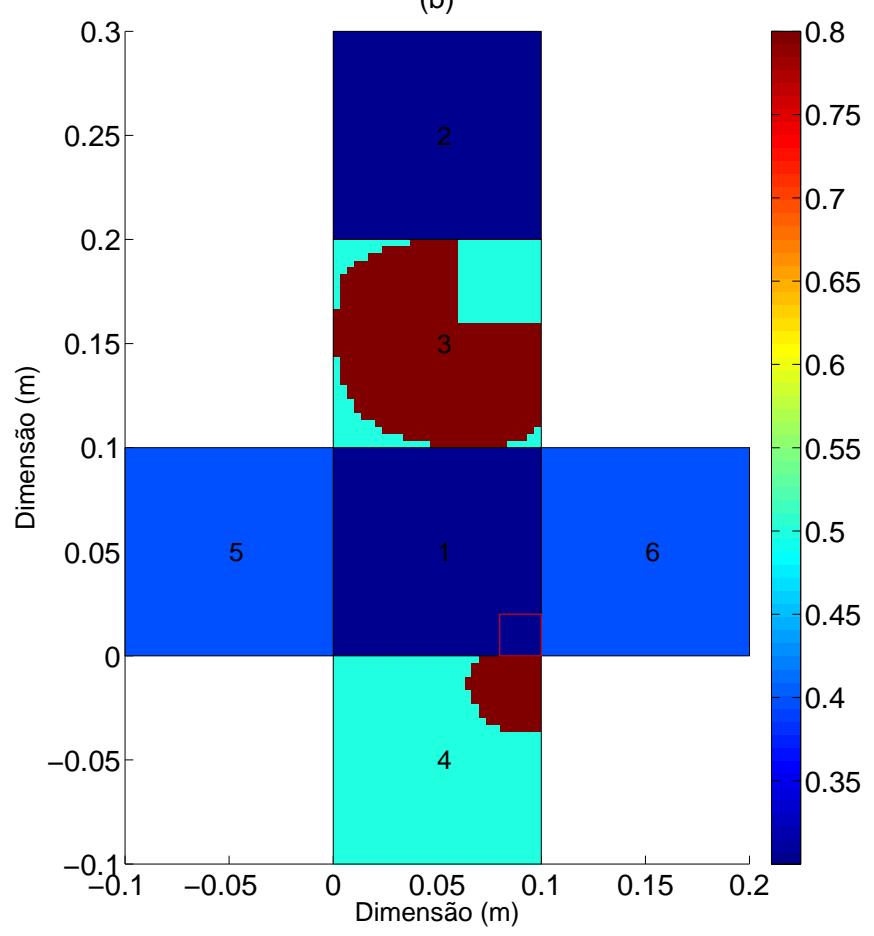

Figura 5.29: Distribuição de material de refletividade igual a 0,8 para o caso de minimização da irradiação: (a) sem restrição de volume (b) com restrição de volume de $30 \%$. 

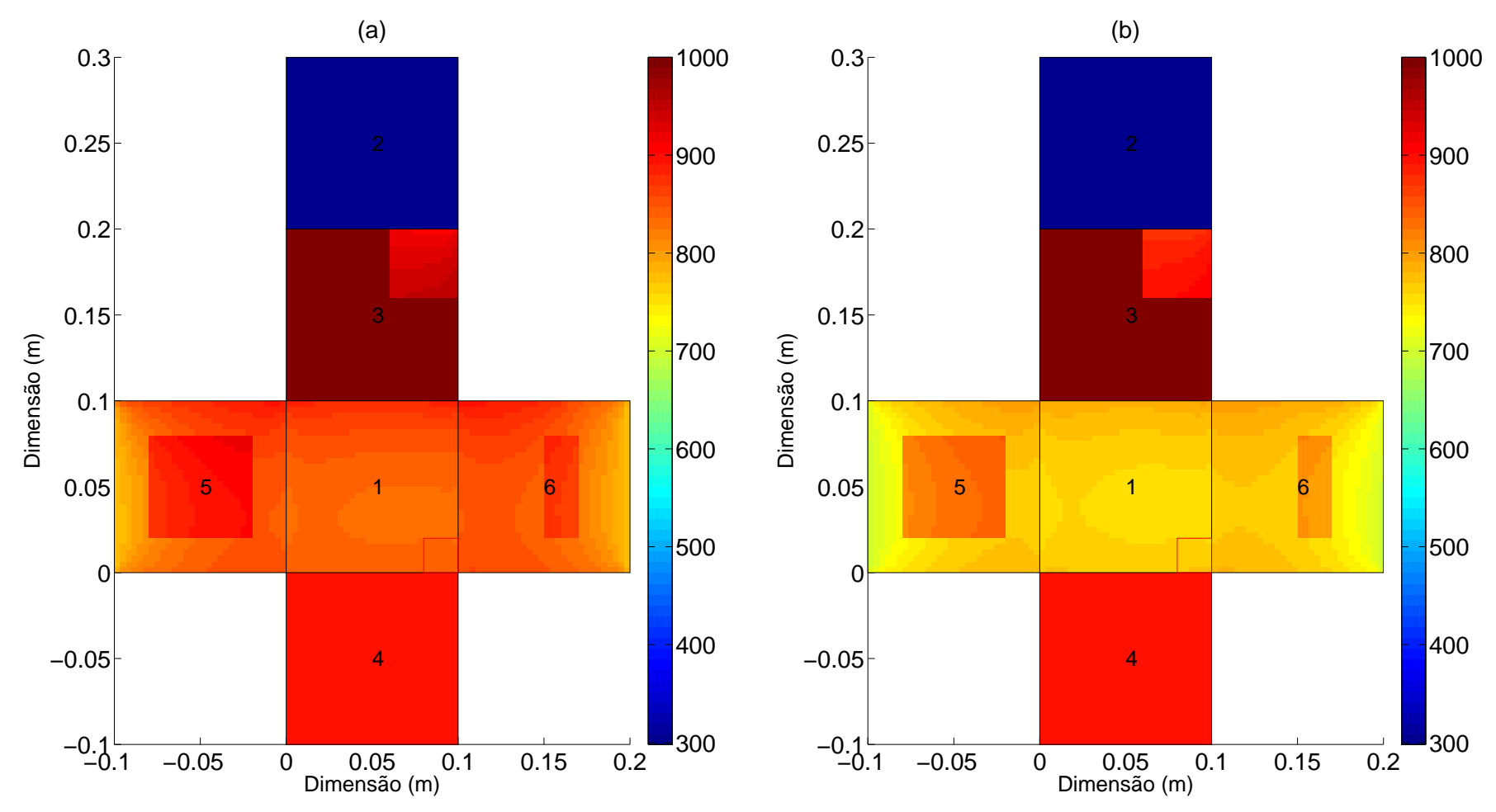

Figura 5.30: Temperaturas $(K)$ para o caso de minimização da temperatura, sem restrição de volume: (a) antes da otimização (b) depois da otimização.
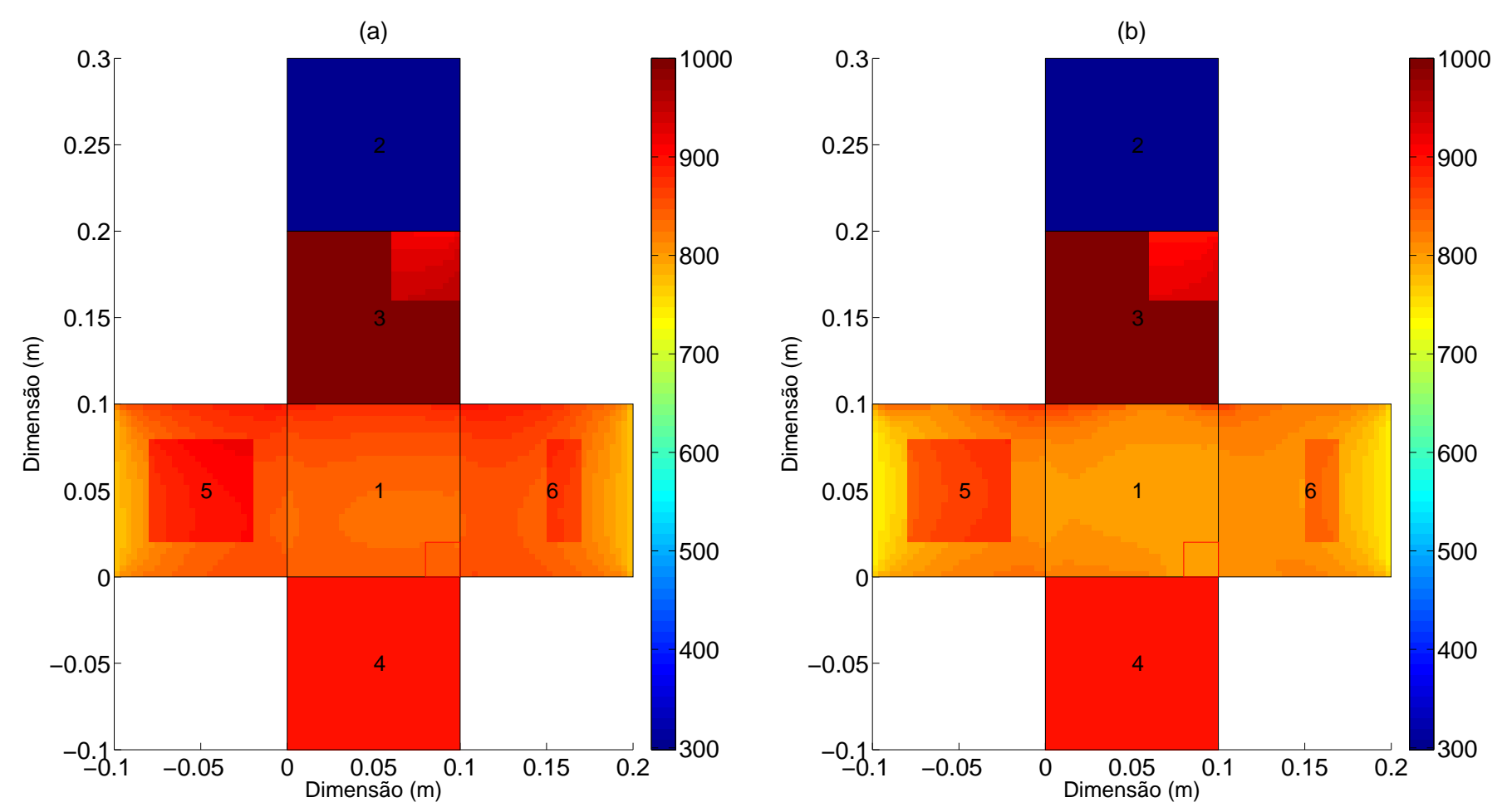

Figura 5.31: Temperaturas $(K)$ para o caso de minimização da temperatura, com restrição de volume de 30\%: (a) antes da otimização (b) depois da otimização.

\subsection{Distribuição de Aquecedores}

Nesta seção, a trivial demanda no projeto de fornos, que se preocupa em entender qual o número otimizado de aquecedores a ser utilizado e onde estes devem estar posicionados 
de forma a se ter um funcionamento mais eficiente deste equipamento, é estudada através de um caso de maximização da irradiação, em que a área alvo da otimização não faz parte do domínio de projeto (não se tem a opção de distribuir aquecedores sobre ela). O problema em questão pode ser enunciado como:

- objetivo: maximização da radiação que chega até o retângulo vermelho apresentado na Figura 5.3b, através da distribuição restrita (30\% do volume total) ou irrestrita de aquecedores;

- onde: no interior de um confinamento de dimensões $0,4 \times 0,5 \times 0,3 \mathrm{~m}$, malhado com 15000 elementos finitos retangulares;

- condições: segundo a abordagem apresentada na seção 4.3.2, ou o otimizador decide que o elemento será um aquecedor que gera $10000 \mathrm{~W} / \mathrm{m}^{2}$, caso em que a variável de projeto é unitária, ou um elemento com temperatura de $1100 \mathrm{~K}$, caso em que a variável de projeto é nula. Portanto, inicialmente todos os elementos possuem ao mesmo tempo estes valores de fluxo de calor e de temperatura. Além disso, as paredes que formam o interior do confinamento tem propriedades refletivas dadas por $\boldsymbol{\rho}=\{0,5 ; 0,5 ; 0,5 ; 0,5 ; 0,5 ; 0,5\}$.

Os gráficos de convergência da função objetivo de maximização da irradiação para este problema, com e sem restrição de volume, podem ser vistos na Figura 5.32. Para o caso sem restrição de volume, uma convergência bem comportada é verificada, enquanto que para o caso com restrição de volume grandes saltos são verificados a cada passo do método da continuidade (mudança no valor do penalizador). Um número maior de iterações para o processo de otimização com restrição de $30 \%$ de volume é necessário para fins de eliminação de regiões cinzas sobre o domínio de projeto. Mesmo tomando-se esse cuidado, uma diferença sensível no valor da função objetivo pode ser observada entre a última iteração do processo de otimização e após o pós-processamento. Isto porque o valor de fluxo de calor atribuído aos aquecedores é consideravelmente alto, o que torna qualquer leve modificação nas variáveis de projeto bastante sensível.

As distribuições de aquecedores, na última iteração do processo de otimização, podem ser visualizadas na Figura 5.33. Fica claro que um resultado praticamente discreto foi obtido para o caso sem restrição de volume, o que não ocorreu para o caso com restrição de volume, em que regiões de escala de cinza são claramente identificáveis. O pós-processamento deste último caso não implica em alterações da geometria do resultado, apenas no escurecimento das regiões de cinza, de forma que julgou-se desnecessário mostrá-lo. A despeito da obviedade do resultado sem restrição de volume, em que todo o domínio de projeto é preenchido por aquecedores, o resultado obtido com restrição 

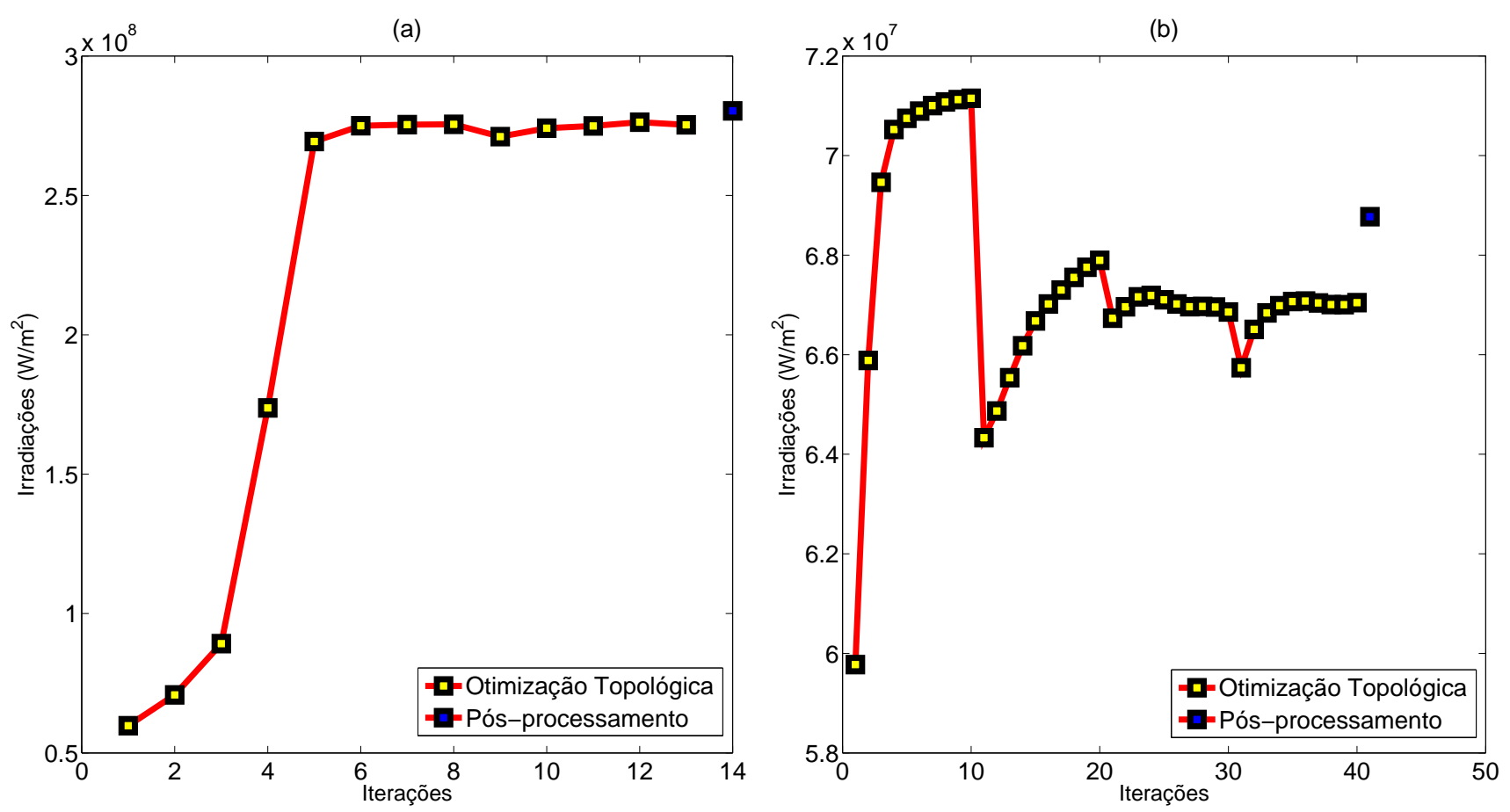

Figura 5.32: Convergência da função objetivo para a maximização da irradiação através da distribuição de aquecedores: (a) sem restrição de volume (b) com restrição de volume de $30 \%$.

de volume apresenta uma distribuição de aquecedores não trivial. Além disso, ambos resultados estão de acordo com a literatura, na medida em que para condições térmicas uniformes em um domínio de projeto tridimensional, a disposição de aquecedores somente na superfície superior de um forno não leva a um resultado otimizado. Isto é alcançado apenas quando os aquecedores são também posicionados nas paredes verticais restantes (CHOPADE et al., 2011a).

Finalizando a discussão deste exemplo, é possível visualizar nas Figuras 5.34 e 5.35 as diferenças entre as distribuições de irradiação sobre o domínio de projeto antes e depois do processo de otimização topológica, para os casos sem e com restrição de $30 \%$ de volume, respectivamente. Para o projeto em questão, não julgou-se pertinente fazer uma comparação de ganho de resultado após a aplicação da otimização topológica, uma vez que, a priori, não se faz uma clara distinção entre elementos com fluxo de calor prescrito (aquecedores) ou com temperatura prescrita no domínio de projeto inicial. 
(a)

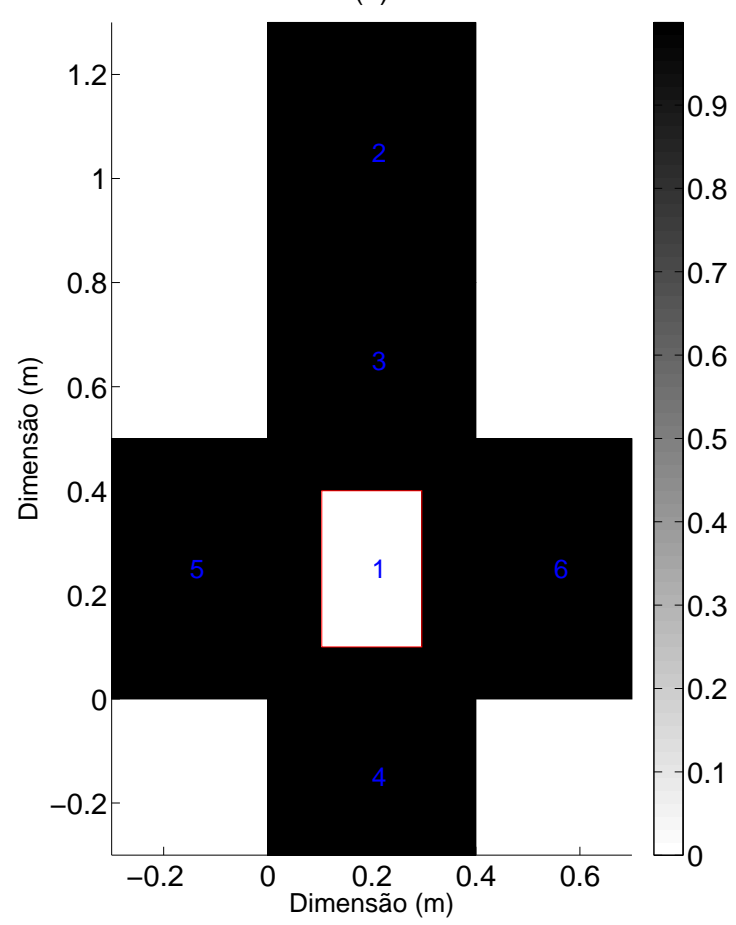

(b)

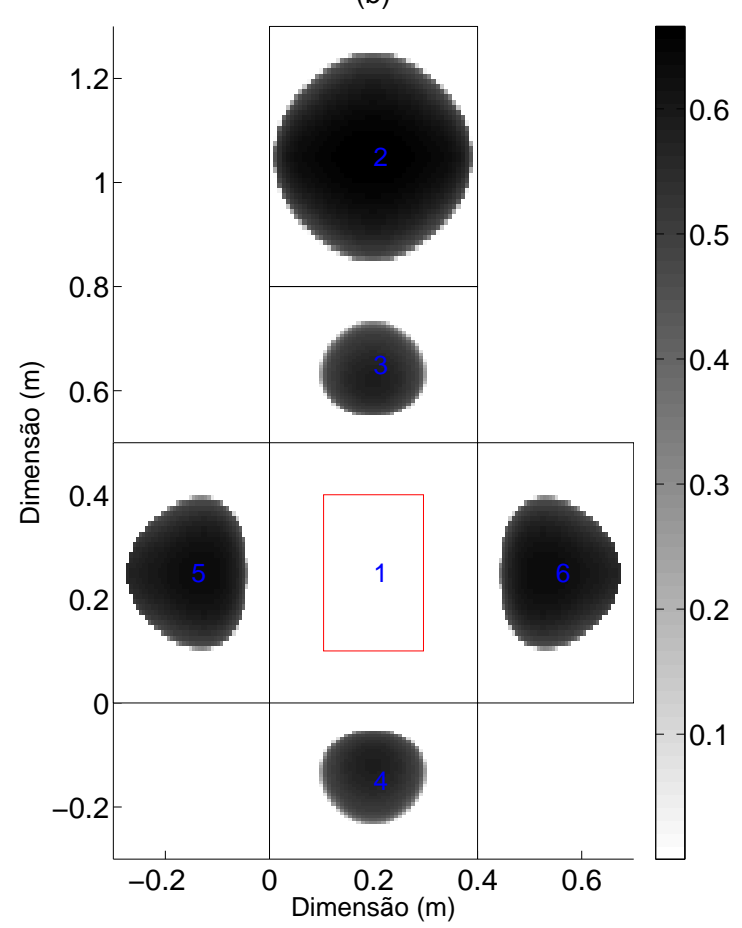

Figura 5.33: Distribuição de aquecedores para a maximização da irradiação na última iteração do processo de otimização topológica: (a) sem restrição de volume (b) com restrição de volume de $30 \%$.

(a)

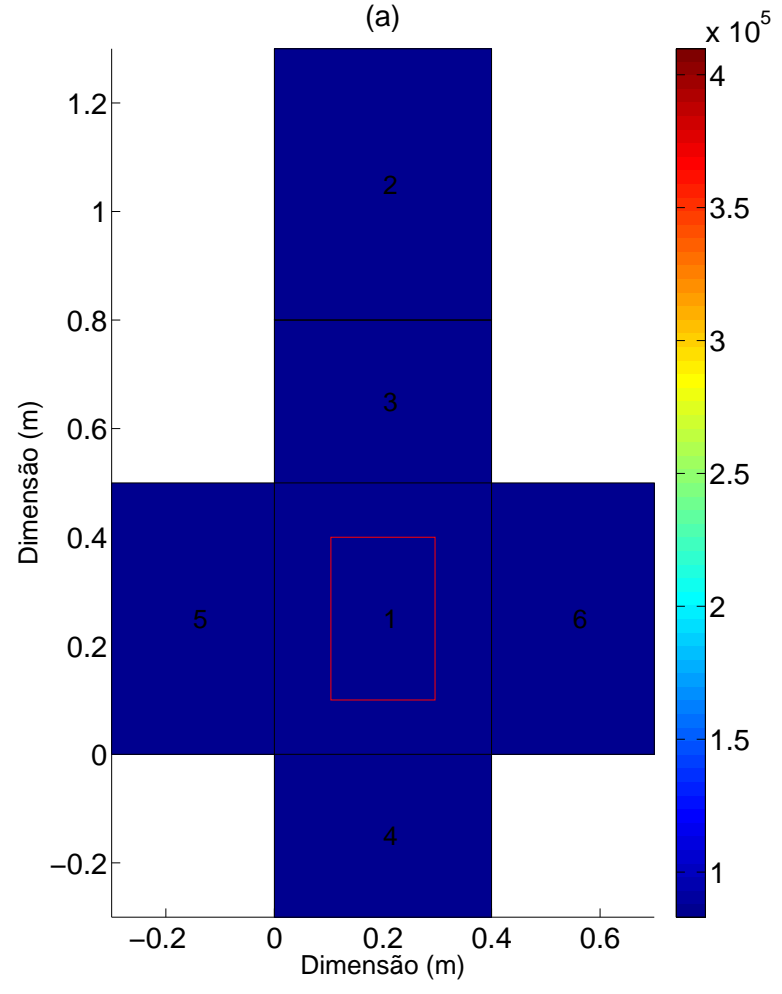

(b)

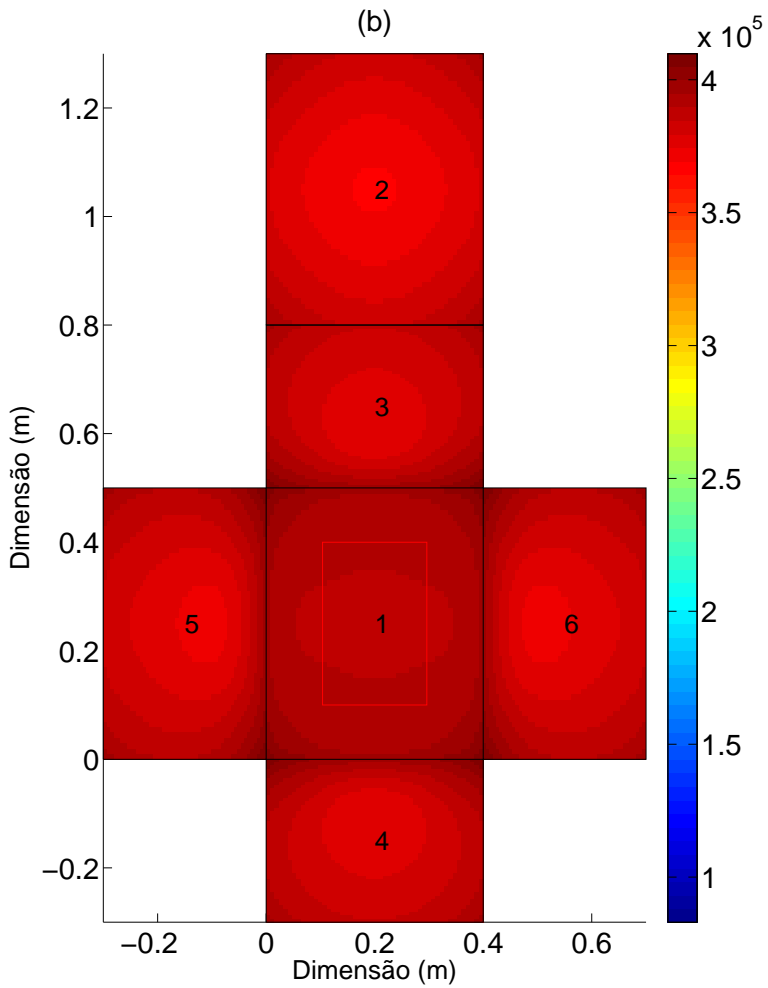

Figura 5.34: Irradiações $\left(W / m^{2}\right)$ para a maximização da irradiação através da distribuição de aquecedores, sem restrição de volume: (a) antes da otimização (b) depois da otimização. 

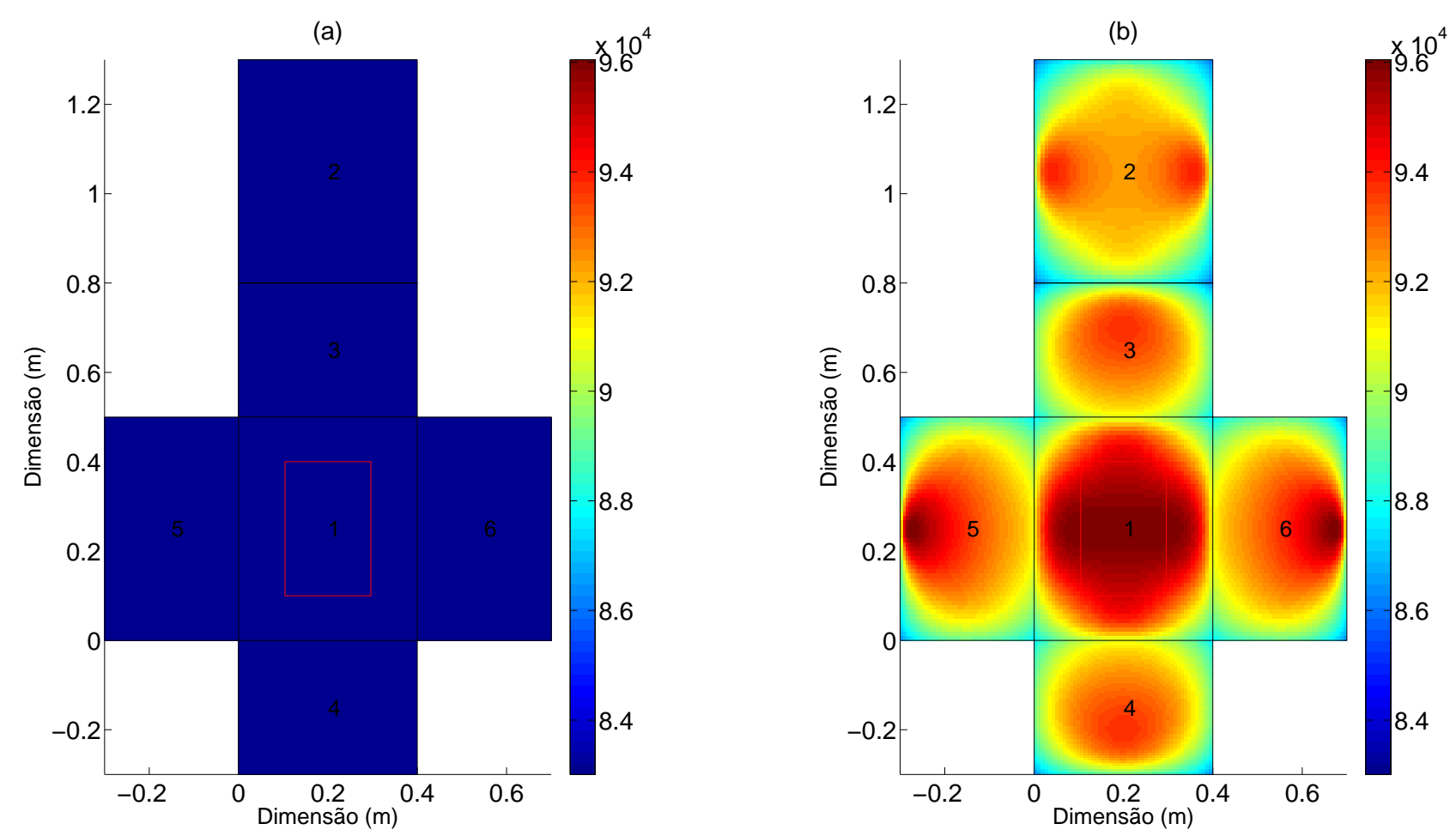

Figura 5.35: Irradiações $\left(W / m^{2}\right)$ para a maximização da irradiação através da distribuição de aquecedores, com restrição de volume de 30\%: (a) antes da otimização (b) depois da otimização. 


\section{Conclusões}

A presente dissertação procurou detalhar a utilização do método da otimização topológica para o projeto otimizado do interior de confinamentos sujeitos à transferência de calor por radiação. Neste sentido, uma ampla gama de fundamentos e resultados, tanto analíticos quanto numéricos, foram apresentados de forma a tornar possível este estudo.

As aferições numéricas realizadas no Apêndice B, além de boa correspondência com o que é prescrito pela teoria analítica, apresentam resultados detalhados para as determinações dos fatores de forma através da quadratura de Gauss e para aplicação do método dos elementos finitos ao fenômeno estudado. Os valores dos fatores de forma entre superfícies convexas, coeficientes chaves para uma boa aproximação numérica do fenômeno de radiação em confinamentos, são calculados de forma precisa e os resultados obtidos através do MEF são confiáveis, tanto para determinação das radiosidades, quanto para determinação das temperaturas e fluxos de calor desconhecidos.

No que tange à aplicação da otimização topológica como ferramenta de projeto, várias funções objetivo foram utilizadas para a concepção otimizada do interior de confinamentos sujeitos à troca radiante. A função objetivo de maximização da irradiação apresentou resultados discretos, com necessidade mínima de interpretação, o que favorece a fabricação dos exemplos analisados. Além disso, ao permitir a distribuição sistemática de material refletor, uma nova perspectiva no projeto de confinamentos foi introduzida, por meio da qual substancial economia de material e eficiência energética podem ser verificados.

A demanda de projeto que se ocupa da proteção contra a radiação também foi abordada. Em uma primeira análise, procurou-se entender como minimizar a incidência de radiação em regiões específicas de um confinamento através da distribuição de material refletor. Posteriormente, um estudo similar foi realizado com o objetivo de minimização da temperatura em uma área do confinamento. Ambas as abordagens obtiveram resultados satisfatórios e contribuem diferencialmente para o projeto de ambientes onde há preocupação com a proteção, segurança e conforto térmico.

Outra linha de projeto frequentemente encontrada na literatura, concernente ao posicionamento otimizado de aquecedores no interior de um forno, foi revisitada. Este 
problema foi solucionado sob o aspecto da utilização da informação de gradientes de uma função objetivo de maximização de irradiação e através de um modelo de material específico para este caso. Apesar de alguma dificuldade de obtenção de soluções discretas ser observada para o problema com restrição de volume, os resultados obtidos mostraram-se adequados e condizentes, em certo nível, aos existentes nas referências consultadas.

Finalmente, apesar da opção por um tratamento, em muitos aspectos, mais simplificado da radiação, a despeito da utilização de materiais com valores de refletividade muitas vezes mais próximos de um comportamento especular do que de um comportamento difuso e apesar da adoção de condições de contorno virtuais para os problemas analisados, dentre outras simplificações, o autor acredita ter contribuído para diversificar a forma de se projetar confinamentos sujeitos à troca radiante, mostrando o potencial e eficiência da distribuição de material nestes ambientes através da otimização topológica.

\subsection{Sugestão de Trabalhos Futuros}

O autor acredita que o tópico discutido neste trabalho é bastante rico e longe de ser facilmente esgotável, de modo que pelo menos duas linhas claras podem ser seguidas no sentido da continuação deste tema. A primeira linha indica um aprofundamento na modelagem do problema de transferência de calor por radiação no interior de confinamentos. Assim, trabalhos futuros poderiam:

- implementar o acoplamento entre condução, convecção e radiação, o que torna a modelagem da transferência de calor no interior do confinamento não linear em função da temperatura (SIEGEL; HOWELL, 2002; HOGAN; GARTLING, 2008; REDDY; GARTLING, 2010);

- considerar a participação de um meio que seja absorvedor, emissor e dispersor de radiação no interior do confinamento (SIEGEL; HOWELL, 2002; AN et al., 2005);

- considerar uma não linearidade das propriedades dos materiais analisados, como por exemplo, fazer com que a emissividade seja dependente da temperatura e do comprimento de onda (SIEGEL; HOWELL, 2002);

- considerar que as superfícies possam ser, além de difusas, especulares (SIEGEL; HOWELL, 2002; KANG; LEE; LEE, 2006); 
- verificar a validade do algoritmo de cálculo de fatores de forma implementado neste trabalho para aplicação em confinamentos formados por superfícies não convexas (BROCKMANN, 1994; VASINA; CHEKSHIN, 1998; MEZRHAB; BOUZIDI, 2005; BOPCHE; SRIDHARAN, 2009; FRANCISCO et al., 2013);

- considerar, no cálculo dos fatores de forma, a interação de superfícies que formam obstáculos (sombra) dentro do confinamento (NISHITA; NAKAMAE, 1985; KAKUTA et al., 2001; WALTON, 2002; SONG; LI, 2003; DEIVEEGAN et al., 2004; RAMANUJAM; ABISHEK; KATTE, 2006; DILAURA et al., 2006);

- considerar o caso da modelagem da transferência de calor por radiação em ambientes não confinados, como o que acontece no aproveitamento da energia solar em coletores solares.

A segunda linha considera possíveis novas abordagens de otimização. Assim, trabalhos futuros poderiam:

- considerar restrições de aumento ou de diminuição de irradiação no domínio de projeto, nas áreas que não são delimitadas como alvo. A mesma análise é válida para o caso de minimização da temperatura no interior de um confinamento;

- utilizar a otimização topológica para modificar a geometria da espessura do confinamento, caso em que a modelagem da transferência de calor no sistema considera o acoplamento com à condução. Esta análise pode ser vinculada a uma possível restrição de tensão, se for considerada que a condução de calor causa estresse térmico na superfície estudada;

- utilizar otimização de forma, juntamente com a otimização topológica, para modificar tanto a geometria do confinamento quanto a distribuição de material refletor no seu interior (DAUN; HOWELL; MORTON, 2003b; DAUN; MORTON; HOWELL, 2003; WIECKERT, 2005; SARVARI, 2007; FAKHRABADI; KOWSARY, 2009; RUKOlAine, 2010; MARSTON; DAUN; COllins, 2011; TAN; ZHAO; LIU, 2011; FARAHMAND; PAYAN; SARVARI, 2012);

- considerar a otimização topológica para distribuição de material refletor no interior de confinamentos que comportem processos transientes (DAUN; HOWELL; MORTON, 2004; MEHDIPOUR et al., 2010; MEHDIPOUR; AGHANAJAFI, 2010; ASHRAFIZADEH; MEHDIPOUR; AGHANAJAFI, 2012; MEHDIPOUR et al., 2012);

- utilizar o discrete material optimization (STEGMANN; LUND, 2005) para escolha otimizada de quais materiais distribuir no interior de um confinamento, dentre uma variedade de materiais com diferentes propriedades refletoras disponíveis; 
- considerar a otimização de estruturas que trocam calor por radiação em ambientes abertos, como coletores solar (TIWARI; AHMAD, 2009; MOGHADAM; TABRIZI; SHARAK, 2011).

Muito da teoria necessária para a abordagem destes temas se encontra discutida neste texto. Além disso, o autor acredita que estas sugestões de trabalhos futuros possuam suficiente respaldo na literatura, bem como representem temas modernos e de aplicação prática. 


\section{Referências}

ABISHEK, S.; RAMANUJAM, S. K.; KATTE, S. S. View factors between disc/rectangle and rectangle in parallel and perpendicular planes. Journal of Thermophysics and Heat Transfer, v. 21, n. 1, p. 236-239, 2007.

AMBIRAJAN, A.; VENKATESHAN, S. P. Accurate determination of diffuse view factors between planar surfaces. International Journal of Heat and Mass Transfer, Pergamon-elsevier Science Ltd, v. 36, n. 8, p. 2203-2208, 1993.

AMIGO, R. C. R. Otimização e fabricação de dispositivos piezelétricos com gradação funcional de material. Tese (Mestrado) - Escola Politécnica, Universidade de São Paulo, 2013.

AMIRI, H.; MANSOURI, S. H.; COELHO, P. J. Inverse optimal design of radiant enclosures with participating media: a parametric study. Heat Transfer Engineering, v. 34, n. 4, p. 288-302, 2013.

AMIRI, H.; MANSOURI, S. H.; SAFAVINEJAD, A.; COELHO, P. J. The optimal number and location of discrete radiant heaters in enclosures with the participating media using the micro genetic algorithm. Numerical Heat Transfer, Part A: Applications, Taylor \& Francis Inc, v. 60, n. 5, p. 461-483, 2011.

AN, W.; RUAN, L. M.; QI, H.; LIU, L. H. Finite element method for radiative heat transfer in absorbing and anisotropic scattering media. Journal of Quantitative Spectroscopy and Radiative Transfer, v. 96, p. 409-422, 2005.

ASHRAFIZADEH, A.; MEHDIPOUR, R.; AGHANAJAFI, C. A hybrid optimization algorithm for the thermal design of radiant paint cure ovens. Applied Thermal Engineering, Pergamon-elsevier Science Ltd, v. 40, p. 56-63, 2012.

BAYAT, N.; MEHRABAN, S.; SARVARI, S. M. H. Inverse boundary design of a radiant furnace with diffuse-spectral design surface. International Communications in Heat and Mass Transfer, v. 37, n. 1, p. 103-110, 2010.

BENDSØE, M. P. Optimal shape design as a material distribution problem. Structural Optimization, v. 1, p. 192-202, 1989.

BENDSØE, M. P. Optimization of structural topology, shape, and material. Berlin, Germany: Springer, 1995.

BENDSØE, M. P.; KIKUCHI, N. Generating optimal topologies in structural design using a homogenization method. Computer Methods In Applied Mechanics and Engineering, Elsevier Science Sa Lausanne, v. 71, n. 2, p. 197-224, 1988.

BENDSØE, M. P.; SIGMUND, O. Topology optimization: theory, methods and applications. Berlin, Germany: Springer, 2003. 
BENIM, A. C. A Finite-element solution of radiative heat-transfer in participating media utilizing the moment method. Computer Methods In Applied Mechanics and Engineering, Elsevier Science Sa Lausanne, v. 67, n. 1, p. 1-14, 1988.

BERGHEAU, J. M.; POTIER, F. Finite-element modeling of coupled radiative and diffusive heat transfer in nonparticipating media including symmetry and periodicity conditions. Numerical Heat Transfer, Part B: Fundamentals, Taylor \& Francis, v. 40, n. 3, p. 229-247, 2001.

BERGLES, A. E. ExHFT for fourth generation heat transfer technology. Experimental Thermal and Fluid Science, Elsevier Science Inc, v. 26, n. 2-4, p. 335-344, 2002.

BOPCHE, S. B.; SRIDHARAN, A. Determination of view factors by contour integral technique. Annals of Nuclear Energy, Elsevier Ltd, v. 36, n. 11-12, p. 1681-1688, 2009.

BORNSIDE, D. E.; KINNEY, T. A.; BROWN, R. A.; KIM, G. Finite element/Newton method for the analysis of Czochralski crystal growth with diffuse-grey radiative heat transfer. International Journal for Numerical Methods in Engineering, John Wiley \& Sons, Ltd, v. 30, n. 1, p. 133-154, 1990.

BREITBACH, G.; ALTES, J.; SCZIMAROWSKY, M. Solution of radiative problems using variational based finite-element method. International Journal For Numerical Methods In Engineering, John Wiley \& Sons Ltd, v. 29, n. 8, p. 1701-1714, 1990.

BROCKMANN, H. Analytic angle factors for the radiant interchange among the surface elements of two concentric cylinders. International Journal of Heat and Mass Transfer, v. 37, n. 7, p. 1095-1100, 1994.

BRUNS, T. E. Topology optimization of convection-dominated, steady-state heat transfer problems. International Journal of Heat and Mass Transfer, v. 50, n. 15-16, p. 2859-2873, 2007.

BRUNS, T. E.; TORTORELLI, D. A. Topology optimization of non-linear elastic structures and compliant mechanisms. Computer Methods in Applied Mechanics and Engineering, v. 190, p. 3443-3459, 2001.

CARBONARI, R. C.; SILVA, E. C. N.; NISHIWAKI, S. Optimum placement of piezoelectric material in piezoactuator design. Smart Materials and Structures, v. 16, n. 1, p. 207-220, 2007.

CARDOSO, E. L.; FONSECA, J. S. O. Complexity control in the topology optimization of continuum structures. Journal of The Brazilian Society of Mechanical Sciences and Engineering, v. 25, n. 3, 2003.

CASSOL, F.; SCHNEIDER, P. S.; FRANÇA, F. H. R.; NETO, A. J. S. Multi-objective optimization as a new approach to illumination design of interior spaces. Building and Environment, Pergamon-elsevier Science Ltd, v. 46, n. 2, p. 331-338, 2011.

CHECCHI, E.; STRAGAPEDE, C.; GROSSETIE, J. C. Diffusely Reflecting Radiosity Technique in Image Synthesis. [S.1.], 1991.

CHENG, K. T.; OLHOFF, N. An investigation concerning optimal-design of solid elastic plates. International Journal of Solids and Structures, Pergamon-elsevier Science Ltd, v. 17, n. 3, p. 305-323, 1981. 
CHOI, K. K.; KIM, N. H. Structural Sensitivity Analysis and Optimization 1: Linear Systems. Berlin, Germany: Springer, 2004.

CHOPADE, R. P.; MISHRA, S. C.; MAHANTA, P.; MARUYAMA, S. Effects of locations of a 3-D design object in a 3-D radiant furnace for prescribed uniform thermal conditions. Applied Thermal Engineering, v. 31, n. 16, p. 3262-3274, 2011.

CHOPADE, R. P.; MISHRA, S. C.; MAHANTA, P.; MARUYAMA, S. Numerical analysis of an inverse boundary design problem of a 3-D radiant furnace with a 3-D design object. Numerical Heat Transfer, Part A: Applications, v. 60, n. 1, p. 25-49, 2011.

CHOPADE, R. P.; MISHRA, S. C.; MAHANTA, P.; MARUYAMA, S. Estimation of power of heaters in a radiant furnace for uniform thermal conditions on 3-D irregular shaped objects. International Journal of Heat and Mass Transfer, v. 55, p. 4340-4351, 2012.

CHOPADE, R. P.; MISHRA, S. C.; MAHANTA, P.; MARUYAMA, S.; KOMIYA, A. Uniform thermal conditions on 3-D object: Optimal power estimation of panel heaters in a 3-D radiant enclosure. International Journal of Thermal Sciences, v. 51, n. 0, p. 63-76, 2012.

CHUNG, T. J.; KIM, J. Y. Radiation view factors by finite-elements. Journal of Heat Transfer-transactions of the Asme, Asme-amer Soc Mechanical Eng, v. 104, n. 4, p. 792-795, 1982.

CLARK, J. A.; KORYBALSKI, M. E. Algebraic methods for the calculation of radiation exchange in an enclosure. Wärme- und Stoffübertragung, v. 7, n. 1, p. 31-44, 1974.

COHEN, M. F.; GREENBERG, D. P. The hemi-cube: a radiosity solution for complex environments. SIGGRAPH Comput. Graph., ACM, New York, NY, USA, v. 19, n. 3, p. 31-40, 1985.

COSSALI, G. E. Radiant heat transfer between grey surfaces: an alternative approach. International Journal of Heat and Mass Transfer, Pergamon-elsevier Science Ltd, v. 44, n. 1, p. 29-37, 2001.

DAUN, K.; FRANÇA, F.; LARSEN, M.; LEDUC, G.; HOWELL, J. R.; FRANCİ§A, F. Comparison of methods for inverse design of radiant enclosures. Journal of Heat Transfer-transactions of the Asme, Asme-amer Soc Mechanical Eng, v. 128, n. 3, p. 269-282, 2006.

DAUN, K. J. Design optimization of radiant enclosures. Tese (Doutorado) - The University of Texas at Austin, 2003.

DAUN, K. J.; HOLLANDS, K. G. T. Infinitesimal-area radiative analysis using parametric surface representation, through NURBS. Journal of Heat Transfer-transactions of the Asme, Asme-amer Soc Mechanical Eng, v. 123, n. 2, p. 249-256, 2001.

DAUN, K. J.; HOWELL, J. R. Inverse design methods for radiative transfer systems. Journal of Quantitative Spectroscopy \& Radiative Transfer, Pergamon-elsevier Science Ltd, v. 93, n. 1-3, p. 43-60, 2005.

DAUN, K. J.; HOWELL, J. R.; MORTON, D. P. Design of radiant enclosures using inverse and non-linear programming techniques. Inverse Problems In Engineering, Taylor \& Francis Ltd, v. 11, n. 6, p. 541-560, 2003. 
DAUN, K. J.; HOWELL, J. R.; MORTON, D. P. Geometric optimization of radiative enclosures through nonlinear programming. Numerical Heat Transfer, Part B:

Fundamentals, Taylor \& Francis Inc, v. 43, n. 3, p. 203-219, 2003.

DAUN, K. J.; HOWELL, J. R.; MORTON, D. P. Optimization of transient heater settings to provide spatially uniform heating in manufacturing processes involving radiant heating. Numerical Heat Transfer, Part A: Applications, Taylor \& Francis Inc, v. 46, n. 7, p. 651-667, 2004.

DAUN, K. J.; MORTON, D. P.; HOWELL, J. R. Geometric optimization of radiant enclosures containing specular surfaces. Journal of Heat Transfer-transactions of the Asme, Asme-amer Soc Mechanical Eng, v. 125, n. 5, p. 845-851, 2003.

DAURELLE, J. V.; OCCELLI, R.; JAEGER, M. Finite element modelling of radiation in a nonparticipating medium coupled with conduction and convection heat transfer with moving boundaries. International Journal of Numerical Methods For Heat \&5 Fluid Flow, Mcb Univ Press Ltd, v. 9, n. 3, p. 257-268, 1999.

DAVIES, M. G. An approximate expression for room view factors. Building and Environment, v. 19, n. 4, p. 217-219, 1984.

DAVIES, M. G. Building heat transfer. Chichester, England: John Wiley \& Sons, 2004.

DEIVEEGAN, M.; RAMAMOORTHY, V.; KATTE, S. S.; RAMAMMORTHY, V. Analytical expressions for view factors with an intervening surface. Journal of Thermophysics and Heat Transfer, v. 18, n. 2, p. 273-277, 2004.

DILAURA, D. L.; MILLER, T.; SEIDER, C.; GOULD, C. The calculation of occluded diffuse and nondiffuse radiative exchange form factors. Leukos, v. 3, n. 1-4, p. $51-67$, 2006 .

EHLERT, J. R.; SMITH, T. F. View factors for perpendicular and parallel rectangular plates. Journal of Thermophysics and Heat Transfer, v. 7, p. 173-175, 1993.

ERTURK, H.; EZEKOYE, O. A.; HOWELL, J. R. The application of an inverse formulation in the design of boundary conditions for transient radiating enclosures. Journal of Heat Transfer-transactions of the Asme, Asme-amer Soc Mechanical Eng, v. 124, n. 6, p. 1095-1102, 2002.

FAKHRABADI, F.; KOWSARY, F. Optimal shape design for radiative enclosures using nurbs. [S.1.]: Amer Soc Mechanical Engineers, 2009. 431-435 p.

FARAHMAND, A.; PAYAN, S.; SARVARI, S. M. H. Geometric optimization of radiative enclosures using PSO algorithm. International Journal of Thermal Sciences, v. 60, n. 0, p. 61-69, 2012.

FEDOROV, A. G.; LEE, K. H.; VISKANTA, R. Inverse optimal design of the radiant heating in materials processing and manufacturing. Journal of Materials Engineering and Performance, v. 7, n. 6, p. 719-726, 1998.

FEINGOLD, A. Radiant-interchange configuration factors between various selected plane surfaces. Proceedings of the Royal Society of London Series A-mathematical and Physical Sciences, Royal Soc London, v. 292, n. 1428, p. 51-\&, 1966. 
FRANÇA, F. H. R.; EZEKOYE, O. A.; HOWELL, J. R. Inverse boundary design combining radiation and convection heat transfer. Journal of Heat Transfer, ASME, v. 123, n. 5, p. 884-891, 2001.

FRANCISCO, S. C.; RAIMUNDO, A. M.; GASPAR, A. R.; OLIVEIRA, a. V. M.; QUINTELA, D. a. Calculation of view factors for complex geometries using Stokes' theorem. Journal of Building Performance Simulation, n. July 2013, p. 1-14, 2013.

GAO, T.; ZHANG, W. H.; ZHU, J. H.; XU, Y. J.; BASSIR, D. H. Topology optimization of heat conduction problem involving design-dependent heat load effect. Finite Elements In Analysis and Design, Elsevier Science Bv, v. 44, n. 14, p. 805-813, 2008.

GEBHART, B. Surface temperature calculations in radiant surroundings of arbitrary complexity-for gray, diffuse radiation. International Journal of Heat and Mass Transfer, v. 3, n. 4, p. 341-346, 1961.

GOULD, D. C. Radiation heat transfer between diffuse-gray surfaces using higher order finite elements. 34th AIAA Thermophysics Conference, NASA Langley Technical Report Server, Hampton, U.S.A, p. 12, 2000.

GREEnBERG, D. P.; COHEN, M. F.; TORRANCE, K. E. Radiosity: a method for computing global illumination. The Visual Computer, v. 2, n. 5, p. 291-297, 1986.

GUEST, J. K.; PRÉVOST, J. H.; BELYTSCHKO, T. Achieving minimum length scale in topology optimization using nodal design variables and projection functions. International Journal for Numerical Methods in Engineering, John Wiley \& Sons, Ltd., v. 61, n. 2, p. 238-254, 2004.

HAFTKA, R.; GURDAL, Z. Elements of structural optimization. Dordrecht, The Nederlands: Kluwer Academic Publishers, 1992.

HAFTKA, R. T.; GRANDHI, R. V. Structural shape optimization - A survey. Computer Methods in Applied Mechanics and Engineering, v. 57, n. 1, p. 91-106, 1986.

HAMILTON, D. C.; MORGAN, W. R. Radiant interchange configuration factors. NACA Tech Note, 2836, 1952.

HASSANI, B.; HINTON, E. Homogenization and structural topology optimization: theory, practice, and software. London, England: Springer, 1999.

HECKBERT, P. S.; WINGET, J. M. Finite element methods for global illumination. 1991.

HOFFMANN, R. S.; SEEWALD, A.; SCHNEIDER, P. S.; FRANÇA, F. H. R. Inverse design of thermal systems with spectrally dependent emissivities. International Journal of Heat and Mass Transfer, v. 53, p. 931-939, 2010.

HOGAN, R. E.; GARTLING, D. K. Solution strategies for coupled conduction/radiation problems. Communications In Numerical Methods In Engineering, John Wiley \& Sons Ltd, v. 24, n. 6, p. 523-542, 2008.

HOWELL, J. R. A Catalog of Radiation Heat Transfer Configuration Factors. out. 2012. Disponível em: <http://www.engr.uky.edu/rtl/Catalog/>. 
HOWELL, J. R.; DAUN, K.; ERTURK, H.; GAMBA, M.; SARVARI, M. H. The use of inverse methods for the design and control of radiant sources. Jsme International Journal Series B-fluids and Thermal Engineering, Japan Soc Mechanical Engineers, v. 46, n. 4, p. $470-478,2003$.

HOWELL, J. R.; EZEKOYE, O. A.; MORALES, J. C. Inverse Design Model for Radiative Heat Transfer. Journal of Heat Transfer, ASME, v. 122, n. 3, p. 492-502, 2000.

HULL, P. V.; TINKER, M.; SANSOUCIE, M.; KITTREDGE, K. Thermal analysis and shape optimization of an in-space radiator using genetic algorithms. Space Technology and Applications International Forum - STAIF 2006, Amer Inst Physics, v. 813, p. 81-90, 2006.

INCROPERA, F. P.; DEWITT, D. P.; BERGMAN, T. L.; LAVINE, A. S. Fundamentals of heat and mass transfer. Chichester, England: John Wiley, 2007.

KAKUTA, N.; YOKOYAMA, S.; NAKAMURA, M.; MABUCHI, K. Estimation of radiative heat transfer using a geometric human model. IEEE Transactions on Bio-medical Engineering, v. 48, n. 3, p. 324-31, 2001.

KANG, S. B.; LEE, W. I.; LEE, J. S. An effective calculation method for radiative exchange in an enclosure with specular surfaces. Numerical Heat Transfer, Part A: Applications, v. 50, n. 9, p. 865-881, 2006.

KEAVEY, M. A. An isoparametric boundary solution for thermal-radiation. Communications In Applied Numerical Methods, John Wiley \& Sons LTD, v. 4, n. 5, p. 639-646, 1988.

KIM, K. W.; BAEK, S. W.; KIM, M. Y.; RYOU, H. S. Estimation of emissivities in a two-dimensional irregular geometry by inverse radiation analysis using hybrid genetic algorithm. Journal of Quantitative Spectroscopy $\&$ Radiative Transfer, Pergamon-elsevier Science Ltd, v. 87, n. 1, p. 1-14, 2004.

KISSELEV, V. B.; ROBERTI, L.; PERONA, G. An Application of the Finite-element Method To the Solution of the Radiative-transfer Equation. Journal of Quantitative Spectroscopy \& Radiative Transfer, Pergamon-elsevier Science Ltd, v. 51, n. 4, p. 603-614, 1994.

KOHN, R. V.; STRANG, G. Optimal design and relaxation of variational problems, I. Communications on Pure and Applied Mathematics, John Wiley \& Sons, v. 39, n. 1, p. 113-137, 1986.

KOHN, R. V.; STRANG, G. Optimal design and relaxation of variational problems, II. Communications on Pure and Applied Mathematics, John Wiley \& Sons, v. 39, n. 2, p. 139-182, 1986.

KOHN, R. V.; STRANG, G. Optimal design and relaxation of variational problems, III. Comm. Pure Appl. Math., Wiley Subscription Services, Inc., A Wiley Company, v. 39, n. 3, p. 113-137, 1986.

KOWSARY, F.; POOLADVAND, K.; POURSHAGHAGHY, A. Regularized variable metric method versus the conjugate gradient method in solution of radiative boundary design problem. Journal of Quantitative Spectroscopy 8 Radiative Transfer, Pergamon-elsevier Science Ltd, v. 108, n. 2, p. 277-294, 2007. 
KRAUS, A. D.; AZIZ, A.; WELTY, J. Extended surface heat transfer. Danvers, U.S.A: John Wiley \& Sons, 2002.

KUPPURAO, S.; DERBY, J. J. Finite-element formulations for accurate calculation of radiant-heat transfer in diffuse-gray enclosures. Numerical Heat Transfer, Part B: Fundamentals, Hemisphere Publ Corp, v. 24, n. 4, p. 431-454, 1993.

LARSEN, M. E.; HOWELL, J. R. Least-squares smoothing of direct-exchange areas in zonal analysis. Journal of Heat Transfer, ASME, v. 108, n. 1, p. 239-242, 1986.

LEDUC, G.; MONCHOUX, F.; THELLIER, F. Inverse radiative design in human thermal environment. International Journal of Heat and Mass Transfer, v. 47, p. 3291-3300, 2004.

LEERSUM, J. van. A method for determining a consistent set of radiation view factors from a set generated by a nonexact method. International Journal of Heat and Fluid Flow, v. 10, n. 1, p. 83-85, 1989.

LIU, L.; TAN, H.; YU, Q. Inverse radiation problem of sources and emissivities in one-dimensional semitransparent media. International Journal of Heat and Mass Transfer, v. 44, n. 1, p. 63-72, 2001.

LIU, L. H.; TAN, H. P.; YU, Q. Z. Simultaneous identification of temperature profile and wall emissivities in one-dimensional semitransparent medium by inverse radiation analysis. Numerical Heat Transfer, Part A: Applications, Taylor \& Francis, v. 36, n. 5, p. 511-525, 1999.

MARSTON, A. J.; DAUN, K. J.; COLLINS, M. R. Geometric optimization of radiant enclosures containing specularly-reflecting curfaces through quasi-monte carlo simulation. Numerical Heat Transfer, Part A: Applications, Taylor \& Francis Inc, v. 59, n. 2, p. 81-97, 2011.

MEHDIPOUR, R.; AGHANAJAFI, C. Design of continuous radiation paint cure ovens using the equivalent isentropic temperature/time. Proceedings of the 2010 International Conference On Mechanical, Industrial, and Manufacturing Technologies (mimt 2010), Amer Soc Mechanical Engineers, p. 361-367, 2010.

MEHDIPOUR, R.; AGHANAJAFI, C.; ASHRAFIZADEH, A. Optimal design of radiation paint cure ovens using a novel objective function. Pigment $\&$ Resin Technology, Emerald Group Publishing Limited, v. 41, n. 4, p. 240-250, 2012.

MEHDIPOUR, R.; AGHANAJAFI, C.; ASHRAFIZADEH, A.; BANIAMERIAN, Z. Developing the proper form of objective function to be applied in gradient optimization technique for designing continuous radiation ovens. Mechanical and Aerospace Engineering, Pts 1-7, Trans Tech Publications Ltd, v. 110-116, p. 2260-2267, 2012.

MEHDIPOUR, R.; ASHRAFIZADEH, A.; DAUN, K. J.; AGHANAJAFI, C. Dynamic optimization of a radiation paint cure oven using the nominal cure point criterion. Drying Technology, Taylor \& Francis Inc, v. 28, n. 12, p. 1405-1415, 2010.

MEZRHAB, A.; BOUZIDI, M. Computation of view factors for surfaces of complex shape including screening effects and using a boundary element approximation. Engineering Computations, Emerald Group Publishing Limited, v. 22, n. 2, p. 132-148, 2005. 
MINKOWYCZ, W. J.; HAJI-SHEIKH, A. The Sparrow-Galerkin solution of radiation exchange and transition to finite element. International Journal of Heat and Mass Transfer, v. 42, n. 8, p. 1353-1362, 1999.

MLEJNEK, H. P. Some aspects of the genesis of structures. Structural Optimization, Springer Verlag, v. 5, n. 1-2, p. 64-69, 1992.

MOGHADAM, H.; TABRIZI, F. F.; SHARAK, A. Z. Optimization of solar flat collector inclination. Desalination, Elsevier B.V., v. 265, n. 1-3, p. 107-111, 2011.

MOSSI, A. C.; VIELMO, H. A.; FRANÇA, F. H. R.; HOWELL, J. R. Inverse design involving combined radiative and turbulent convective heat transfer. International Journal of Heat and Mass Transfer, v. 51, p. 3217-3226, 2008.

NARAYANA, K. B. View factors for parallel rectangular plates. Heat Transfer Engineering, v. 19, n. 1, p. 59-63, 1998.

NISHITA, T.; NAKAMAE, E. Continuous tone representation of three-dimensional objects taking account of shadows and interreflection. ACM SIGGRAPH Computer Graphics, v. 19, n. 3, p. 23-30, 1985.

OLHOFF, N.; BENDSØE, M. P.; RASMUSSEN, J. On CAD-integrated structural topology and design optimization. Computer Methods in Applied Mechanics and Engineering, v. 89, n. 1-3, p. 259-279, 1991.

OSNES, J. D. A method for efficiently incorporating radiative boundaries in finite element programs. Proceedings of the Third International Conference on Numerical Methods in Thermal Problems, Seattle, Washington, 1983.

PAYAN, S.; SARVARI, S. M. H.; AJAM, H. Inverse boundary design of square enclosures with natural convection. International Journal of Thermal Sciences, v. 48, n. 4, p. 682-690, 2009.

PLANCK, M. On the law of distribution of energy in the normal spectrum. Annalen der Physik, v. 4, p. 553+, 1901.

PLANCK, M. The theory of heat radiation. Philadelphia, U.S.A: P. Blakiston's Son \& Co., 1914.

PODESTA, M. D.; UNDERWOOD, R.; SUTTON, G.; MORANTZ, P.; HARRIS, P.; MARK, D. F.; STUART, F. M.; VARGHA, G.; MACHIN, G. A low-uncertainty measurement of the Boltzmann constant. Metrologia, v. 50, n. 4, p. 354-376, 2013.

PORTER, J. M.; LARSEN, M. E.; BARNES, J. W.; HOWELL, J. R. Metaheuristic optimization of a discrete array of radiant heaters. Journal of Heat Transfer-transactions of the Asme, Asme-amer Soc Mechanical Eng, v. 128, n. 10, p. 1031-1040, 2006.

POURSHAGHAGHY, A.; POOLADVAND, K.; KOWSARY, F.; KARIMI-ZAND, K. An inverse radiation boundary design problem for an enclosure filled with an emitting, absorbing, and scattering media. International Communications in Heat and Mass Transfer, v. 33, n. 3, p. 381-390, 2006.

RAHMANI, R. K.; MOLAVI, H.; AYASOUfi, A.; KOOMUlliL, R. P.; CHENG, G. Solution of Radiative Boundary Design Problems Using a Combined Optimization Technique. Numerical Heat Transfer Part B-fundamentals, Taylor \& Francis Inc, v. 57, n. 5, p. 348-371, 2010. 
RAMANUJAM, K. S.; ABISHEK, S.; KATTE, S. S. Differential view factor for a rectangle with intervening parallelepiped or sphere. Journal of Thermophysics and Heat Transfer, v. 20, n. 3, p. 10-13, 2006.

RAO, V. R.; SASTRI, V. M. K. Efficient evaluation of diffuse view factors for radiation. International Journal of Heat and Mass Transfer, v. 39, n. 6, p. 1281-1286, 1996.

REDDY, J. N.; GARTLING, D. K. The finite element method in heat transfer and fluid dynamics. Boca Raton, U.S.A: CRC Press, 2010.

ROHSENOW, W. M.; HARTNETT, J. P.; CHO, Y. I. Handbook of heat transfer. New York, U.S.A: McGraw-Hill, 1998.

ROZVANY, G. I. N.; ZHOU, M.; BIRKER, T. Generalized shape optimization without homogenization. Structural Optimization, v. 4, n. 3, p. 250-252, 1992.

RUKOLAINE, S. A. The shape gradient of the least-squares objective functional in optimal shape design problems of radiative heat transfer. Journal of Quantitative Spectroscopy \& Radiative Transfer, Pergamon-elsevier Science Ltd, v. 111, n. 16, p. 2390-2404, 2010.

SAFAVINEJAD, A.; MANSOURI, S. H.; SAKURAI, A.; MARUYAMA, S. Optimal number and location of heaters in 2-D radiant enclosures composed of specular and diffuse surfaces using micro-genetic algorithm. Applied Thermal Engineering, v. 29, p. 1075-1085, 2009.

SARVARI, S. M. H. Inverse determination of heat source distribution in conductive-radiative media with irregular geometry. Journal of Quantitative Spectroscopy and Radiative Transfer, v. 93, p. 383-395, 2005.

SARVARI, S. M. H. Optimal geometry design of radiative enclosures using the genetic algorithm. Numerical Heat Transfer, Part A: Applications, Taylor \& Francis Inc, v. 52, n. 2, p. 127-143, 2007.

SARVARI, S. M. H.; HOWELL, J. R.; MANSOURI, S. H. Inverse boundary design conduction-radiation problem in irregular two-dimensional domains. Numerical Heat Transfer, Part B: Fundamentals, v. 44, n. 3, p. 209-224, 2003.

SARVARI, S. M. H.; MANSOURI, S. H.; HOWELL, J. R. Inverse boundary design radiation problem in absorbing-emitting media with irregular geometry. Numerical Heat Transfer, Part A: Applications, Taylor \& Francis, v. 43, n. 6, p. 565-584, 2003.

SARVARI, S. M. H.; MANSOURI, S. H.; HOWELL, J. R. Inverse design of three-dimensional enclosures with transparent and absorbing-emitting media using an optimization technique. International Communications in Heat and Mass Transfer, Pergamon-elsevier Science Ltd, v. 30, n. 2, p. 149-162, 2003.

SCHNEIDER, P. S. S.; MOSSI, A. C. C.; FRANÇA, F. H. R. H. R.; SOUSA, F. L. de; da Silva Neto, A. J. Application of inverse analysis to illumination design. Inverse Problems in Science and Engineering, Taylor and Francis Ltd, v. 17, n. 6, p. 737-753, 2009.

SHAPIRO, A. B. Computer implementation, accuracy, and timing of radiation view factor algorithms. Journal of Heat Transfer, ASME, v. 107, n. 3, p. 730-732, 1985. 
SHUAI, Y.; XIA, X.-L.; TAN, H.-P. Radiation performance of dish solar concentrator/cavity receiver systems. Solar Energy, v. 82, n. 1, p. 13-21, 2008.

SIEGEL, R.; HOWELL, J. R. Thermal radiation heat transfer. New York, U.S.A: Taylor \& Francis Group, 2002.

SIGMUND, O. A 99 line topology optimization code written in Matlab. Structural and Multidisciplinary Optimization, Springer-verlag, v. 21, n. 2, p. 120-127, 2001.

SIGMUND, O. On the usefulness of non-gradient approaches in topology optimization. Structural and Multidisciplinary Optimization, Springer, v. 43, n. 5, p. 589-596, 2011.

SIGMUND, O.; PETERSSON, J. Numerical instabilities in topology optimization: A survey on procedures dealing with checkerboards, mesh-dependencies and local minima. Structural Optimization, Springer-Verlag, v. 16, n. 2, p. 68-75, 1998.

SONG, S. P.; LI, B. Q. Boundary integral solution of thermal radiation exchanges in axisymmetric furnaces. Numerical Heat Transfer, Part B: Fundamentals, Taylor \& Francis, v. 44, n. 5, p. 489-507, 2003.

SOWELL, E. F.; O'BRIEN, P. F. Efficient computation of radiant-interchange factors within an enclosure. Journal of Heat Transfer, v. 49, n. 3, p. 326-328, 1972.

SPARROW, E. M. Application of variational methods to radiation heat-transfer calculations. Journal of Heat Transfer, ASME, v. 82, n. 4, p. 375-380, 1960.

SPARROW, E. M. A new and simpler formulation for radiative angle factors. Journal of Heat Transfer, 1963.

SPARROW, E. M.; CESS, R. D. Radiation heat transfer. New York, U.S.A: Hemisphere Pub. Corp., 1978.

SPARROW, E. M.; LIN, S. L. Radiation heat transfer at a surface having both specular and diffuse reflectance components. International Journal of Heat and Mass Transfer, v. 8, n. 5, p. 769-779, 1965.

STASIEK, J. Generalized net-radiation method for open and closed enclosure filled with isothermal optical medium. Wärme- und Stoffübertragung, v. 22, n. 5, p. 259-267, 1988.

STEGMANN, J.; LUND, E. Discrete material optimization of general composite shell structures. International Journal for Numerical Methods in Engineering, v. 62, n. 14, p. 2009-2027, 2005.

SUZUKI, K.; KIKUCHI, N. A homogenization method for shape and topology optimization. Computer Methods in Applied Mechanics and Engineering, v. 93, n. 3, p. 291-318, 1991.

SVANBERG, K. The Method of Moving Asymptotes - A New Method For Structural Optimization. International Journal For Numerical Methods In Engineering, John Wiley \& Sons Ltd, v. 24, n. 2, p. 359-373, 1987.

TAJOURI, A.; El Hitti, G.; NEMER, M. Optimization of radiant heater power for heating of flat plates using metaheuristic methods. Numerical Heat Transfer, Part A: Applications, Taylor \& Francis Inc, v. 59, n. 7, p. 503-520, 2011. 
TAN, J. Y.; ZHAO, J. M.; LIU, L. H. Geometric optimization of a radiation-conduction heating device using meshless method. International Journal of Thermal Sciences, Elsevier France-editions Scientifiques Medicales Elsevier, v. 50, n. 10, p. 1820-1831, 2011.

TIWARI, G. N.; AHMAD, M. J. Optimization of tilt angle for solar collector to receive maximum radiation. The Open Renewable Energy Journal, v. 2, n. 1, p. 19-24, 2009.

TORTORELLI, D. A.; HABER, R. B.; LU, S. C. Y. Design sensitivity analysis for nonlinear thermal-systems. Computer Methods In Applied Mechanics and Engineering, Elsevier Science Sa, v. 77, n. 1-2, p. 61-77, 1989.

VASINA, E. G.; CHEKSHIN, V. M. An approach to view factor calculation for radiation transfer simulation in 2D axisymmetric geometries. Nuclear Instruments and Methods in Physics Research Section A: Accelerators, Spectrometers, Detectors and Associated Equipment, v. 415, p. 127-132, 1998.

WALTON, G. N. Calculation of obstructed view factors by adaptive integration. [S.1.]: U.S. Dept. of Commerce, Technology Administration, National Institute of Standards and Technology, 2002.

WIDMER, G. An efficient sparse finite element solver for the radiative transfer equation. Journal of Heat Transfer-transactions of the Asme, Asme-amer Soc Mechanical Eng, v. 132, n. 2, p. 23403, 2010.

WIECKERT, C. Design studies for a solar reactor based on a simple radiative heat exchange model. Journal of Solar Energy Engineering-transactions of the Asme, Asme-amer Soc Mechanical Eng, v. 127, n. 3, p. 425-429, 2005.

ZOLTI, E. Radiation heat transfer procedure for two-dimensional finite element models. Computers 85 Structures, v. 40, n. 3, p. 539-547, 1991. 


\section{Anexo A - Formulação de um Variacional para Transferência de Calor por Radiação}

Uma abordagem mais completa para a dedução do variacional formulado por Sparrow e sua aplicação no desenvolvimento do MEF para transferência de calor por radiação podem ser encontrados em (SPARROW, 1960), (SPARROW; LIN, 1965) e (MINKOWYCZ; HAJI-SHEIKH, 1999). Um tratamento similar, que apresenta um aprofundamento na avaliação numérica do MEF, pode também ser obtido em (BREITBACH; ALTES; SCZIMAROWSKY, 1990). O que será mostrado nas próximas linhas são compilações das deduções contidas nestes artigos.

O estudo da formulação variacional de Sparrow é básico para derivação do MEF que permite computar a troca de calor por radiação entre superfícies. As equações que governam a troca de calor por radiação são equações integrais do tipo Fredholm. Na década de 1950, Sparrow introduziu um método variacional para a solução de problemas deste tipo. Mais recentemente, ficou comum estender-se o método de Galerkin para a solução desta forma de equação integral.

A extensão do método de Galerkin para o problema da troca de calor por radiação conduz a exatamente a mesma solução introduzida por Sparrow na década de 1950, obtida através do método variacional de Ritz. Assim, as formulações variacionais propostas por Sparrow são equivalentes às formulações do MEF baseadas em resíduos ponderados.

Como visto na seção 2.1.4.5, através da equação (2.78) a radiosidade pode ser genericamente escrita como (SPARROW; LIN, 1965; COSSALI, 2001):

$$
J_{i}=\varepsilon_{i} \sigma T_{i}^{4}+\rho_{i} \sum_{j=1}^{N} \int_{A_{j}} F_{j i} J_{j} d A_{j}
$$

A equação (A.1) possui um formato padrão, conhecido por equação integral de Fredholm, e pode ser reescrita como:

$$
\chi_{i}\left(\mathbf{r}_{i}\right)=\psi_{i}\left(\mathbf{r}_{i}\right)+\lambda_{i} \sum_{j=1}^{N} \int_{A_{j}} \chi_{j}\left(\mathbf{r}_{j}\right) K_{i j}\left(\mathbf{r}_{i}, \mathbf{r}_{j}\right) d A_{j} \quad(i=1,2, \ldots, N)
$$


em que $\mathbf{r}_{i}$ e $\mathbf{r}_{j}$ são vetores de posição para as superfícies $i$ e $j$ e $K_{i j}\left(\mathbf{r}_{i}, \mathbf{r}_{j}\right)$ é uma função relacionada ao ângulo que determina os fatores de forma, $d F_{i j}=K_{i j}\left(\mathbf{r}_{i}, \mathbf{r}_{j}\right) d A_{j}$. A relação de reciprocidade (2.59) é válida, de tal forma que $K_{i j}=K_{j i}$. O variacional generalizado, proposto por Sparrow, é dado por (MINKOWYCZ; HAJI-SHEIKH, 1999):

$$
\begin{aligned}
I & =\sum_{i=1}^{N} \frac{1}{\lambda_{i}} \int_{A_{i}}\left[\chi_{i}\left(\mathbf{r}_{i}\right)\right]^{2} d A_{i}-2 \sum_{i=1}^{N} \frac{1}{\lambda_{i}} \int_{A_{i}} \chi_{i}\left(\mathbf{r}_{i}\right) \psi_{i}\left(\mathbf{r}_{i}\right) d A_{i}- \\
& -\sum_{i=1}^{N} \int_{A_{i}} \int_{A_{i}} \chi_{i}\left(\mathbf{r}_{i}\right) \chi_{i}\left(\mathbf{r}_{i}^{\prime}\right) K_{i i}\left(\mathbf{r}_{i}, \mathbf{r}_{i}^{\prime}\right) d A_{i} d A_{i}^{\prime}- \\
& -2 \sum_{j=2}^{N}\left[\sum_{i=1}^{j-1} \int_{A_{i}} \int_{A_{j}} \chi_{i}\left(\mathbf{r}_{i}\right) \chi_{j}\left(\mathbf{r}_{j}\right) K_{i j}\left(\mathbf{r}_{i}, \mathbf{r}_{j}\right) d A_{j} d A_{i}\right]
\end{aligned}
$$

A minimização da equação (A.3) resulta na equação (A.2). Isto pode ser demonstrado fazendo-se:

$$
\chi_{k}\left(\mathbf{r}_{k}\right)=\bar{\chi}_{k}\left(\mathbf{r}_{k}\right)+\omega_{k} \eta_{k}\left(\mathbf{r}_{k}\right) \quad(k=1,2, \ldots, N)
$$

em que a função que minimizará o funcional $I$ é dada por $\bar{\chi}, \omega$ é o parâmetro variacional e $\eta$ é uma função arbitrária. É importante observar que $\omega_{k}$ é membro de um conjunto identificado por $\Omega=\left\{\omega_{1}, \omega_{2}, \ldots, \omega_{N}\right\}$ e $\Omega=0$ implica que cada membro do conjunto é igual a zero.

O extremo desta função é obtido quando:

$$
\left(\frac{\partial I}{\partial \omega_{k}}\right)_{\Omega=0}=0
$$

Logo, vale que:

$$
\int_{A_{k}} \eta_{k}\left(\mathbf{r}_{k}\right)\left[\frac{1}{\lambda_{k}} \chi_{k}\left(\mathbf{r}_{k}\right)-\frac{1}{\lambda_{k}} \psi_{k}\left(\mathbf{r}_{k}\right)-\sum_{j=1}^{N} \int_{A_{j}} \chi_{j}\left(\mathbf{r}_{j}\right) K_{k j}\left(\mathbf{r}_{k}, \mathbf{r}_{j}\right) d A_{j}\right] d A_{k}=0
$$

Cada função $\bar{\chi}$ torna-se $\chi$, quando $\Omega=0$. Como a equação (A.6) é válida para todos os valores de $\eta_{k}\left(\mathbf{r}_{k}\right)$, então a quantidade contida entre colchetes deve valer zero, portanto, a minimização da equação (A.3) resulta na equação (A.2). Para que este extremo seja um mínimo, a segunda derivada de $I$ em relação à $\omega_{k}$ tem que ser positiva. Esta derivada, após a utilização da relação $(2.59)$ em $K_{i j}$, vale:

$$
\begin{aligned}
\frac{\partial^{2} I}{\partial \omega_{k}^{2}} & =2\left\{\frac{1}{\lambda_{k}} \int_{A_{k}}\left[\eta_{k}\left(\mathbf{r}_{k}\right)\right]^{2} d A_{k}-\int_{A_{k}} \int_{A_{k}}\left[\eta_{k}\left(\mathbf{r}_{k}^{\prime}\right)\right]^{2} K_{k k}\left(\mathbf{r}_{k}, \mathbf{r}_{k}^{\prime}\right) d A_{k}^{\prime} d A_{k}\right\}+ \\
& +\int_{A_{k}} \int_{A_{k}}\left[\eta_{k}\left(\mathbf{r}_{k}\right)-\eta_{k}\left(\mathbf{r}_{k}^{\prime}\right)\right]^{2} K_{k k}\left(\mathbf{r}_{k}, \mathbf{r}^{\prime}{ }_{k}\right) d A^{\prime}{ }_{k} d A_{k}>0
\end{aligned}
$$

Se os dois termos do lado direito da equação (A.7) forem positivos, a inequação será válida. A função $\eta_{k}$ é real e $\eta_{k}^{2}$ é sempre positiva e pode ser considerada como uma radiosidade 
abstrata da superfície $k$. A integral

$$
\int_{A_{k}} \int_{A_{k}}\left[\eta_{k}\left(\mathbf{r}_{k}^{\prime}\right)\right]^{2} K_{k k}\left(\mathbf{r}_{k}, \mathbf{r}_{k}^{\prime}\right) d A_{k}^{\prime} d A_{k}
$$

dentro das chaves da equação (A.7) representa uma fração de energia abstrata que a superfície $k$ irradia sobre ela mesma. Toda a energia que deixa $k$ é dada por:

$$
\int_{A_{k}}\left[\eta_{k}\left(\mathbf{r}_{k}\right)\right]^{2} d A_{k}
$$

Assim, o valor líquido do termo dentro das chaves na relação (A.7) é positivo, implicando que $\partial^{2} I / \partial \omega_{k}^{2}>0$. É importante notar que quando $I=-I$ a equação (A.6) não se modifica, mas neste caso, $\partial^{2} I / \partial \omega_{k}^{2}<0$. Portanto, somente o extremo da função $I$ é condição suficiente para satisfazer as equações para troca de energia entre as superfícies.

\section{A.1 Dedução do Método dos Elementos Finitos}

Este método permite uma solução para as equações que descrevem a troca de radiação entre superfícies. No artigo (SPARROW; LIN, 1965), propõe-se substituir $\chi_{k}\left(\mathbf{r}_{k}\right)$ na equação (A.3) por:

$$
\chi_{k}\left(\mathbf{r}_{k}\right)=\sum_{m=1}^{M} d_{k, m} f_{k, m}\left(\mathbf{r}_{k}\right) \quad(k=1,2, \ldots, N)
$$

em que $f_{k, m}$ representa uma função base (na sua formulação, Sparrow utiliza $f_{k, m}=$ $\left.x^{2(m-1)}\right)$ e $d_{k, m}$ seu coeficiente. Depois desta substituição, diferencia-se o variacional $I$ em relação à $d_{k, m}$ para se obter um conjunto de equações simultâneas. A substituição de $\chi_{k}\left(\mathbf{r}_{k}\right)$ na equação (A.6) resulta no seguinte conjunto de equações:

$$
\begin{gathered}
\int_{A_{k}} f_{k, n}\left(\mathbf{r}_{k}\right)\left[\frac{1}{\lambda_{k}} \sum_{m=1}^{M} d_{k, m} f_{k, m}\left(\mathbf{r}_{k}\right)-\frac{1}{\lambda_{k}} \psi_{k}\left(\mathbf{r}_{k}\right)-\right. \\
\left.-\sum_{j=1}^{N} \int_{A_{j}} \sum_{m=1}^{M} d_{j, m} f_{j, m}\left(\mathbf{r}_{j}\right) K_{k j}\left(\mathbf{r}_{k}, \mathbf{r}_{j}\right) d A_{j}\right] d A_{k}=0
\end{gathered}
$$

para $k=1,2, \ldots, N$, em que $N$ representa o número total de superfícies. Contudo, $M$ pode variar de superfície para superfície. A equação (A.9) representa um conjunto algébrico de $M \times N$ equações simultâneas. A solução deste conjunto de equações é dada como:

$$
\mathbf{A d}=\psi
$$

Os coeficientes formam um conjunto $\mathbf{d}=\left\{\mathbf{d}_{1}, \mathbf{d}_{2}, \ldots, \mathbf{d}_{N}\right\}$, em que cada membro do $k$-ésimo subconjunto tem os elementos $\mathbf{d}_{k}=\left\{d_{k, 1}, d_{k, 2}, \ldots, d_{k, M}\right\}$. Os elementos da matriz 
A na equação (A.10) são dados como:

$$
\begin{aligned}
a_{m, n}^{k, j} & =\frac{\delta_{k j}}{\lambda_{k}} \int_{A_{k}} f_{k, n}\left(\mathbf{r}_{k}\right) f_{j, m}\left(\mathbf{r}_{k}\right) d A_{k} \\
& -\int_{A_{k}} \int_{A_{j}} f_{k, n}\left(\mathbf{r}_{k}\right) f_{j, m}\left(\mathbf{r}_{k}\right) K_{k j}\left(\mathbf{r}_{k}, \mathbf{r}_{j}\right) d A_{j} d A_{k}
\end{aligned}
$$

em que $\delta_{k j}=1$, quando $k=j$, e $\delta_{k j}=0$, quando $k \neq j$. Para cada par de $(k, j), a_{m, n}^{k, j}$ descreve uma matriz quadrada $\mathbf{A}_{k, j}$, cuja localização na matriz quadrada $\mathbf{A}$ é mostrada abaixo:

$$
\mathbf{A}=\left[\begin{array}{cccc}
\mathbf{A}^{1,1} & \mathbf{A}^{1,2} & \ldots & \mathbf{A}^{1, N} \\
\mathbf{A}^{2,1} & \mathbf{A}^{2,2} & \ldots & \mathbf{A}^{2, N} \\
\vdots & \vdots & \ddots & \vdots \\
\mathbf{A}^{N, 1} & \mathbf{A}^{N, 2} & \ldots & \mathbf{A}^{N, N}
\end{array}\right]
$$

Cada membro da matriz A é uma matriz $M \times M$

$$
\mathbf{A}^{k, j}=\left[\begin{array}{cccc}
a_{1,1}^{k, j} & a_{1,2}^{k, j} & \ldots & a_{1, M}^{k, j} \\
a_{2,1}^{k, j} & a_{2,2}^{k, j} & \ldots & a_{2, M}^{k, j} \\
\vdots & \vdots & \ddots & \vdots \\
a_{M, 1}^{k, j} & a_{M, 2}^{k, j} & \ldots & a_{M, M}^{k, j}
\end{array}\right]
$$

e satisfaz a relação $\mathbf{A}^{j, k}=\mathbf{A}^{k, j}$, indicando que a matriz $\mathbf{A}$ é simétrica. O vetor representado por $\psi=\left\{\psi_{1}, \psi_{2}, \ldots, \psi_{N}\right\}$ é do tipo coluna e consiste de subvetores $\psi_{k}$. Cada subvetor destes contém os elementos $\psi_{k}=\left\{\psi_{k, 1}, \psi_{k, 2}, \ldots, \psi_{k, M}\right\}$, dados por:

$$
\psi_{k, m}=\int_{A_{k}} \frac{1}{\lambda_{k}} f_{k, m}\left(\mathbf{r}_{k}\right) \psi_{k}\left(\mathbf{r}_{k}\right) d A_{k}
$$

A formulação propriamente dita do MEF começa com a equação (A.6). Cada superfície $k$ é subdividida em $M_{k}$ pequena superfícies e cada uma é tratada como uma superfície separada para inclusão na equação (A.6). O próximo passo consiste em definir as funções $\chi$ e $\eta$ para todos os elementos. Semelhante ao procedimento básico feito no MEF, as funções $\chi$ são descritas por funções lineares em função de coordenadas locais em cada elemento:

$$
\chi_{k}\left(\xi_{m}, \zeta_{m}\right)=\left(1-\xi_{m}-\zeta_{m}\right) \chi_{k, m}+\xi_{m} \chi_{k, l}+\zeta_{m} \chi_{k, p}
$$

em que $\chi_{k, m}, \chi_{k, l}$ e $\chi_{k, p}$ são os nós dos cantos do elemento $m$, tendo as coordenadas $(0,0)$, $(1,0)$ e $(0,1)$, respectivamente, no sistema de coordenadas local $\left(\xi_{m}, \zeta_{m}\right)$. Desta forma, todas as integrais na equação (A.9) terão valores exatos, exceto aquelas que possuem a função $K_{k j}$ em seu integrando, que podem ser avaliadas numericamente, como feito em 3.1.3. A partir da aplicação destas definições, pode-se então utilizar as equações de (A.10) 
a (A.14) para solução do problema analisado. 


\section{Anexo B - Aferição dos Métodos Numéricos}

Neste apêndice, são apresentados e discutidos benchmarks numéricos da determinação dos fatores de forma através da integral no contorno, tal qual discutido em 3.1.3, bem como benchmarks da aferição do método dos elementos finitos aplicado à troca radiante no interior de confinamentos, previamente introduzido na seção 3.2. Os resultados numéricos apresentados aqui foram obtidos através de implementação computacional utilizando o software comercial Matlab ${ }^{\circledR}$.

\section{B.1 Aferição dos Fatores de Forma calculados Numericamente}

Os fatores de forma foram computacionalmente calculados utilizando a quadratura de Gauss aplicada à integral no contorno discutida em 3.1.3 e dada pela formulação (3.5). Obviamente, por se tratar de um cálculo complexo e computacionalmente custoso, como previamente discutido em 3.1.1, optou-se por abordar apenas os casos em que estes fatores geométricos são calculados entre dois retângulos alinhados paralelamente e entre retângulos perpendiculares com um vértice comum, como feito analiticamente através das expressões (2.57) e (2.58).

Uma vez que a otimização topológica é um processo iterativo, os fatores de forma deveriam ser ciclicamente calculados (vide Figura 4.9). Porém, como neste trabalho não são feitas mudanças na geometria ou forma da cavidade, mas sim na distribuição de material com propriedade radiante no seu interior, a estratégia adotada para evitar o cálculo repetitivo e desnecessário dessas medidas geométricas foi similar a tomada por (MEHDIPOUR et al., 2010), que consiste em armazenar os valores destas medidas geométricas em arquivos de textos, de acordo com o número de elementos da malha que descreve a cavidade e de acordo com o número de pontos de Gauss de integração utilizados para solução numérica da equação (3.5).

Apesar de possível, este trabalho não faz uma comparação elemento a elemento entre os valores de fator de forma numericamente calculados através da equação (3.5) e os 
Tabela B.1: Fatores de forma calculados analiticamente para as paredes de um confinamento de dimensão $L \times L \times L$.

\begin{tabular}{|c|c|c|c|c|c|c|}
\cline { 2 - 8 } \multicolumn{1}{c|}{} & \multicolumn{6}{c|}{ Fatores de Forma Analíticos } \\
\hline Paredes & 1 & 2 & 3 & 4 & 5 & 6 \\
\hline 1 & 0,000000 & 0,199824 & 0,200043 & 0,200043 & 0,200043 & 0,200043 \\
\hline 2 & 0,199824 & 0,000000 & 0,200043 & 0,200043 & 0,200043 & 0,200043 \\
\hline 3 & 0,200043 & 0,200043 & 0,000000 & 0,199824 & 0,200043 & 0,200043 \\
\hline 4 & 0,200043 & 0,200043 & 0,199824 & 0,000000 & 0,200043 & 0,200043 \\
\hline 5 & 0,200043 & 0,200043 & 0,200043 & 0,200043 & 0,000000 & 0,199824 \\
\hline 6 & 0,200043 & 0,200043 & 0,200043 & 0,200043 & 0,199824 & 0,000000 \\
\hline
\end{tabular}

Tabela B.2: Porcentagem de erro médio no cálculo dos fatores de forma das paredes de um confinamento de dimensão $L \times L \times L$.

\begin{tabular}{|c|c|c|c|c|c|c|}
\cline { 2 - 7 } \multicolumn{2}{c|}{} & \multicolumn{6}{|c|}{ Porcentagem de Erro Médio no Cálculo dos Fatores de Forma } \\
\hline Elementos & 1 & 2 & 3 & 4 & 5 & 6 \\
\hline 1 & 7,2246 & 0,1332 & 0,0028 & $1,7 \mathrm{E}-06$ & $1,9 \mathrm{E}-06$ & $9,7 \mathrm{E}-08$ \\
\hline 150 & 2,5384 & 0,2126 & 0,0489 & 0,0170 & 0,0074 & 0,0037 \\
\hline 600 & 1,4692 & 0,1201 & 0,0275 & 0,0095 & 0,0042 & 0,0021 \\
\hline 2400 & 0,7999 & 0,0635 & 0,0145 & 0,0050 & 0,0022 & 0,0011 \\
\hline 5400 & 0,5501 & 0,0431 & 0,0098 & 0,0034 & 0,0015 & 0,0007 \\
\hline 9600 & 0,4202 & 0,0326 & 0,0074 & 0,0026 & 0,0011 & 0,0006 \\
\hline 15000 & 0,3398 & 0,0262 & 0,0060 & 0,0021 & 0,0009 & 0,0005 \\
\hline
\end{tabular}

valores analíticos (EHLERT; SMITH, 1993), dado o custo desta aferição. Ao invés disto, os valores numericamente calculados são agrupados de maneira a se obter os fatores de forma entre as paredes que compõem o interior do confinamento. Este resultados são então comparados com valores analíticos apresentados nas Tabelas B.1 e B.3 (nestas Tabelas, as paredes do confinamento são referenciadas tal qual feito na Figura 2.14). Através destes resultados, uma média aritmética do erro foi efetuada e os valores estão organizados nas Tabelas B.2 e B.4, em função do número de elementos que malham o confinamento, do número de pontos de Gauss necessários para o cálculo da equação (3.5) e das dimensões das placas que compõem um confinamento como o dado no item 2.1.4.6.

Os dados apresentados pelas Tabelas B.2 e B.4 mostram que a convergência no cálculo dos fatores de forma entre superfícies planas é razoavelmente bem comportada, exibindo erros abaixo de $1 \%$ a partir de 2 pontos de Gauss, para qualquer quantidade de elementos testada. A precisão a ser utilizada na determinação destes fatores (e intrinsecamente a escolha adequada da quantidade de elementos e pontos de Gauss), depende contudo, diretamente da precisão desejada para modelagem da radiação no interior do confinamento 
Tabela B.3: Fatores de forma calculados analiticamente para as paredes de um confinamento de dimensão $0,4 \times 0,5 \times 0,3 \mathrm{~m}$.

\begin{tabular}{|c|c|c|c|c|c|c|}
\cline { 2 - 7 } \multicolumn{1}{c|}{} & \multicolumn{6}{c|}{ Fatores de Forma Analíticos } \\
\hline Paredes & 1 & 2 & 3 & 4 & 5 & 6 \\
\hline 1 & 0,000000 & 0,316319 & 0,251398 & 0,251398 & 0,254668 & 0,254668 \\
\hline 2 & 0,316319 & 0,000000 & 0,251398 & 0,251398 & 0,254668 & 0,254668 \\
\hline 3 & 0,150839 & 0,150839 & 0,000000 & 0,116827 & 0,152150 & 0,152150 \\
\hline 4 & 0,150839 & 0,150839 & 0,116827 & 0,000000 & 0,152150 & 0,152150 \\
\hline 5 & 0,191001 & 0,191001 & 0,190187 & 0,200043 & 0,000000 & 0,186363 \\
\hline 6 & 0,191001 & 0,191001 & 0,190187 & 0,200043 & 0,186363 & 0,000000 \\
\hline
\end{tabular}

estudado, como ficará claro na seção B.2. É preciso lembrar também que, segundo Feingold (1966), uma precisão da ordem de 6 casas decimais é minimamente recomendável no uso de valores de fatores de forma analiticamente calculados. O autor procurou seguir, sempre que possível, este padrão de qualidade na obtenção dos seus resultados numéricos.

É interessante notar ainda, que os valores mais precisos são obtidos, na média, quando foram utilizados apenas um elemento em cada superfície e seis pontos de Gauss em cada contorno. Esta conclusão, que aparentemente mostra uma extrema eficiência do método utilizado, uma vez que, com apenas um elemento o algoritmo é mais rápido e menos custoso, não pode ser tomada como estritamente verdadeira. O que acontece é que a otimização topológica classicamente apresenta resultados mais expressivos com o uso de uma quantidade maior de elementos, por isso é interessante obter resultados precisos da modelagem do fenômeno também para um número maior de elementos. Além disso, Walton (2002) afirma que dependendo da dimensão do confinamento, quando as superfícies que o compõem estão relativamente próximas, métodos numéricos requerem um número maior de divisões dos contornos de integração, o que indica que um malha refinada é a mais adequada para o cálculo dos fatores de forma nestes casos. Uma malha mais grosseira seria suficiente, porém, em casos em que as superfícies estão relativamente separadas, o que pode parcialmente justificar a precisão alcançada para fatores de forma calculados com apenas um elemento.

Como discutido na seção 3.1.1, o cálculo dos fatores de forma, mesmo na sua formulação mais simples, através da equação (2.55), pode ser computacionalmente bastante trabalhoso. A escolha adequada do número de elementos e pontos de Gauss para determinação dos fatores de forma não é uma tarefa simples, portanto. O algoritmo desenvolvido para o cálculo dos fatores de forma deste trabalho mostra-se consideravelmente lento para um número de elementos acima de 9600 e exige uso intensivo de memória RAM. 
Tabela B.4: Porcentagem de erro médio no cálculo dos fatores de forma das paredes de um confinamento de dimensão $0,4 \times 0,5 \times 0,3 \mathrm{~m}$.

\begin{tabular}{|c|c|c|c|c|c|c|}
\cline { 2 - 7 } \multicolumn{2}{c|}{} & \multicolumn{6}{|c|}{ Porcentagem de Erro Médio no Cálculo dos Fatores de Forma } \\
\hline Elementos & 1 & 2 & 3 & 4 & 5 & 6 \\
\hline 1 & 9,5898 & 0,1440 & 0,0048 & 0,0005 & $6,5 \mathrm{E}-06$ & $9,6 \mathrm{E}-07$ \\
\hline 150 & 2,7092 & 0,2238 & 0,0514 & 0,0179 & 0,0078 & 0,0039 \\
\hline 600 & 1,5560 & 0,1265 & 0,0289 & 0,0100 & 0,0044 & 0,0022 \\
\hline 2400 & 0,8446 & 0,0669 & 0,0153 & 0,0053 & 0,0023 & 0,0011 \\
\hline 5400 & 0,5809 & 0,0454 & 0,0104 & 0,0036 & 0,0016 & 0,0008 \\
\hline 9600 & 0,4430 & 0,0343 & 0,0078 & 0,0027 & 0,0012 & 0,0006 \\
\hline 15000 & 0,3582 & 0,0276 & 0,0063 & 0,0022 & 0,0009 & 0,0005 \\
\hline
\end{tabular}

\section{B.2 Aferição do MEF aplicado à Troca Radiante em Confinamentos}

O método dos elementos finitos aplicado à troca radiante em cavidades foi introduzido em 3.2.2 e em 3.2.3, e é representado pela equação (3.6), para o cálculo das radiosidades incógnitas, e pela equação (3.15), para o cálculo das temperaturas e fluxos de calor desconhecidos. Dois benchmarks são propostos para a verificação da precisão da implementação computacional deste método e os resultados são comparados com valores obtidos analiticamente.

\section{B.2.1 Primeiro Benchmark}

O primeiro benchmark trata-se de um problema rápido e eficaz para verificação da validade do método implementado. Um confinamento tridimensional, como o discutido no exemplo 2.1.4.6, possui agora dimensões idênticas $(L \times L \times L)$. Se as emissividades das paredes do forno forem todas iguais $\left(\varepsilon_{1}=\varepsilon_{2}=\ldots=\varepsilon_{6}=0,5\right)$, bem como as temperaturas $\left(T_{1}=T_{2}=\ldots=T_{6}=900 \mathrm{~K}\right)$, o fluxo de calor por radiação esperado é nulo e a radiosidade igual a 37203,49 W/ $\mathrm{m}^{2}$ em cada parede deste confinamento. Os resultados numéricos são apresentados na forma de uma média aritmética de todos os valores de fluxo de calor calculados no interior do confinamento na Tabela B.5 e na forma de uma média aritmética do erro no cálculo das radiosidades na Tabela B.6. Estes valores estão em função do número de elementos que malham o confinamento e do número de pontos de Gauss que foram utilizados na determinação dos fatores de forma.

É possível inferir da Tabela B.5 que para 5 e 6 pontos de Gauss os resultados no cálculo dos fluxos de calor são homogeneamente mais precisos. Esta precisão na validação do primeiro benchmark influenciou o autor a optar por trabalhar, sempre que possível, 
Tabela B.5: Média aritmética dos fluxos de calor sobre todas as paredes para o primeiro benchmark.

\begin{tabular}{|c|c|c|c|c|c|c|}
\hline \multicolumn{7}{|c|}{ Fluxos de Calor $\left(W / m^{2}\right)$} \\
\hline Elementos & 1 Ponto de Gauss & 2 Pontos de Gauss & 3 Pontos de Gauss & 4 Pontos de Gauss & 5 Pontos de Gauss & 6 Pontos de Gauss \\
\hline 1 & 1604,46 & $-26,64$ & 0,51 & 0,00 & 0,00 & 0,00 \\
\hline 150 & 1039,82 & 94,63 & 21,80 & 7,57 & 3,30 & 1,67 \\
\hline 600 & 619,12 & 53,49 & 12,27 & 4,26 & 1,86 & 0,00 \\
\hline 2400 & 341,56 & 28,29 & 6,47 & 2,25 & 0,98 & 0,49 \\
\hline 5400 & 236,13 & 19,20 & 4,39 & 1,52 & 0,66 & 0,33 \\
\hline 9600 & 180,56 & 14,53 & 3,32 & 1,15 & 0,50 & 0,25 \\
\hline 15000 & 146,22 & 11,69 & 2,67 & 0,92 & 0,40 & 0,20 \\
\hline
\end{tabular}

Tabela B.6: Porcentagem de erro médio no cálculo das radiosidades sobre todas as paredes para o primeiro benchmark.

\begin{tabular}{|c|c|c|c|c|c|c|}
\hline \multicolumn{7}{|c|}{ Porcentagem de Erro Médio no Cálculo das Radiosidades $\left(\mathrm{W} / \mathrm{m}^{2}\right)$} \\
\hline Elementos & 1 Ponto de Gauss & 2 Pontos de Gauss & 3 Pontos de Gauss & 4 Pontos de Gauss & 5 Pontos de Gauss & 6 Pontos de Gauss \\
\hline 1 & $-4,3127$ & 0,0716 & $-0,0014$ & 0,0000 & 0,0000 & 0,0000 \\
\hline 150 & $-2,7950$ & $-0,2544$ & $-0,0586$ & $-0,0204$ & $-0,0089$ & $-0,0045$ \\
\hline 600 & $-1,6642$ & $-0,1438$ & $-0,0330$ & $-0,0114$ & $-0,0050$ & 0,0000 \\
\hline 2400 & $-0,9181$ & $-0,0760$ & $-0,0174$ & $-0,0060$ & $-0,0026$ & $-0,0013$ \\
\hline 5400 & $-0,6347$ & $-0,0516$ & $-0,0118$ & $-0,0041$ & $-0,0018$ & $-0,0009$ \\
\hline 9600 & $-0,4853$ & $-0,0391$ & $-0,0089$ & $-0,0031$ & $-0,0014$ & $-0,0007$ \\
\hline 15000 & $-0,3930$ & $-0,0314$ & $-0,0072$ & $-0,0025$ & $-0,0011$ & $-0,0005$ \\
\hline
\end{tabular}

com 15000 elementos na descrição do confinamento. Já a Tabela B.6 mostra que para a determinação das radiosidades do primeiro benchmark, resultados satisfatórios são alcançados para praticamente qualquer combinação analisada. Além disso, se comparados os erros obtidos nos cálculos dos fatores de forma (Tabela B.2) com a ordem de grandeza do módulo dos erros apresentados na Tabela B.6, percebe-se que, para muitas combinações de elementos e número de pontos de Gauss, estes erros tem praticamente a mesma dimensão, o que pode indicar uma relação direta entre a precisão na determinação destas diferentes medidas.

\section{B.2.2 Segundo Benchmark}

No segundo benchmark, a solução do problema do confinamento tridimensional dado em 2.1.4.6 é refeita, com as mesmas condições de contorno de temperatura e fluxo de calor 
e com as mesmas propriedades em cada parede do confinamento, ou seja:

$$
\left\{\begin{array} { l } 
{ \varepsilon _ { 1 } = 0 , 9 0 } \\
{ \varepsilon _ { 2 } = 0 , 7 0 } \\
{ \varepsilon _ { 3 } = 0 , 8 0 } \\
{ \varepsilon _ { 4 } = 0 , 3 0 } \\
{ \varepsilon _ { 5 } = 0 , 9 0 } \\
{ \varepsilon _ { 6 } = 0 , 9 0 }
\end{array} \quad \left\{\begin{array} { l } 
{ T _ { 1 } = 5 0 0 \mathrm { K } } \\
{ T _ { 2 } = 8 0 0 \mathrm { K } } \\
{ T _ { 3 } = 1 0 0 0 \mathrm { K } } \\
{ T _ { 4 } = 1 2 0 0 \mathrm { K } }
\end{array} \quad \left\{\begin{array}{l}
Q_{5}=0 \\
Q_{6}=0
\end{array}\right.\right.\right.
$$

Os resultados analíticos obtidos para cada parede do confinamento são:

$$
\mathbf{T}=\left[\begin{array}{c}
500,00 \\
800,00 \\
1000,00 \\
1200,00 \\
846,77 \\
846,77
\end{array}\right] K \quad \mathbf{q}=\left[\begin{array}{c}
-27918,42 \\
-3896,05 \\
25221,75 \\
27802,36 \\
0,00 \\
0,00
\end{array}\right] W / m^{2} \quad \mathbf{J}=\left[\begin{array}{l}
6646,04 \\
24895,69 \\
50398,56 \\
52709,22 \\
29153,73 \\
29153,73,
\end{array}\right] \mathrm{W} / \mathrm{m}^{2}
$$

As médias aritméticas percentuais dos erros nos cálculos das radiosidades em cada parede do forno, das temperaturas nas paredes 5 e 6 e dos fluxos de calor nas paredes de 1 a 4 (para numeração das paredes do forno, consultar Figura 2.14) são apresentadas nas Tabelas B.7, B.8, B.9 e B.10, em função do número de elementos que descrevem o domínio analisado e do número de pontos de Gauss utilizados na determinação dos fatores de forma através da equação (3.5). Uma verificação da primeira lei da termodinâmica aplicada ao sistema em questão é feita na Tabela B.11 e, de acordo com a equação (2.90), quanto mais próximo de zero for o resultado apresentado nesta tabela, mais conservativo é o sistema. Somente valores obtidos para 2400, 5400, 9600 e 15000 elementos são discutidos, por considerar-se que tais valores são os mais adequados para geração de resultados refinados na otimização topológica.

Os resultados obtidos na determinação das variáveis desconhecidas do sistema mostraram-se satisfatórios, apresentando em muitos casos erros próximos a $0 \%$. Uma anomalia é identificada na determinação do fluxo de calor na parede número 2, contudo. Mesmo com um aumento do número de pontos de Gauss para determinação dos fatores de forma e do número de elementos, a tendência é que um erro em torno de $5 \%$ seja obtido na determinação numérica desta variável. Acreditando tratar-se de um problema vinculado às condições de contorno utilizadas, um teste foi feito a partir da modificação da temperatura da parede 2 para $500 \mathrm{~K}$, mantendo-se todas as outras condições iguais ao do segundo benchmark. Para 6 pontos de Gauss e 15000 elementos, um erro médio de apenas $-0,4330 \%$ em relação ao valor analítico foi encontrado para o fluxo de calor calculado 
Tabela B.7: Porcentagem de erro médio no cálculo das variáveis desconhecidas do segundo benchmark, modelado com 2400 elementos.

\begin{tabular}{|c|c|c|c|c|c|c|}
\hline \multicolumn{7}{|c|}{ Porcentagem de Erro Médio no Cálculo das Incógnitas - 2400 Elementos } \\
\hline Resultados & 1 Ponto de Gauss & 2 Pontos de Gauss & 3 Pontos de Gauss & 4 Pontos de Gauss & 5 Pontos de Gauss & 6 Pontos de Gauss \\
\hline$J_{1}$ & $-1,7335$ & $-0,9302$ & $-0,8742$ & $-0,8634$ & $-0,8601$ & $-0,8589$ \\
\hline$J_{2}$ & $-0,4427$ & 0,2891 & 0,3405 & 0,3505 & 0,3535 & 0,3546 \\
\hline$J_{3}$ & $-0,0558$ & 0,1397 & 0,1533 & 0,1559 & 0,1567 & 0,1570 \\
\hline$J_{4}$ & 0,1152 & 0,7948 & 0,8422 & 0,8514 & 0,8541 & 0,8552 \\
\hline$J_{5}$ & $-1,5353$ & 0,0497 & 0,1596 & 0,1808 & 0,1872 & 0,1897 \\
\hline$J_{6}$ & $-1,5353$ & 0,0497 & 0,1596 & 0,1808 & 0,1872 & 0,1897 \\
\hline$T_{5}$ & $-0,5424$ & $-0,1557$ & $-0,1293$ & $-0,1243$ & $-0,1227$ & $-0,1221$ \\
\hline$T_{6}$ & $-0,5424$ & $-0,1557$ & $-0,1293$ & $-0,1243$ & $-0,1227$ & $-0,1221$ \\
\hline$q_{1}$ & $-3,7140$ & $-1,9929$ & $-1,8730$ & $-1,8497$ & $-1,8428$ & $-1,8401$ \\
\hline$q_{2}$ & $-6,6002$ & 4,3111 & 5,0770 & 5,2256 & 5,2701 & 5,2872 \\
\hline$q_{3}$ & 0,4458 & $-1,1167$ & $-1,2250$ & $-1,2460$ & $-1,2523$ & $-1,2547$ \\
\hline$q_{4}$ & $-0,0936$ & $-0,6458$ & $-0,6843$ & $-0,6917$ & $-0,6940$ & $-0,6948$ \\
\hline
\end{tabular}

nesta parede. Este teste comprova a necessidade de analisar caso a caso a convergência dos valores obtidos, uma vez que o método aqui discutido pode se mostrar relativamente impreciso na determinação de algumas incógnitas, dada a forma como as condições de contorno do problema foram inicialmente prescritas.

Cabe ainda analisar se o método utilizado para determinação das radiosidades, temperaturas e fluxos de calor respeita a primeira lei da termodinâmica. Isto é feito verificando-se a conservação da energia no sistema analisado, da mesma forma como recomendado no quarto passo apresentado na seção 2.1.4.5. A Tabela B.11 mostra que os melhores resultados são obtidos a partir de 4 pontos de Gauss e com o aumento do número de elementos.

Mesmo sabendo que não seria necessário, por preciosismo o autor optou, sempre que possível, em utilizar o máximo número de elementos e pontos de Gauss. O leitor, todavia, teve acesso nas últimas linhas a uma série de dados que podem levá-lo a uma escolha computacionalmente mais econômica.

Ao final da leitura deste apêndice, o leitor precisa estar ciente que uma precisão, muitas vezes abaixo de $1 \%$ para o cálculo dos fatores de forma e das variáveis envolvidas na modelagem da radiação no interior de confinamentos, não representa uma demanda ousada. Mesmo que a solução da equação (3.5) e as soluções dos sistemas lineares descritos pelas equações (3.6) e (3.15) possam ser tarefas computacionalmente custosas, a literatura indica que tamanha precisão é minimamente necessária para a correta modelagem do fenômeno aqui discutido (FEINGOLD, 1966). 
Tabela B.8: Porcentagem de erro médio no cálculo das variáveis desconhecidas do segundo benchmark, modelado com 5400 elementos.

\begin{tabular}{|c|c|c|c|c|c|c|}
\hline \multicolumn{7}{|c|}{ Porcentagem de Erro Médio no Cálculo das Incógnitas - 5400 Elementos } \\
\hline Resultados & 1 Ponto de Gauss & 2 Pontos de Gauss & 3 Pontos de Gauss & 4 Pontos de Gauss & 5 Pontos de Gauss & 6 Pontos de Gauss \\
\hline$J_{1}$ & $-1,4664$ & $-0,9122$ & $-0,8745$ & $-0,8671$ & $-0,8650$ & $-0,8641$ \\
\hline$J_{2}$ & $-0,1974$ & 0,3089 & 0,3438 & 0,3506 & 0,3526 & 0,3534 \\
\hline$J_{3}$ & 0,0110 & 0,1475 & 0,1568 & 0,1586 & 0,1592 & 0,1594 \\
\hline$J_{4}$ & 0,3475 & 0,8252 & 0,8579 & 0,8642 & 0,8661 & 0,8668 \\
\hline$J_{5}$ & $-1,0027$ & 0,0991 & 0,1741 & 0,1886 & 0,1929 & 0,1946 \\
\hline$J_{6}$ & $-1,0027$ & 0,0991 & 0,1741 & 0,1886 & 0,1929 & 0,1946 \\
\hline$T_{5}$ & $-0,4132$ & $-0,1457$ & $-0,1278$ & $-0,1244$ & $-0,1234$ & $-0,1230$ \\
\hline$T_{6}$ & $-0,4132$ & $-0,1457$ & $-0,1278$ & $-0,1244$ & $-0,1234$ & $-0,1230$ \\
\hline$q_{1}$ & $-3,1417$ & $-1,9544$ & $-1,8735$ & $-1,8578$ & $-1,8531$ & $-1,8513$ \\
\hline$q_{2}$ & $-2,9430$ & 4,6050 & 5,1258 & 5,2268 & 5,2570 & 5,2686 \\
\hline$q_{3}$ & $-0,0881$ & $-1,1793$ & $-1,2535$ & $-1,2679$ & $-1,2722$ & $-1,2739$ \\
\hline$q_{4}$ & $-0,2823$ & $-0,6705$ & $-0,6970$ & $-0,7022$ & $-0,7037$ & $-0,7043$ \\
\hline
\end{tabular}

Tabela B.9: Porcentagem de erro médio no cálculo das variáveis desconhecidas do segundo benchmark, modelado com 9600 elementos.

\begin{tabular}{|c|c|c|c|c|c|c|}
\hline \multicolumn{7}{|c|}{ Porcentagem de Erro Médio no Cálculo das Incógnitas - 9600 Elementos } \\
\hline Resultados & 1 Ponto de Gauss & 2 Pontos de Gauss & 3 Pontos de Gauss & 4 Pontos de Gauss & 5 Pontos de Gauss & 6 Pontos de Gauss \\
\hline$J_{1}$ & $-1,3256$ & $-0,9024$ & $-0,8739$ & $-0,8683$ & $-0,8667$ & $-0,8661$ \\
\hline$J_{2}$ & $-0,0681$ & 0,3192 & 0,3456 & 0,3508 & 0,3523 & 0,3529 \\
\hline$J_{3}$ & 0,0463 & 0,1513 & 0,1584 & 0,1597 & 0,1602 & 0,1603 \\
\hline$J_{4}$ & 0,4708 & 0,8396 & 0,8646 & 0,8695 & 0,8709 & 0,8715 \\
\hline$J_{5}$ & $-0,7211$ & 0,1243 & 0,1812 & 0,1922 & 0,1955 & 0,1968 \\
\hline$J_{6}$ & $-0,7211$ & 0,1243 & 0,1812 & 0,1922 & 0,1955 & 0,1968 \\
\hline$T_{5}$ & $-0,3450$ & $-0,1405$ & $-0,1269$ & $-0,1243$ & $-0,1235$ & $-0,1232$ \\
\hline$T_{6}$ & $-0,3450$ & $-0,1405$ & $-0,1269$ & $-0,1243$ & $-0,1235$ & $-0,1232$ \\
\hline$q_{1}$ & $-2,8401$ & $-1,9333$ & $-1,8722$ & $-1,8604$ & $-1,8569$ & $-1,8555$ \\
\hline$q_{2}$ & $-1,0159$ & 4,7591 & 5,1536 & 5,2300 & 5,2529 & 5,2617 \\
\hline$q_{3}$ & $-0,3703$ & $-1,2094$ & $-1,2659$ & $-1,2768$ & $-1,2801$ & $-1,2813$ \\
\hline$q_{4}$ & $-0,3825$ & $-0,6822$ & $-0,7025$ & $-0,7064$ & $-0,7076$ & $-0,7081$ \\
\hline
\end{tabular}


Tabela B.10: Porcentagem de erro médio no cálculo das variáveis desconhecidas do segundo benchmark, modelado com 15000 elementos.

\begin{tabular}{|c|c|c|c|c|c|c|}
\hline \multicolumn{7}{|c|}{ Erro no Cálculo das Incógnitas - 15000 Elementos } \\
\hline Resultados & 1 Ponto de Gauss & 2 Pontos de Gauss & 3 Pontos de Gauss & 4 Pontos de Gauss & 5 Pontos de Gauss & 6 Pontos de Gauss \\
\hline$J_{1}$ & $-1,2386$ & $-0,8961$ & $-0,8732$ & $-0,8688$ & $-0,8675$ & $-0,8670$ \\
\hline$J_{2}$ & 0,0118 & $0,32560,3468$ & & 0,3510 & 0,3522 & 0,3527 \\
\hline$J_{3}$ & 0,0682 & 0,1535 & 0,1592 & 0,1603 & 0,1606 & 0,1608 \\
\hline$J_{4}$ & 0,5474 & 0,8480 & 0,8683 & 0,8722 & 0,8733 & 0,8738 \\
\hline$J_{5}$ & $-0,5467$ & 0,1395 & 0,1854 & 0,1943 & 0,1969 & 0,1980 \\
\hline$J_{6}$ & $-0,5467$ & 0,1395 & 0,1854 & 0,1943 & 0,1969 & 0,1980 \\
\hline$T_{5}$ & $-0,3029$ & $-0,1372$ & $-0,1263$ & $-0,1242$ & $-0,1236$ & $-0,1233$ \\
\hline$T_{6}$ & $-0,3029$ & $-0,1372$ & $-0,1263$ & $-0,1242$ & $-0,1236$ & $-0,1233$ \\
\hline$q_{1}$ & $-2,6538$ & $-1,9199$ & $-1,8709$ & $-1,8614$ & $-1,8586$ & $-1,8575$ \\
\hline$q_{2}$ & 0,1753 & 4,8541 & 5,1715 & 5,2330 & 5,2514 & 5,2585 \\
\hline$q_{3}$ & $-0,5450$ & $-1,2270$ & $-1,2726$ & $-1,2814$ & $-1,2840$ & $-1,2850$ \\
\hline$q_{4}$ & $-0,4448$ & $-0,6890$ & $-0,7055$ & $-0,7086$ & $-0,7096$ & $-0,7100$ \\
\hline
\end{tabular}

Tabela B.11: Verificação do princípio da conservação da energia, através da equação (2.90), para o segundo benchmark.

\begin{tabular}{|c|c|c|c|c|c|c|}
\hline \multicolumn{7}{|c|}{ Somatória das Taxas de Calor $(W)$} \\
\hline Elementos & 1 Ponto de Gauss & 2 Pontos de Gauss & 3 Pontos de Gauss & 4 Pontos de Gauss & 5 Pontos de Gauss & 6 Pontos de Gauss \\
\hline 2400 & 269,1741 & 22,3388 & 5,1152 & 1,7761 & 0,7751 & 0,3913 \\
\hline 5400 & 186,2703 & 15,1864 & 3,4751 & 1,2065 & 0,5265 & 0,2658 \\
\hline 9600 & 142,5313 & 11,5016 & 2,6310 & 0,9134 & 0,3986 & 0,2012 \\
\hline 15000 & 115,4783 & 9,2556 & 2,1168 & 0,7349 & 0,3207 & 0,1619 \\
\hline
\end{tabular}

